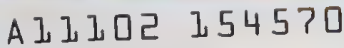

NAT'L INST OF STANDARDS \& TECH R.I.C.

I.

A11102154570

/NBS bullding sclence serles

$\therefore-7$
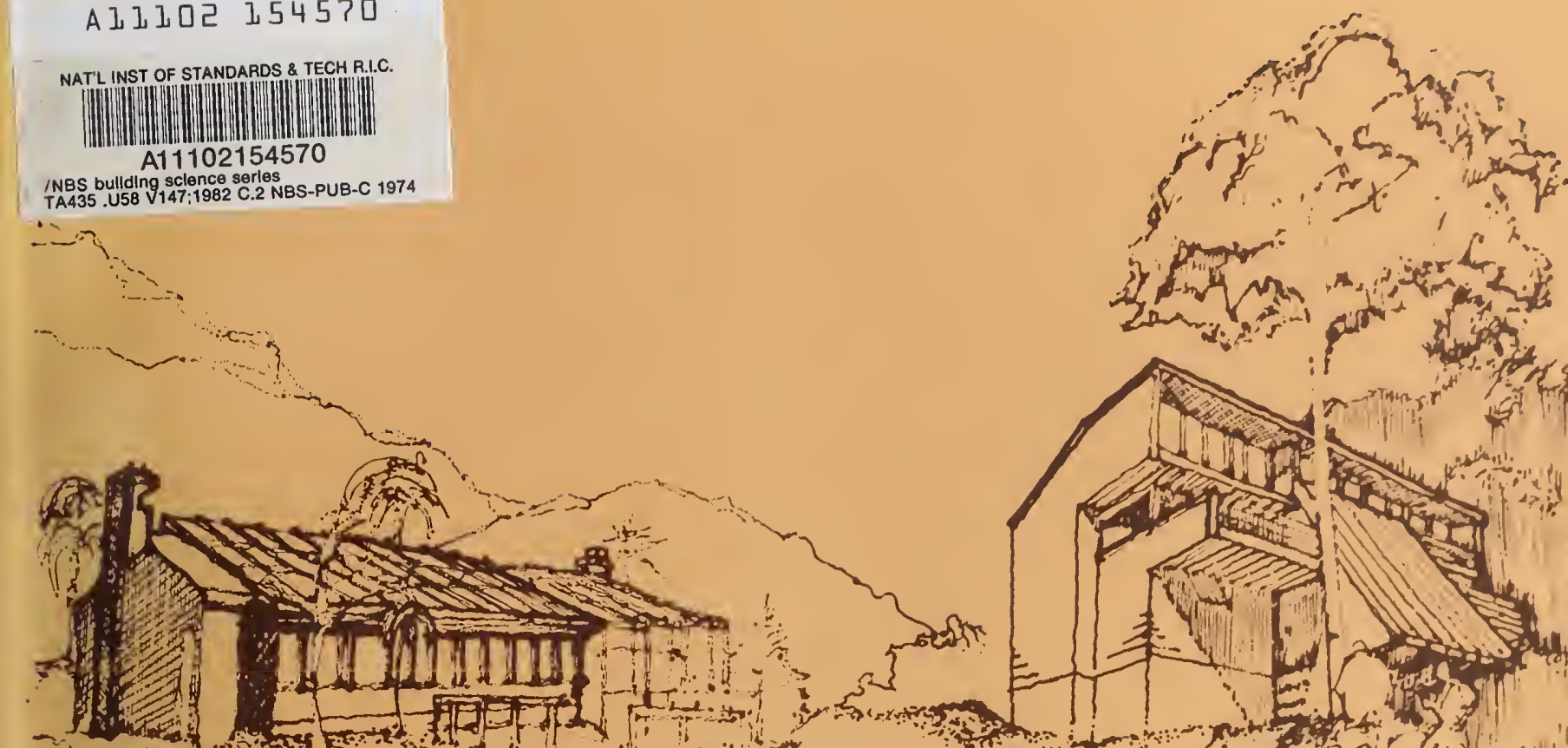

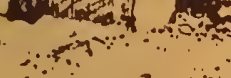

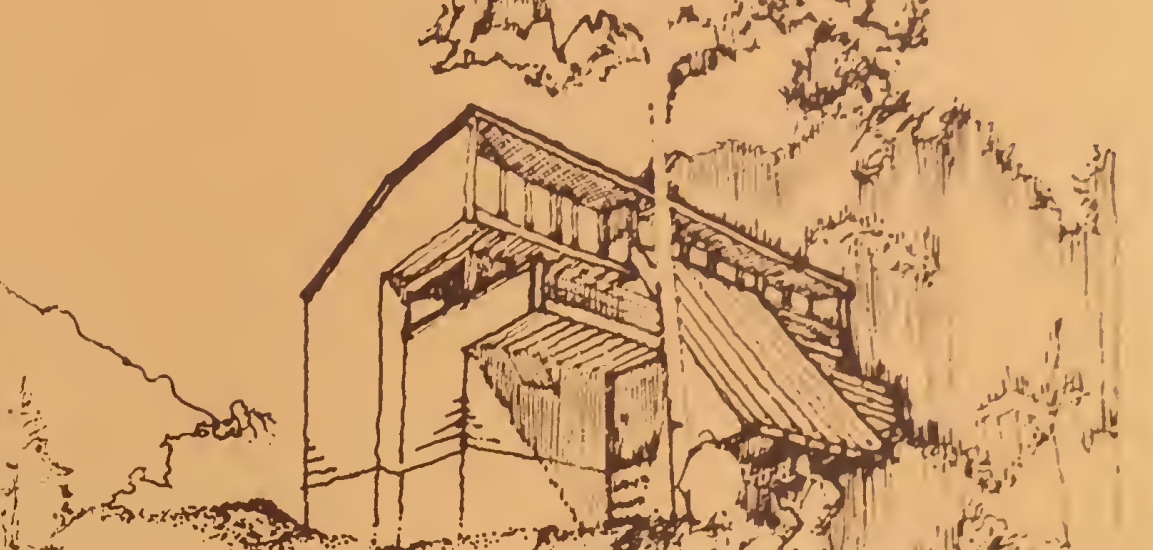
is

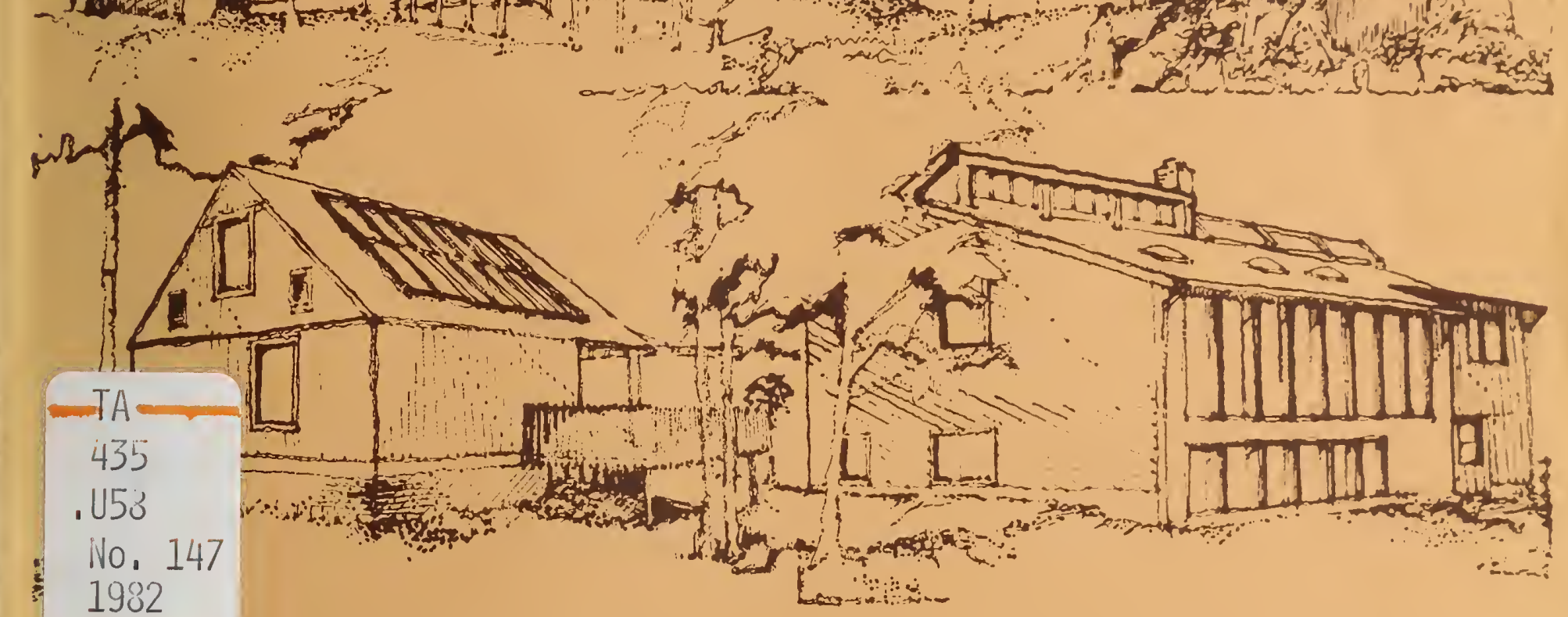

c. 2

NBS BUILDING SCIENCE SERIES 147

\title{
Performance Criteria for Solar Heating and Cooling Systems in Residential Buildings
}

Prepared for:

U.S. DEPARTMENT OF HOUSING AND URBAN DEVELOPMENT

OFFICE OF POLICY DEVELOPMENT AND RESEARCH 


\section{NATIONAL BUREAU OF STANDARDS}

The National Bureau of Standards' was established by an act of Congress on March 3, 1901. The Bureau's overall goal is to strengthen and advance the Nation's science and technology and facilitate their effective application for public benefit. To this end, the Bureau conducts research and provides: (1) a basis for the Nation's physical measurement system, (2) scientific and technological services for industry and government, (3) a technical basis for equity in trade, and (4) technical services to promote public safety. The Bureau's technical work is performed by the National Measurement Laboratory, the National Engineering Laboratory, and the Institute for Computer Sciences and Technology.

THE NATIONAL MEASUREMENT LABORATORY provides the national system of physical and chemical and materials measurement; coordinates the system with measurement systems of other nations and furnishes essential services leading to accurate and uniform physical and chemical measurement throughout the Nation's scientific community, industry, and commerce; conducts materials research leading to improved methods of measurement, standards, and data on the properties of materials needed by industry, commerce, educational institutions, and Government; provides advisory and research services to other Government agencies; develops, produces, and distributes Standard Reference Materials; and provides calibration services. The Laboratory consists of the following centers:

\section{Absolute Physical Quantities ${ }^{2}$ - Radiation Research - Chemical Physics - Analytical Chemistry - Materials Science}

THE NATIONAL ENGINEERING LABORATORY provides technology and technical services to the public and private sectors to address national needs and to solve national problems; conducts research in engineering and applied science in support of these efforts; builds and maintains competence in the necessary disciplines required to carry out this research and technical service; develops engineering data and measurement capabilities; provides engineering measurement traceability services; develops test methods and proposes engineering standards and code changes; develops and proposes new engineering practices; and develops and improves mechanisms to transfer results of its research to the ultimate user. The Laboratory consists of the following centers:

Applied Mathematics - Electronics and Electrical Engineering ${ }^{2}$ - Manufacturing Engineering - Building Technology - Fire Research - Chemical Engineering ${ }^{2}$

THE INSTITUTE FOR COMPUTER SCIENCES AND TECHNOLOGY conducts research and provides scientific and technical services to aid Federal agencies in the selection, acquisition, application, and use of computer technology to improve effectiveness and economy in Government operations in accordance with Public Law 89-306 (40 U.Ś.C. 759), relevant Executive Orders, and other directives; carries out this mission by managing the Federal Information Processing Standards Program, developing Federal ADP standards guidelines, and managing Federal participation in ADP voluntary standardization activities; provides scientific and technological advisory services and assistance to Federal agencies; and provides the technical foundation for computer-related policies of the Federal Government. The Institute consists of the following centers:

Programming Science and Technology-Computer Systems Engineering.

'Headquarters and Laboratories at Gaithersburg, MD, unless otherwise noted; mailing address Washington, DC 20234.

${ }^{2}$ Some divisions within the center are located at Boulder, CO 80303. 
NBS BUILDING SCIENCE SERIES 147

\section{Performance Criteria for Solar Heating and Cooling Systems in Residential Buildings}

Center for Building Technology

National Engineering Laboratory

National Bureau of Standards

Washington, DC 20234

Prepared for:

U.S. Department of Housing and Urban Development Office of Policy Development and Research

Building Technology Division

Washington, DC 20410

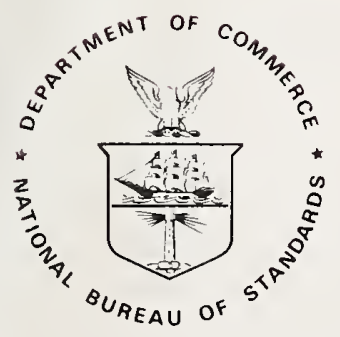

U.S. DEPARTMENT OF COMMERCE, Malcolm Baldrige, Secretary NATIONAL BUREAU OF STANDARDS, Ernest Ambler, Director 
Library of Congress Catalog Card Number: 82-600581

National Bureau of Standards Building Science Series 147

Natl. Bur. Stand. (U.S.), Bldg. Sci. Ser. 147, 236 pages (Sept. 1982)

CODEN: BSSNBV 
TABLE OF CONTENTS

Page

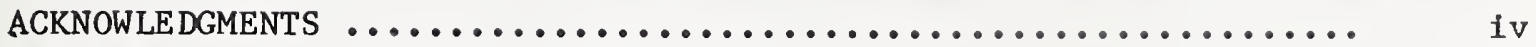

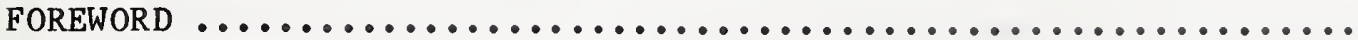

INTRODUCTION

TERM INOLOGY

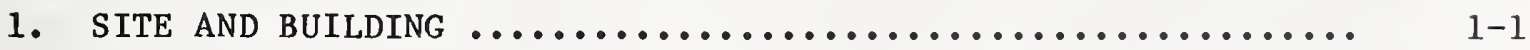

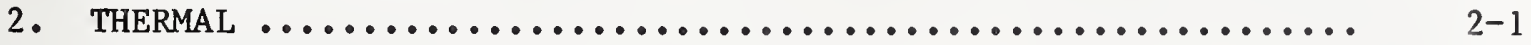

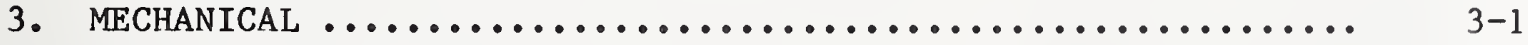

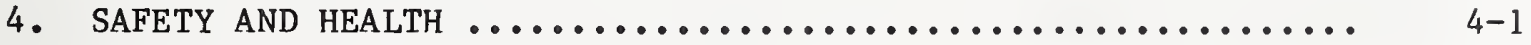

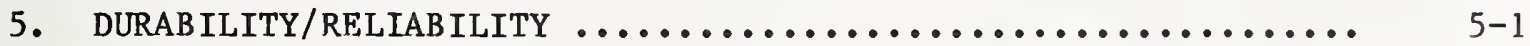

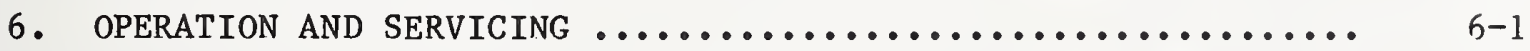

APPENDIX A $\ldots \ldots \ldots \ldots \ldots \ldots \ldots \ldots \ldots \ldots \ldots \ldots \ldots \ldots \ldots \ldots \ldots \ldots \ldots \ldots \ldots$

DURABILITY/RELIABILITY SECTIONS (Sec, 1 thru Sec. 10) ...... A-1

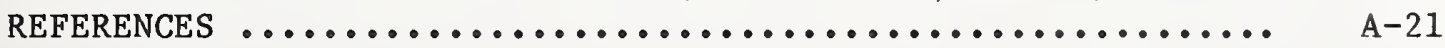

APPENDIX В $\ldots \ldots \ldots \ldots \ldots \ldots \ldots \ldots \ldots \ldots \ldots \ldots \ldots \ldots \ldots \ldots \ldots \ldots \ldots$

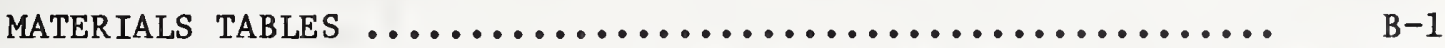

TECHNICAL REVIEW ITEMS $\ldots \ldots \ldots \ldots \ldots \ldots \ldots \ldots \ldots \ldots \ldots \ldots \ldots$ B -8

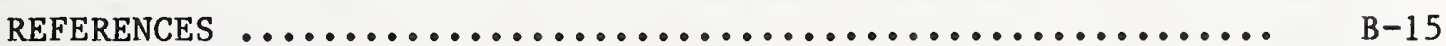

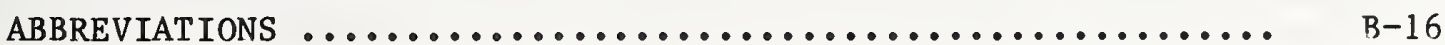

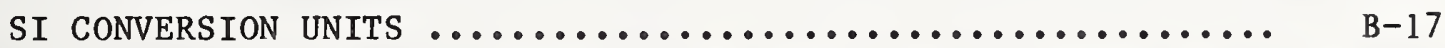

COMPOSITE INDEX $\ldots \ldots \ldots \ldots \ldots \ldots \ldots \ldots \ldots \ldots \ldots \ldots \ldots \ldots \ldots \ldots \ldots \ldots \ldots$ 


\section{ACKNOWLEDGMENTS}

This document was prepared by the Center for Building Technology staff of the National Bureau of Standards. Members who participated in the preparation of these performance criteria include:

F. Eugene Metz (Former project leader)

John K. Holton (Former project leader)

Thomas H. Boone

Leopold F. Skoda

Michael F. McCabe

Elmer P. Streed

Lawrence W. Masters

Elizabeth J. Clark

Paul W. Brown

W. Douglas Walton (Center for Fire Research)

David Waksman

Thomas K. Faison

Belinda C. Reeder

Robert D. Dikkers

Acknowledgment is also made of the helpful comments and suggestions received from William Freeborne and David Moore of the Department of Housing and Urban Development, David E. Cassel and the staff of Mueller Associates. Special thanks is given to Leslie Suddueth, Ulesia Gray, and Brenda Thompson for their patience and excellent job of typing this document as well as many early drafts. Thanks is also given to Walter E. Shipp for preparing the composite index to the document.

The buildings drawn on the cover are representative of projects that were built under the HUD Solar Residential Demonstration Program. They are located in Washington State; Shelton, Connecticut; Shenandoah, Georgia; and Palo Alto, California. They demonstrate applications of passive and air and liquid active systems. 


\section{FOREWORD}

The Solar Heating and Cooling Demonstration Act of 1974 (Pub. L. 93-409) authorized a five-year program for research, demonstration, and market development of solar heating and cooling systems in residential and commerical buildings. As part of this program, the Act directed the Secretary of the Department of Housing and Urban Development (HUD), utilizing the services of the Director of the National Bureau of Standards (NBS), to develop and publish Interim Performance Criteria for solar heating and cooling systems and buildings within 120 days of enactment, and to use these criteria in the selection of solar systems and demonstration projects. The Interim Criteria were published on January 1, 1975. The Act further directed (HUD), utilizing the services of NBS and information developed in the demonstration program, to develop and publish "definitive performance criteria" as soon as feasible.

In the period from 1975 through 1979, HUD awarded 783 grants to support demonstrations of solar heating, cooling, and domestic hot water systems in 12,423 dwelling units. A number of these projects were equipped with sophisticated instrumentation systems to measure the solar system performance. In addition, operating, maintenance, and repair information was collected from many more projects. This information has been used by HUD and NBS to evaluate the effectiveness of the original Interim Performance Criteria and to develop new, more precise criteria for solar system performance, thereby meeting the requirements of Section 8 of the Act. Extensive use also has been made of technical information developed from concurrent Department of Energy solar research, development, and demonstration activities.

These Performance Criteria are not intended to be used as mandatory standards governing the procurement or acceptability of solar systems proposed for HUD or other Federal solar activities. Instead, the document will serve as a technical reference and resource for the solar industry, the building industry, and Federal, State, and local agencies concerned with assessing the design and performance of solar systems in buildings. For example, HUD relies on HUD 4930.2, the Intermediate Minimum Property Standards (IMPS) Supplement for Solar Heating and Domestic Hot Water Systems to control the quality of solar systems proposed for use in HUDassisted housing programs. These IMPS are based on the performance requirements of the original Interim Performance Criteria; further revisions will reflect the new Performance Criteria requirements.

The document is intended to establish minimum levels of performance with regard to health and safety and the various aspects of technical performance. The criteria for health and safety put primary emphasis on compliance with existing codes and standards. The criteria on thermal and mechanical performance, durability/reliability, and operation/servicing present performance requirements considered to be representative of acceptable levels. By the use of performance language in the document, it is believed that sufficient latitude has been provided to allow the 
innovation and flexibility that is essential for the stimulation of a viable solar industry at this time and in the future.

In developing these criteria, several sources have been utilized:

- Performance criteria developed by the National Bureau of Standards (NBS) for the Department of Housing and Urban Development (HUD) and the Department of Energy (DoE).

- "Interim Performance Criteria for Solar Heating and Combined Heating/Cooling Systems and Dwellings" - January 1975

- "Interim Performance Criteria for Solar Heating and Cooling Systems in Commercial Buildings" - NBSIR 76-1187, November 1976

- "HUD Intermediate Minimum Property Standards Supplement, 1977 Edition, Solar Heating and Domestic Hot Water Systems" -4930.2

- "Interim Performance Criteria for Solar Heating and Cooling Systems in Residential Buildings" - NBSIR 78-1562, November 1978

- "Performance Criteria for Solar Heating and Cooling Systems in Residential Buildings" (Draft for Public Comment) - NBSIR 80-2095, Revised January 1981, Federal Register, Vo1. 46, No. 121, pp. 32740-32823, June 24, 1981.

- Experience gained in the Federal Solar Demonstration Program (Residential/Commercial) through feedback as provided for in P.L. 93-409

- Findings from solar research activities

- Government laboratories - National Bureau of Standards, Los Alamos Scientific Laboratory, National Aeronautics and Space Administration, Argonne National Laboratory

- Sponsored research - Dubin-Bloome Associates, Planning Research Corporation Energy Analysis Company, Boeing Aerospace Company, International Business Machines, University of Wisconsin, Colorado State University, Mueller Associates, Automation Industries (Vitro Laboratory Division).

- Critique and commentary from

- Model code groups - Council of American Building Officials, National Conference of States on Building Codes and Standards, International Conference of Building Officials, Building Officials and Code Administrators International, Inc., Southern Building Code Congress International. 
- Technical standards organizations - American Society for Testing and Materials, American Society of Heating, Refrigerating and Air-Conditioning Engineers, American Society of Mechanical Engineers, Inc., American National Standards Institute.

- Industry organizations - Solar Energy Industries Association, Inc., Solar Energy Research and Education Foundation, AirConditioning and Refrigeration Institute, Sheet Metal and AirConditioning Contractors National Association, Inc.

- Professional organizations - American Institute of Architects

- Special studies - Burt-Hill-Kosar-Rittelman Associates, TravisBraun Associates, Robertson Ward, Jr., FAIA, Florida Solar Energy Center, Polytechnic Institute of New York, Mueller Associates.

- Various organizations and individuals responding to request for public comments on NBSIR 80-2095, (Federal Register, Vol. 46, No. 121 , pp. 32740-32823, June 24, 1981.) 


\section{Abstract}

This performance criteria, developed for the Department of Housing and Urban Development, is a baseline document for criteria and standards for the design, development, technical evaluation, and procurement of solar heating and cooling systems for residential buildings in accordance with the requirements of section 8 of Public Law 93-409, the "Solar Heating and Cooling Demonstration Act of 1974." The document is intended to establish minimum levels of performance with regard to health and safety and the various aspects of technical performance. The criteria for health and safety put primary emphasis on compliance with existing codes and standards. The criteria on thermal and mechanical performance, durability/ reliability and operation/servicing present performance requirements considered to be representative of acceptable levels. By the use of performance language in the document, it is believed that sufficient latitude has been provided to allow the innovation and flexibility that is essential for the stimulation of a viable solar industry at this time and in the future.

Key Words: building; cooling; heating; hot water; performance criteria; solar energy; standards. 
INTRODUCTION

\section{Background}

Public Law 93-409 provides for "demonstration within a three-year period of the practical use of solar heating technology, and . . . . the development and demonstration within a flve-year period of the practical use of combined heating and cooling technology." Under the provisions of the Act, HUD has utilized the services of NBS to develop this document.

\section{Objectives}

These criteria have the following objectives:

1. Aid consumer acceptance by the provision of validated consensus performance measures;

2. Assist industry growth through accepted uniform methods of technical performance assessment;

3. Assist the administration of Federal incentives programs, including tax credits, by the establishment of standard performance measures;

4. Assist regulatory authorities in developing and interpreting health and safety code provisions;

5. Aid financial and insurance organizations by the provision of standard performance criteria upon which to base risk assessment;

6. Assist public and private building programs through provision of a technical performance assessment base from which project construction specifications may be developed; and

7. Guide industry, professional and educational organizations in the development of appropriate good practice manuals.

\section{Scope}

The performance criteria cover both passive and active solar heating cooling, and domestic hot water installations or combinations thereof 1 \} in individual buildings or central systems for groups of buildings both new and existing.

1/ Although not specifically mentioned in P.L. 93-409, it is recognized in this document that not all cooling systems are combined with heating systems. 
The criteria do not cover swimming pool heaters but they do cover pools within buildings used to moderate environmental conditions or to store heat for reuse. They do not cover photovoltaic, wind, biomass, or process heating or cooling applications. The criteria are related primarily to technical performance and do not directly address economic considerations, energy conservation, lighting either natural or artificial, or site selection.

The criteria given in this document primarily consider aspects of planning and design that are different from conventional buildings by reason of the solar energy systems under consideration and are intended to:

1. Establish minimum levels for health and safety that are consistent with those presently established for conventional systems used in building applications;

2. Ensure that the proposed heating, cooling, and hot water systems or combinations thereof, are capable of providing levels of performance consistent with those provided by conventional systems used in building applications;

3. Verify that proposed systems and components are capable of providing their design performance levels;

4. Ascertain that the systems and components are durable, reliable, readily maintainable, and generally constructed in accordance with good practice; and

5. Provide appropriate instructions and information for the operation and servicing of the systems and components.

Many of the problems and circumstances discussed in the criteria are unique to solar installations. Several useful references drawn from the Federal Solar Demonstration Program give insight into such problems, References $[1,2,3,4,5,6,7,8]$ *

Reference is also made to the American National Standard Recommended Requirements to Code Officials for Solar Heating, Cooling, and Hot Water Systems, Reference [9]. This document identifies health and safety requirements for solar systems.

The performance criteria are intended to be flexible in order to allow freedom of design and encourage innovation in keeping with the intent of P.L. 93-409.

Many of the criteria which explicitly address active solar systems also have implications with regard to passive systems. The majority of the

* Numbers in brackets [ ] indicate references at the end of this introductory section. 
criteria which are directly intended for passive systems are found in Chapters 1 and 2. Several of the other criteria, especially those dealing with health and safety concerns are applicable to passive systems, as well as active ones. Judgement must be exercised in applying the criteria to assure that passive system concerns are adequately addressed.

\section{Organization and Format}

This document is organized on the basis of performance criteria dealing with heating, cooling, and hot water systems and their integration into buildings.

Performance statement entries, with the exception of Chapter 1, are presented in the Requirement, Criterion, Evaluation and Commentary format. The Requirement is a qualitative statement giving the user need or expectation for the item being addressed. It is a general statement of what the system or its components shall be able to do. The Criterion is generally a quantitative statement giving the level of performance required to meet the application or expectation for the item being addressed. The one or more criteria associated with each requirement state those considerations that are necessary to meet the requirement. Due to limitations in the state-of-the-art, a quantitative statement is not always contained in each criterion in this document. In addition, quantitative statements have been intentionally omitted in some criteria where these values will be provided by the designer. The Evaluation sets forth the record of experience, methods of test and/or other information upon which an evaluative judgment of compliance with a criterion will be based. It states the standards, inspection methods, analyses, review procedures, historical documentation, or other methods that may be used in evaluating whether or not the system and its components as designed comply with the criterion. It is expected, in many cases, that the review of documentation of in-use performance or professional judgment will be used as evaluative tools in lieu of testing. The Commentary provides background for the reader and presents the rationale behind the selection of specific data presented in the Requirement, Criterion or Evaluation. The commentary is intended for informational purposes and in some instances, provides design guidelines. Such guidelines are only one suggestion of appropriate methods; in most instances, there will be other methods equally as effective. Including a commentary in the presentation ensures a workable process of updating these performance criteria. The commentary provides the rationale for selection of performance levels and methods of evaluation. When questions arise as to the basis for a particular criterion, the reader will have available the rationale behind the criterion. With the present state-of-the-art, there will be a need for periodic updates to adjust levels of acceptability for both systems and components.

The document is organized into chapters on the basis of the performance attributes listed below: 
1. Site and Building performance statements deal with the interactions between the solar energy system and its surrounding environment, the site, and building. These performance statements provide for integrating the building and site with the system and its components without seriously degrading the environment or impairing the normal function of the building and its components. Because of their more general nature, the statements in this chapter are not organized in the Requirement/Criterion/ Evaluation/Commentary format discussed previously.

2. Thermal performance statements are used to evaluate the ability of systems and their components, as designed, to operate and provide their rated output and, in some cases, to evaluate the determination of that output. The ability of the solar heating system to maintain the building at a specified temperature under a given set of outdoor conditions is an example of a thermal consideration.

3. Mechanical performance statements address the mechanical design and performance of the solar energy systems and their components. Factors such as the ability of the system to withstand norma1 design service conditions, e.g., pressure and temperature, are considered under this category.

4. Safety and Health deals with the mitigation of hazards that would result in personal injury or property damage. Hazards such as those due to scalding, lacerating, toxic and/or flammable materials are also considered under this category.

5. Durability/Reliability relate to the ability of systems and their components to perform designed functions for a specified interval under designated use conditions. Corrosion and thermal degradation are typical durability/reliability related items.

6. Operation and Servicing deals with the features of systems and their components that allow them to be maintained in good operating condition for extended periods of time. Manuals and instructions, routine scheduled maintenance, corrective maintenance, replacements, and repairs are considered under this category Accessibility is an important maintainability consideration.

Appendices $A$ and $B$ reference conditions for and methods of testing and evaluation that can be used to prove compliance with stated requirements. As a general rule, concensus standards are to be used when applicable. The Technical Review. Items included in Appendix B can be used as a guide to system design and technical evaluation. The Abbreviations section offers the names of Code Groups, Associations, and Government Agencies. The SI Conversion Units section offers metric conversion factors for all quantitative units appearing in the text. 
The Composite Index locates components, materials, operations, and other technical topics according to their appearance in the text.

For the purposes of this document, the various systems and components, both active and passive, treated in this document are abbreviated as follows :
(H) Heating system
(C) Cooling system
(HW) Hot water system (domestic HW)
$(\mathrm{H} / \mathrm{C} / \mathrm{HW})$ is used when a requirement or criterion is applicable to the individual H, C, HW system or any combination thereof. 


\section{References}

1. Proceedings of the Solar Heating and Cooling Demonstration Program Contractors $^{\prime}$ Review, December 5-7, 1977, New Orleans, LA, Vol. 2, CONF 771229, Department of Energy. 3 /

2. Proceedings of 3rd Annual Solar Heating and Cooling Research and Development Branch Contractors' Meeting, September 24-27, 1978, Washington, DC, Department of Energy.1f

3. Conference Proceedings- Solar Heating and Cooling Systems Operational Results, November 28-December 1, 1978, Colorado Springs, C0, Department of Energy. I/

4. Standard Practice for Installation and Service of Solar Space Heating Systems for One- and Two-Family Dwellings, ASTM E683-79, 1979, ASTM, 1916 Race Street, Philadelphia, PA 19103.

5. Installation Guidelines for Solar DHW Systems in One- and Two-Family Dwellings, HUD-PDR-407, GPO 023-000-00520-4, U.S. Department of Housing and Urban Development, April 1979.2/

6. Weinstein, S., Architectural Concerns in Solar System Design and Installation, Solar/0801-79/01, U.S. Department of Energy, March 1979.11

7. Easterly, J., Engineering Concerns in Solar System Design and Operation, Solar/0811-79/01, U.S. Department of Energy, March 1979.I/

8. National Solar Heating and Cooling Demonstration Program - Project Experience Handbook, Preliminary Draft, DoE/CS-0045/0, U.S. Department of Energy, September 1978.1/

9. American National Standard Recommended Requirements to Code Officials for Solar Heating, Cooling and Hot Water Systems, ANSI/CABO 1.0-1981, Council of American Building Officials, 1981.

1/ Technical Information Center, P.0. Box 62, 0ak Ridge, TN 37830 .

2/ Superintendent of Documents, U. S. Government Printing Office, Washington, DC 20402 .

3/ National Technical Information Service, 5285 Port Royal Road, Springfield, VA 22161. 


\section{TERMINOLOGY*}

Absorber: The part of the solar collector that receives the incident solar radiation and transforms it into thermal energy.

Absorptance: The ratio of the amount of radiation absorbed by a surface to the amount of radiation incident upon it.

Active solar system: A method of space conditioning or water heating that utilizes solar radiation primarily by means of mechanical equipment rather than building elements.

Air chamber: A closed section of pipe or a container filled with air entrapped at atmospheric pressure that when mounted in a water supply line absorbs the pressure surges caused by the rapid opening and closing of valves.

Air mass: The ratio of the mass of atmosphere in the actual earth-sun path to the mass that would exist if the sun were directly overhead at sea level.

Aperture: An opening in a building wall, roof, or other collection device that transmits solar radiation.

Applicable authority: The organization, office, or individual responsible for approving equipment, an installation, procedures, or performance levels. An applicable authority may range from a code official to an individual owner.

Auxiliary energy system: Equipment utilizing energy other than solar both to supplement the output provided by the solar energy system as required by the design conditions and to provide necessary energy back up requirements during periods when the solar $\mathrm{H}, \mathrm{C}$ or $\mathrm{HW}$ systems are inoperable. It may be integrated directly into the solar energy system or it may be completely separate from it and contain its own means for delivery of heating, cooling, and/or hot water to the building.

Backflow: The flow in pipes, ducts, and other chambers opposite to the intended direction of flow. Backflow may occur under two conditions: pressure greater than atmospheric and pressure that is subatmospheric (see "Backsiphonage").

* The definitions given here are for use in this document only. 
Backflow preventer: A device or means to prevent backflow, especially in regard to the potential for contamination of potable water supply.

Backsiphonage: A form of backflow due to a negative or subatmospheric pressure.

Chemical incompatibility: The inability of materials to remain in contact with each other without chemical interaction, such as electrolytic action or plasticizer migration.

Closed system: An arrangement in hydronic systems where ambient air is not allowed to enter the system under normal operating conditions.

Collector array: Group of solar collectors or absorbing surfaces connected by pipes or ducts and including any pipes or ducts to the point where there is only one inlet and one outlet.

Collector array manifold: All pipes or ducts within the collector array but external to the collector panels.

Collector azimuth angle: The angle between the direction the collectors face and due south (in the northern hemisphere).

Collector efficiency (ASHRAE 93-77): The amount of energy reinoved by the transfer fluid per unit of gross collector area during the specified time period divided by the total solar radiation incident on the collector per unit area during the same time period, under steady state or quasi-steady state conditions.

Collector orientation: Combination of collector tilt and azimuth angles.

Collector tilt angle: The acute angle between the collector plane and horizontal.

Cooling degree days: The number of degrees that the daily mean temperature is above $65^{\circ} \mathrm{F}\left(18.3^{\circ} \mathrm{C}\right)$. These are totaled to give cooling degree days per month or per year.

Cooling (C) system: The complete assembly necessary to convert solar energy into thermal energy and use this energy in combination with auxiliary energy, where required, for space cooling purposes. (Where cooling is required, nocturnal radiation, evaporative cooling and/or other means may be used in combination with, or in lieu of, heat actuated space cooling).

Combustible liquid: Combustible liquid shall mean any liquid having a flash point at or above $100^{\circ} \mathrm{F}\left(37.8^{\circ} \mathrm{C}\right.$ ) (See "Flammable liquid").

Combustible material: See noncombustible material. 
Contaminants (hazardous): Materials (solids, liquids or gases) which when added unintentionally (or intentionally) to the potable water supply cause it to be unfit for human consumption.

Control system: Devices and their electrical, mechanical, pneumatic, or hydraulic auxiliaries used to regulate the processes of collecting, transporting, storing, and utilizing energy in response to the thermal, safety, and health requirements of the building occupants or building.

Creep: A time-dependent deformation of material resulting from sustained loads which can be influenced by factors such as temperature and solar radiation.

Depletable energy: Energy from any source other than solar energy converted to thermal energy at the building site or from thermal energy extracted from the air, groundwater, or ground. Depletable energy sources include coal, natural or manufactured gas, oil, other petroleum products, wood, and electricity. Electricity produced offsite is considered to be depletable energy, even though the source of the electricity may be some form of solar energy such as hyd ropower or wind.

Depletable energy limit: Allowable depletable energy use over one year for a H/C/HW system based on predicted system performance.

Design hot water load: The rate of energy required to be added by the mechanical system to the water at design maximum hot water use rate and temperature, not including energy to offset standby water heater, recirculation, and distribution losses. Normally, the design hot water load is determined by a combination of recovery rate and hot water storage capacity.

Design 1ife: The period of time during which an $\mathrm{H} / \mathrm{C} / \mathrm{HW}$ system is expected to perform its intended function without requiring major maintenance or replacement.

Design maximum flow temperature: The maximum temperature that will be obtained in a component when the heat transfer fluid is flowing through the system.

Design maximum no-flow temperature: The maximum temperature that will be obtained in a component when the heat transfer fluid is not flowing through the system.

Design space cooling load: The instantaneous rate of energy required to be removed by the mechanical system from the space being cooled to achieve space cooling under summer design conditions. 
Design space heating load: The instantaneous rate of heat required to be added by the mechanical system to the space being heated to achieve space heating under winter design conditions.

Design working pressure: The value of the pressure used in design calculations for pressure related operational and construction characteristics. This is the maximum allowable working pressure for which a specific part of a system is designed.

Dielectric fitting: An insulating fitting used to isolate electrochemically dissimilar materials.

Draindown system: Function of an open-loop solar water system in which all water drains out of the collectors and exposed piping at a pre-set point above the freezing temperature.

Drainback system: A 1iquid solar collector system in which the collector fluid drains down to an interior storage tank when the collector is not operating.

Ease of ignition: The time elapsed between the exposure of a material to a controlled heat or flame source and the onset of flaming. The ease of ignition may be used in analyzing the relative fire hazard of the materials.

Emittance: The ratio of the radiant energy emitted by a body to the energy emitted by a black body at the same temperature.

Energy transport system: Those portions of the $\mathrm{H} / \mathrm{C} / \mathrm{HW}$ systems that convey energy from one place to another. Heat transfer from the collector to storage and from storage to the point of use is accomplished through the energy transport system.

Failure (structural): Failure of a structure or any structural element is defined as one of the following: (a) Sudden, locally-increased curvature, major spalling, or structural collapse. (b) The inability of the structure to resist a further increase in load. (c) Structural deflections under design loads that cause significant performance degradation of the component or subsystem.

Flammable liquid: Any liquid having a flash point below $100^{\circ} \mathrm{F}\left(37.8^{\circ} \mathrm{C}\right)$ and having a vapor pressure not exceeding 40 pounds per square inch $\left(275 \mathrm{KPa}\right.$ ) absolute $\left(2068.6 \mathrm{~mm} \mathrm{Hg}\right.$ ) at $100^{\circ} \mathrm{F}\left(37.8^{\circ} \mathrm{C}\right.$ ) (NFPA 321 ) (see "Combustible 1iquid").

Flash point: The minimum temperature of a liquid at which sufficient vapor is given off to form an ignitible mixture with the air near the surface of the liquid or within the vessel used as determined by appropriate test procedures and apparatus as specified in NFPA 321 . 
Flow condition: The situation that exists when the heat transfer fluid is moving through the collector array under normal conditions.

Fully conditioned space: The volume within the building envelope in which a temperature of $70^{\circ} \mathrm{F}\left(21^{\circ} \mathrm{C}\right)$ is capable of being maintained during the $97-1 / 2$ percent winter outdoor heating design temperature conditions.

Glazing: A membrane or sheet of transparent or translucent material (glass or plastic) used for admitting light. Glazing retards heat losses due to reradiation and convection. Examples: windows, skylights, greenhouse and collector coverings.

Gross floor area: Floor area of the building measured to the outside of exterior walls that enclose fully conditioned spaces and to the center of party walls and walls adjacent to semi-conditioned spaces.

Gross solar contribution: Total solar input of a passive solar energy system less excess energy discharge (venting) losses due to the passive solar energy system.

H/C/HW system: The mechanical space heating, space cooling, or hot water system, or any combination thereof, in which solar energy intercepted at the building site is converted to usable thermal energy to satisfy partially or fully the respective energy requirements. This includes systems having discrete collectors with thermosiphon-driven control for air- or liquid-type collectors.

Hazardous substances: See "Federal Hazardous Substances Act Regulations," Code of Federal Regulations (CFR), Title 16, Part 1500.3 (b)(4)(i). The following is an extraction of the definition: "Any substance or mixture of substances which is toxic, corrosive, an irritant, a strong sensitizer, flammable or combustible, or generates pressure through decomposition, heat or other means, if such substance or mixture of substances may cause substantial personal injury or substantial illness during or as a proximate result of any customary or reasonably foreseeable handling or use, including reasonably foreseeable ingestion by children. 'Hazardous substances' shall not apply to substances intended for use as fuels when stored in containers and used in the heating, cooling, or refrigeration system of a house."

Heating degree days: The number of degrees that the daily mean temperature is below $65^{\circ} \mathrm{F}\left(18.3^{\circ} \mathrm{C}\right)$. These are totaled to give heating degree days per month or per year.

Heating (H) system: The complete assembly of systems necessary to convert solar energy into thermal energy and use this energy in combination with auxiliary energy, where required, for space heating purposes.

Highly toxic: See "Federal Hazardous Substances Act Regulations," Code of Federal Regulations (CFR), Title 16, Part 1500.3(b)(6)(i). The 
following is an extraction of the definition: "'Highly toxic' means any substance producing a lethal dose in half (LD50) of white rats, when ingested as a single dose, of $50 \mathrm{mg}$ or less per $\mathrm{kg}$ of body weight." Part 1500.3(c)(1)(i) and (ii) also gives further specific definitions relative to inhalation and absorption. Human data, when available, shall take precedence (see also "Toxic").

Hot water energy requirements: Energy required over a given period of time to heat the supply water to a designated use temperature, including energy required to offset standby water heater, recirculation and distribution losses, but not including hot water system operating energy.

Hot water (HW) system: The complete assembly of subsystems or components necessary to convert solar energy into thermal energy and use this energy in combination with auxiliary energy, where required, to provide hot water in the building. It may either be integrated directly into the $\mathrm{H}, \mathrm{C}$ or combined $\mathrm{H}$ and $\mathrm{C}(\mathrm{H} / \mathrm{C})$ system or be completely separate from them.

In-service conditions: The conditions to which a solar H/C/HW system will be exposed during its operational lifetime.

Langley: The meteorologist's unit of solar radiation intensity, equivalent to 1.0 gram calorie per square centimeter, usually used in terms of langleys per minute. 1 langley per minute $=221.2$ Btu per hour per square foot $=697$ watts per square meter.

Liquid heat transfer fluid: The operating or thermal storage liquid including water or other liquid base and all additives at the concentration used under operating conditions.

Load: Peak rate of energy demand on a mechanical H/C/HW system. Load is energy per unit time or power.

Maximum service temperature: The maximum temperature at which a system is designed to operate either with or without the flow of heat transfer fluid.

Mechanical system: All equipment and controls required to satisfy space heating, cooling, or hot water energy requirements. The mechanical system may contain both solar and auxiliary components, including pumps, pipes, blowers, ducts, insulation, solar collectors, thermal storage, heat exchangers, valves, and electrical wiring.

Minimum service temperature: The minimum temperature at which a system is designed to experience either with or without the flow of heat transfer fluid.

Net solar contribution: Solar radiation transmitted through a portion of the building envelope and absorbed within the building during a 
given daily, monthly, or annual cycle, less the transmission, and ventilation (excess energy discharge) losses due to the same portion of the building envelope during the same period. This is equivalent to net solar gain.

Nocturnal cooling: The cooling of a building or heat storage device by the radiation of heat to the night sky.

"No-flow" condition: The situation that exists when the heat transfer fluid is not flowing through the collector array due to shutdown or malfunction and the collector is exposed to the amount of solar radiation that it would receive under normal operating conditions. Heat transfer fluid may or may not be in the collector but it is not flowing if present. This condition is sometimes referred to as the "stagnation" condition.

Noncombustible material: Material which does not act to aid combustion or add appreciable heat to an ambient fire when tested in accordance with ASTM E136-79, "Standard Test Method for Behavior of Materials in a Vertical Tube Furnace at $750^{\circ} \mathrm{C}$," and pass the tests set forth therein.

Normal operating condition: Condition of operation during which no applicable parameter (e.g. temperature, pressure or flow rate) is at or near an extreme or unexpected value.

Open system: An arrangement in hydronic systems where ambient air is allowed to enter the system under normal operating conditions.

Operating energy: Energy required to operate pumps, compressors, fans, blowers, valves, controls, movable shutters, or any other equipment, but not energy intended to directly satisfy a load. Operating energy, as defined here, includes energy to operate a heat pump compressor, and defrost energy for heat pumps, when these components are an integral part of the solar system.

Operative temperature: The average of the dry bulb temperature and the mean radiant temperature at a given location.

Optimum collector orientation: Collector orientation that results in the maximum annual solar energy collected and used. The optimum orientation depends on factors such as site location, system type, annual solar fraction, local weather conditions, load profile, and thermal storage size.

Outgassing: The emission of gases by materials and components usually during exposure to elevated temperature or reduced pressure.

Passive solar components: Components of a building that serve to modify the space conditioning energy requirements by means of reflecting, absorbing, transmitting, or storing solar energy. These components 
include fixed and movable apparatus which can be operated either manually or automatica11y. Examples of passive solar components are: shading devices, windows, attached greenhouses, Trombe wa11s, and mass placed for storage of solar energy.

Passive solar energy system: A method of space heating or cooling that utilizes solar radiation primarily by means of building elements rather than mechanical equipment. In passive systems, the energy flows are primarily by natural means (radiation, convection, conduction). For the purposes of this document, this definition includes some systems in which at least one energy flow is by natural means and at least one is by forced means, otherwise known as hybrid systems.

Physical incompatibility: The inability of materials in contact with each other to resist degradation by physical actions such as differential thermal expansion.

Pitting: The process by which localized material loss is caused in materials by erosion or chemical decomnosition.

Plasticizer migration: The movement of plasticizers used in plastic materials. These plasticizers may concentrate in a narrow boundary area or migrate to another material in contact with the plastic.

Potable water: Water free from impurities present in amounts sufficient to cause disease or harmful physiological effects and conforming in its bacteriological and chemical quality to the requirements of the Public Health Service Drinking Water Standards or the regulations of the public health authority having jurisdiction.

Potential heat: The difference between the heat of combustion of a representative specimen of material and the heat of combustion of any residue remaining after exposure to a simulated standard fire, determined by combustion calorimetric techniques.

pphm: Parts per hundred million.

Premature failure: Failure that occurs before the end of the design 1ife.

Pyranometer: A device used to measure the total solar radiation incident upon a surface per unit time per unit area. This energy includes the direct radiation, the diffuse sky radiation, and the solar radiation reflected from the foreground.

R-value: Resistance to heat flow given in units of $\mathrm{ft}^{2} \cdot{ }^{\circ} \mathrm{F} \cdot \mathrm{h} / \mathrm{Btu}$

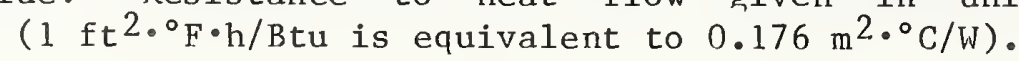

Radiation: The process of heat transfer by the transmission of electromagnetic waves between two or more bodies in sight of each other. 
These radiant waves are converted to heat only after being absorbed by matter.

Rate of heat release: A measure of the heat production of a material under a specified set of fire exposure conditions which may be used in evaluating the relative hazard of the material.

Recovery rate: The rate at which a water heater can replenish its supply of hot water, traditionally expressed in gallons per hour per $100^{\circ} \mathrm{F}$ $\left(37.8^{\circ} \mathrm{C}\right)$ temperature rise.

Safety glazing materials: Glazing materials so constructed, treated, or combined with other materials as to minimize the likelihood of cutting and piercing injuries when these glazing materials are broken.

Service loads: Loads that are expected during the service life of a structure and upon which the design of the structure is based.

Shall: Where "shall" is used with a special provision, that provision is mandatory if compliance with the criterion is claimed.

Should: Term used to indicate a criterion that is not mandatory but is desirable as good practice.

Significant (deterioration, loss, etc.): Deterioration that results either in a decrease in performance greater than that allowed for in the design, or in the creation of a hazard.

Solar constant: The average intensity of solar radiation reaching the earth outside the atmosphere; amounting to 2 langleys or 1.94 calories per square centimeter, per minute equal to $430 \mathrm{Btu} / \mathrm{h} \cdot \mathrm{ft}^{2}$ or 1353 watts $/ \mathrm{m}^{2}$.

Solar degradation: The process by which exposure to sunlight deteriorates materials.

Solar energy: Solar radiation or energy from solar radiation intercepted and converted to thermal energy at the building site.

Solar fraction: The ratio of solar energy applied to the load by the active solar energy system to the total load. Solar fraction may be calculated for any time period, for example monthly or annually. Solar energy applied to the load may include uncontrolled heat losses from the active solar energy system if these losses contribute to meeting the load and is reduced by uncontrolled heat losses if these losses increase the load (cooling systems).

Solar time: The hours of the day as reckoned by the apparent position of the sun. Solar noon is that instant on any day at which time 
the sun reaches its maximum altitude for that day. Solar time is very rarely the same as local standard time in any locality.

Space cooling load: Rate at which heat must be removed from the conditioned space by the mechanical system to maintain indoor temperature at a constant value. Space cooling load reflects sensible and latent heat gain due to external and internal sources. However, storage capacity within the building and contents affects the relationship between heat gain and space cooling load.

Space cooling system: The mechanical system containing all equipment and controls required to satisfy the space cooling load.

Space heating load: Rate at which heat must be added to the conditioned space by the mechanical system to maintain interior temperature at a constant value.

Space heating system: The mechanical system containing all equipment and controls required to satisfy the space heating load. The space heating system may include solar collectors, thermal storage, energy transport devices, and auxiliary energy equipment. The space heating and space cooling systems may have some components in common. Fireplaces and wood stoves used for heating are considered to be part of the space heating system.

Storage system: Equipment in which thermal energy is stored so that it can be used when required. Specific designs may utilize more than one heat storage temperature (e.g., dual temperature storage) and may also employ cold storage in all or part of the storage subsystem.

System: The complete assembly necessary to supply heat, domestic hot water, or other usable form of solar energy to a structure.

Tap temperature: The temperature at which water is discharged from an outlet at the point of use.

Thermal stratification: Separation into different temperature regions. Thermal statification usually occurs vertically in liquid thermal storage containers but may also occur horizontally in rock bins.

Thermosiphon: Flow of fluid through a closed loop induced by density difference in the fluid caused by temperature difference which is in turn caused by heat transfer into and out of the loop.

Total solar input: Amount of solar radiation transmitted through the aperture of a passive solar energy system and absorbed within the building during a specified time period.

Toxic: See "Federal Hazardous Substances Act Regulations," Code of Federal Regulations (CFR), Title 16, Part 1500.3(b)(5) and (c)(2). "'Toxic' shall apply to any substance (other than a radioactive 
substance) which has the capacity to produce personal injury or illness to man through ingestion, inhalation, or absorption through any body surface." An extraction of the more specific definition in (c)(2) adds the following: "'Toxic' means any substance producing a lethal dose in half (LD50) of white rats when ingested as a single dose, of from $50 \mathrm{mg}$ to $5 \mathrm{~g}$ per $\mathrm{kg}$ of body weight." Part $1500.3(c)(2)(i)$, (ii) and (iii) also give further specific definitions relative to inhalation and absorption (see also "Highly toxic").

Transmittance: The ratio of the radiant flux transmitted through and emerging from a body to the total flux incident on it.

UV: Ultraviolet radiation, that part of the terrestrial solar energy between 0.3 and 0.4 micrometers (300-400 nanometers).

Water hammer: Potentially damaging forces, exemplified by pressure surges and attendant pounding noises and vibration that develop in a pipe system when a column of liquid flowing through a pipe line is stopped abruptly.

Zero hardness: A property of softened water such that no calcium or magnesium can be found in it by ordinary analytical methods.

2-1/2 percent summer design temperaure: The outdoor air temperature will be higher than the stated value not more than 73 hours per year (2-1/2 percent of the 2,928 hours in June through September).

97-1/2 percent winter design temperature: The outdoor air temperature will be lower than the stated values for not more than 54 hours per year (2-1/2 percent of the 2,160 hours in December, January and February). 
CHAPTER 1

SITE AND BUILDING

Page

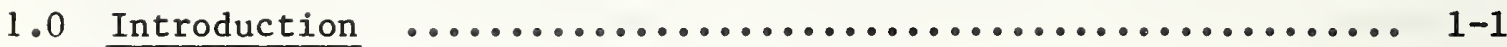

1.1 Climate and regional considerations $\ldots . . \ldots \ldots \ldots \ldots \ldots \ldots \ldots . . . .1-1$

1.2 Site considerations $\ldots \ldots \ldots \ldots \ldots \ldots \ldots \ldots \ldots \ldots \ldots \ldots \ldots \ldots \ldots$

1.3 Building considerations $\ldots \ldots \ldots \ldots \ldots \ldots \ldots \ldots \ldots \ldots \ldots \ldots \ldots \ldots$

1.4 Building/solar system interaction $\ldots \ldots \ldots \ldots \ldots \ldots \ldots \ldots \ldots \ldots$

References $\ldots \ldots \ldots \ldots \ldots \ldots \ldots \ldots \ldots \ldots \ldots \ldots \ldots \ldots \ldots \ldots \ldots \ldots \ldots \ldots \ldots \ldots \ldots$ 
CHAPTER 1

SITE AND BUILDING

1.0

Introduction This chapter sets forth considerations of the use of solar energy as related to broadly encompassing impacts beyond the scale of the solar energy system itself. The performance criteria for solar energy systems exist within a context of requirements that increase in scope from the building for which the system is designed, to the site, to the region and its climate, up to the scale of national energy goals. At each level, certain requirements have evolved which will influence solar installations. Policy decisions concerning energy conservation tax incentives, grant programs, reduced interest financing, fuel pricing, or sun rights are examples of issues that may have profound influence on solar energy applications.

It is critical that solar installations work in harmony with the overall conditions of climate, site, building characteristics, and use patterns of the occupants. Proper and efficient performance of the site and building will increase the probability for efficiency of the solar energy system and in turn the level of performance of components and materials as well. A comprehensive check list of factors used to assess the overall suitability of passive and active designs proposed for HUD's Cycle 5 Residential Solar Demonstration is given in Appendix B, Technical Review Items.

$1 \cdot 1$

Climate and regional considerations. Regional climate and resource conditions may exert a strong influence on designs. Certain construction materials have strong indigenous applications and establish constraints within which the designer or any solar building project must work.

Specific regional climatic considerations include the following and are subdivided into categories of natural, man made, and climatic factors.

Natural Factors:

(a) Sun altitude and declination - for consideration of collector aperture tilt and shading, etc.

(b) Orientation - due south vs. magnetic south - to determine orientation and building geometry 
(c) Topography - for consideration of building into slopes, earth berming, and otherwise maximizing southern exposure and minimizing others, References [1, 2]*

(d) Altitude - for the effects of atmospheric density

(e) Vegetation - as it affects shading, reflection and air movement, References [1, 2]

(f) Ground temperature - as it affects ground water temperature and earth exchange cooling

(g) Water table height - for considerations of excavation, burying of storage elements, earth contact housing, and wetting of insulation

(h) Water quality - its mineral content, pH, etc., when used for heat transfer fluid or thermal storage

Man Made Factors:

(a) Density and growth of development - in consideration of solar rights, shading, glare, obtrusive installations, References [2, 3, 4]

(b) Pollution of air - as it affects insolation, corrosion of exposed parts, stain and dirt deposits on collector cover plates, or glazing

(c) Building materials and architectural character consideration of mass and geometry or prevalent building types

(d) Building codes - to the extent that they constrain solar applications, Reference [4]

Climatic Factors:

Macro-climatic factors have a direct influence on solar $\mathrm{H} / \mathrm{C} / \mathrm{HW}$ systems. Typical sources of climate data are the Climatic Atlas, Reference [5] and Comparative Climatic Data, Reference [6]. Reference [7] describes adaptation of building form for regional climate characteristics. Following is a tabulation of typical climate factors:

(a) Temperature (annual average, seasonal, and daily)

(b) Solar radiation (annual, monthly, daily, hourly) Note: data on a weekly basis would offer many advantages but is usually not tabulated in that form

(c) Wind or air movement (direction, velocity, frequency)

(d) Relative humidity

(e) Rainfall and snow

* Numbers in brackets [ ] indicate references at the end of this chapter. 
Micro-climatic factors are those of specific interest to an individual building, site, and immediate surroundings. Climatic characteristics become more focused at this scale and may be tempered or exaggerated by local features, creating weather characteristics unique to the site. The characteristics unique to the site may be caused by its topography, landscaping, and proximity to surrounding buildings, hills, lakes, or open plains, Reference [1]. The following characteristics should be considered at this scale:

(a) Shading - time, duration, and season of occurrence are important for heating as well as cooling

(b) Air movement (direction, velocity, frequency)

(c) Atmospheric quality (fog, haze) and direct vs. diffuse solar radiation

(d) Relative humidity

Site considerations. Site design and siting criteria for energy conserving buildings incorporating solar energy systems are similar to good practice guidelines for non-solar buildings. The difference is in the special affinity for the sun and the sun's path required for solar energy applications. The performance uncertainties at this time and marginal energy balances often experienced in the operation of solar energy systems require greater consideration of the subtleties of the building/environment relationships. In passive solar applications, the entire building is likely to be affected by these relationships and for applications at least the solar energy system will be affected. Over-design as a means of coping with the performance uncertainties of solar energy installations is expensive and not likely to be cost effective.

Achieving an optimum orientation for the building and/or collector apertures is of primary importance. During the winter months, approximately 90 percent of the sun's energy occurs between the hours of $9: 00 \mathrm{a} \cdot \mathrm{m}$. and $3: 00 \mathrm{p} \cdot \mathrm{m}$. It is important that solar collection surfaces not be significantly shaded during this time. Site planning should also take into account the direction of prevailing winds.

The judicious use of vegetation and other landscaping techniques can play a significant role in solar energy efficiency as well as energy conservation in general. The use of trees and vines to provide summer shading while still permitting full exposure to solar radiation in the winter is particularly important in passive applications. Various ground cover materials can increase reflection or reduce glare as may be appropriate. Trees may be used to channel cooling breezes and evergreens can be used as 
effective wind breaks to moderate cold winter winds. Fences, screens, walls, and earth berms are other site design elements which would be considered to provide sun capturing spaces or as barriers to heat loss. References $[1,2,8,9,10,11]$ describe siting considerations and Reference [7] describes the extensive influence these have on passive designs.

Building considerations. A well designed solar energy system must include a building that is energy conserving since collector area and sizing of other solar hardware components are proportional to the building load requirements.

There are several aspects that may be considered. One consideration is the exterior envelope of the building where energy can be conserved by modifying factors such as: color, thermal resistance, thermal mass, Reference, [15], orientation, shading, surface area, and weather tightness. ASHRAE Standard 90A-1980, Reference [12] sets forth requirements for the design of the exterior envelope of new buildings for effective use of energy. Insulation to levels greater than those specified in $90 \mathrm{~A}-1980$ is normally desirable in solar buildings to minimize heating load. In the case of passive buildings, it may be desirable to tailor the design to the optimum use of glazed areas, thermal mass, insulation, ventilation, and other appurtenances for heating, cooling, and illumination. Listed in Table B-5 of Appendix B are typical properties of selected building materials that may be beneficial to the user selecting building components and materials for solar application.

A second consideration is the mass of the building which can exert considerable influence on the building's thermal behavior. Studies have indicated the beneficial peak leve1ing and carryover characteristics of properly designed building mass, Reference [13].

A third consideration is space planning and coordinating space use with natural temperature variations. The planning of interior spaces and proper temperature zoning is important for energy conservation and especially important in passive buildings. Such interior planning has a significant effect on the movement of energy (natural and mechanical) in buildings for both the heating and cooling seasons and the maintaining of comfort conditions corresponding with the activity within the spaces. Spaces having minimal heating and lighting requirements may serve as an effective buffer zone when placed in the north facing portion of the building. Spaces having greater heating and lighting requirements and more frequent use, can benefit from place- 
ment adjacent to southern exposures. In some passively designed buildings, the probability of large temperature swings may also affect zoning and room placement. The protection of entrances from winter winds by the use of a double entry or vestibule can be advantageous. Reference [14] presents a number of projects which illustrate design response to these needs. The need for grouping of mechanical spaces to take advantage of shorter piping and duct runs and associated thermal losses is similar to non-solar buildings but potentially more important in solar applications. Waste heat recovery and storage in the thermal storage mass of passive solar buildings is often possible. Which combination of options is chosen and how effective the selection will be is dependent on design conditions and design goals.

Bullding/solar system interaction. The adverse effect(s) that a building or site might have on solar $\mathrm{H} / \mathrm{C} / \mathrm{HW}$ systems or components and their performance must be considered in the design. The adverse effect(s) that the solar H/C/HW systems or components have on the building or site are addressed in Chapters 2 through 6 as appropriate.

Solar components should be located where the potential for their misuse is minimized. The proximity of system components to sidewalks and playgrounds should be examined to minimize potential misuse or vandalism.

Bullding exhausts, plumbing vents, or other air discharge openings through roofs or exterior walls should not be located such that their emission will cause the deposition of grease, lint, condensation, or other deleterious materials on solar components, especially apertures or collector glazing. Similarly, solar components should not interfere significantly, either physically or aerodynamically, with building vents, flues, and exhausts.

Interior items such as rugs, carpets, wall hangings, and furniture which may cover passive solar components such as thermal storage, absorbers, or apertures may seriously reduce the thermal performance of these passive components.

Routine malntenance of the building should not have adverse effects on the solar components, nor should required maintenance of the solar systems have adverse effects on the building components. Maintenance of building and site and roof surfaces are specifically covered in Criteria. 6.2.4 and $6 \cdot 2 \cdot 5$. 
1. Plants, People and Environmental Quality, National Park Service, U.S. Department of Commerce, Washington, DC and American Society of Landscape Architects Foundation, 1972.1/

2. Site Planning for Solar Energy Utilization, American Society of Landscape Architects Foundation, for NBS and HUD, 1975.2/

3. Jaffe, M. and Erley, D., Protecting Solar Access for Residential Development, for HUD, HUD-PDR 445, GPO 023-000-00523-9. If

4. A Strategy for Energy Conservation, Proposed Energy Conservation and Solar Utilization Ordinance for the City of Davis, California, City of Davis, CA 95616, 1974.

5. Climatic Atlas of the United States, NOAA, National Climate Center, Federal Building, Ashville, NC 28801, 1977.

6. Comparative Climatic Data, NOAA, National Climate Center, Federal Building, Ashville, NC 28801, 1978.

7. Regional Guidelines for Building Passive Energy Conserving Homes, AIA Research Corporation for HUD, HUD-PDR 355, GPO 023-000-00481-0, $1978.1 /$

8. Mazria, E., The Passive Solar Energy Book, Rodale Press, 33 East Minor Street, Emmaus, PA 18049, 1979.

9. Wright, D., Natural Solar Architecture, A Passive Primer, Van Nostrand Reinhold Co., 135 West 50th Street, New York, NY 10020, 1978.

10. Olgyay, V., Design with Climate, Princeton University Press, Princeton, NJ 08540, 1963.

11. Olgyay, V., Olgyay, A., Solar Control and Shading Devices, Princeton University Press, Princeton, NJ 08540, 1976.

12. Energy Conservation in New Building Design, Standard 90A-1980, American Society of Heating, Refrigeration and Air-Conditioning Engineers, 1791 Tullie Circle, NE, Atlanta, GA 30329, 1981.

13. Peavy, B., Powel1, F., Burch, D., Dynamic Thermal Performance of an Experimental Masonry Building, BSS 45, National Bureau of Standards, $1973 . \underline{3}$ 
14. The First Passive Solar Home Awards, Franklin Research Center, Philadelphia, PA, for HUD, GPO 023-000-00517-4, 1979.1/

15. Petersen, Stephen R., Barnes, Kimberly A., and Peavy, Bradley A., Determining Cost-Effective Insulation Levels for Masonry and WoodFrame Walls in New Single Family Housing, NBS Building Science Series 134, National Bureau of Standards, Washington, DC 20231, 1981.

1/ Superintendent of Documents, U.S. Government Printing Office, Washington, D.C. 20402.

2/ American Society of Landscape Architects Foundation, 1750 old Meadow Road, McLean, VA 22101.

3/ National Technical Information Service, 5285 Port Royal Road, Springfield, VA 22161. 

CHAPTER 2

THERMAL

Page

2.0 Introduction $\ldots \ldots \ldots \ldots \ldots \ldots \ldots \ldots \ldots \ldots \ldots \ldots \ldots \ldots \ldots \ldots \ldots$

2.1 Passive space conditioning $\ldots \ldots \ldots \ldots \ldots \ldots \ldots \ldots \ldots \ldots \ldots \ldots . \ldots \ldots$

2.1.1 Net solar contribution ...................... 2-3

2.1 .2 Thermal storage ........................... 2-5

2.1 .3 Building overheating ....................... 2-7

2.1 .4 Mechanical cooling energy .................... 2-9

2.1.5 Thermal environmental conditions ............... 2-9

2.2 Mechanical space conditioning $. . \ldots \ldots \ldots \ldots \ldots \ldots \ldots \ldots \ldots \ldots . \ldots . \ldots 1$

2.2.1 Mechanical heating system size ................. 2-11

2.2.2 Auxiliary heating system size ................. 2-13

2.2.3 Cooling system size ........................ 2-13

2.2.4 Auxiliary cooling system size ................. 2-14

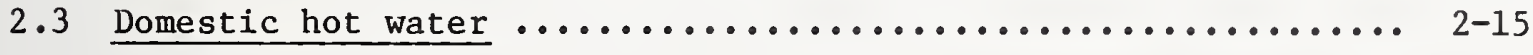

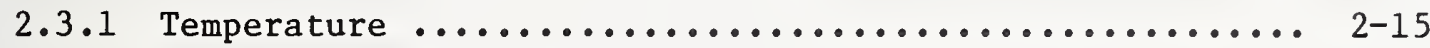

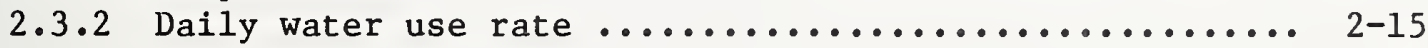

2.3 .3 Hourly recovery rate ........................ 2-16

2.3.4 Auxiliary water heating system ................. 2-16

2.4 Collector array performance $\ldots \ldots \ldots \ldots \ldots \ldots \ldots \ldots \ldots \ldots \ldots \ldots$ 2-17

2.4.1 Collector orientation ..................... 2-17

2.4 .2 Panel performance in array ................... 2-18

2.4.3 Array manifold energy loss .................... 2-18

2.4 .4 Heat loss during non-collection periods ............ 2-19

2.4 .5 Energy rejection ........................... 2-20

2.4 .6 Collector/storage combination .................. 2-21

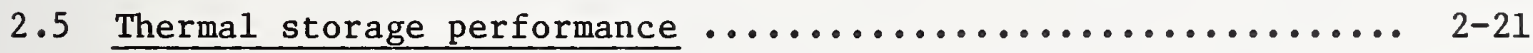

2.5.1 Thermal energy loss ........................ 2-21

2.5 .2 Thermal stratification ...................... 2-22

2.5.3 Addition of auxiliary energy to thermal storage ...... 2-23

2.6 Energy transport performance $\ldots \ldots \ldots \ldots \ldots \ldots \ldots \ldots \ldots \ldots \ldots \ldots . \ldots \ldots$

2.6.1 Thermal energy loss ....................... 2-23

2.6 .2 operating energy ........................... 2-24

2.6 .3 Collector loop transfer rate .................... 2-25

2.6 .4 Energy transfer to 1 oad ....................... 2-25 


\section{CHAPTER 2 - (Continued)}

THERMAL

Page

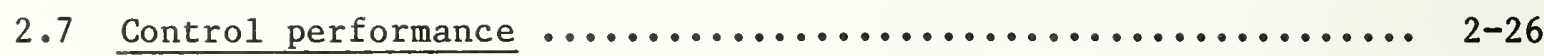

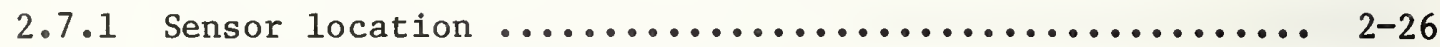

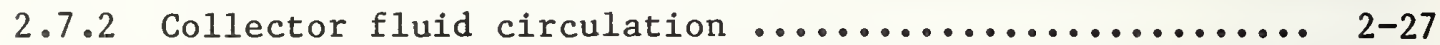

2.7 .3 Priority of energy use ..................... 2-27

2.7 .4 Control valve and damper leakage ................ 2-28

2.7 .5 Control set points ......................... 2-28

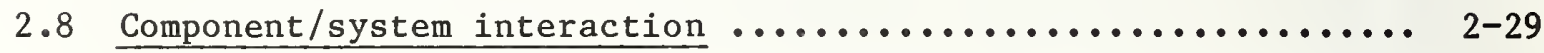

2.8 .1 Collector selection $\ldots \ldots \ldots \ldots \ldots \ldots \ldots \ldots \ldots \ldots \ldots \ldots \ldots \ldots$ 2-29

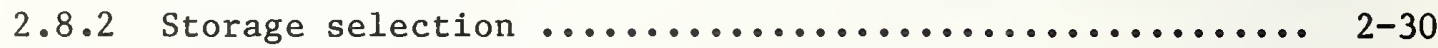

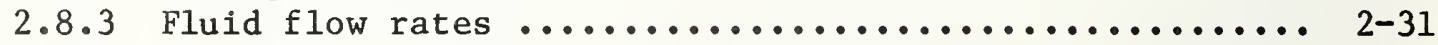

2.8 .4 Auxiliary equipment selection $\ldots \ldots \ldots \ldots \ldots \ldots \ldots \ldots \ldots . . \ldots \ldots$

2.8 .5 Load temperature requirements $\ldots \ldots \ldots \ldots \ldots \ldots \ldots \ldots \ldots \ldots$ 2-32

2.9 Effective use of depletable energy $\ldots \ldots \ldots \ldots \ldots \ldots \ldots \ldots \ldots \ldots \ldots$

2.9.1 Depletable energy use ...................... 2-33

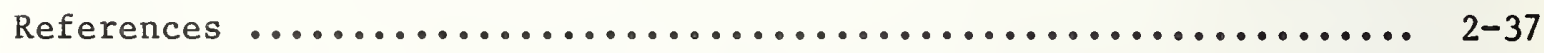




\section{CHAPTEK 2}

\section{THERMAL}

2.0

Introduction This chapter sets forth the requirements and criteria that determine acceptable thermal performance of passive and active solar energy systems in residential buildings. Some of the criteria apply only to either active or passive systems, therefore, a means of categorizing systems by type is required for purposes of thermal analysis. Passive solar energy systems are considered to be primarily part of the building structure, whereas active solar energy systems are considered to be part of the mechanical heating, ventilating, and air conditioning (HVAC) equipment. Energy flows in passive systems are primarily by natural means (radiation, convection, conduction), in contrast to forced flows (by blower or pump) in active systems. Systems in which energy flows are accomplished by a combination of natural and forced means are sometimes referred to as "hybrid" although for the purpose of this document they are considered passive. Passive solar energy systems are distinguished from other elements of the building in that they are capable of controlling solar energy by blocking, transmitting, absorbing, reflecting, or storing it to provide space heating or cooling as desired. Likewise, active solar energy systems are distinguished from other mechanical equipment in that they utilize solar radiation as an energy source. Conventional HVAC equipment used in conjunction with the active solar energy system is referred to as the auxiliary energy system and is considered to be part of the active solar energy system, since the control functions of each are not normally independent. The classification of a solar energy system as active or passive should be done on the basis of whether the system consists primarily of building elements or primarily of mechanical HVAC equipment. See Reference [1]* for a classification of passive and hybrid systems. A passive system may include, in addition to natural energy flow, mechanical equipment for control or heat distribution. An active system may include energy transport by natural convection or solar collectors incorporated as part of the building envelope although the system is primarily mechanical in nature.

Requirements $2.1,2.2$, and 2.3 apply to the design of the solar heating, cooling, and hot water systems with respect to the ability of the system to provide the applicable

* Numbers in brackets [] indicate references at the end of this chapter. 
functions at peak or design conditions. Each criterion under these sections represents a "spot check" of the system capability under selected conditions. The design conditions are not extremes that the system could actually experience, but represent normal probabilities of occurrence, for example the ASHRAE 97-1/2 percent winter outdoor design temperature. Passive solar energy systems (direct gain, mass walls, attached greenhouses, etc.) are treated as building components that utilize radiant solar energy to modify the space conditioning energy requirements. Thus, the energy required for the mechanical equipment (including the active solar energy system) results from exposure of the building, including any passive solar components, to ambient weather conditions such as temperature and solar radiation while maintaining required indoor comfort conditions. For solar energy systems that combine two or more functions, for example, a combined space heating and domestic hot water system with common collectors and storage components, it must be shown separately under the applicable requirements that each function can be met at the design conditions.

Requirements 2.4 through 2.8 apply primarily to active solar energy systems (including auxiliary energy systems). These sections present criteria which specify that individual components and subsystems must meet certain minimum levels of thermal performance as well as interact properly for efficient overall system performance. Space heating, space cooling, and domestic hot water system components must comply with the requirement of these sections if solar energy is utilized for these purposes in a residential building. Thermosiphon HW systems are considered to be active and are included in these sections.

If both passive and active solar features are included in the building design, both are to be included in the analysis for determining the calculated depletable energy use. The end result is the determination of the amount of depletable energy required to be input to mechanical system and/or to the passive components to achieve acceptable system operation.

2.1

Requirement Passive space conditioning. Passive solar heating and cooling systems, if provided, shall be properly designed and integrated into the building to reduce the space conditioning energy requirements for the mechanical system. Passive systems designed for a particular function (heating or cooling) shall not adversely affect the operation of the mechanical system or adversely affect the habitability of the building. 

ed, this requirement is not applicable. Requirements for solar HW systems are described in Requirement 2.3.

Passive solar designs that utilize large south-facing windows to admit winter sun for heating purposes can have a deleterious effect on space cooling loads or habitability, unless sultable precautions are taken to exclude solar radiation during the cooling season using such measures as external shading, internal movable insulation, or venting.

2.1 .1

Criterion Net solar contribution. Passive solar heating systems shall provide a positive net solar contribution to the fully conditioned space for the month of January.

Evaluation A daily 24 hour energy balance for the passive solar heating system sha11 be computed for an average day in January. The option may be taken to demonstrate a net solar contribution for the entire heating season instead of only for the month of January, to account for unusual circumstances (i.e., weather pattern, shading, etc.). The gross solar contribution must exceed the sum of heat losses from the passive system and excess energy discharges, if any, due to the system. The energy balance calculation shall include either solar radiation clear sky data from ASHRAE, Reference [3], Chapter 57, multiplied by the mean percentage of possible sunshine, Reference [4], for January 21, or average daily solar radiation for the month as tabulated in Reference [5] or Appendix A of Reference [6]. The results of energy balance calculations using the clear day data multiplied by the mean percentage of possible sunshine has shown to be reasonably accurate for those parts of the country having high percentages of sunshine, but can be seriously in error for those areas having low percentages of sunshine. The solar radiation data shall be adjusted for the appropriate tilt and azimuth angles of the solar aperture. Gross solar contribution may be calculated by multiplying the total daily solar radiation on the aperture, the transmittance of the glazing, and the absorptance of the receiving surface as described in ASHRAE design heat gain calculation. Reflection and shading shall also be considered. Thermal energy loss through the aperture may be calculated using the product of surface area of the passive aperture, the appropriate overall heat transfer coefficient, and the difference between $70^{\circ} \mathrm{F}\left(21^{\circ} \mathrm{C}\right)$ and average daily outdoor temperature for the month of January. Outdoor temperature data are widely avallable and are also included in the above four references. Mass storage wall components such as Trombe walls or water walls may require more comprehensive analyses than given above if it is 
questionable whether they meet the criterion, but the steady-state calculation should be adequate in most cases provided a rational basis for estimating the storage wall exterior surface temperature is available. More detailed calculations may be provided by the designer.

Commentary Computer programs are available for handheld calculators for analysis purposes, References $[7,8]$ as well as sophisticated computer programs, References $[9,10,11]$. Reference [12] is a brief but comprehensive survey of passive solar building design computer programs.

This criterion is not intended to prevent the use of conventional windows that transmit solar radiation into the residence but are not a part of the passive solar heating system and do not give a net solar contribution.

South-facing windows in cold climates have often been found to be net losers of energy in the winter even though they transmit considerable quantities of solar energy during sunny winter days. Various means can be used to increase the net solar contribution of a passive solar heating system; for example, reflectors to increase incident solar radiation, multiple glazings to reduce heat loss, movable insulation to reduce night time thermal energy loss and appropriately located mass to absorb and store thermal energy. For direct-gain systems, three layers of glazing is usually justifiable in climates of more than 5,000 degree-F days (2800 degree-C days). Balcomb, Reference [6], Chapter E, provides discussion and recommendations for the number of glazings, with and without night insulation, for applications in cities with mild, moderate and severe climates.

The month of January was chosen for evaluation because it is coldest for most locations in the United States. If the passive solar heating system provides a net solar contribution in January, it will probably do so for the less severe winter heating season months. A one-month calculation was chosen for simplicity and to avoid the ambiguity of defining the limits of the heating season. This is not intended to be representative of seasonal thermal performance, but only a check for minimum acceptable performance. Passive solar heating systems that are net heat losers in the coldest month place an undue burden on the mechanical heating system.

Vertical double-glazed windows facing south in Baltimore, Maryland meet this criterion without night insulation. With single glazing, night insulation having an R-value as little as $\mathrm{R}-1$ is needed to meet this criterion. In 
Fairbanks, Alaska, 120 miles (200 km) south of the Arctic Circle, triple glazed south-facing vertical surfaces give a net solar contribution in January even with no night insulation, but assuming some reflection from snow. Two glazings with R-5 night insulation also qualify with no credit for snow reflection.

Of 266 projects selected for awards for the HUD Passive Residential Design Competition, Reference [13] and the HUD Cycle 5 Residential Solar Demonstration Program, Reference [68], 90 percent have a calculated positive net solar contribution in January, Reference [69].

Determination of the optimum aperture area may involve a life-cycle cost analysis as described in Chapter $H$ of Reference [6].

The size of the aperture may affect the net solar contribution in January if the aperture area is large enough (and insufficient storage is provided) so that venting of excess heat is required, since discharged heat reduces net solar contribution. A given size system that provides a positive net solar contribution will continue to do so as the aperture area is increased until the size is reached where venting loss to prevent overheating causes the net solar contribution to become negative. A passive solar heating component having a negative net solar contribution cannot be made to have a positive net solar contribution by increasing its aperture area. Balcomb, Reference [6], Chapter D, gives rules of thumb for sizing solar collection area. The range of values is different for each location. It is recommended that the larger number not be exceeded to prevent building overheating on clear winter days.

$2 \cdot 1 \cdot 2$

Criterion

Evaluation

Commentary
Thermal storage. Thermal storage in the building mass or in thermally-coupled thermal storage areas shall be sized and located to effectively absorb, store, and release thermal energy, reduce space temperature variations, and minimize the space conditioning energy requirements for the mechanical system.

Review drawings, specifications, and calculations. Calculations shall take into account the amount of the mass, location relative to solar gain areas, forced or natural convection of air to and from storage, and presence of insulating materials such as carpets or hangings over massive floors or walls that prevent direct solar radiation.

The need for storage depends on the size of the aperture relative to the size of the heated space. In some 
instances, the thermal storage of the building mass alone may be adequate. Generally 30 to $45 \mathrm{Btu} /{ }^{\circ} \mathrm{F} \cdot \mathrm{ft}^{2}(600$ to 900 $\mathrm{KJ} /{ }^{\circ} \mathrm{C} \cdot \mathrm{m}^{2}$ ) based on aperture area is recommended. The lower end of the range should be used for small aperture areas relative to building size and the upper end to large aperture areas. Storage mass which directly receives sunlight will store up to four times as much thermal energy as mass which is not in direct sunlight, and storage capacity should be adjusted accordingly. To prevent overheating of the conditioned space, it is extremely important that sufficient thermal storage is provided when the aperture area is large. Venting of excess heat, instead of redistributing it to remote storage, reduces the net solar contribution of the system. (see Criterion 2.1.1).

If locating the storage so that it is exposed to direct solar radiation is not practical, it may be remotely located. For large systems this has the advantage of distributing heat to other parts of the building and enabling a very large storage. The low temperature of heat stored by this means, however, makes air-flow heat transfer back to the living space very inefficient and direct thermal coupling of storage to space is preferred. Remote thermal mass charged by air may be effective for attached sunspaces but are not advisable for direct gain systems because of the moderate temperatures of any available heat. Rock bins may be located directly under floors for satisfactory operation. See Criteria 2.5.1-2.5.3 for further discussion of isolated thermal storage.

Storage mass thickness, exposed area, location relative to aperture and conditioned space, and thermal characteristics not only influence heating effectiveness but also have a pronounced effect on space temperature fluctuations. Reference [13] describes these effects and Reference [14] provides procedures for predicting them. For the direct gain zone in general, massive surfaces should be relatively dark in color and low density surfaces should be relatively light. The time delay of thermal conduction should be considered in determining the thickness of passive storage mass. Thermal properties, including absorptance characteristics, for commonly used storage materials are given in Table B.5 of Appendix B of this document as well as in Reference [14].

In direct gain situations and for a fixed quantity of thermal storage mass, spreading the mass over as large an area as possible will maximize performance and will minimize the thickness of the mass layer. Mass near the surface is more effective than mass at a greater depth because it is more directly coupled with the conditioned space. Floor 
slabs directly over dry earth, and with perimeter insulation only, will likely have a tempering effect on interior temperatures during long, cold, cloudy periods, although temperatures may drop somewhat.

2.1 .3

Criterion

Evaluation

Commentary
Building overheating. Heat gain from passive solar components shall not cause the instantaneous dry bulb temperature in occupied spaces to exceed $82^{\circ} \mathrm{F}\left(28^{\circ} \mathrm{C}\right)$ or $5^{\circ} \mathrm{F}\left(3^{\circ} \mathrm{C}\right)$ above the simultaneously-occurring outdoor dry bulb temperature, whichever is greater, if mechanical cooling is not provided. (If mechanical cooling is provided, see Criterion 2.1.4.)

Review drawings, specifications, and calculations. Review local weather data and sun angles. Compliance shall be demonstrated for both the months of July and October.

The $82^{\circ} \mathrm{F}$ limit has been established by the American Ventilation Association as the temperature at which reasonably comfortable conditions can be provided through whole house ventilation, Reference [15]. With ventilation, the $5^{\circ} \mathrm{F}$ limit can be maintained. The ASHRAE Thermal Comfort requirements do not apply in situations where space conditioning is not supplied. The intent of the Criterion is to make the comfort requirements for passive solar houses reasonably consistent with conditions found in non-solar, non-air conditioned houses.

The following three methods might be considered to prevent building overheating:

1. Shading

2. Provision of adequate thermal storage

3. Whole-house ventilation

First, it may be shown that appropriate shading devices are utilized to prevent transmission of solar radiation affecting the fully conditioned space. Suitable methods include fixed or movable shades, movable insulation, and venting of semi-conditioned spaces such as in attached sunspaces or the space between glazings and mass storage walls. In the case of shading, the solar aperture should be fully shaded from three hours before until three hours after solar noon at mid month.

Reference [6], Appendix C, provides data for determining monthly solar radiation on the collection surface, considering factors such as latitude, solar declination for the month, overhang, tilt, and azimuth of the collector. Clear 
sky solar radiation values for either the 15 th or 21 st (whichever is available) of the month should be used.

Second, it may be shown that thermal energy storage within the space effectively absorbs and stores heat to limit the maximum space temperature to the required value. An hourly simulation for 24 hours should be performed, considering such factors as solar radiation transmitted, the absorptance of receiving surfaces, placement and capacity of thermal storage devices, and timing and flow rate of ventilation air. However, there is some concern that excessive mass in a building may absorb internal heat gains and may prevent the ability to cool down living spaces quickly using natural ventilation at nighttime. Fan-forced remote rock bin storage may be used and may avoid this potential conflict. Handheld calculator programs such as PEGFIX, Reference [8] and TEANET, Reference [7] are available and should assist in carrying out the analysis.

Third, when the normal maximum outdoor temperature is above $75^{\circ} \mathrm{F}\left(24^{\circ} \mathrm{C}\right)$, it may be shown that whole-house ventilation is provided and adequately sized to maintain indoor temperatures less than $5^{\circ} \mathrm{F}\left(3^{\circ} \mathrm{C}\right)$ above the simultaneouslyoccurring outdoor temperature. A complete discussion of whole-house ventilation effects is given in Reference [15], pages 73-104.

Overheating is a potential problem for passive solar heating systems designed to provide heating during the winter. Shading of the aperture is an effective way to prevent overheating. Significant sources of information for controlling solar heat gain are in References [16, 17 and 18]. Temperatures may rise in attached greenhouses or other semi-conditioned spaces above the outdoor ambient temperature. Venting of these spaces will help to control temperatures in adjacent fully conditioned spaces. Vent area equal to 10 percent of the glazed area is generally suggested, with outlets being slightly larger than inlets.

Fixed shading devices designed to shade at the summer solstice (about June 22nd) or in July may not be effective in late summer or early fall due to lower sun angles. The month of October presents a particularly difficult design problem to prevent overheating because of the low sun angle combined with relatively warm weather in many climatic regions. Various devices such as screens, curtains, shutters, reflective shades, blinds, awnings, vegetation, and especially adjustable overhangs can be effective in controlling solar radiation. The concern is that these devices be properly sized and detailed. 
A method for estimating temperature swings in direct gain spaces is given in Reference [6], Chapter F. Direct gain spaces are more susceptible to large temperature variations than indirect-gain types such as Trombe walls or water walls.

2.1 .4

Criterion

Evaluation

Commentary

2.1 .5

Criterion
Mechanical cooling energy. The net solar contribution from passive solar components shall not significantly increase the energy requirement of the mechanical space cooling system relative to typical wall and roof sections during a typical sunny July day, if mechanical cooling is provided.

Daily net solar contribution to the fully conditioned space shall be calculated for the passive solar component and for a substituted conventional wall/roof section for a typical, sunny July day. The substitute wall section shall have the same heat transfer coefficient as other exterior walls for 85 percent of its area and shall be considered glazed for 15 percent of its area. The glazed portion shall have a transmissivity of 0.80 and a heat transfer coefficient of $0.6 \mathrm{Btu} / \mathrm{h} \cdot{ }^{\circ} \mathrm{F} \cdot \mathrm{ft}^{2}\left(3.4 \mathrm{~W} / \mathrm{K} \cdot \mathrm{m}^{2}\right)$ and shall be considered to be fully exposed to direct sunlight throughout the day. Average daily values of outside temperature and solar radiation may be used in the calculations. Inside temperatures may be fixed at $78^{\circ} \mathrm{F}\left(26^{\circ} \mathrm{C}\right)$. Calculation of net solar contribution for each case shall be equivalent in detail to the evaluation procedure of Criterion 2.1.1. Alternatively, complete shading of the passive solar component for three hours before and after solar noon shall be sufficient evidence that this criterion is met.

The month of July was chosen for simplicity and because it has the highest dry bulb temperature for many locations in the United States. The alternative wall section parameters are based on a typical wall for conventional residences with a double-glazed window. The net solar contribution calculation has three components: (1) total solar input, (2) heat transfer through the solar components (including infiltation), which will be from outside to inside if the average daily outdoor temperature is above $78^{\circ} \mathrm{F}\left(26^{\circ} \mathrm{C}\right)$, and (3) ventilation losses to discharge excess heat gain, for example, venting of a mass wall or sunspace.

Thermal environmental conditions. For fully conditioned spaces, passive solar systems shall not cause the thermal conditioning to exceed the ranges specified by ASHRAE Standard 55-81 [19]. The 1imits of acceptable comfort conditions that are given in the ASHRAE Standard are summarized in the following commentary. Should there be conflict 
between this and Criterion 2.1.3, Criterion 2.1.3 shall prevail.

Evaluation Review drawings, specifications, and calculations. Compliance shall be demonstrated for the months of January, July, and October. Corresponding calculations for these months as required in 2.1 .1 and 2.1 .3 can be used. Some conditions may require more detailed analysis such as the effects of mean radiant temperature.

Commentary The intent of this criterion is to assure reasonable thermal comfort for the occupants as well as account for thermal environment variations that are appropriate for many passive applications. The operation of many passive systems are dependent upon temperature gradiants to get thermal energy into and out of storage and to transport energy from one location to another. Moderate temperature fluctuations, approximately 6 to $8^{\circ} \mathrm{F}$ ( 3 to $4^{\circ} \mathrm{C}$ ), outside the comfort zone may be appropriate during non-use periods such as night hours (winter).

In addition to air temperature, the thermal comfort in interior spaces is affected by the temperature of interior surfaces, air velocity, as well as clothing characteristics of the occupants. The mean radiant temperature (MRT) is as important as air temperature in affecting heat loss and comfort. When air movement is low, the operative temperature is approximately the average of air temperature and MRT. A thorough discussion of these factors and design guidelines are given in ASHRAE Standard 55-81, Reference [19].

The following comfort zone parameters are summarized from ASHRAE Standard 55-81:

- Winter/summer operative temperature ranges: winter 67$76.4^{\circ} \mathrm{F}\left(19-22.7^{\circ} \mathrm{C}\right)$; summer $73-79^{\circ} \mathrm{F}\left(21.9-23.7^{\circ} \mathrm{C}\right)$. These temperatures are acceptable by $80 \%$ of sedentary building occupants and considers typical seasonal clothing.

- The thermal effect of humidity (within the range of 30 to $70 \mathrm{RH})$ on the comfort of sedentary persons is small.

- Normal acceptable air movement is $30 \mathrm{fpm}$ (.153 mps) (winter) and $50 \mathrm{fpm}$ (.255 mps) (summer) but it can be extended in some cases to $160 \mathrm{fpm}$ (.816 mps) to extend the upper boundary of the comfort zone to $82.5^{\circ} \mathrm{F}\left(28.5^{\circ} \mathrm{C}\right)$ in summer.

- The rate of cyclic temperature change should not exceed $4^{\circ} \mathrm{F} / \mathrm{h}\left(2^{\circ} \mathrm{C} / \mathrm{h}\right)$ if the peak to peak variation exceeds $2^{\circ} \mathrm{F}$ $\left(1^{\circ} \mathrm{C}\right)$. 
- Slow rates of temperature change (approximately $1^{\circ} \mathrm{F} / \mathrm{h}$ ) $\left(.5^{\circ} \mathrm{C} / \mathrm{h}\right)$ during the occupied perlod are acceptable provided the temperature during this "drift" does not extend beyond the comfort zone by more than $1^{\circ} \mathrm{F}\left(.5^{\circ} \mathrm{C}\right)$ for longer than one hour.

- Asymmetric radiation from hot and cold surfaces and from direct sunlight can cause local discomfort and reduce the thermal acceptability level of the space. In general, people are more sensitive to asymmetric radiation caused by a warm ceiling than caused by hot and cold vertical surfaces.

- To minimize foot discomfort, the surface temperature of the floor for people wearing appropriate indoor footwear should be between $65^{\circ} \mathrm{F}\left(18.3^{\circ} \mathrm{C}\right)$ and $84^{\circ} \mathrm{F}\left(28.8^{\circ} \mathrm{C}\right)$.

Although the system may be operated by choice outside the comfort range, it should be demonstrated that the system is capable of providing these conditions.

2.2

Requirement Mechanical space conditioning. The mechanical space heating and space cooling systems, which include the active solar energy and auxiliary energy systems, shall be capable of maintaining comfortable indoor conditions during periods of occupancy and automatically operating to protect the building and its contents against damage due to temperature extremes when the building is unattended.

Commentary The mechanical systems must meet the remaining heating and cooling energy requirements after these requirements have been reduced by the use of passive solar techniques, if provided. Provisions should be made to prevent simultaneous heating and cooling. See Criterion 2.7.3.

2.2 .1

Criterion Mechanical heating system size. The mechanical (combined active solar and auxiliary) heating system shall be capable of providing $70^{\circ} \mathrm{F}\left(21^{\circ} \mathrm{C}\right)$ in fully conditioned spaces at 97-1/2 percent winter outdoor design conditions.

Evaluation Review drawings, specifications, and calculations. Design load calculation shall exclude instantaneous solar gains and internal heat release from occupants, lights, and appliances. A building heat loss calculation procedure comparable in detail to the method outlined by ASHRAE, Reference [20] or [16], Chapters 22, Infiltration and Ventilation; 23, Design Heat Transmission Coefficients; 24, Weather Data and Design Considerations; and 25, Heating Load, shall be used. For heat loss calculations, exterior thermal storage 
walls associated with passive solar components shall be assumed to be at room temperature. The design load may be reduced by an amount equivalent to the rate of energy released from thermal storage within the building mass if shown to be appropriate for the historical frequency of occurrence of low ambient temperature and solar radiation. (These frequency distributions have not yet been developed.) For discussion of typical storage capability and sizing procedures see Reference [21]. At design load conditions, all movable passive solar components shall be considered to operate as designed.

Reference [22] provides acceptable methods of design of conventional space heating systems that are also useful for solar energy systems.

Commentary

Although the residence may not be operated to maintain $70^{\circ} \mathrm{F}$ $\left(21^{\circ} \mathrm{C}\right)$ during any or all of the heating season, the mechanical system must be capable of meeting the design load based on these conditions. Calculation of the amount of depletable energy used by the system during the heating season need not necessarily be based on maintaining $70^{\circ} \mathrm{F}$ $\left(21^{\circ} \mathrm{C}\right)$. This calculation may be based on an interior temperature specified by the applicable authority and should reflect current trends in energy conservation. This calculation is not required here but is addressed in Requirement 2.9, Effective Use of Depletable Energy.

Comfort conditions combining the effects of dry bulb temperature, mean radiant temperature, and relative humidity are presented in ASHRAE Standard 55-81, Reference [19]. Occupied spaces for sedentary activities in normal dress are usually designed for heating to maintain a recommended indoor temperature of $70^{\circ} \mathrm{F}\left(21^{\circ} \mathrm{C}\right)$ dry bulb, References $[17,19]$. However, mean radiant temperature may be used on an equal basis to calculate comfort conditions. Minimum and maximum temperature and humidity conditions are also specified in ASHRAE Standard 55-81, Reference [19]. Spaces intended to be used as part of a passive system may be designed for temperature fluctuations compatible with their functional use. Housing for the elderly and caretype facilities may use other indoor design temperatures and design parameters, References [22, 23].

Chapter XII of Reference [24] provides a comprehensive description of considerations in the design of solar space heating systems. References [25, 26, 27] describe some problems encountered in heating system designs in the National Solar Demonstration Program. 


\section{2 .2}

Criterion

Evaluation

Commentary

\section{2 .3 \\ Criterion}

Evaluation
Auxiliary heating system size. The auxiliary space heating system shall be sized and designed to operate automatically to maintain indoor temperature at or above $55^{\circ} \mathrm{F}\left(13^{\circ} \mathrm{C}\right)$ in fully conditioned spaces at the $97-1 / 2$ percent outdoor winter design conditions, Reference [16]. Manually-operated passive solar components (such as movable insulation but not exhaust vents) shall be considered to be left in the maximum-heat-loss position.

Review drawings, specifications, and weather data. The auxiliary system must function independently of the solar energy portion of the system, when appropriate. Refer to Criterion 2.2.1 for calculation of space heating load. For building heat loss calculations see ASHRAE, Reference [20] or [16]. ASHRAE, Reference [22] provides acceptable methods of design of space heating systems.

The auxiliary space heating system is the part of the mechanical system that utilizes depletable energy sources, rather than solar energy, to meet the heating load. The purpose of this criterion is to maintain habitability and protection of occupied spaces for periods when there is insufficient solar energy to operate the system as designed and for periods when the solar heating system is not operated due to maintenance or repairs. Depending on the building and space heating system design, the auxiliary space heating system may also be required to meet $70^{\circ} \mathrm{F}\left(21^{\circ} \mathrm{C}\right) \mathrm{com}-$ fort conditions in fully conditioned spaces (see Criterion 2.2.1). Spaces which may not be fully conditioned and are susceptible to temperature fluctuations should not contain elements which would be susceptible to freezing.

Cooling system size. The mechanical (combined active solar and auxiliary) space cooling system, if provided, shall be capable of providing temperature and relative humidity specifled by the applicable authority in fully conditioned spaces at 2-1/2 percent summer outdoor design conditions, Reference [16].

Review design climatic conditions, design indoor comfort conditions, and cooling load calculations. A bullding coolIng load calculation procedure comparable in detall to the method out1ined in Reference [16], or Reference [20] shall be used. The design load may be changed due to the operation of passive solar components such as shading devices and movable insulation and due to thermal storage within the bullding mass if justified by statistical analysis of weather patterns. For one- or two-family residences, the design load may be calculated using the simplied procedure 
described in Reference [16]. However, the design load shall include all sensible and latent heat load from all solar energy system equipment. Most cooling calculations require consideration of indoor temperature and humidity and the applicable authority should establish limits for these factors.

The space cooling system, if provided, must maintain comfort conditions when passive solar components for space heating and/or mechanical components for water heating are operated as designed. Reference [22], provides recommended design criteria for conventional space cooling systems that are also useful for solar space cooling applications. Chapter XIII of Reference [24] provides a description of several methods that directly utilize solar energy for space cooling. Reference [25] describes some generic system problems encountered with space cooling system designs from the National Solar Demonstration Program, and Reference [28] provides a summary of measured thermal performance of several of the instrumented space cooling systems.

Cooling equipment utilizing conventional energy, ambient air, ground sink or stored thermal energy may be used in conjunction with the solar system in an assist or auxiliary mode. The use of evaporation, nocturnal radiation, desiccant cooling, or other passive techniques should be designed to operate in conjunction with devices that collect, store, or distribute the converted thermal energy in a controllable manner.

Occupied spaces for sedentary activities in normal dress are usually designed for cooling to maintain a recommended indoor temperature of $75^{\circ} \mathrm{F}\left(24^{\circ} \mathrm{C}\right)$, References $[19,23]$. Minimum and maximum temperatures are also specified in the ASHRAE Standard 55-81, Reference [19]. Indoor design temperatures have not been specified in this criterion because they vary depending on when and how a space is used. Spaces intended to be used as part of a passive system may be designed for temperature fluctuations compatible with their functional use. Buildings with special functional requirements such as care-type facilities and housing for the elderly may use other indoor design temperatures and design parameters, References [19, 23].

2.2 .4

Criterion

Auxiliary cooling system size. The auxiliary cooling system, if provided, shall be capable of providing temperature and relative humidity specified by the applicable authority in fully conditioned spaces at $2-1 / 2$ percent summer outdoor design conditions, Reference [16]. 
Evaluation

Commentary

2.3

Requirement

Commentary

2.3 .1

Criterion

Evaluation

Commentary

2.3 .2

Criterion
Review drawings, specifications, and calculations. Design cooling load and system design procedure shall be equivalent to that in Criterion 2.2 .3 except the interior temperature and/or relative humidity requirements may be less stringent for the auxiliary cooling system. For building cooling load calculations, see ASHRAF, Reference [16] or ASHRAE, Reference [20].

No auxiliary cooling system is required.

Domestic hot water. The combined solar and auxiliary domestic hot water system shall efficiently utilize solar energy to reduce the consumption of depletable energy while providing domestic hot water at required temperatures and delivery rates.

Domestic hot water systems may be passive or mechanical type (including thermosiphon collection loops). Passive design may be as simple as a dark color water tank exposed to solar radiation and enclosed by an insulated box with a transparent cover. Frequently, movable insulation is used as a nighttime cover to reduce heat losses. Mechanical systems are designated by type of solar collection fluid and type of freeze protection, for example, pumped vs. thermosiphon flow, direct vs. indirect heat exchange with collectors, or water vs. antifreeze systems.

If the solar domestic hot water system is combined with a solar space conditioning system, this requirement applies to the combined system to the extent sufficient to show that the domestic hot water function is met.

Temperature. The hot water system (combined solar and auxiliary) shall be capable of providing hot water at a tap temperature up to $140^{\circ} \mathrm{F}\left(60^{\circ} \mathrm{C}\right)$, except in housing for the elderly and care-type facilities, for which hot water temperatures are specified in Section $615-6.1$ of MPS 4910.1, Reference [29] and MPS 4920.1, Reference [30].

Review drawings, specifications, and calculations.

See Criterion 4.3 .4 for health and safety related provisions.

Dally water use rate. The hot water system shall be designed to provide daily hot water usage for single family and multifamily dwellings of up to 20 units based on 20 gal/day ( $76 \mathrm{~L} /$ day) per person for the first two persons and 
Evaluation

Commentary

2.3 .3

Criterion

Evaluation

2.3 .4

Criterion

Evaluation

Commentary
15 gal/day ( $57 \mathrm{~L} /$ day) for each additional person with a minimum usage of $40 \mathrm{gal} /$ day $(150 \mathrm{~L} /$ day $)$. Dally hot water usage for each dwelling unit in a larger multifamily building shall be based on $40 \mathrm{gal} / \mathrm{day}$ ( $150 \mathrm{~L} / \mathrm{day}$ ) for buildings having 21 to 200 units and 35 gal/day $(130 \mathrm{~L} /$ day $)$ for buildings having over 200 units, Reference [22].

Review drawings, specifications, and calculations. This criterion may be met by storage of a sufficient quantity of hot water such that the combination of storage volume and temperature will provide the stated daily usage at the tap temperature given in Criterion 2.3.1. Heat losses from the storage container and distribution losses must be subtracted from the stored energy to determine the net quantity of hot water available for use at the tap. Energy in solar storage containers (heated only by solar energy and not by auxiliary energy) may not be included in the daily usage total unless justification is provided based on historical solar radiation data.

Auxiliary heaters may be provided having a recovery rate (per hour) equal to the total daily usage rate instead of storage. Large storage relative to collector area can prevent achieving useful temperature as well as causing excess heat losses. Even a very well insulated solar storage container of extremely large capacity will seldom get sufficiently hot, thus requiring auxiliary energy to boost water temperature to set the temperature.

Hourly recovery rate. The hot water system shall be capable of providing hot water at draw and recovery rates as shown in Tables 6-15.2 and 6-15.3 of HUD Minimum Property Standards, Reference [31] or as given in ASHRAE Systems Handbook, Reference [22] for multifamily as well as care type facilities.

Review drawings, specifications, and calculations.

Auxiliary water heating system. The auxiliary water heating system shall be capable of providing 100 percent of the hot water temperature and recovery rates specified in Criteria 2.3 .1 and 2.3.3.

Review of drawings, specifications, and calculations.

Most well-designed solar hot water systems provide over half of the annual hot water energy requirements with solar energy. On an hourly basis, however, there are many times when these systems must operate with no available solar 
energ., such as at night or cloudy days. Therefore, the auxiliary heating system must be capable of meeting the hourly loads.

2.4

Requirement

Commentary

2.4 .1

Criterion

Evaluation

Commentary
Collector array performance. The solar collector array shall be capable of absorbing solar radiation and converting it into useful thermal energy for providing the functions of space heating, space cooling, and/or domestic water heating.

Typical values for the ratio of actual collected solar energy to theoretical collected energy using collector test data are given in Reference [32]. Array performance reduction of less than 10 percent relative to individual collector panel test data values can be expected in well-designed systems.

Collector orientation. The collector array shall be positioned so that the seasonal/annual incident solar radiation per unit area shall not be significantly less than the seasonal/annual incident solar radiation on a reference collector array at optimum collector orientation with no shading, except where special circumstances require nonoptimum orientation.

Collector orientation factors are given for converting radiation on a horizontal surface in Chapter 3 of Reference [33]. Examine the solar radiation data for the geographic location, orientation of collector array, shading (external shading and self-shading by other collectors in the array) and building shape and orientation.

Retrofit situations may result in deviation from thermally optimum orientation. Typically, annual/season incident solar radiation should not be less than 80 percent of the radiation that would be received at the optimum orientation. In general, collectors should face due south and have a tilt angle equal to (a) local latitude for water heating only or for combined space heating and cooling, (b) local latitude minus 15 degrees for space cooling only, and (c) local latitude plus 15 degrees for space heating only or combined space and water heating. High-rise buildings with small roof areas or unfavorable building orientation may require special architectural integration and preclude thermally-optimum orientation, yet these systems may be technically and economically appropriate. Tilt deviations of $+15^{\circ}$ from the above values and deviations of $20^{\circ}$ east and $30^{\circ}$ west of true south will not likely decrease performance by more than 10 percent. Local conditions such as 


\section{4 .2}

Criterion

Evaluation

Commentary

\section{4 .3 \\ Criterion}

shading or fog, or the particular advantages of emphasizing morning or afternoon gain should be considered.

Panel performance in array. An individual collector panel in the array shall not operate at significantly less efficiency than the test efficiency curve due to differences between test and actual operating fluid flow rate and fluid properties.

Procedures equivalent in accuracy to ASHRAE Standard 93-77, Reference [34], shall be used to determine collector test efficiency curves. Post-stagnation test, as given in Section 10 of the Appendix (modification of test in NBSIR 781305A), Reference [35], is required. Calculation of flow rate through the lowest flow panel is required. Hydraulic and thermal calculations shall be made for the condition of normal total flow rate through the array. Consideration must be taken for turbulent/laminar flow in the collectors and manifolds, fluid properties, and array configuration. Reference [36], page 148, may be used to determine loss in efficiency due to flow rate and fluid property changes for a typical liquid collector. Reference [37] gives the effect of flow rate on a typical air-type collector and also gives typical collector efficiency curves. Internal manifolding of collector panels in an array may increase efficiency relative to single-panel tests by reducing edge losses.

The middle collectors in parallel arrays tend to have reduced flow and therefore run hot, resulting in increased losses. To alleviate this, a high ratio of pressure drop across any panel to the pressure drop across the manifold is required. The minimum flow through a panel is important but it is not necessary to have balance of flow to all collectors in the array. Flow should be maintained within the manufacturer's stated range of flow rates in all collectors in the array. Too many collectors in series increases the inlet temperature of the latter collectors and should be avoided. Any change in inlet temperature will shift the operating point on the efficiency curve. Experimental studies, Reference [66], of the influence of flow rate and fluid type in a broad class of flat plate collectors resulted in thermal performance variations of up to 10 percent.

Array manifold energy loss. During normal operating conditions, heat loss, including that due to air leaks (infiltration or exfiltration) from the collector array manifolds and piping within the collector array shall not exceed 15 percent of the solar energy collection rate. 
Evaluation

Commentary

2.4 .4

Criterion

Evaulation

Review drawings and specifications. Examine the insulation properties, air leaks in the system, and typical collection fluid operating temperature.

Heat loss from internal manifolds and within individual collector panels is taken into consideration in the panel performance (Criterion 2.4.2) and is not included in this criterion.

Typical heat loss levels that have been achieved in the National Solar Demonstration Program are less than 10 percent of the solar energy collection rate for liquid systems and 15 percent for air systems. Air leakage from ducts can significantly increase thermal energy loss (see Criterion 3.3.4 for specification of allowable air leakage). There is evidence that malntaining a slight negative pressure in the collector array to ensure any leaks result in air infiltration, may be more beneficlal than allowing air exfiltration from the array. Reference [38] provides a simple analytical technique for analyzing the thermal effects of collector air leakage. A similar procedure for analyzing the effect of heat loss from collector supply and return ducts or pipes on system performance is described in Reference [39]. Chapter 9 of Reference [40] recommends suitable insulation type and thickness for collector array manifold pipes and ducts. Reference [41] describes methods for determination of economically optimum insulation thickness.

Heat loss during non-collection periods. Heat loss from the collector array during times other than normal operating conditions shall not exceed 10 percent of the design monthly collected solar radiation in the month of January.

Heat loss due to thermosiphoning, capacitance effects, and freeze protection shall be evaluated separately.

Review drawings and specifications. Check valves or backdraft dampers must be present to prevent reverse thermosiphoning when the collectors are colder than storage, if the collectors are located above the storage, remain filled and the configuration permits thermosiphoning.

Capacitance effects shall be calculated for an average day in January and compared with the solar energy collected during that same day. When the collection fluid remains in the collector during periods of non-operation, daily heat loss due to capacitance effects may be calculated as the product of fluid mass in the collector and exterfor piping or ducts, fluid heat capacity, and the difference between the temperature of the hot fluld at the time of system 
Commentary

shutdown and the temperature to which it cools ("normal minimum" for the month of January, Reference [4]).

Heat loss due to freeze protection (draindown, fluid circulation, etc.) shall be calculated for an average day in January and compared with solar energy collected during the same 24-hour period. If circulation of liquid from storage is used as the freeze protection method, heat loss from collector and exterior piping shall be calculated for the length of time liquid is circulated. Calculations shall consider ambient temperature, sky temperature (approximately $10^{\circ} \mathrm{F}\left(6^{\circ} \mathrm{C}\right)$ below ambient), storage temperature, insulation of pipes, and heat loss factor of collector $\left(F_{R} U_{L}\right)$. The time of freeze control circulation shall be calculated based on control strategy (Requirement 2.7 ), length of day, percent possible sunshine, and statistical ambient temperature data. Energy loss due to other methods and freeze protection such as heat tapes and motorized valves shall be included.

Draining of all liquid from collector and exterior piping to the storage tank when energy is not available (collector drain back system) eliminates heat loss due to thermosiphoning, capacitance, and freeze protection and is recommended for many applications. Recirculation requires proper sensor location and temperature set points for optimum thermal efficiency. Criteria 2.7.1 and 2.7.5 discuss sensor location and control set points, respectively. The effect of leaking dampers in air-type systems is discussed in Reference [42]. Leakage of dampers which serve to isolate the collector loop from the rest of the system should be limited to two to five percent. Spring loaded check valves should be considered for preventing thermosiphoning in liquid systems. See Criteria 3.2.9 and 3.3.3. The non-collection period addressed in this criterion does not include shutdown for repairs and maintenance.

2.4 .5

Criterion

Evaluation

Cornmentary
Energy rejection. If energy rejection is provided for in the design, the collectors shall be capable of rejecting energy at the required rate.

Review drawings, speciffcations, collector heat loss test data, and calculations. Collector heat loss rate may be estimated using the slope of the ASHRAE 93-77, Reference [34] test efficiency curve. The effect of the collector loop heat exchanger must be considered.

The use of the slope of the ASHRAE 93-77 thermal efficiency curve, $F_{R} U_{L}$, when multiplied by the collector area and difference between ambient and fluid temperatures, will give 
a conservative value of heat rejected, and is satisfactory for design purposes. More accurate (and higher) values of heat rejected may be calculated using more refined analyses, including the effective temperature of the night sky, since higher losses would be experienced at night than during the daytime when the ASHRAE 93-77 curve is determined. Efficient solar collectors are inherently inefficient heat rejectors, especially designs utilizing selective absorbing surfaces, double glazing or evacuated tubes. It is difficult to reject at night the amount of heat collected during a typical sunny day; therefore, special heat rejection panels may have to be incorporated into the collector array.

2.4 .6

Criterion

Evaluation

Commentary

2.5

Requirement

Commentary

2.5 .1

Criterion

Evaluation

\section{Collector/storage combination.}

Collector/storage combinations shall collect or dissipate energy at the design rate.

Review drawings, specifications, test data, and calculations •

Collector/storage combinations can be packaged systems designed to be placed adjacent to a house and filled with storage materials such as rocks or can be built in place. Trombe walls and similar passive components are not covered under this criterion (see Criterion 2.1.1). For packaged systems, it is recommended that test data be developed in accordance with the procedures given in Reference [43].

Thermal storage performance. The thermal storage subsystem shall be capable of efficiently accepting thermal energy, storing it, and releasing it to satisfy partially or fully the space heating, space cooling, and/or hot water load.

If thermal storage is not provided, this requirement is not applicable. Refer to Criterion 2.8.2 for information concerning the size of thermal storage and its effect on system performance.

Thermal energy loss. Thermal energy loss from thermal storage, including loss due to air leakage (in or out) shall not exceed 15 percent of the energy input to the storage subsystem for those months in which the load exceeds the collected solar energy.

Review drawings, calculations, and specifications. Examine for conductive heat loss through insulation, losses through storage container structural supports, and losses due to air leakage. 
Commentary Specification of allowable air leakage from thermal storage containers is given in Criterion 3.3.4. Storage containers for air systems should be sealed in accordance with Criterion 3.3.2. See also Criterion 3.1.3 for coverage on insulation.

Typical measured values in the solar demonstration program show heat loss as low as five percent of the energy input to storage, during the heating season. Reference [44], Section S-615-7.3.4, requires for residences that "the thermal energy loss from storage containers located outside the heated dwelling shall not exceed 10 percent of the maximum operating thermal energy capacity over an average 24hour winter design day," and Reference [40], Section 9.5, limits heat loss to two percent of the stored energy over a 12-hour period unless heat loss will supplement the space heating requirement. Reference [21], page 19, gives a simple calculation procedure for determining the required insulation to limit heat loss to two percent in 12 hours.

If thermal losses from storage are limited to the levels specified by this criterion, the adverse effect on the cooling load during any summertime operation should be acceptably low.

2.5 .2

Criterion Thermal stratification. Thermal stratification in the storage subsystem shall be promoted to reduce the inlet temperature to collectors and increase the temperature to loads.

Evaluation Review drawings and specifications. Examine the geometry of storage container, location of inlets and outlets, velocity of heat transfer fluid, presence of baffles, and use of multiple storage containers.

Commentary Thermal stratification in the storage container is usually desirable in order to provide low collector inlet temperatures and to provide high temperatures to load or equipment. Consideration should be given to trade-offs between stratification and heat losses from a second tank in the case. of solar water heaters. F-Chart, Reference [33] assumes fully mixed storage. Improved thermal performance may be achieved in practice with stratified storage. 
The thermal performance of a well-insulated tank in the demonstration program was improved greatly by eliminating short-circuiting from inlet to outlet by means of baffles.

In single-tank HW systems, the electrical heating element should be placed at approximately the upper third of the tank to promote stratification. Short-circuiting of water flow paths between the inlet and outlet of storage should be prevented. Reference [45] describes the effect of stratification by use of mathematical models.

2.5 .3

Criterion

Evaluation

Commentary

2.6

Requirement

2.6 .1

Criterion

Evaluation
Addition of auxiliary energy to thermal storage. Addition of auxiliary energy to the thermal storage subsystem shall not significantly reduce the collected solar energy or increase the heat loss from the storage container, except where special circumstances justify non-optimum design.

Review of drawings and specifications. Examine the system configuration, control logic, storage configuration, location of inlets and outlets, and stratification.

The addition of auxiliary heat to thermal storage containers can severely decrease collection efficiency by increasing collector inlet temperature.

If the solar and auxiliary subsystems are not separate, the auxiliary energy may be added to thermal storage if done in such a way as to preserve thermal stratification in the storage, for example, in the case of single tank solar hot water systems.

See Criterion 2.5.2 for discussion of stratification.

Energy transport performance. The energy transport system shall be capable of efficient transfer of thermal energy among or between the various components and subsystems.

Thermal energy 1oss. Under normal operating conditions, thermal energy loss from the energy transport system shall not exceed 15 percent of the energy to be transported.

Review drawings, specifications, and calculations. An instantaneous calculation of energy loss shall be performed considering insulation thickness and conductivity value on pipes and ducts, pipe or duct hangers or other thermal "shorts," insulation of pumps, blowers, heat exchangers, location of blower motors (inside or outside of air stream), and air leaks from ducts and air handling units. 
Commentary

For other than domestic hot water systems and when such heat loss does not have adverse effect on the cooling load, thermal energy losses that can be traced directly to heated spaces and, therefore, reduce the heating load, are not required to be included in the 15 percent limitation.

Specification of allowable air leakage from the primary solar duct system is given in Criterion 3.3 .4 .

This criterion does not apply to the distribution system within the conditioned space (see Reference [23], for pipe and duct insulation guidelines). Typically, heat loss should be less than 5 percent of the energy transferred for liquid systems, and 10 percent for air systems under normal operating conditions. Collector-to-storage losses for systems in the National Solar Demonstration Program are as low as three percent of the collected solar energy. Reference [49] discusses the effect of energy transport losses on the thermal performance of solar energy systems. Chapter 9 of Reference [40] indicates insulation thickness for pipes and ducts for residential applications.

There is concern that heat loss from the energy transport system, especially air leakage, could significantly degrade the control of energy flow.

If thermal losses from the energy transport system are maintained at the levels specified by this criterion, the adverse effects on the cooling load during any summertime operation should be acceptably low.

\section{6 .2 \\ Criterion}

Evaluation

Commentary
Operating energy. Under normal operating conditions, operating power for fluid transport of solar thermal energy to or from storage shall not exceed 10 percent of the energy transferred.

Review drawings, specifications, and calculations. Examine the size of pump or blower relative to flow and pressure drop in system, viscosity of heat transfer fluid as a function of temperature and fluid type, motor rated capacity, pump or fan efficiency, electrical energy input to motor and fluid flow rate, temperature differential, and thermal capacity of fluid.

All operating energy including that for pumps, fans, blowers, solenoid valves and controls, should be considered for solar components. Under normal operating conditions, operating energy for a given heat transfer loop should not exceed 5 percent of energy transferred for liquid systems or 10 percent for air systems. Reference [50] includes 
values for operating energy in thermal performance analysis of selected projects monitored in the National Solar Demonstration Program. The use of thermosiphon loops can be effective in reducing operating energy where feasible.

\section{6 .3 \\ Criterion}

Evaluation

Commentary

2.6 .4

Criterion

Evaluation

Commentary
Collector loop transfer rate. The energy transport system shall provide adequate transfer rate for the collection of solar energy during periods of maximum solar radiation.

Review heat exchanger effectiveness under normal and peak design conditions, heat transfer fluid flow rate and properties, collector array area, maximum rate of incident solar radiation, and collector efficiency curve. For thermosiphon or draindown systems, review the piping size and slope, and the height of storage above collectors.

Reduced collector 1oop transfer rate will result in high collector temperature and hence, reduced collection efficlency. If there is a collector loop heat exchanger, the approach temperature difference should be as low as practical, $5^{\circ} \mathrm{F}-15^{\circ} \mathrm{F}\left(3^{\circ} \mathrm{C}-8^{\circ} \mathrm{C}\right)$ as recommended in Reference [47]. Thermosiphon HW systems for single-family residences should have at least $3 / 4$ inch nominal diameter pipe and long radius elbows.

Energy transfer to load. The energy transport system shall be capable of transferring the required solar and auxiliary thermal energy to the space heating, space cooling and/or hot water loads at a rate at least equal to the design load. If a heat exchanger is used between storage or collector array and the load, the heat transfer surface area and rates of fluid flow shall be adequate for effective operation of the storage and/or collectors and transfer energy at a rate to satisfy the design load.

Heat transfer surface area, fluid flow rates, and design load sha1l be reviewed. Design loads as determined under Criterion $2.2 .1,2.2 .3$, and 2.3 .3 shall be used in the calculations.

Liquid-to-air heat exchanger coils in space heating ducts must be sized large enough to adequately transfer heat at typical collector or storage outlet temperatures. It is important that hot water heating coils be large enough to avold unnecessary use of auxiliary energy. Information is generally available from manufacturers on heat exchanger performance parameters. The temperature ranges will be somewhat lower for solar applications and should be reflected in the calculations and documentation. 
During conditions of depleted storage, solar energy will be wasted or collection efficiency will be decreased if the storage charging rate is too low. Insufficient heat transfer area is the most 1ikely cause of too low charging rate.

Due to the low temperatures encountered in residential solar energy systems, much larger heat exchangers are required than for conventional systems. Several design guides, References [46] and [47], contain useful guidance on sizing heat exchangers for solar energy applications.

Too low a discharging rate will impair system performance by requiring excess auxiliary energy to be used and keeping stored energy longer, which allows greater thermal storage losses. Reference [48] gives procedures for determining the storage discharging rate.

2.7

Requirement Control performance. The control system shall be capable of proper and efficient regulation of all other systems to fulfill the space heating, space cooling, and/or hot water system requirements.

Commentary Simpler control systems have been found to be just as efficient as complicated ones and are often less prone to malfunctions. Extensive coverage of control system design is presented in Reference [51].

2.7 .1

Criterion

Sensor location. Location of control sensors shall not significantly increase the use of depletable energy by the system due to improper location.

Evaluation Review drawings and specifications. Examine the presence or absence of flow at all times past sensor locations, backflow or thermosiphon effects during non-operation, and precision of sensors.

Commentary Sensor location should not increase depletable energy use of the system. Normally the temperature differential between the sensor and the point of desired measurement should not exceed the precision range of the sensor. The sensed condition at all times should be considered when determining sensor placement. In particular, it is the plate temperature, not the ambient temperature, that indicates the need for recirculation freeze protection. Radiation losses to the night sky can lower collector temperatures below the ambient temperature. If the sensor is used to deactivate the freeze protection mode, multiple sensors may be required to assure all parts of the collector loop have recelved heated water. Thermosiphon 
or backflow in an idle loop can cause sensors to give erroneous indications of system operating conditions. Proper placement, insulation from external conditions, and the use of check valves or backdraft dampers will reduce sensor susceptibility to the influence of detrimental, extraneous, or uncontrolled heat flows. Reference [26] discusses the implications of sensor location on system performance. A general discussion of freeze protection strategies and their benefits and drawbacks is given in Reference [67].

2.7 .2

Criterion

Evaluation

Comment ary

2.7 .3

Criterion

Evaluation

Commentary

Collector fluid circulation. The circulation of heat transfer fluid through the collectors shall occur only when useful heat can be collected except as required for freeze protection, heat rejection, or dumping of excess energy.

Review drawings and specifications. Examine the type of controller, deadband range, temperature turn on and off points, and means of prevention of unwanted thermosiphoning.

Collector pump or blower cycling can be reduced by proper deadband in on/off controllers. Studies have shown that proportional controllers are not substantailly more effective than on/off controllers, References [51, 52]. Heat rejection from collectors may be used for nocturnal cooling purposes or for overheat protection (see Criterion 2.4.5).

Priority of energy use. The controls shall prioritize the use of energy such that solar energy is first applied toward meeting the load if possible, then auxiliary thermal energy is used if necessary to supply the balance, unless such prioritizing increases the depletable energy use of the system.

Review drawings and specifications. Examine the control logic, system configuration, and operation of space or HW thermostat.

The intent of this criterion is to use solar energy whenever possible to reduce storage losses and enhance collection efficiency. It is good practice to keep the solar and auxiliary subsystems separate with, for example, the solar coil first in the air stream and the auxiliary coil second. This criterion is not intended to prevent the simultaneous use of solar and auxiliary energy. Simultaneous heating and cooling should be prevented. Guidelines provided in ASHRAE 90A-1980, Reference [23], Section 5.5, should be followed. 
2.7 .4

Criterion

Evaluation

Commentary

2.7 .5

Criterion

Evaluation

Commentary
Control valve and damper leakage. Leakage past control valves and dampers shall not significantly increase the depletable energy use of the system or significantly degrade system operation.

Review drawings and specifications. Examine the control logic, operation of control dampers and valves, flow paths, and temperature of leaking fluids.

As described in Reference [42],it is important that dampers in the air collection loop close tightly. Leakage past valves can reject energy to a collection loop or cooling tower, resulting in system performance degradation. See Criterion 3.3.3 for specification of allowable damper leakage.

Large heat losses can occur because of thermosiphoning from storage to collector at night if valves or dampers in the collector-storage loop do not close tightly.

Control set points. Controller set points shall maximize the use of solar energy in effectively meeting the load.

Review drawings and specifications. Examine the control strategy, set points, fluid flow paths, fluid velocities, and collector characteristics.

Collection loop set points should be determined considering operating energy versus energy collected. Under no circumstances should the collection loop operate when operating energy exceeds solar energy collected.

Set points should address the freeze protection needs of the system for the local climatic conditions. Sensors that initiate freeze protection by sensing the ambient temperature shall have sufficiently high set points to prevent freezing due to collector radiative losses. Set points of $45^{\circ} \mathrm{F}\left(7.2^{\circ} \mathrm{C}\right)$ for recirculation systems and $55^{\circ} \mathrm{F}\left(12.8^{\circ} \mathrm{C}\right)$ for draindown systems have been used effectively. The set point for a recirculation system must also be sensitive to the thermal energy lost (Criterion 2.4.4) and the operating energy used (Criterion 2.6.2). Efforts should be made to avoid excessive cycling of the controller which can result in significant system component degradation over time.

See Criterion 5.2.2. The use of a differential controller with a time delay to minimize cycling should be considered. 


\section{8}

Requirement

Commentary

2.8 .1

Criterion

Evaluation

Commentary
Typical set points include a delta-T of $10^{\circ} \mathrm{F}\left(6^{\circ} \mathrm{C}\right)$ between storage and collector temperature for start up and a delta$\mathrm{T}$ of $3^{\circ} \mathrm{F}\left(2^{\circ} \mathrm{C}\right)$ for shutoff for liquid direct heating and drain back collection systems. Higher temperature differentials should be used for air collector systems and those systems with a heat exchanger in the collector loop. References [51, 52] provide useful information for the determination of set points. Absorption chiller performance in cooling systems is sensitive to control set points. Small temperature variations at the generator (hot water) and evaporator (chilled water) inlets can have large effects on the chiller coefficient of performance.

Component/system interaction. All components in the $\mathrm{H} / \mathrm{C} / \mathrm{HW}$ system shall be selected and integrated into the system in such a manner to reduce the use of depletable energy by the system.

Interaction of components is extremely important for mechanical solar energy systems. In addition to providing thermally efficient collection, storage, energy transfer, and control, components must be carefully selected, sized, and integrated to require minimum depletable energy input while satisfying system energy requirements.

Collector selection. The solar collector shall be selected based on efficient operation in the desired operating temperature range of the equipment to which collected solar energy is delivered.

Post-stagnation, Reference [35], test data, Reference [34] or [53], shall be submitted for the collector used. Temperature requirements of equipment, heat exchanger approach temperature difference, solar radiation intensity, ambient temperature, wind, and diffuse/beam solar radiation data shall be reviewed.

High-temperature applications,for example, cooling systems, may require low-loss collectors. Low temperature applications (space and water heating) can use collectors with a higher loss coefficient depending on ambient temperature and solar radiation intensity. Heat exchangers with high approach temperature differences require that the collectors work at a high inlet temperature. See commentary in Criterion 2.6.3. Degradation of collectors and the effect on selection is discussed in Chapter 5. Direct/diffuse radiation data is discussed in Chapter 3 of Reference [36]. 
Although cost is not within the scope of these criteria, a number of collector characteristics will affect operation efficiency and cost effectiveness. These characteristics might include:

- number and material of cover plate(s)

- heat transfer medium (air, 1iquid) and flow rate

- freeze protection technique

- absorber coating type

- absorber plate and conduit material, gauge, and integrating technique

- insulation material effectiveness

Reference [47] gives useful information and discussion on system design.

2.8 .2

Criterion

Storage selection. The thermal capacity of the thermal storage system shall not adversely affect overall system efficiency.

Evaluation Review drawings and specifications. Examine the storage volume and heat capacity of storage media, collector array area and efficiency, frequency of periods of no collectable solar radiation, temperature requirements of equipment supplied by solar energy, number and type (hot or cold) of units, and load. Justification must be made in design for abnormally undersized or oversized storage.

Commentary Storage may not be provided, see Requirement 2.5. Storage size affects collection efficiency, temperature stability of the system, and cycling of equipment (especially absorption chillers). Too small storage results in waste of collectable solar energy. Too large storage can result in unacceptably high losses or too low temperatures to load.

The size, or even the presence or absence of storage, depends on the system design. Storage sizes in the National Solar Demonstration Program for residential applications are predominantly between 10 and $20 \mathrm{Btu} /{ }^{\circ} \mathrm{F} \cdot \mathrm{ft}^{2}(200-400 \mathrm{x}$ $10^{3} \mathrm{~kJ} /{ }^{\circ} \mathrm{C} \cdot \mathrm{m}^{2}$ ) of collector area, although some systems have more than $70 \mathrm{Btu} /{ }^{\circ} \mathrm{F} \cdot \mathrm{ft}^{2}\left(1400 \times 10^{3} \mathrm{~kJ} /{ }^{\circ} \mathrm{C} \cdot \mathrm{m}^{2}\right)$.

Reference [21], page 10, states that for residential space and water heating systems, storage capacity should be about 10 to $15 \mathrm{Btu} /{ }^{\circ} \mathrm{F} \cdot \mathrm{ft}^{2}\left(200\right.$ to $\left.300 \times 10^{3} \mathrm{~kJ} /{ }^{\circ} \mathrm{C} \cdot \mathrm{m}\right)$ of collector surface.

The 10 to $15 \mathrm{Btu} /{ }^{\circ} \mathrm{F} \cdot \mathrm{ft}{ }^{2}$ (200 to $300 \times 10^{3} \mathrm{~kJ} /{ }^{\circ} \mathrm{C} \cdot \mathrm{m}$ ) range, though typical, does not apply in cases such as: solar assisted heat pumps ( $2-3$ times this amount is needed), 
seasonal or annual storage systems, solar powered chiller systems, systems so small in relation to load that collector output is used immediately.

The use of unlined concrete storage vessels with aqueous heat transfer fluids is not recommended. Over a period of time some of the calcium hydroxide from the concrete will go into solution. As the temperature of the solution increases, the capacity of the fluid to hold the calcium hydroxide in solution decreases. In the presence of carbon dioxide, the calcium hydroxide will convert to calcium carbonate which tends to deposit on surfaces such as heat exchangers, piping and pump impellers, and housings. These calcium deposits can degrade the system performance and possibly cause physical damage to some of the components.

2.8 .3

Criterion

Evaluation

Commentary

2.8 .4

Criterion

Evaluation

Commentary
Fluid flow rates. Heat transfer fluid flow rates shall be compatible among the various subsystems with regard to capacity and heat transfer rates. Heat exchangers and other devices shall be sized to effectively transfer energy from one subsystem to another.

Review drawings and specifications. Examine the required flow rate ranges of all components in a loop and system configuration, parallel or series arrangement of components.

Overall system efficiency can suffer due to specification of equipment in the same loop requiring different flow rates. Equipment sizes and arrangements (in series or parallel) should be chosen considering compatibility of flows and heat transfer rates.

Auxiliary equipment selection. Auxiliary energy equipment shall meet or exceed the minimum efficiency as required in the applicable energy code, standard, or regulation. Auxiliary energy equipment shall be integrated with the solar heating/cooling/hot water system to minimize the use of depletable energy by the system.

Review drawings and specifications. Energy Efficiency Ratings (EER's) of all equipment shall be stated. Justification shall be made for the selection of auxiliary energy source. Arrangement of auxiliary equipment relative to load and solar energy equipment will be closely examined. In particular, source temperature for heat pumps shall be specified and justified.

Point-of-use auxiliary heaters, electric baseboard space heaters and gas or electric water heaters, may use less 
depletable energy than central systems. Point-of-use heaters eliminate stand-by tank losses and line losses and offer the possibility of distributed control. Electric baseboard space heaters allow flexibility in zone heating and are compatible with programmable thermostats. Pointof-use water heaters can also eliminate the need for hot water plumbing. Central heating plants, sized to meet the entire load, may generate much more heat than is necessary when auxiliary heating is required at only one location or zone.

The thermal storage mass of a passive space heating system should not also serve as part of the auxillary space heating system. Supplying auxiliary energy to the thermal storage reduces the storage capacity and thereby reduces the overall performance of the passive system. In general, auxiliary space heaters used with a passive space heating system should heat only the air within the space. Auxillary heating of the storage mass may disrupt the designed thermal cycles of the passive system.

Parallel solar/auxiliary heat pumps may not be efficient in cold climates. In this arrangement, the heat pump uses outside air as a heat source when the solar portion of the system cannot supply the load. However, since the heat pump coefficient of performance and capacity is reduced at low source temperature, this arrangement is not always advantageous. In general, solar/auxillary heat pump mechanical systems suffer a lack of performance as they colncidentally depend on the same energy source, the sun.

Two basic methods of augmenting a solar heated absorption chiller have been used: an independent auxiliary electric chiller and the use of fossil fuel to fire a boller to provide the heating energy for the absorption chiller in the absence of solar heat. One consideration is the peak load on the electric utility at times of peak cooling power requirements. Such conditions indicate using a fossil fuel fired boiler. Independent electric chillers provide for increased reliability in case of absorption chiller fallure.

2.8 .5

Criterion

Evaluation
Load temperature requirements. Component interaction shall be such that the system is able to meet higher temperature load requirements before lower temperature loads are satisfled when higher temperature energy is available and a higher temperature load exists.

Review drawings, specifications, system configuration, and control logic. 
Cooling applications usually require higher temperatures than water and space heating systems. As an example, the efficiency of an absorption chiller decreases with decreasing hot water firing temperature, so a combined cooling and hot water system should supply the hottest solar-heated water to the chiller and lower-temperature water to the water heating system.

2.9

Requirement

Commentary

2.9 .1

Criterion

Evaluation
Effective use of depletable energy. The bullding including passive solar components, and the mechanical H/C/HW system, including active solar and auxiliary energy systems, shall be designed to minimize the use of depletable energy.

Requirements 2.1 through 2.8 deal with the thermal characteristics of the solar energy system design (passive and active), and component performance. This requirement, 2.9 , links the solar energy system performance to the bullding system performance with respect to use of depletable energy. All of the system components should be designed and constructed in a manner consistent with the practices delineated in Criteria 2.4-2.8 to ensure that performance determined by Requirement 2.9 is a realistic estimate of what would be achieved in practice. The assembled components must be assessed as a total working system. The building/system combination needs to be evaluated to ensure that building and system are working together in a manner that will provide reasonable savings of depletable energy. The determination of depletable energy used by the total system is of considerable imporrtance to the owner/developer and their 'need to know' for making economic decisions. The depletable energy use will also give an indication of the effectiveness of the total building/system thermal performance, and this determination can be used for acceptance in jurisdictions having limits on the use of depletable energy.

Depletable energy use. The annual depletable energy used in space conditioning and/or the heating of hot water shall be determined and not exceed the limit established by the owner, designer, or local jurisdiction, as applicable.

The calculation of annual depletable energy use shall be based on analytical predictions or correlations derived from simulations using hourly values of solar radiation, ambient temperature, and system load for at least one day a month including operating energy requirements and heat losses, and $\mathrm{H} / \mathrm{C} / \mathrm{HW}$ system and component performance characteristics. Otherwise, it shall be based on experimental data for similar solar energy systems in similar buildings in the same climatic area. 
The energy-use calculation shall be based on design conditions provided by the applicable authority. Energy records of comparable residential buildings may be used to substantiate calculated energy use, Reference [2].

Depletable energy includes coal, oil, natural and manufactured gas, other petroleum products, electricity, and wood. Depletable energy does not include solar energy converted to heat or electricity at the building site or thermal energy extracted from the air, groundwater, or ground at the site. Electricity produced off-site by hydropower or wind is considered to be depletable energy.

The end result of the calculation shall be the total annual energy use for each depletable energy type (oil, electricity, etc.) as delivered to the building site.

For active systems, collector output should be based on actual fluid flow rate and fluid properties as installed in the array (see Criterion 2.4.2). The prediction of system performance shall take into consideration, where information is available,expected normal degradation of components resulting from environmental deterioration or system wear. Fouling factors of heat exchangers and post-stagnation collector efficiency data are examples of system performance degradation.

Experimental verification of complete system performance or actual usage data from similar projects may not be available; therefore, analytical simulation methods employing empirical subsystem or component performance may need to be used to calculate the performance over the full range of operating conditions.

A11 systems that provide the functions of heating and/or cooling require a thermal load analysis to determine the total system energy demand. This analysis can vary from simplified methods such as described in the ASHRAE Systems Handbook, Reference [22] and based on the modified degreeday method for heating and the equivalent full-load hour method for cooling, to sophisticated computer programs such as NBSLD, Reference [54] which perform dynamic simulation of hourly thermal loads for each building. zone for an entire year. Reference [55] provides a summary of computer programs available for heating and cooling thermal load determination. Refinements to the simplified energy calculation procedures, Reference [56] are currently being developed to include elements deemed essential to the accuracy of the calculation procedure. 
The choice of a particular method used to calculate building thermal load depends on the specific application. Residential buildings containing two or less zones and not utilizing passive solar components can usually be evaluated using the simplified procedures; however, larger, multiplezoned bulldings and buildings having passive solar compoonents should utilize the more comprehensive methods, Reference [57]. The annual thermal performance of al1 $\mathrm{H} / \mathrm{C} / \mathrm{HW}$ systems can be evaluated using a variety of methods after the respective energy demands are determined.

Simplified methods, such as the F-Chart method, Reference [33], varying from handbook calculation procedures to interactive computer programs, Reference [58] are suitable for many smaller mechanical solar energy systems. The F-Chart method is a correlation to liquid and air active solar systems for space heating and hot water, hot water only, and space heating only. The F-Chart method is not yet suitable for use with:

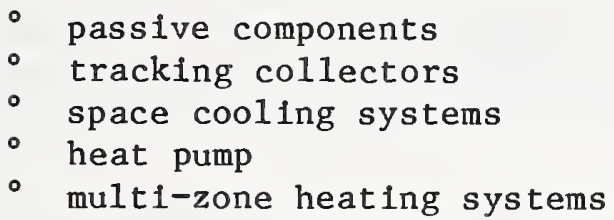

Anticlpated advances in the interactive computer version, F-Chart, are expected to increase the list of system types that can be modeled. Operating energy for pumps, blowers, and controls is not calculated by the method and must be estimated separately.

SOLCOST, Reference [59] is another simplified method of calculating system thermal performance. In addition to the systems that can be modeled by the F-Chart method, SOLCOST is also applicable to heat pump systems, both solarassisted and solar augmented, and for single and double axis tracking collectors. Like F-Chart, SOLCOST does not calculate operating energies for pumps, blowers, and controls. Detailed simulation methods such as TRNSYS, Reference [11] are warranted for mechanical systems installed in large complex buildings or for systems not covered by the simplified procedures. A listing of computer programs for solar system thermal performance is ava11able from the Conservation and Renewable Energy Inquiry and Referral Service, Reference [60] and a more comprehensive summary of calculation procedures are described in Reference $[61]$.

Although the thermal performance of bulldings containing passive solar components such as direct-gain bulldings can 
usually be calculated using the previously described building thermal load techniques, thermal network analysis techniques may be required for buildings having indirectgain features such as Trombe walls. General purpose thermal analyzers such as SINDA, Reference [62] or specialized programs such as PASOLE, Reference [10] are available for these types of bulldings. Hand calculation procedures such as the Solar/Load Ratio method, Reference [6], are also avallable. Reference [12] is a brief but comprehensive survey of passive solar building design computer programs. The choice of a calculation procedure for estimating solar energy system thermal performance depends on the application.

In recent experiments on solar HW systems at NBS, Reference [63], the predicted long-term thermal performance using the F-Chart, SOLCOST and TRNSYS programs were all within 8 percent of the measured results. Similar efforts have been made to compare space heating system measured performance with F-Chart predictions using instrumented data from the National Solar Demonstration Program, References [64, 65]. 


\section{Chapter 2 References}

1. Holtz, M., Place, W., Kammerud, R., A Classification Scheme for the Common Passive and Hybrid Heating and Cooling Systems," SERI/TP-63218, SERI, Golden, CO, August 1979.2/

2. Energy Performance Standards for New Buildings, Proposed Rule, Office of Conservation and Solar Energy, Department of Energy, Federal Register, Vol. 44, No. 230, November 28, 1979.

3. Handbook and Product Directory, Applications, ASHRAE, 1982.1/

4. Climatic Atlas of the U.S., National Oceanic and Atmospheric Administration, 1974, Asheville, NC 28801.

5. Klein, S, Beckman, W, Duffle, J., Monthly Average Solar Radiation on Inclined Surfaces for 171 North American Cities, Report No. 44, University of Wisconsin, 1977.

6. Balcomb, J., et. al., Passive Solar Design Handbook, Volume Two of Two Volumes: Passive Solar Design Analys1s, DoE/CS-0127/2, Los Alamos Sclentific Laboratory, for the Department of Energy, January $1980 . \underline{4}$

7. TEANET: A Numerical Simulation of System Behavior Using Thermal Network Methods, Total Environmental Action, Inc., Harrisville, NH 03450 .

8. Glennie, W., PEGFIX/PEGFLOAT Passive Solar Design Program, Princeton Energy Group, 729 Alexander Road, Princeton, NJ 08450.

9. Arumi-Noe, F., DEROB Computer Program, School of Architecture, University of Texas, Austin, TX 78712, May 1978.

10. McFarland, R., PASOLE: A General Simulation Program for Passive Solar Energy, Los Alamos Scientif1c Laboratory Internal Report, LA-7473-MS, P.0. Box 1663, Los Alamos, NM 87545, October 1978.

11. Klein, S., et. al., TRNSYS - A Transient Simulation Program, Report 38-10, Manual describing TRNSYS-Version 10 computer program, Solar Energy Laboratory, University of Wisconsin, Madison, WI 53706, June 1979.

12. Solar Passive Bullding Design Computer Programs: A Brief Survey With Comments, New England Solar Energy Association, Battleboro, VT, 1979.

13. The First Passive Solar Home Awards, HUD-PDR-376, HUD, 1979, GPO 023-000-00517-4, 1979.. 
14. Mazria, E., The Passive Solar Energy Book, Rodale Press, Emmaus, PA, 1979.

15. Burch, D., Treado, S., "Ventilating Residences and Their Attics for Energy Conservation - An Experimental Study," Summer Attic and Whole-House Ventilation, NBS Special Publication 548, National Bureau of Standards, Washington, DC 20234, July 1979.2/

16. Handbook, Fundamentals, ASHRAE, 1981.1/

17. Olgyay, V., Olgyay, A., Solar Control and Shading Devices, Princeton University Press, Princeton, NJ 08540, 1976.

18. Ramsey, C., Sleeper, B., Architectural Graphic Standards, John Wiley \& Sons, $3053 \mathrm{rd}$ Avenue, New York, NY.

19. Thermal Conditions for Human Occupancy, Standard 55-81, ASHRAE, 1981.1

20. Cooling and Heating Load Calculations Manual, GRP-158, ASHRAE, 1979.1

21. Cole, R., et. al., Design and Installation Manual for Thermal Energy Storage, ANL 79-15, Argonne National Laboratory, January $1980 . \underline{4}$

22. Handbook and Product Directory, Systems, ASHRAE, 1980.1/

23. Energy Conservation in New Building Design, Standard 90A-80, ASHRAE, $1980 . .1$

24. Application of Solar Energy for Heating and Cooling of Buildings, GRP 170, ASHRAE, 1977.I

25. National Solar Heating and Cooling Demonstration Program Project Experience Handbook, Preliminary Draft, DoE/CS-0045/0, Department of Energy, September 1978. 2 /

26. Building the Solar Home, HUD-PDR-296-1, HUD, GPO 023-000-00455-1, June 1978. 3 -

27. Easterly, J., Engineering Concerns in Solar System Design and Operation, Solar 10811-79/01, Department of Energy, March 1979.

28. Bartlett, J., Thermal Performance of Space Cooling Solar Energy Systems in the National Solar Data Network, Solar/0023-79/40, Department of Energy, July 1979.기

29. HUD Minimum Property Standards, Multifamily Housing, 4910.1, HUD, 1973.3 
30. HUD Minimum Property Standards, Care-Type Housing, 4920.1, HUD, 1973.근

31. HUD Minimum Property Standards, One- and Two-Family Dwellings, 4900.1, HUD, 1973. 3/

32. McCumber, W., Jr., Collector Array Performance Report for Sites of the National Solar Heating and Cooling Demonstation Program, IBM, July $1979 . \underline{\text { II }}$

33. Beckman, W., Klein, S., Duffie, J., Solar Heating Design - By the F-Chart Method, Wiley-Interscience Publication, John Wiley and Sons, New York, NY, 1977.

34. Methods of Testing to Determine the Thermal Performance of Solar Collectors, Standard 93-77, ASHRAE, 1977.17

35. Provisional Flat Plate Solar Collector Testing Procedures: First Revision, NBSIR 78-1305A, National Bureau of Standards, Washington, DC 20234, June 1978.4/

36. Duffie, J., Beckman, W., Solar Energy Thermal Processes, Wiley Interscience Publication, John Wiley and Sons, New York, NY, 1974.

37. Experimental Verification of a Standard Test Procedure for Solar Collectors, NBS Building Science Series 117, National Bureau of Standards, Washington, DC 20234, January 1979.4/

38. Jones, D., Shaw, L., Lof, G., "Air Leakage Effects on Active AirHeating Solar Collector System Performance," Preconference Proceedings - Solar Heating and Cooling Systems Operational Results Conference, Colorado Springs, CO, November 1979.

39. Beckman, W., Duct and Pipe Losses in Solar Energy Systems, Solar Energy Journa1, Vol. 21, Number 6, 1978, p. 531 .

40. Heating and Air Conditioning Systems Installation Standards for Oneand Two-Family Dwellings and Multifamily Housing Including Solar, Sheet Metal and Air Conditioning Contractors' National Association, Inc., P.0. Box 70, Merrifield, VA 22116, 1981.

41. Jones, G., Lior, N., Optimal Insulation of Pipes and Tanks for Solar Heating Systems, DoE Publication AL0-5319-2, University of Pennsylvania, Department of Mechanical Engineering, February 1979.2/

42. The Effect of Air Damper Leaks on Solar Energy System Performance, National Solar Data Program, Solar/0012-78/29, DoE, 1978.

43. Jones, D., Hill, J., Performance of a Packaged Solar Space Heating System Used with a Mobile Home, NBSIR 79-1799, National Bureau of Standards, Washington, DC 20234, 1979. 
44. HUD Intermediate Minimum Property Standards Supplement, 1977 Edition, Solar Heating and Domestic Hot Water Systems, (No. 4930.2), Department of Housing and Urban Development, Washington, DC, 1977.3 )

45. Wu, S., Han, S., "A Liquid Solar Energy Storage Tank Mode1-1. Formulation of a Mathematical Model," Modeling, Simulation, Testing and Measurements for Solar Energy Systems, J. M. Nash, et. al., editor, ASME, presented at the winter annual meeting of the American Society of Mechanical Engineers, San Francisco, CA, December 10-15, 1978.

46. Montgomery, R., The Solar Decision Book, Dow Corning Corporation, Midland, MI 48640, 1978.

47. Solar Heating System Design Manual, Revision 1, Bulletin TESE-576, Bel1 and Gossett ITT, 8200 N. Austin Avenue, Morton Grove, IL $60053,1977$.

48. Methods of Testing Thermal Storage Devices Based on Thermal Performance, Standard 94-77, ASHRAE, 1977. If

49. Ward, D., Solar Heating and Cooling System Efficiency as a Function of Design and Installation, Solar Energy Applications Laboratory, Colorado State University, Fort Collins, C0 80521, September 1978.

50. Volume One: Federal Program Presentations and National Solar Data Program, Proceedings of the U.S. Department of Energy's Regional Solar Updates, Dearborn, MI; Orlando, FL; Philadelphia, PA; Los Angeles, CA, July-August 1979.

51. Pejsa, J., et. al., Cost Effective Control System for Solar Heating and Cooling Applications, Final Report, SAN-1592-1, DoE, 1978.2f

52. Swanson, T., Ollendorf, S., "Study on the Application of NASA Energy Management Techniques for Control of a Terrestrial Solar Water Heating System," AIAA Terrestrial Energy Systems Conference, June 4-6, 1979, Orlando, FL, 1290 Avenue of the Americas, New York, NY 10019.

53. Methods of Testing to Determine the Thermal Performance of Unglazed Flat-Plate Liquid-Type Solar Collectors, Standard 96-80, ASHRAE, $1980.1 /$

54. Kusuda, T., NBSLD, the Computer Program for Heating and Cooling Loads in Buildings, NBS Building Science Series 96, July 1976.4/

55. Bibliography on Available Computer Programs in the General Area of Heating, Refrigerating, Air Conditioning and Ventilating, ASHRAE, 1980 ._ 
56. Kusuda, T., Saitch, T., Simplified Heating and Cooling Energy Analysis Calculations for Residential Applications, NBSIR 80-1961, National Bureau of Standards, Washington, DC 20234, July 1980.

57. Solar Heating and Cooling of Residential Buildings, (Vol. 1, Design of Systems, Vo1, 2, Sizing, Installation and Operation of Systems), prepared at Solar Energy Applications Laboratory, Colorado State University (for the Department of Commerce), October 1977..3/

58. F-Chart Version 3.0 Users Manual, Solar Engineering Laboratory, University of Wisconsin, Madison, WI 53715, June 1978.

59. SOLCOST, Solar Energy Design Program for Non-Thermal Specialists, Users Guide, Martin Marietta Aerospace, Denver Division, P.0. Box 179, Denver, C0 80901, April 1978.

60. Conservation and Renewable Energy Inquiry and Referral Service, P.0. Box 8900, Silver Spring, MD 20907.

61. Versteegan, P., Casse1, D., "A Survey of Existing Solar System Simulation Methods," Proceedings of the 1979 International Congress of the International Solar Energy Society, Atlanta, GA, May 28June 1, 1979.

62. SINDA - Systems Improved Numerical Differencing Analyzer, available from COSMIC, the University of Georgia, Athens, GA 30602.

63. Fanney, A., Liu, S., "Experimental System Reference and Comparison with Computer Predictions for Six Solar Domestic Hot Water Systems," Proceedings of the 1979 International Congress of the International Solar Energy Society, Atlanta, GA, May 28-June 1, 1979.

64. Shenfish, K., Solar Energy System Performance Evaluation - Scattergood School Recreation Center, West Branch, Iowa - June 1978 through April 1979, Department of Energy, Report No. SOLAR/2003-79/14.

65. Shenfish, K., Solar Energy System Performance Evaluation - Northview Elementary School (Howard's Grove) Howard's Grove, Wisconsin September 1978 through April 1979, Department of Energy, Report SOLAR/2041-79/14.2/

66. Youngblood, W., Schultz, W., Barber, R., Solar Collector Fluid Parameter Study, NBS-GCR 79-184, Wyle Laboratories for the National Bureau of Standards, October 1979.21

67. Schiller, Steven R., "Freeze Protection," Solar Age, American Section of the International Solar Energy Society, Vol. 6, Number 8, August 1981. 
68. Cycle 5 Residential Solar Demonstrations, Request for Grant Application: H-8800, U.S. Department of Housing and Urban Development, Washington, DC, 1979.

69. Sabatiuk, P., Casse1, D., McCabe, M., Scarbrough, C., "Development of Thermal Performance Criteria for Residential Passive Solar Buildings," Vo1. 51, Proceedings of the American Section of the International Solar Energy Society, The 5th National Passive Solar Conference, Amherst, Massachusetts, 1980.

1/ American Society of Heating, Refrigerating and Air Conditioning Engineers, Inc., 1791 Tullie Circle, NE, Atlanta, GA 30329.

2/ Technical Information Center, P.0. Box 62, Oak Ridge, TN 37830 .

3/ Superintendent of Documents, U.S. Government Printing office, Washington, DC 20402 .

4/ National Technical Information Service, 5285 Port Royal Road, Springfield, VA 22161 .

5/ AS/ISES, P.0. Box 1416, Killeen, TX 76541. 
CHAP TER 3

MECHANICAL

$\underline{\text { Page }}$

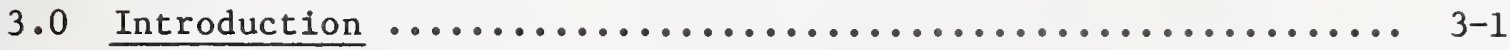

3.1 System design conditions $\ldots \ldots \ldots \ldots \ldots \ldots \ldots \ldots \ldots \ldots \ldots \ldots \ldots$

3.1 .1 Solar collectors .......................... 3-1

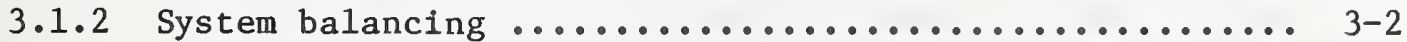

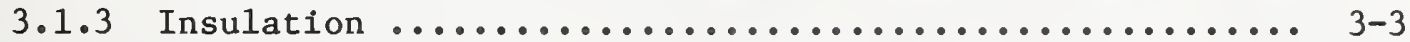

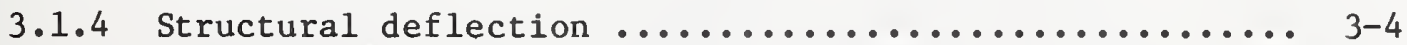

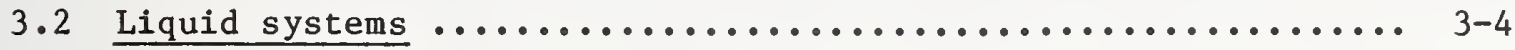

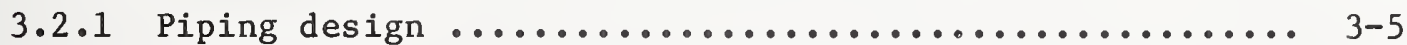

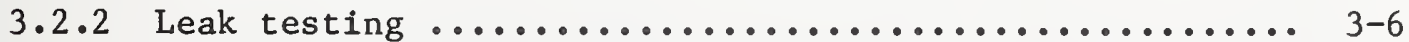

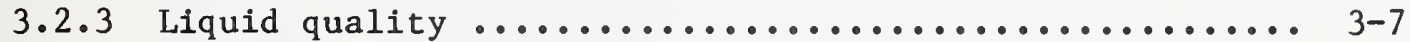

3.2 .4 Thermal expansion of fluids .................. 3-7

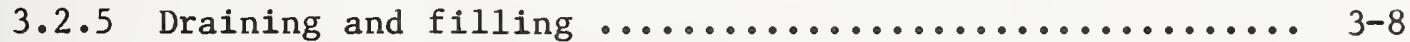

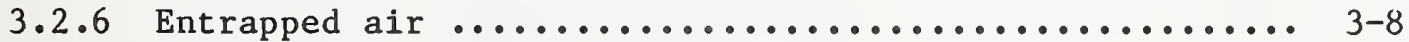

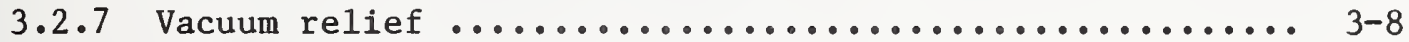

3.2 .8 Thermal expansion of materials ................. 3-9

3.2 .9 Valves ................................ 3-9

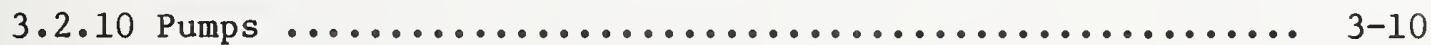

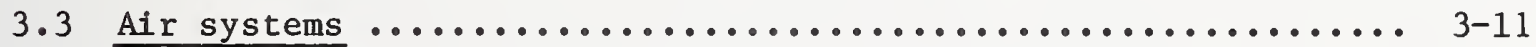

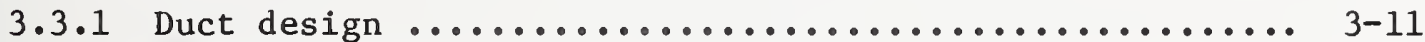

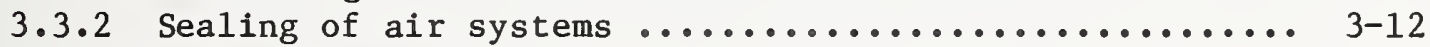

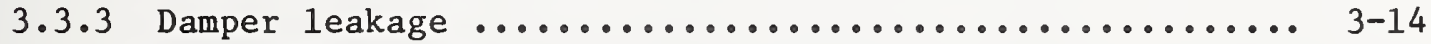

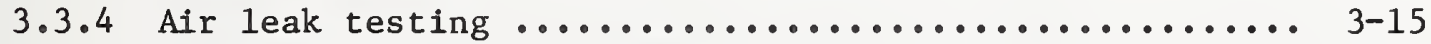

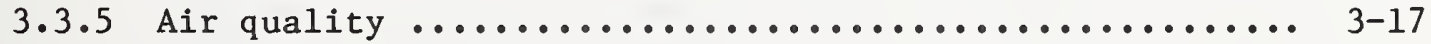

3.4 Building solar (passive) components $\ldots \ldots \ldots \ldots \ldots \ldots \ldots \ldots \ldots . \ldots 17$

3.4.1 Energy transport and distribution ............... 3-18

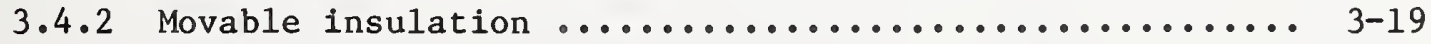

3.5 Control system $\ldots \ldots \ldots \ldots \ldots \ldots \ldots \ldots \ldots \ldots \ldots \ldots \ldots \ldots \ldots \ldots \ldots$

3.5.1 Inhabited space temperature control .............. 3-20

3.5.2 Domestic hot water temperature .................... 3-20

3.5.3 System temperature and pressure limit control ....... 3-20

3.5 .4 Temperature sensor installation ................ 3-21

3.5 .5 Auxiliary system control .................... 3-22

3.5.6 Tracking collector controls .................... 3-22

3.5 .7 Control wiring ........................... 3-22 
CHAP TER 3 - (Continued)

MECHANICAL

Page

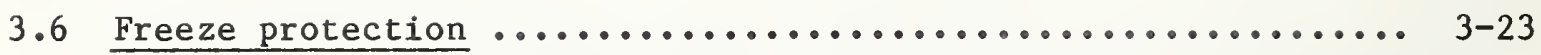

3.6 .1 Antifreeze concentration ..................... 3-23

3.6 .2 Draindown, drainback systems .................. 3-23

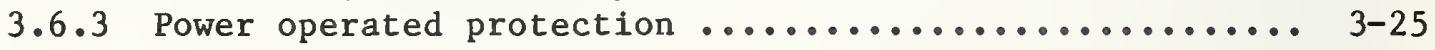

3.6 .4 Freeze tolerant designs ...................... 3-26

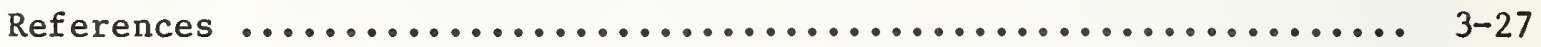


CHAPTER 3

MECHANICAL

3.0

Introduction This chapter presents performance criteria for the mechanical aspects of solar energy systems. The mechanical requirements are directly related to active systems. For passive systems, many of the design features can be considered structural, as well as mechanical. Where appropriate, these criteria have been included. For simplicity, both are considered in this chapter. Criteria that pertain to passive systems are incorporated into sections throughout the chapter under applicable topics (for example, sealing of air systems) and are not limited to Requirement 3.4 .

3.1

Requirement System design conditions. The $\mathrm{H} / \mathrm{C} / \mathrm{HW}$ system and components shall be capable of being operated over the flow rate, pressure and temperature ranges, and under structural conditions anticipated in actual service without significant impairment and shall conform to applicable local and nationally recognized codes and standards.

Commentary It is desirable that the design consist of components that are covered by recognized standards, where available, and are specified by the manufacturer to be suitable for the pressure, temperature, and flow application. Available codes and standards are listed by ASHRAE, Reference [1]*. Underwriters' Laboratories currently has under development a set of standards for solar collectors that may be applicable.

Heat transfer through the system may use a number of different transfer approaches such as gravity (or thermosiphon) circulation, combined forced and gravity circulation, or forced circulation. Systems or applications that do not lend themselves to engineering analysis may require prototype tests or documented performance under in-use conditions. A standard practice for installation and service of solar heating systems (H), Reference [2] and installation guidelines for solar hot water systems (HW), Reference [3] have been prepared.

3.1 .1

Criteria Solar collectors. The solar collectors shall be designed to accommodate the specified pressure drops and to resist

* Numbers in brackets [] indicate references at the end of this chapter. 
stagnation and thermal stress conditions.

Criteria involving thermal performance are covered in Requirement 2.4 .

Evaluation Review drawings, specifications, manufacturer's literature, test data, and design calculations. Provisional tests described in test methods 7.2 (no-flow 30-day degradation) and 7.6 (thermal cycling) of NBSIR 78-1305A, Reference [4] are one means of assessing the effects of several of these conditions on collectors. ASHRAE 93-77, Reference [5] provides coverage of collector pressure drop.

Commentary Collectors must often withstand considerable thermal cycling and weathering conditions. Thermal performance may be reduced by the degradation of glazings, seals, and absorber materials.

$3 \cdot 1 \cdot 2$

Criterion

System balancing. The energy transport system shall be designed with provisions for balancing of all specified design flows and shall be balanced after installation to ensure that specified flow rates are achieved.

Evaluation Flow rates shall be adjusted to meet the requirements of Criteria 2.4.2, 2.5.3, 2.5.4, 2.6.3, 2.6.4, and 2.8.3. Two methods for balancing are Procedural Standards for Testing, Adjusting, and Balancing of Environmental Systems, NEBB, Reference [6] and National Standards for Field Measurement and Instrumentation, Total System Balance, $A A B C$, Reference [7]. These methods are cited as examples of currently used air balancing test methods. Review of drawings, specifications, historical performance, previous test data, and design calculations or testing can provide the basis for judging compliance.

Commentary Flow rates can vary widely or even short circuit areas within collector arrays, storage assemblies, and energy transport systems resulting in reduced performance.

Typically, liquid flow is about $0.02 \mathrm{gal} / \mathrm{min} \cdot \mathrm{ft}^{2} \quad(0.014$ $\mathrm{L} / \mathrm{s}^{\cdot} \mathrm{m}^{2}$ ) of collector. Reverse return piping configurations are self-balancing within certain limits. Balancing devices must be provided on each parallel leg of a direct return system. For air collectors, a flow rate of $2 \mathrm{ft}^{3} / \mathrm{min}^{*}$ $\mathrm{ft}^{2}\left(0.01 \mathrm{~m}^{3} / \mathrm{s}^{\cdot} \mathrm{m}^{2}\right)$ of collector is typical. Balancing dampers placed in ducts having excessive air flow rates is a common means of balancing air systems. 
Flow rates and velocities for thermosiphon systems will vary dynamically and will not necessarily fall within stated ranges.

3.1 .3

Criterion

Evaluation

Commentary
Insulation. Insulation of collectors, piping, ducts, thermal storage containers and heat exchangers shall be of a type satisfactory for its intended purpose and installed in accordance with recognized standards and practices.

Review drawings and specifications. Insulation design and installation shall be in accordance with ASHRAE, Reference [8], and NFPA 90B, Reference [24], as applicable. Factory manufactured insulated ducts shall satisfy the requirements of UL 181, Reference [9]. Fibrous glass ducts shall satisfy SMACNA requirements, Reference [10].

Protection of exterior pipe and duct and storage container insulation is of great importance in preventing thermal losses. Joints in waterproof coverings may allow moisture intrusion into the insulation resulting in decreased Rvalue. Requirements for resistance to weathering and ultraviolet exposure are contained in Criteria 5.1.1 and 5.1.2, for thermal stability in 5.2 .1 , and for fire resistance in 4.4 .3 and 4.4 .4 .

Insulation should be protected against compressive loads from pipe and duct supports and storage tanks. Some insulating materials such as cellular glass foam have high compressive strength and may be suitable for insulating both around and under earth supported storage containers. Most insulation materials do not have adequate compressive strength and may require additional supporting devices, when used beneath storage containers or other heavy components. Care should be taken that thermal shorts through supports and fittings are minimized. Insulation on underground and unsheltered above ground components must be well waterproofed. Provisions for sub-surface drainage are highly recommended. Construction in high water-table areas may be impractical. Concrete or other storage mass on grade should have perimeter insulation either vertically along the foundation wall or horizontally under the storage mass, from the perimeter inward for a distance of 1 to 2 $\mathrm{ft}(.3-.6 \mathrm{~m})$. Such insulation may be placed outside the foundation wall to increase the volume of the insulated thermal mass, but only if well protected from physical damage and weathering, and be impervious to moisture absorption. ASHRAE, Reference [8], and Reference [11] contain guidance. 
3.1 .4

Criterion Structural deflection. Under the effect of deflections caused by the loads defined in Criterion 4.6 .1 , in addition to the anticipated creep deflections, the system as a whole or any component, connection or support thereof, shall not suffer permanent damage which would require replacement or repair, or which would impair its intended function during its service life.

Evaluation

Review documentation of data for design, tests, and installations. Evaluate and/or test components and elements where deemed essential. Determine compliance with generally accepted standards, and engineering and trade practices, where applicable.

The criterion is deemed satisfied if it can be demonstrated that deflections caused by the specified loads can be accommodated by suitable details or adequate flexibility .

Commentary The intent of this criterion is to provide for the proper functioning of the system under service loading conditions without breakdown or permanent impairment beyond levels comparable to conventional heating and cooling systems.

Loads lower than required ultimate loads should not cause large, irrecoverable deformations. The deflection of conventional elements supporting the system elements should not exceed the limits of conventional engineering standards for the appropriate materials and for nonconventional elements the deflection should not exceed the limitations specified in Section 13.2.4 of Reference [13].

Reference [14] gives a range of limits on deflection depending on circumstances that may be used for guidance in assessing compatibility. Safety concerns such as broken glazing and hazardous fluid leaks that may be caused by excessive deflections are covered in Criteria 4.6.1, and 4.3 .3$.

3.2

Requirement Liquid systems. The subsystems and components of liquid systems shall be designed for flow rates, temperatures, pressures, mechanical stresses, material properties, and heat transfer liquid characteristics to provide proper and efficient performance.

Commentary In liquid systems, maximum pressure and temperature are primarily a function of fluid properties and relief valve settings, along with the properties of the materials that comprise system components. Fluid compatibility is an important consideration and is covered in Requirement 5.3. 
See 6.2 and 6.3 for requirements for system maintenance, servicing, and monitoring. Illustrations of recommended design practices are contained in References $[1,2,3,12]$.

$3 \cdot 2 \cdot 1$

Criterion

Evaluation

Commentary
Plping design. Plpe sizing shall be in accordance with accepted design practice or recognized methods and velocities shall not exceed the values 11 sted in Tables 5.3 and 5.4. Anchorage shall be provided where necessary. Support shall be provided to prevent piplng from deflecting beyond acceptable limits and to maintain a slope for positive drainage.

Review drawings, specifications, and design calculations for compliance with applicable local and national codes and standards.

Since the size and energy requirements of pumps are a function of the system flow resistance, pressure drops should be kept as low as practical. Fittings such as bends, tees, globe valves, reducers, or other obstructions to flow should be minimized or simplified by careful arrangement of piping runs. For long runs, smooth turns with soft temper pipe or large radius elbows should be considered. Accepted practices for plumbing design are discussed in standard plumbing guides, References [15, 16]. Velocities are given in Tables 5.3 and 5.4 for the materials listed to prevent erosive wear.

A thermosiphon water heating system is an example where pipe sizing is essential as hot water circulation results from the change in density of the fluid with temperature. Movement of a heat transfer fluid by natural convection is achieved by relatively low pressure differentials and low pressure drops are essential. Design considerations and equipment performance data are available in References [17, $18,19,20]$.

Adequate anchorage and support are necessary in order to prevent damage to the piping, insulation, or bullding surfaces from sagging, vibration, and thermal cycling. Support and anchorage systems are 1llustrated in Reference [21] Maximum intervals for supports for horizontal runs should be eight foot $(2.4 \mathrm{~m})$ for drawn copper tubes, six foot $(1.8 \mathrm{~m})$ for annealed copper tube, twelve foot $(3.7 \mathrm{~m})$ for threaded pipe, one to two foot $(.3-.6 \mathrm{~m})$ for rigid plastic pipe, and six foot $(1.8 \mathrm{~m})$ for alumintum tubing. 
See also Chapter 5, especially 5.1, 5.2, and 5.3 for additional concerns including non-metallic piping and coupling hoses.

3.2 .2

Criterion

Evaluation

Commentary
Leak testing. The portions of installed $\mathrm{H} / \mathrm{C} / \mathrm{HW}$ systems that contain pressurized liquid heat transfer fluids shall not leak when exposed to designated pressures.

Review specifications and testing. The portions of the $\mathrm{H} / \mathrm{C} / \mathrm{HW}$ systems that contain pressurized liquid heat transfer fluids and are not directly connected to the potable water supply shall be leak tested at pressures not less than 1-1/2 times their design working pressure for a minimum of 15 minutes, when filled with a recommended testing fluid. Those portions of the system designed to operate at atmospheric pressure shall be filled with a recommended testing fluid and tested for a minimum of 30 minutes. Those portions of installed $\mathrm{H} / \mathrm{C} / \mathrm{HW}$ systems that are directly connected to the potable water supply system shall be tested in accordance with applicable local and nationally recognized codes and standards. Pipes and tanks shall be leak tested before enclosing, backfilling, or insulating. The test pressure shall be applied for the period of time necessary to inspect for leakage. The temperature of the liquid shall be within $5^{\circ} \mathrm{F}\left(3^{\circ} \mathrm{C}\right)$ of the initial ambient conditions. Provisional tests for evaluating the leakage and pressure resistance of solar collectors are described in test method 7.12 of NBSIR 78-1305A, Reference [4].

In most applications, the leak testing should be done with the specified heat transfer fluid. Glycol mixtures and oils have lower surface tensions than water and can leak through normally watertight connections. In addition, use of water in systems later filled with oils or other immiscible liquids could lead to fluid deterioration or corrosion due to residual water. If the fluid temperature is significantly lower than that of the ambient conditions, sweating may result and proper examination will be difficult. In addition, the use of hot liquids can result in the swelling of packings and joint materials, thus, concealing leaks.

Provisions should be made at the highest point or points in the system to permit venting of all air in the piping during the filling operation. See also Criterion 3.2.6. In applying the pressure, caution should be exercised so that excess pressure is not applied to the system. Protection of certain components such as expansion tank(s), air vent(s) and pressure gauge(s) and capping of pressure 
relief devices should be considered to avold damage of these components during pressure testing.

3.2 .3

Criterion

Evaluation

Commentary

3.2 .4

Criterion

Evaluation

Comment ary
Liquid quality. The systems shall have strainers, filters, or other means to collect particulate matter that could impair the flow of the heat transfer fluid and result either in a reduction of system efficiency or deterioration of system components beyond acceptable limits.

Review drawings and specifications.

The piping in some solar collectors and heat exchangers may have small cross sections in which blockage by dirt, scale, pieces of gasket material, pieces of packing, or other foreign matter in the heat transfer fluid could occur. The buildup of sludge may be the result of decomposition of the heat transfer liquid, reactions with additives within the liquid itself, or reactions of the heat transfer fluid with piping materials or extraneous impurities such as pipe dope, solder flux, cutting oils, or general system dirt. A strainer with a brass or stainless steel screen should be installed ahead of the pump to remove foreign matter that might damage the pump, clog collector or heat exchanger passages, or cause galvanic corrosion in the system. The change in $\mathrm{pH}$ of some heat transfer fluids due to their decomposition at elevated temperatues is of great concern. See Criteria 5.2.1, 5.3.1, and 6.2.1.

To aid in preventing sludge, the system piping should be thoroughly cleaned and flushed prior to the introduction of the heat transfer fluid. Problems can develop when liquids such as "hard" water are used. See also Criteria 6.1.5 and 6.2 .1 .

Thermal expansion of fluids. Adequate provisions for the thermal expansion of heat transfer fluids and thermal storage fluids that can occur over the service temperature range shall be incorporated into the system design.

Review drawings, specifications, and design calcuations. Expansion tanks shall be sized in accordance with ASHRAE Handbook/Systems, Reference [16].

Water expands about 4 percent in volume when heated from $40^{\circ} \mathrm{F}$ to $200^{\circ} \mathrm{F}\left(4^{\circ} \mathrm{C}\right.$ to $\left.93^{\circ} \mathrm{C}\right)$. Other heat transfer fluids will have different coefficients of volumetric expansion. Means should be provided in the systein design to contain this additional fluid volume without exceeding the relief pressure of the system resulting in venting of fluid. 
Provisions for expansion of fluids should be located in all loops in which thermal energy may be added to or removed from the fluid and that may be isolated by valves.

3.2 .5

Criterion

Evaluation

Commentary

3.2 .6

Criterion

Evaluation

Commentary

3.2 .7

Criterion
Draining and filling. Fill and drain devices shall be provided for the flushing, filling and periodic recharging of the system, and to facilitate maintenance and repair of liquid systems. In systems employing toxic or combustible fluids, such devices shall be in compliance with Criteria 4.2 .2 and 4.2 .4 .

Review drawings, specifications, and naintenance instructions.

In systems using toxic or combustible liquids, it may be desirable to design fill and drain devices so that only skilled maintenance personnel can service the system.

See Criteria 6.2 .1 and 3.2 .3 for further discussion of maintaining the quality of heat transfer liquids.

Water wall units, barrels, columns, and other collector/ storage assemblies may require draining and filling provisions for the individual liquid containers.

Entrapped air. When liquid heat transfer fluids are used, the system shall provide suitable means for air or gas removal from the piping and liquid containment system.

Review drawings and specifications.

Entrapped air in piping and collectors can impede the flow of liquids through piping, reduce heat transfer effectiveness, and otherwise reduce overall system efficiency. The freezing of exterior uninsulated air vents has been known to occur and create trapped air conditions in solar piping systems. Air vents are typically installed in the high points of the system and above the air eliminator. Automatic float vents must be mounted vertically and the cap must not be tightened.

Vacuum relief. Closed storage tanks, expansion tanks, and piping located at elevations above the system served shall be protected against collapsing when subjected to vacuum. Such components shall be designed to withstand negative pressures or have vacuum relief protection. 
Evaluation

Commentary

$3.2 \cdot 8$

Criterion

Evaluation

Commentary

3.2 .9

Criterion

Evaluation

Commentary
Review drawings and specifications.

Possible collapse of tanks and piping from being subjected to negative pressure is an important design consideration, Reference [22]. If vacuum relief valves are used, it is important to protect them from freezing. See also Criterion 3.6.2. (These valves are also used in drain down systems to permit drainage by admitting air at atmospheric pressure.)

Thermal expansion of materials. The system components and assemblies shall be designed to allow for the thermal expansion and contraction and the flexing of plumbing and fittings that will occur over the service temperature range.

Review drawings, specifications, and calculations.

Piping, solar collectors, and other components may experience changes in dimensions as a result of temperature changes. Such changes can result in excessive stresses within the piping, piping supports and anchorages, structural elements, pumps, and solar collectors if means are not incorporated in the system design to allow for the thermal movement. These problems are especially severe in long pipe runs and pipes with connecting lines. Movement due to thermal changes can also result in inadvertent dissimilar metals contact with other components or building elements, leading to possible corrosion problems. See also Criterion 3.2 .1 .

Expansion coefficients for commonly used materials are given in Tables $\mathrm{B} .2$ and $\mathrm{B} .5$ of Appendix B.

Valves. Valves shall be specified and located to provide proper and efficient system performance and be in accordance with applicable local and nationally recognized codes and standards. Valves shall be specified and set to avoid system or components damage.

Review drawings and specifications for proper design application and code compliance.

Improper application or installation, malfunction, and failure of valves has caused significant problems in solar energy demonstration projects. 
Valves may be either manual or motor operated. Motor operated valves that control the draindown cycle of a draindown type solar energy system are covered in 3.6.2. Motor operated valve installations should be designed for failsafe operation in the event of power failure. Solenoid valves may also present problems due to incomplete closure. Globe valves should not be used as isolation (shut-off) valves because of the restriction they introduce. Gate or ball valves are preferable for shut-off. Square head cocks, ball or globe valves are commonly used as balancing valves. Gate valves are unsuited for balancing. Temperature and pressure relief valves and vented backflow preventors should be set to avoid system damage and should not be located in such a way that they can discharge near personnel, electrical components, and other vulnerable items. See also Criterion 4.3.1. Because of the low flows generated in thermosiphoning, check valves used to prevent such thermosiphoning should be mounted carefully to ensure closure. The use of control valves with visual position indicating devices is encouraged.

$3.2 \cdot 10$

Criterion

Evaluation

Commentary
Pumps. Pumps shall be specified to provide proper and efficient performance. Selection and installation shall be in accordance with the requirements of the Hydraulic Institute, Reference [23] and local and nationally recognized codes and standards where applicable.

Review drawings, manufacturer's literature, and specifications for compliance with Hydraulic Institute Standards.

Pump selection in accordance with the heat transfer fluid is important with respect to viscosity, specific heat, and specific gravity. Sizing of pumps should consider additional static head during filling operations. The energy consumption of pumps must be considered in satisfying Criterion 2.6.2 which establishes the limit for operating energy.

Bronze or stainless steel pumps should be used in open systems to prevent corrosion. Cast iron pumps should be used with glycol/water heat transfer fluids in closed systems. It is important that the fluid corrosion inhibitors be maintained. Galvanized pumps should not be used with glycol solutions. As a general rule, dissimilar metals should be avoided where possible. Specific coverage of materials/heat transfer fluid degradation is given in Criterion 5.3.1. 
In draindown systems, the pump must be a certain distance below the minimum water level in the receptor tank to retain prime and provide adequate positive suction head. Running air-bound for more than ten seconds may damage the pump.

3.3

Requirement

Commentary

3.3 .1

Criterion

Evaluation

Commentary
Air systems. The subsystems and components of air systems shall be designed for capacity, temperatures, mechanical stresses, materials properties, and flow rates to provide proper and efficient performance.

For active systems, see 6.2 and 6.3 for requirements for system maintenance, servicing, and monitoring. Illustrations of recommended design practices are contained in References [1, 2, 3]. For passive systems, particularly those with separate air distribution systems (such as envelope designs), care should be taken to meet the intent of this requirement.

Duct design. The sizing and specification of ducts, duct joints, dampers, air movers, and other air handling components shall be in accordance with recognized standards. Installation shall comply with National Fire Protection Association (NFPA) Standards 90B, Reference [24], 31, Reference [47], and 54, Keference [48]. Velocities shal1 not exceed $900 \mathrm{ft} / \mathrm{min}(4.6 \mathrm{~m} / \mathrm{s})$.

Review plans and specifications. Design of all heating and cooling duct systems shall be in accordance with recommendations as applicable in ASHRAE Fundamentals, Reference [8], the Air Conditioning Contractors of America (ACCA), Reference [25] and/or the Sheet Metal and Air Conditioning Contractors National Association (SMACNA), Reference [19]. See Criterion 4.4.3.

Ducts should be designed for the shortest practical run and elbows should be kept to a minimum. Constrictions should be avoided whenever possible. The use of turning vanes should be considered at duct bends to reduce pressure losses. Recommended air velocities for main trunk ducts, air collector manifold ducts, and air collector riser ducts fall in the range of 700-900 ft/min $(3.6-4.6 \mathrm{~m} / \mathrm{s})$, References $[19,26]$. The gauge pressure of the air in the collectors should be slightly negative and as close to atmospheric as possible to minimize leakage. This usually requires the collectors to be on the suction side of the air mover.

Air flow through ducts,filters, heat exchangers, collectors, and other flow restrictions will establish the total pres- 
sure loss, which should be kept to a minimum in order to reduce blower operating cost. Blowers sized near the center of their performance curves and the use of variable speed or belt-driven fans will allow for "tuning" flexibility in air flow; however, sizing should also consider efficiency of operation. Standards for design, sizing, construction, and installation of ducts used with solar energy systems are covered in Reference [19].

\section{3 .2}

Criterion
Sealing of air systems. The following sealing requirements shall be used for the various components of air systems. Restrictions on the percentage of air leakage for various components are given in Criterion 3.3.4. Requirements for sealing according to high pressure duct standards does not imply that these components will function at high pressures.

(a) Primary solar duct system (PSDS) (duct system between the collectors and thermal storage and the ducts making connection to the space distribution system; this does not include the manifold-to-collector connection): The PSDS shall be sealed in accordance with Seal Class A of SMACNA High Pressure Duct Construction Standards, Reference [27] or otherwise constructed in such a manner to provide equivalent air tightness. Fibrous glass ducts shall be sealed in accordance with SMACNA Fibrous Glass Duct Construction Standards, Reference [26] and any applicable conditions of listing for Class 1, UL 181 ducts, Reference [9].

(b) Space distribution duct system (SDDS): The SDDS shall be sealed in accordance with Seal Class B, C, or D of SMACNA Low Pressure Duct Construction Standards, Reference [28] for the appropriate pressures where losses may be considered non-detrimental. This occurs where losses are to heated space and the components are not used to transport heat during the cooling season. In cases where leakage is detrimental or to unheated spaces, the SDDS shall be sealed in accordance with Seal Class A. In either case, construction that will provide equivalent airtightness shall be allowed in lieu of the sealing requirement.

(c) Thermal storage: Thermal storage shall be constructed of or lined with low permeability materials and sealed or otherwise fabricated to limit air leakage. This is not intended to apply to storage which is directly coupled to heated spaces as commonly done in passive applications. Sealing shall include joints in thermal storage, duct, and access openings. 
(d) Collector arrays and other components: Collector arrays and other manufactured components such as air handling units, heat exchangers, and filters shall be assembled and sealed in accordance with manufacturers' instructions. Sealing shall include all joints between manufactured components and ducts. Equivalent airtightness shall be provided for site-built collector arrays.

(e) Passive air transport assemblies exposed to the outdoors or semi-conditioned spaces shall be tightly constructed in accordance with energy conservation guidelines to control air infiltration and leakage, Ref erences $[29,30,31,32,33]$.

Evaluation Review drawings and specifications. Airtightness of equivalent construction shall be demonstrated by documentation of satisfactory long-term performance under in-use conditions or testing in accordance with Criterion 3.3.4.

Commentary

These requirements are beyond standard practice for small scale conventional HVAC installations. However, the prevalence of air leakage in many demonstration projects and evidence of detrimental effect on thermal performance dictate these sealing levels for all air solar systems. The principals described in the SMACNA Standards, References [10, 27, 28] should be utilized in deciding upon techniques and materials to be used in providing equivalent air tightness.

(a) PSDS: Sealing to Class A levels should limit PSDS leakage to one percent of system operating air flow. All metal ducts should be examined to gain an indication of airtightness. Application of such ducts in a solar system may require extensive sealing of seams and joints. Flexible canvas connections will probably have too much leakage to be satisfactory in the PSDS. Checking for leakage and sealing leaks are best accomplished during the process of field assembly before the installation is covered by other construction. Sealing as required above includes connections to all ancilliary units such as storage and blowers, but does not include manifold-to-collector connections.

(b) SDDS: Sealing of SDDS to the recommended levels should limit air leakage to 5 percent of system operating air flow for Class $B, C$, or $D$ sealing and to one percent for Class $A$.

(c) Thermal Storage: Thermal storage using metal as the airtight barrier may be sealed in accordance with Seal 
Class $\mathrm{A}$ and should achieve air leakage rates of one percent or less of system operating air flow. Thermal storage using plastic may be appropriate for similar treatment. Construction involving wood, masonry, or other porous materials may call for other methods, but techniques which would make the container airtight while simultaneously being able to withstand all service temperatures would seem appropriate. The objective of such sealing should be to limit leakage to one to five percent of system operating air flow.

Concrete should be considered potentially porous and may require lining and sealing to bring air leakage within acceptable limits. Problems associated with shrinking, warping, and cracking should be considered when detailing storage containers made of wood.

(d) Collector arrays and other components: In designing collectors, air handling units, heat exchangers, etc., for solar applications, designers should pay particular attention to details of construction and field installations that will minimize air leakage. Airtightness of manufactured as well as site-built units may be addressed through numerous techniques including basic product configuration and materials selection as well as factory installed gaskets, felts, mastics, etc. Careful attention to the collector-to-manifold connection detail will result in decreased leakage. Reference [34] discusses the effect of air leakage on system performance.

(e) Passive air transport assemblies: Since air pressures in passive systems are essentially those generated by natural buoyancy, good construction practices used for the control of infiltration should provide acceptable airtightness. Attention to the quality of construction for leakage control is very important. The surface areas involved in passive air transporting assemblies are sometimes very large and contain many sources for air leakage.

$3 \cdot 3 \cdot 3$

Criterion Damper leakage. Volume control dampers and back draft dampers in the PSDS shall comply with SMACNA Solar Installation Standards, Reference [19] and shall have resilient blade edges, such as felt, or shall be otherwise constructed to ensure tight cutoff of the air stream.

Evaluation Review drawings and specifications to determine that correct damper type is specified. 
Damper leakage has a major effect on the performance of the system. Analysis of some operating systems has shown a 40 percent system performance loss due to leaky dampers, Reference [35]. Leaking back draft dampers have allowed cold night air to circulate over domestic HW coils and cause freezing. Leakage should be limited to two to five percent on critical dampers, particularly those which serve to isolate the collector loop from the rest of the system. Carefully designed, constructed, and installed dampers should be capable of meeting this level of performance. Details of damper design are as important in ensuring tight cutoff over an extended service life as the materials used. Adequate sealing can be achieved using felt, vinyl, foamed plastic, and other materials. Specifically designed "low leakage" dampers may be required. Many seal materials are especially prone to deterioration after a period of use. Access ports should be provided for inspection and periodic maintenance.

See Criterion 6.2.2 for access requirements. Lightweight back-draft dampers used in passive applications, i.e., Trombe walls, are discussed in Criterion 3.4.1.

3.3 .4

Criterion

Air leak testing. Specification for installations with more than $1500 \mathrm{ft}^{2}\left(139 \mathrm{~m}^{2}\right.$ ) of total active collector gross area shall contain provisions for testing in accordance with Chapter 10 of SMACNA High Pressure Duct Construction Standards, Reference [27]. A minimum of 25 percent of each of the following portions of the system for each category (unheated or non-detrimental loss) shall be arbitrarily selected and tested. Leaks shall be corrected to restrict leakage to the percentages of total system design air flow rate, as indicated below. If losses from ducts and storage are into the heated space and these portions of the system are not used during the cooling season, the losses shall be considered non-detrimental.

$\begin{array}{cc}\text { Non-detrimental } \\ \text { Unheated spaces } & \text { losses }\end{array}$

Primary Solar Duct System Space Distribution Duct System*

Thermal Storage**

Collector Array

$\begin{array}{rr}2 \% & 2 \% \\ 2 \% & 10 \% \\ & \\ 2-10 \% & 10 \% \\ 15 \% & \text { N/A }\end{array}$

* Systems exempt from this requirement are defined in Criterion 3.3.2b.

** Varies according to material of construction. See Criterion 3.3.2c (Commentary). 
Evaluation

Commentary
For active systems, leak testing shall be performed in accordance with SMACNA High Pressure Duct Construction Systems, Reference [27] as applicable.

These threshold leakage limits are based on the achievable levels noted in Criterion 3.3.2 for each portion of the system. There are no criteria yet established for air leakage in passive systems. See Commentary below for subjective evaluation of passive system leakage using visual inspection and the more quantitative techniques of pressurized and the trace gas testing for determining building/ system performance.

Higher leakage rates for the PSDS in non-detrimental loss situations are not allowed because control of energy flows in the solar system is of critical importance. Uncontrolled leakage, even to heated spaces, may result in inefficient utilization of thermal storage and thus, higher auxiliary energy use.

In order to perform leakage tests, it may be necessary to make provisions for blanking dampers at various locations in the system.

In small installations, not governed by this requirement, it may be desirable to conduct simple leak tests by operating the system (with outlets appropriately covered over) and feeling or listening for points of leakage or introducing smoke from a smoke bomb or other chemical source and making a visual inspection.

Correct duct design can significantly impact air leakage (see Criterion 3.3.2). References [34, 36] discuss certain aspects of air leakage in air systems.

For passive systems, a method of checking for gross leakage is to conduct a careful visual inspection of the building exterior at night with strong light sources inside the building. Leakage paths will be revealed by the presence of visible openings. Another technique that may be useful for determining building tightness is the fan pressurization or depressurization procedure, Reference [37]. Tracer gas decay and air bag techniques might also be useful. Section 301.4 of Reference [30] gives quantitative information for air leakage rates for some building components and includes a standard test method for air leakage.

Differences between the above values for loss rates and those in the commentary of 3.3 .2 reflect the difference between what is achievable $(1 \%, 5 \%)$ and what may be considered a reasonable minimum ( $2 \%, 10 \%)$. 
3.3 .5

Criterion

Evaluation

Commentary

Air quality. Adequate means shall be provided to prevent the accumulation of dust, dirt, water, or gases that could result either in a reduction of system efficiency, deterioration of system components, or discomfort of building occupants.

Review drawings and specifications.

The gravel used for rock bed storage with air systems should be selected for size and freedom from dirt and dust. The use of smooth and washed material and of filtered air is desirable. Health requirements for air quality are given in Criterion 4.1.4.

ASTM C33-81, "Standard Specification for Concrete Aggregate," [49] gives some guidelines that are helpful for quality control of gravel.

To facilitate rock bed washing to remove drain water that may have leaked into the storage container, or to remove condensed molsture, it may be desirable to construct rock storage containers with water resistant interior surfaces and drainage provisions. Drains should not be the normal water trap type because the water will probably be evaporated by the heat from storage, thereby destroying the trap and allowing sewer gases to enter rock bed storage. Better arrangements might simply employ a removable plug or valve in the bottom corner of the rock bed.

In air collectors, performance reduction due to internal dirt accumulation from the system may be a significant problem. In collectors where air flow is in contact with glazing, normal dirt build up from air drawn from occupied spaces could cause a deterioration of heat transfer ability and spectral properties of the absorber. High temperatures could bake on such deposits. Filtering of such air flow may be desirable.

A similar situation may exist in passive systems with air circulation (Trombe walls, air thermosiphons, etc.) where dirt deposits may occur on absorber or glazed surfaces. Because of the low air velocities involved with passive systems, filtration may be impractical and access for cleaning should be considered.

3.4

Requirement Building solar (passive) components. Proper and reliable distribute, control, and prevent the loss of passively collected solar energy. 
$3.4 \cdot 1$

Criterion

Evaluation

Commentary
Energy transport and distribution. Mechanical devices, when used in conjunction with passive solar components for energy transport and distribution, shall provide proper and reliable performance.

Review drawings and specifications.

Inadequate or inefficient energy distribution systems have been reported as one of the most common design faults in passive projects in the Federal solar heating and cooling demonstration program.

Passive systems rely primarily upon natural means of energy flow. However, some designs work more effectively when supplemented by devices that enhance and/or control such energy movement. Location, sizing, and details of devices should be of concern when designing means of distributing thermal energy to achieve desired temperature levels and for exhausting excessive heat.

Thermocirculation control vents should avoid undue restriction to air flows and provide airtight closure against backdraft. Lightweight ( 1 to $1.5 \mathrm{mil}$ ), (.0254 mm to $.0381 \mathrm{~mm}$ ) plastic film one-way dampers have demonstrated adequate performance in Trombe wall applications. The vent opening with which they operate must also be well constructed to assure a tight fit. A backing of wire mesh or other means may be required in larger vent openings or when strong drafts are anticipated to prevent suction of the film into the openings. Typically the size of these vents are approximately one percent of the Trombe wall area (this percentage being for the lower vents with upper vents of equal size). Reference [38] provides a full discussion of the effects of vent size on thermal performance.

A number of areas of potential mechanical inadequacy should be noted:

(a) Lightweight backdraft dampers may be fragile and of limited reliability. Such components should be accessible for inspection and repair.

(b) Overheat vents may be located in remote positions and be operated only on a periodic basis. Such vents should be accessible for inspection and cleaning to assure effective opening and closure. 
(c) Thermally activated operators such as freon cylinders and liquid pistons should be selected for reliable service and installed in a manner which will allow periodic inspections.

(d) Installations of heat pipes and thermic diode assemblies should be done with a recognition of the need for future inspection and possible removal for testing or recharging.

3.4 .2

Criterion

Evaluation

Commentary

\section{5}

Requirement

Movable insulation. Manual or automatic movable insulation shall be designed and installed for proper perimeter sealing and reliable manipulation, operation, and storage.

Review drawings and specifications, especially for details of fit and closure of insulation at the perimeter of glazed openings.

There are three general categories of movable insulation applications; manual, thermally driven, and motor driven. Some applications combine movable insulation with shading and/or reflection devices. To be effective, surface mounted insulation must make a tight and well-sealed cover for the aperture to prevent drafts behind the insulation panel which will render it ineffective. Night insulation is likely to improve performance more than double glazing if a tight seal is achieved. The higher the $\mathrm{R}$-value of the insulation, the tighter the air seals it should have. Unless the edges are adequately sealed, an R-factor greater than five is questionable, Reference [39]. Some of the techniques used to provide effective seals include channels or slots in jambs and sills, magnets, weights, and friction fit.

of particular concern is the potential for binding, racking, and inadequate closure of large area coverage devices. Also, there have been problems with blowers and suction equipment in some applications utilizing pelletized or granular movable insulation materials. Condensation between tight fitting insulation and glazing has been a problem. See Criterion 4.4.3 for fire hazards of insulation.

For further discussion including guidelines and assessment methods, see References [37, 39].

Control system. The control system shall be designed to operate the solar and auxiliary $\mathrm{H} / \mathrm{C} / \mathrm{HW}$ system in a proper and efficient manner. 

been found to be a major source of operational difficulties in Federal demonstration programs as described in the National Solar Data Network, Reference [41]. Reference [42] also gives guidelines for control systems and components.

3.5 .1

Criterion

Inhabited space temperature control. Each space conditioning system shall be capable of providing occupied space temperature regulation by at least one adjustable control capable of adjustment within a minimum range from $55^{\circ} \mathrm{F}$ to $75^{\circ} \mathrm{F}\left(13^{\circ} \mathrm{C}\right.$ to $\left.23^{\circ} \mathrm{C}\right)$ where used to control heating only and $70^{\circ} \mathrm{F}$ to $85^{\circ} \mathrm{F}\left(20^{\circ} \mathrm{C}\right.$ to $\left.30^{\circ} \mathrm{C}\right)$ where used to control cooling only and $55^{\circ} \mathrm{F}$ to $85^{\circ} \mathrm{F}\left(13^{\circ} \mathrm{C}\right.$ to $\left.30^{\circ} \mathrm{C}\right)$ where used to control both heating and cooling.

Evaluation Review drawings and specifications.

Commentary Controls may be automatic or manual. This is intended to include manual adjustment of devices such as wood stoves used as auxiliary or back-up. Localized controls for building heating and cooling are discussed in Reference [1]. See also Section 2.2.2 for requirements for auxiliary heating systems size.

3.5 .2

Criterion

Domestic hot water temperature. The temperature control for the combined solar and auxiliary energy source shall be capable of adjustment over the range of temperatures acceptable for the intended use.

Evaluation Review drawings and specifications. Review mechanical design for compliance with Criterion 4.3.4.

Commentary Small residential domestic HW tanks are typically equipped with a thermostat capable of controlling heating in the temperature range of $120^{\circ} \mathrm{F}$ to $160^{\circ} \mathrm{F}\left(49^{\circ} \mathrm{C}\right.$ to $\left.66^{\circ} \mathrm{C}\right)$. Temperature control devices used with solar energy systems must be compatible with safety requirements and may require the capability to cool the discharged water as does a tempering valve. Controls and valves should fail-safe to a position that would prevent scalding of a hot water user (see Criterion 4.3.4).

$3.5 \cdot 3$

Criterion System temperature and pressure limit control. Controls shall maintain the $\mathrm{H} / \mathrm{C} / \mathrm{HW}$ system within the temperature and pressure operating limits of the equipment specified in the design. See also 2.3 .1 and 4.3.4.

Evaluation Review drawings and specifications. 
Control provisions may be required for the dumping of heat when temperatures approach unacceptable levels. Should the temperature or pressure exceed specified limits, deterioration of components may occur and/or system function may be impaired due to such factors as boiling, vapor locks, cavitation, degradation of insulation and seals, and unacceptable expansion of fluids or materials. Bleeding in of cold water to replace hot water in storage is one means of achieving this control. For safety in use provisions, see Requirement 4.3 .

In systems that are not capable of withstanding thermal shock created by filling hot collectors with cool fluids, control subsystems may be required to protect the system from cold filling. Such controls would limit filling to non-insolation periods.

Thermal shock and cycling stresses can be severe over the life of many system components. Mechanical components and system control functions should be designed to optionally minimize the effects of such stresses. Some collector types such as evacuated glass tubular collectors may be especially sensitive to these stresses, and appropriate means of protection should be provided. Provisions for thermal shock resistance of components and materials are given in Criterion 5.2.3.

3.5 .4

Criterion

Evaluation

Commentary
Temperature sensor installation. Temperature control sensors shall be specified to be installed in a manner as to provide proper system control. See Criterion 2.7.1.

Review drawings, specifications, and system diagrams.

Problems of sensors giving erroneous readings of system operating conditions have been experienced because of heating or cooling in the immediate vicinity of the sensors due to extraneous heat flows and improper physical placement of the sensors. Degraded performance, incorrect indication of system performance, or system failure by freeze-up can result from such erroneous readings. Problems have occurred with sensor installations for storage containers as well as collector components.

The sensor should be in direct contact with the measured object or substance. Heat transfer pastes may be used to increase contact areas. Sensors for sensing fluid temperatures should be immersed directly in fluids or in direct contact with the containment device. Insulation of sensors from extraneous heat flows can increase the accuracy of the readings obtained from them. 
Location of sensors based on their influence on system thermal performance is specified in Criterion 2.7.1. Reference [43] gives guidance in the correct installation of sensors and probes.

3.5 .5

Criterion

Evaluation

Comment ary

3.5 .6

Criterion

Evaluation

Comment ary

\section{5 .7}

Criterion
Auxiliary system control. Provisions shall be made in the control system to allow separate operation of the auxiliary system.

Review drawings, specifications, and control system.

Installations with integrated solar and auxiliary control systems have caused the auxiliary heating system to become inoperative when the control failed on the solar side. Such failure leaves the building without any heat.

Separate control provisions are also desirable with integrated solar cooling control systems but failure of such controls will not result in a level of hazard comparable to failure of the heating system. In most systems, it is desirable that controls be designed so that the solar components and auxiliary components will operate both jointly and independently.

Tracking collector controls. Control devices and drive mechanisms of tracking collectors shall be capable of maintaining the focus of collectors on the daily path (or reflection) of the sun within design limits. For tracking collectors that cannot tolerate stagnation, control devices shall be capable of moving the collectors off-focus during no-flow periods or other protective measures shall be provided.

Control devices shall be specified to automatically stow the collectors if the wind velocity exceeds the specified limits; otherwise, the collectors shall be designed to withstand maximum design wind speeds at that location.

Review past performance data, drawings, and specifications.

Malfunction of sensors and associated circuitry, elongation and slippage of cables, shearing of gears, and binding of rotational elements have resulted in improper tracking and reduced performance of the collector array.

Control wiring. Control wiring designed for exterior use shall be suitable for weather exposure or protected from 
Evaluation

Commentary

3.6

Requirement Freeze protection. System components shall be protected from or tolerant of damage by freezing of heat transfer liquids at the lowest ambient temperatures that will be encountered in actual use.

Commentary

Various methods of freeze protection are available including the use of freeze-inhibited fluids such as glycol solutions and oils, warm water circulation, and draindown. Antifreeze solutions and oils are incompatible with many standard seal materials. Studies of freeze associated problems are detailed in Reference [45].

3.6 .1

Criterion

Evaluation

Commentary

Antifreeze concentration. Systems using antifreeze solutions shall have an adequate concentration of antifreeze to prevent freezing at the coldest ambient temperatures expected to occur in the geographic location for which they are installed.

Review specifications and weather data.

At the approach of cool weather, the antifreeze content should be checked for proper concentration. System leaks and improper solution make-up may result in inadequate concentrations. For this reason, the use of automatic water-only make-up techniques are not recommended. See Criteria 6.1.5 and 6.2 .1 and Requirements 4.1 and 4.2. Reference [45] provides detailed recommendations for antifreeze systems.

3.6 .2

Criterion
Draindown, drainback systems. Systems using automatic draindown for freeze protection shall provide for complete and timely drainage of components exposed to freezing 
Evaluation

Commentary conditions by the proper combination of sensing and control mechanisms, valves, vents, pipe slopes, flow and pressure control.

Review drawings and specifications.

References [20,45] provide detailed recommendations for draindown systems. Draindown systems require control provisions to provide venting for draining and refill (see Criterion 3.2.7) and may require special provisions to prevent corrosion of system components during these operations. For this reason, pumps for open systems using water as the heat transfer liquid should be either bronze or stainless steel. Pumps in closed systems may be cast iron. See Criterion 3.2.10.

Automatic air vents, vacuum relief valves, and draindown valves should be insulated to protect them from freezing. The rate of draindown should be such that ice blockages do not form in the process of draindown. It is important that draindown systems be designed and installed so that all lines are pitched to drain a minimum of $1 / 4$ inch per foot (21 mm/meter) since roof deflection can counter this by as much as $1 / 10$ inch per foot ( $8 \mathrm{~mm} /$ meter). It is also important that lines are adequately supported and joints are leaktight. In air-assisted draindown systems, moistureladen warm air may be drawn from storage into exterior components. If this is not prevented, the moist air can freeze a control valve or create blockage in the exposed collector loop resulting in severe freeze problems.

Fail-safe freeze protection methods are desirable since, in the event of power failure, freeze protection methods involving pumps, heaters, and valves that require electric power will be inoperative.

Draindown systems are frequently designed to drain at an outdoor temperature of about $38^{\circ} \mathrm{F} \quad\left(3^{\circ} \mathrm{C}\right)$ and to refill at about $42^{\circ} \mathrm{F}\left(6^{\circ} \mathrm{C}\right)$. Such set points may be used but with the penalty of not collecting useful energy when solar radiation is available at the time of cold ambient temperatures. This problem can be avoided by initiating draindown based on the collector absorber plate temperature. The temperature sensor initiating draindown should be located on the component having the snallest thermal time constant. Collector panel time constants are available from the ASHRAE test, Reference [5]. However, the water pipe time constant would have to be calculated based on its heat capacity and insulation R-value. 
3.6 .3

Criterion

Evaluation

Commentary
The hardness or mineral content of the water used in drain down systems should be evaluated for the potential bulld-up of scaling products in piping, valves, or collector passages. See Criterion 3.2.3.

The collector loop holding tank or the expansion tank should be properly located with respect to the system pumps and should be placed in a warm space. Water level indication should be marked on the storage tank, clearly distinguishing between the appropriate water level during normal operation and level at drainback to allow adequate capacity for drainage. The control valves should be properly located, be air and water tight, and fail safe in a manner that assures system drainage.

Power operated protection. Systems using the circulation of warm water or other methods that use electrical power for freeze protection shall have provisions for back-up protection of the system in the event of power fallure. The method and degree of automation of back-up protection shall be related to the probability of concurrence of power fallure with freezing conditions and the presence of operating personnel.

Review drawings and specifications.

Continuous circulation of heat transfer fluid should not be used for freeze protection due to the excessive energy loss this causes. Pulse or intermittent warm water circulation or heat tapes may be justified in very mild climates where freezing temperatures are infrequent.

Back-up protection methods should be selected for the level of potential risk that is projected. If, for example, records indicate freezing will occur once every 20 years, the probability of this happening concurrently with a power fallure and with no one present to manually drain the system is probably acceptably low and reliance on simple drain methods without backup would be justified. For small HW systems, manual methods might be considered acceptable for somewhat more frequent freezing recurrence intervals. Judgement must be exercised as experience has shown the simultaneous occurrence of freezing conditions and power outage, or exceedingly high power demand to be reasonably high. Larger systems would probably warrant consideration of more automated back-up provisions such as automatic draindown or possibly even stand-by electrical generation. Back-up stand-by power is probably most feasible where it is being considered for other back-up reasons as well. 
Reference [46] contains a detailed discussion of freeze protection for warm climates.

3.6 .4

Criterion Freeze tolerant designs. Components that will experience freezing conditions (based upon 20 year extreme weather data) and are not provided with specific freeze protection techniques shall be capable of withstanding freezing conditions and perform reliably after exposure to such conditions.

Evaluation Review drawings and specifications. Freeze tolerance of collectors shall be tested in accordance with test method 7.6 of NBSIR 78-1305A, Reference [4].

Commentary Stresses in collector assemblies caused by differential thermal expansion and contraction and by freezing of heat transfer fluids, if any, can cause permanent damage: distortions, dislocations, and bursting of collector components. Care is necessary to ensure that all components exposed to freezing conditions, not just collectors, be freeze tolerant. Also, differential controllers should not allow pumps to start when ice in the upper part of the collector warms and melts while the lower part is still blocked with ice. Water wall units, drums, etc., normally thought to be protected may be exposed to freezing conditions during extreme conditions, $i . e$. , when the building is shutdown in the winter. Under ordinary operating conditions, these water walls would be protected by auxiliary back up.

Designs which utilize vacuum insulation for protection can freeze if this vacuum is lost due to leakage or for other reasons. Freeze tolerant designs should be tested for reliability. 


\section{Chapter 3 References}

1. Handbook and Product Directory Equipment, ASHRAE, 1979.1/

2. Standard Practice for Installation and Service of Solar Space Heating Systems for One and Two Family Dwellings, ANSI/ASTM E683-79 (1979).기

3. Installation Guldelines for Solar DHW Systems in One- and Two-Family Dwellings, HUD-PDR-407. U.S. Department of Housing and Urban Development, GPO 023-000-00520-4, Apri1 1979.3/

4. Provisional Flat Plate Solar Collector Testing Procedures, First Revision, NBSIR 78-1305A, National Bureau of Standards, Washington, DC, June 1978, PB $272500 . \underline{4}$

5. Methods of Testing to Determine the Thermal Performance of Solar Collectors, Standard 93-77, ASHRAE, 1977.I-

6. Procedural Standards for Testing, Adjusting and Balancing of Environmental Systems, National Environmental Balancing Bureau, 8224 old Courthouse Road, Vienna, VA $22180,1981$.

7. National Standards for Field Measurement and Instrumentation, Total System Balance, Associated Air Balance Counc1l, 1000 Vermont Avenue, N.W., Washington, DC 20005, 1974 .

8. Handbook, Fundamentals, ASHRAE, 1981.1/

9. Standard for Factory Made Air Duct Materials and Air Duct Connectors, UL 181, Underwriters' Laboratories, 333 Pfingston Road, Northbrook, IL $60062,1974$.

10. Fibrous Glass Duct Construction Standards, Fifth Edition, SMACNA, 1979.17

11. Williams, K. (ed.), Burt, Hill and Assoctates, Planning and Building the Minimum Energy Dwelling, Craftsman Book Company, 542 Stevens Avenue, Solana Beach, CA, 1977.

12. Avery, J. and Krall, J., Corrosion Prevention and Fluid Malntenance in Active Solar Systems: The State-of-the-Art, Los Alamos Scientific Laboratory, LA-UR 81-3339.127

13. Performance Criteria Resource Document for Innovative Construction, NBSIR 77-1316, National Bureau of Standards, Washington, DC, November $1977.4 /$ 
14. Building Code Requirements for Reinforced Concrete, ACI 318-77, American Concrete Institute, P.0. Box 19150, Redford Station, Detroit, MI 43219, 1977.

15. National Standard Plumbing Code, as recommended by the National Association of Plumbing-Heating-Cooling Contractors, Appendix B, $1971 . \underline{5}$

16. Handbook and Product Directory, Systems, 1980.1/

17. Baughn, J. W. and Dougherty, D. A., "Experimental Investigation and Computer Modeling of Solar Natural Circulation System," Proceedings of the 1977 American Section of ISES Annual Meeting, Orlando, FL. G

18. Applications of Solar Energy for Heating and Cooling of Buildings, 1977, GRP 170, ASHRAE.17

19. Heating and Air-Conditioning Systems Installation Standards for Oneand Two-Family Dwellings and Multi-Family Housing Including Solar, SMACNA, 1981.I-

20. Solar Heating Systems Design Manual, Revision 1, TESE-576 ITT, Bel1 \& Gossett, 8200 N. Austin Avenue, Morton Grove, IL 60053, 1977.

21. Active Solar Energy Design Practice Manual, Solar/0802-79/01, Mueller Associates, Inc., The Ehrenkrantz Group, for DoE, October 1979.81

22. Windenburg, D., "Vessels Under External Pressure," Mechanical Engineering, pp. 601-607, January 1937.9/

23. Hydraulic Institute Standards for Centrifugal, Rotary and Reciprocating Pumps, 13th Edition, 1975, The Hydraulic Institute, 1230 Keith Building, Cleveland, OH 44155.

24. Warm Air Heating and Air Conditioning, NFPA No.90B, 1980.10/

25. The Standards and Manuals of the Air Conditioning Contractors of America (ACCA), $122817 \mathrm{th}$ Street, N.W., Washington, DC 20036.

26. Fundamentals of Solar Heating, (Correspondence Course), HCP/M4038-01, SMACNA for DoE, January 1978.41

27. High Pressure Duct Construction Standards, Third Edition, 1975, SMACNA.II

28. Low Pressure Duct Construction Standards, Fifth Edition, 1976, SMACNA. 77

29. Thermal Performance Guidelines for One- and Two-Family Dwellings, NAHB Research Foundation, Inc., P.0. Box 1627, Rockville, MD 20850. 
30. BOCA Basic Energy Conservation Code - 1977, Building Officials and Code Administrators International, Inc., 1313 East 60th Street, Chicago, IL 60637.

31. Energy Conservation in New Building Design, Standard 90A-1980, ASHRAE.II

32. Watson, D., (ed), Energy Conservation Through Building Design, McGraw-Hill, New York, NY, 1979.

33. Insulation Manual - Homes, Apartments, Second Edition, NAHB Research Foundation, Inc., P.0. Box 1627, Rockville, MD 20850, 1979.

34. Overton, R., Cassel, D., McCabe, M., "Evaluation of Proposed Modification to F-Chart to Include Collector Array Air Leakage," Proceedings of the ASME 1980 Winter Annual Meeting, Chicago, IL, November 16-21, 1980.

35. The Effects of Air Damper Leaks on Solar Energy Systems Performance, DoE Report Solar/0012-78/29, Department of Energy, 1978.8/

36. Close, D. and Yusoff, M., "The Effects of Air Leaks on Solar Air Collector Behavior," Solar Energy, Vol. 20, No. 6, ISES, 1978. 6 /

37. Tamura, G., "Measurement of Air Leakage Characteristics of House Enclosures," ASHRAE Transactions, Vol. 81, Part 1, pp. 202-211, $1975.1 /$

38. Balcomb, J., et. al., Passive Solar Design Analysis, Vol. Two, DOE/CS-0127/2, Dist. Cat. UC-59.4

39. The First Passive Solar Home Awards, HUD-PDR-376, U.S. Department of Housing and Urban Development, GPO 023-000-00517-4, Apri1 1979.

40. Mazria, E., The Passive Solar Energy Book, Rodale Press, Emmaus, PA, 1979.

41. Britnel1, 0., Thermal Performance Analysis of Space Heating Systems in the National Solar Data Network, IBM, DoE Solar/0025-78/42, 1979.81

42. Pejsa, J., et. a1., Cost Effective Control Systems for Solar Heating and Cooling Applications, Final Report, SAN-1592-1, DoE, 1978.87

43. Waite, E., et. al., Reliability and Maintainability Evaluation of Solar Control Systems, ANL/SDP-TM-79-5, Argonne National Laboratory. 4/

44. National Electric Code, NFPA No. 70, National Fire Protection Association, 470 Atlantic Avenue, Boston, MA 02210, 1978. 
45. Chopra, P. and Wolosewicz, R., Reliability and Maintainability Evaluation of Freezing Solar Systems, ANL/SDP-TM-78-3, Argonne National Laboratory, 1978. 3/

46. Massena, P., Rool, D., Starr, S., and Walker, R., Solar Water and Pool Heating Installation and Operation, Florida Solar Energy Center, 300 State Road 401, Cape Canaveral, FL 32920, 1978.

47. Oil Burning Equipment, NFPA No. 31, 1974 (Also ANSI 2951).10,11/

48. Gas Appliances and Gas Piping Installation, NFPA No. 54, 1974. (Also ANSI Z21.22 and ANSI Z83.1, 1972).10,11/

49. Standard Specification for Concrete Aggregates, ASTM C33-81.2I

1/ American Society of Heating, Refrigerating and Air Conditioning Engineers, Inc., 1791 Tullie Circle, N.E. Atlanta, GA. 30329.

2/ American Society for Testing and Materials, 1916 Race Street, Philadelphia, PA 19103.

3/ Superintendent of Documents, U.S. Government Printing Office, Washington, DC 20402 .

4/ National Technical Information Service, 5285 Port Royal Road, Springfield, VA 22161 .

5/ National Association of Plumbing-Heating-Cooling Contractors, 1016 20th Street, N.W., Washington, DC 20036.

6/ AS/ISES, P.0. Box 1416, Killeen, TX 76541.

7/ Sheet Metal and Air Conditioning Contractors National Association, Inc., P.0. Box 70, Merrifield, VA 22116.

8/ Technical Information Center, P.0. Box 62, Oak Ridge, TN 37830 .

9/ The American Society of Mechanical Engineers, Inc., 345 East 47 th Street, New York, NY 10017.

10/ National Fire Protection Association, Battery March Park, Quincy, MA 02269.

11/ American National Standards Institute, Inc., 1430 Broadway, New York, NY 10018.

12/ Los Alamos Scientific Laboratory, P.0. Box 1663, Los Alamos, NM 87545. 
CHAP TER 4

SAFETY AND HEALTH

$\underline{\text { Page }}$

4.1 Contamination hazards $\ldots \ldots \ldots \ldots \ldots \ldots \ldots \ldots \ldots \ldots \ldots \ldots \ldots . . . \ldots$

4.1 .1 Protection of potable water .................. 4-1

4.1 .2 Separation of circulation loops .................. 4-1

4.1 .3 Backflow prevention ............................ 4-2

4.1 .4 Contamination of air ........................... 4-3

4.1 .5 Growth of fungi ............................ 4-3

4.2 Control of hazardous substances $\ldots \ldots \ldots \ldots \ldots \ldots \ldots \ldots \ldots \ldots . \ldots 4-4$

4.2 .1 Toxic fluids ............................ 4-4

4.2.2 Identification of hazardous fluids ............... 4-5

4.2 .3 Detection of hazardous fluids ................... 4-5

4.2 .4 Disposal of hazardous fluids .................. 4-6

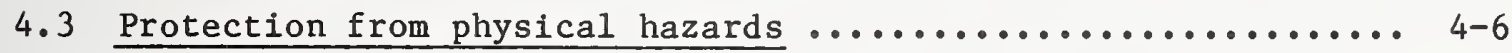

4.3.1 Pressure and/or temperature relief devices ......... 4-6

4.3.2 System failure prevention :.................. 4-7

4.3 .3 Glazing materials .......................... 4-7

4.3 .4 Scalding .................................. 4-9

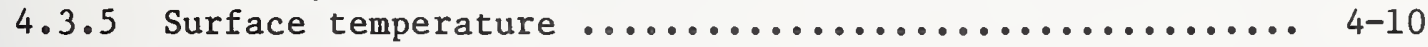

4.3 .6 Water storage hazards ....................... 4-10

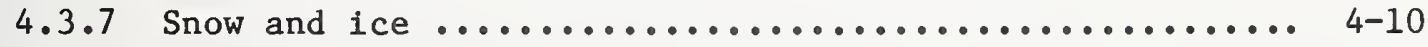

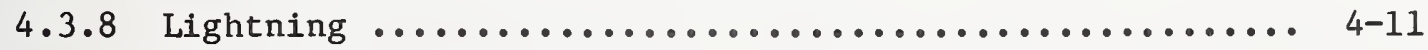

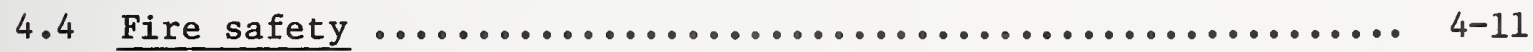

4.4 .1 Liquid flash point ......................... 4-12

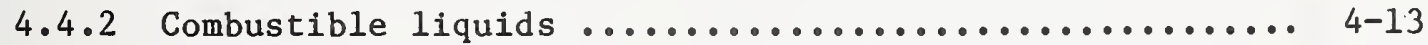

4.4.3 Flame spread classification of insulation .......... 4-14

4.4 .4 Areas of application of insulation .............. 4-14

4.4 .5 Fire resistance requirements ................... 4-15

4.4 .6 Roof covering fire performance .................. 4-16

4.4 .7 Self-ignition of combustibles .................. 4-16

4.5 Installation arrangement $\ldots \ldots \ldots \ldots \ldots \ldots \ldots \ldots \ldots \ldots \ldots \ldots \ldots . \ldots \ldots$

4.5.1 Identification and location of controls ........... 4-17

4.5 .2 Emergency egress and access ................... 4-18

4.5 .3 Electrical wiring .......................... 4-18 
CHAP TER 4 - (Continued)

SAFETY AND HEALTH

Page

4.6 Structural safety $\ldots \ldots \ldots \ldots \ldots \ldots \ldots \ldots \ldots \ldots \ldots \ldots \ldots \ldots \ldots \ldots \ldots$

4.6.1 Structural resistance of $\mathrm{H} / \mathrm{C} / \mathrm{HW}$ systems $\ldots \ldots \ldots \ldots \ldots$ 4-20

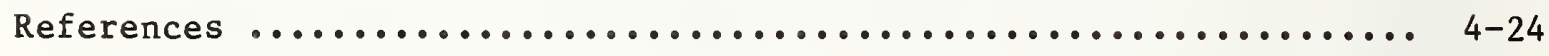


CHAPTER 4

SAFETY AND HEALTH

4.1

Requirement Contamination hazards. No material, form of construction, fixture,appurtenance, or item of equipment shall be employed that will support the growth of microorganisms or introduce toxic substances, impurities, bacteria, or chemicals into potable water and air circulation systems in quantities sufficient to cause disease or harmful physiological effects.

4.1 .1

Criterion Protection of potable water. Potable water shall not come in contact with materials that affect the taste, odor, or physical quality and appearance of the water in an undesirable manner.

Evaluation Review of plans and specifications. The quality of the water shall be in compliance with the National Interim Primary Drinking Water Regulation, Reference [1].*

Commentary This criterion is not intended to preclude using dyes suitable for ingestion as a means for the detection and warning of leaks in the system.

4.1 .2

Criterion

Separation of circulation loops. Potable water systems shall be separated from circulation loops of systems utilizing non-potable heat transfer or thermal storage fluids by a minimum of two physically separated walls or interfaces between the potable water supply and the non-potable liquid or shall be protected in such a manner that equivalent safety is provided. Alternative protection shall be provided in a manner acceptable to the applicable authority(ies) having jurisdiction.

Evaluation Review drawings and specifications. Alternate levels of protection shall be directly related to the toxicity potential of the heat transfer fluid used. For example, a suggested guideline for levels of protection is currently being examined by ASME.1/

Commentary It is very difficult for the system designer to assess the safety of the heat transfer fluids that are currently on the market. It is also very difficult for the designer to

* Numbers in brackets [] indicate reference at end of this chapter. 
determine the safeguards that must be taken to ensure safe system operation. Data are available in the literature that rank various heat transfer liquids on the basis of their relative toxicity. $2 /$ These data do not indicate the cut-off points at which various degrees of protection must be taken; however, consensus standards (in development) 1 ) may consider these relationships for solar applications. This problem is compounded by factors such as: (1) the use of additives to modify fluid properties; (2) the possible formation of harmful decomposition products, e.g., by thermal degradation; (3) dilution of the heat transfer fluid in the potable water stream, should failure occur, will help to reduce the level of toxicity hazard; (4) the fact that liquids are generally avallable in varying grades of chemical purity; (5). the possibility that the system will be refilled in the future with a hazardous liquid; and (6) the possibility that the circulation in a closed loop system for prolonged periods of time will even result in the contamination of potable liquids, e.g. by metal ion buildup. Thus, one must consider the attributes of the actual fluid as used in the system.

$4 \cdot 1.3$

Criterion

Backflow prevention. Backflow of non-potable fluids into the potable water systems shall be prevented in a manner approved by the applicable authority.

Evaluation Review drawings and specificiations. Inspect assembled systems.

Commentary Pollution of the potable water supply can occur by way of backflow caused by back pressure and/or backsiphonage within an inadvertent cross connection between the potable supply and non-potable fluid in the system.

Piping arrangements, backflow prevention and/or air gaps are commonly used to prevent contamination of potable water systems. A check valve is not a substitute for an approved backflow preventor and should not be used in its place.

1/ A preliminary draft standard prepared by the ASME Solar Energy Standards Committee in June 1980, contains guidelines for liquid-to-liquid heat exchangers which relate the toxicity of the fluid to the extent of protection provided.

2/ Toxicity ratings of commercial substances from two widely acknowledged sources, Gosselin, Reference [2] and Durham, Reference [3] are available. These have been summarized and tabulated in a convenient manner for many materials commonly used in solar systems in Reference [4]. 
Reference [5] provides discussion as well as evaluation of some of the many backflow prevention devices avallable.

$4 \cdot 1.4$

Criterion

Evaluation

Commentary

$4 \cdot 1.5$

Criterion

Evaluation
Contamination of air. Materials which come in contact with air shall not affect the odor or biological quality of the air in an occupied space in an undesirable manner.

Review drawings and specifications.

Special consideration should be given to the presence of fungus, mold, or mildew in air handling systems since such nicroorganisms are often allergenic. Filtering of air streams to reduce dust which may carry such microorganisms is desirable. Such provisions in passive systems with low air velocities may be impractical. Rock containing asbestos should not be used due to the potential carcinogenic hazard. Cleanliness of the rock storage medium is further covered in Criterion 3.3.5.

There is growing concern over the possible occurrence of harmful air pollutants in tightly sealed buildings, Reference [46]. Release of radioactive radon gas in particular has been associated with some masonry and concrete products such as those that may be used in large quantities in passive solar components or in rock storage bins, References $[6,7,8]$. Release of formaldehyde gas from the resins used in urea formaldehyde foam insulation, adhesives, and binders could present a problem when associated with air carrying components such as storage units or collectors.

Protection from contamination of the air supplied to occupied spaces may be accomplished by the use of suitable, non-corrosive heat exchangers. The use of heat exchangers will penalize the thermal performance of the system to some degree.

Growth of fungi. Components and materials used in the $\mathrm{H} / \mathrm{C} / \mathrm{HW}$ systems that come in contact with air being supplied to a conditioned space or with potable water and that operate under conditions that promote the growth of fungi, mold, or mildew shall not support such growth.

The materials shall be capable of withstanding exposure to fungus as defined by either Method 10 of UL 181, Reference [9] or Appendix D, Section E, of the MPS 4900.1 and 4910.1, References [10, 11]. Review environmental and design operation conditions. 
Fungi can feed on some organic materials and generally thrive in warm, moist environments. The potential for fungus growth in a rock storage container which becomes damp due to the failure of waterproofing membrane around underground or exterior containers or other causes could be a substantial problem requiring periodic maintenance. Use of a fungicide in such maintenance could introduce another potential airborne hazard and, therefore, other methods may be preferable.

The formation of condensation is a related problem that is also a concern. Condensation may occur on materials when used for cooling storage in air systems as well as on aperture glazing and between glazing and movable insulation.

\section{2}

Requirement Control of hazardous substances. The use of hazardous substances within the solar energy system shall be controlled in such a manner to prevent any unreasonable risk or danger to the occupants, building, or surrounding area.

Commentary

See the Terminology section for the definition of "hazardous substances" and the indicated reference providing guidelines to regulations regarding such substances.

$4.2 \cdot 1$

Criterion

Toxic fluids. The use of toxic fluids shall comply with the Federal Hazardous Substances Act, Reference [12] and the requirements of the applicable authority. (See definition of "toxic" in Terminology section.)

Evaluation Review specifications.

Commentary Toxic fluids are those having the capacity to produce personal injury or illness to man through ingestion, inhalation or absorption through any body surface, Reference [12]. A compilation of the toxicity characteristics of materials used in solar systems has been prepared, Reference [4]. When evaluating the toxicological properties of fluids, special consideration should be given to the effect of a system failure on the occupants. The evaluation should include the effects from contacting both the liquid directly and the vapor given off by the liquid.

The toxicological effects of the fluid should be evaluated at the elevated temperatures expected during system operation as well as at ambient temperatures. Characteristics of the complete fluid mixture must be considered in determining toxicity. For example, the addition of inhibitors and/or buffers to antifreeze/water mixtures or to water may affect toxicity characteristics. 
$4 \cdot 2.2$

Criterion

Identification of hazardous fluids. Systems using heat transfer fluids or thermal storage fluids that are designated as toxic or flammable by the supplier or the applicable authority shall be identifiable, and drains and other designated fluid discharge or fill points in the solar system should be labeled with: a warning identifying and summarizing the hazardous properties of the fluid, instructions concerning the safe handling of the fluid, safe means of disposal, and emergency first aid procedures.

Evaluation

Review drawings, specifications, and labeling (size, color, etc.) for compliance with the Federal Hazardous Substances Act, Reference [12].

Commentary

The original fluid containers will frequently be discarded after the system is charged which could result in no record of the fluid's properties being retained. The system drain is the point at which the owner or service personnel are most likely to contact the heat transfer fluid and permanent labeling should be retained at that point. Identification may be provided by attaching a tag containing the required information such as may be supplied by the heat transfer fluid manufacturer.

4.2 .3

Criterion

Detection of hazardous fluids. Means shall be provided to indicate a failure of the fluid transfer system (e.g., leakage, pump failure, or activation of relief valves) and the provision of warning when leaks occur if heat transfer fluids or thermal storage fluids that require special handling are used. The extent of warning (i.e. whether solely maintenance personnel or all of the occupants of a building) shall be determined on the basis of the degree of hazard presented by the fluid used and the type of occupancy.

Evaluation Review drawings and specifications. Test detection and warning system(s), i.e., visibility of a dye or operation of warning device.

Commentary It is common practice to relate toxicity and flammability ratings to the level of hazard created at ambient temperatures. Heat transfer fluids which do not present a hazard at ambient temperatures may be hazardous at the temperatures developed in the system. These substances may be treated in a manner similar to antifreeze and gases when providing for tell-tale indicators. For instance, antifreeze agents, such as ethylene glycol, may be treated with non-toxic dyes which distinguish them clearly. 
4.2 .4

Criterion

Evaluation

Commentary

4.3

Requirement Protection from physical hazards. The $\mathrm{H} / \mathrm{C} / \mathrm{HW}$ systems shall not create a hazard to people greater than those found in conventional buildings.

4.3 .1

Criterion

Evaluation

Disposal of hazardous fluids. Systems utilizing toxic, corrosive, combustible, or explosive heat transfer fluids or thermal storage fluid shall provide for the catchment and/or harmless removal and disposal of these fluids from drains, recharge points, vents, or points of probable leakage (i.e., leakage from components that would not normally be expected to last the life of the system) as approved by applicable authority.

Review drawings and specifications and local disposal regulations.

The discharge of toxic, corrosive, combustible, or explosive fluids into sewers can create serious health and safety hazards both within the community and at a considerable distance along watercourses into which the sewers discharge. Safe disposal of these fluids requires, among other things, the consideration of the fluid composition, its concentration and frequency of discharge, and the nature of the sewage treatment and disposal system available to the site. In some instances, catchment of this discharge and removal to the specialized treatment facilities may be the only acceptable disposal method. Under such conditions, adequately sized and protected catch basins must be provided.

The leakage of toxic fluids into the ground could contaminate ground water. In addition, leakage of some heat transfer fluids can damage roofing, sealants, and other building materials. The leakage of combustible fluids may pose a fire hazard when exposed to external ignition.

\section{conventional buildings.}

Pressure and/or temperature relief devices. Pressure and/ or temperature relief devices shall be provided in each portion of the system where excessive pressure and temperatures can develop and shall be set to open at not more than the maximum pressure and temperature for which the system is designed.

Review drawings and specifications and/or determine that methods, devices, and materials to be used are approved by a recognized testing and evaluation agency as being suitable for the proposed use. 
Care should be taken in the design and layout of the fluid transport system to prevent conditions in which locally excessive pressures or temperatures are developed as a result of flow restrictions or air locks. Large pressure or temperature changes due to flow of vapors or boiling fluids should be considered in the selection and location of relief devices. Relief devices must be protected from freezing as conditions can occur when relief is needed and the relief valves are inoperable because they are frozen. General requirements for use and installation of pressure relief devices are given in Reference [45].

4.3 .2

Criterion

Evaluation

Commentary

$4 \cdot 3 \cdot 3$

Criterion
System failure prevention. The control subsystem shall be designed so that, in the event of a power failure, or a failure of any of the components in the system, the temperatures and/or pressures developed in the $\mathrm{H} / \mathrm{C} / \mathrm{HW}$ systems will not present a danger to the occupants or damage any of the components of the system or the building.

Review drawings, specifications, and design calculations.

Excessive pressure and temperatures that can build up within or on collectors under "no-flow" conditions are an important consideration. Consideration should be given to the thermal shock which could occur when cool heat transfer fluids are introduced into collectors which have been exposed to solar radiation under "no-flow" conditions. Due to the possibility of large hydrostatic head pressures on tanks that may be greatly in excess of pressures elsewhere in the system, care should be taken in the selection of the location of safety devices. In systems which are designed for maximum temperatures less than the maximum no-flow temperature (see Appendix A, Section 1) it is essential that some means of protection such as energy dumping be provided. System protection for failure at low temperature conditions is covered in Requirement 3.6, Freeze Protection.

Glazing materials. Glazed solar components with slopes less than $45^{\circ}$ from the horizontal and which are lower than 8 feet $(2.4 \mathrm{~m})$ above a walking surface for unrestricted traffic adjacent to the component shall be safety glazed or otherwise protected against impact of persons falling against the glazing. Application of glazing materials in solar components that otherwise might present a risk of injury to persons because of falling or blowing of broken pieces or shards shall consist of safety glazing or be protected against breakage or restrained from falling. 
Evaluation

Commentary
Review plans and specifications for glazing locations and characteristics. Review compliance certification documents or test in accordance with procedures specified in "Federal Mandatory Standard for Architectural Glazing Materials", Reference [13] and "Performance Specification and Method of Test for Safety Glazing Materials Use in Buildings", Reference [14].

This criterion and references cited in the Evaluation are intended to reduce the risk of injuries to people from accidental contact with solar glazing materials. It is intended that they be applied to glazing materials in solar systems only in those areas where there is a likelihood that people might accidentally come in contact with the glazing, such as installations on which children might climb or against which a passerby might fall or which is overhead and susceptable to breakage.

An additional concern is for glazing materials presenting a risk of injury to persons because of broken, sharp pieces or sheets that could fall from their mounting or be picked up and driven by wind.

Glazing considered by this criterion include those used as covers for flat plate solar collectors, as tubes in solar collectors, as solar reflectors, as roof or wall panels in passive installations, and as storage containers which are routinely accessible.

Traditionally, greenhouse type structures have been considered to provide adequate protection against the hazard of persons falling against them. It is not the intent of this criterion to impose new requirements on greenhouses of conventional design when used for solar applications.

For tubular type collectors, safety glazing may be inappropriate and should be considered on the basis of their particular design. In such cases other means of protection such as screening, etc., may be required where installations fall under this criteria.

Where large expanses of glazing are used, as in passive installations, the Federal safety standard for architectural glazing materials, Reference [13] should be reviewed for its applicability with respect to physical location and arrangement of the glazing and exposure risk of persons nearby.

Potential safety hazards exposed to frequent hail projectiles with regard

should be considered in areas storms, falling limbs or other to installation of skylights, 
clerestory windows, and collector arrays. Where safety glazing is not employed, consideration should be given to provisions to restrain or deflect broken glass which may slide off elevated solar system components over entrances and locations of pedestrian and vehicular traffic ways. It is not the intent of this criterion to completely prevent punching or local cracking of nonstructural elements such as cover plates of collector panels under hail impact, but rather to control damage by keeping it at a level which would not create hazards by excessive shattering of glazed elements.

Film-type glazing materials for the outermost cover plates, if unsupported, may be unacceptable if they undergo large deflection under load, e.g., a flexible type glazing could deflect to the extent that a person's hand could touch the hot absorber surface, resulting in personal injury. See Criterion 4.3.5.

$4 \cdot 3 \cdot 4$

Criterion

Evaluation

Commentary
Scalding. Domestic hot water systems shall limit the temperature of the hot water for personal use at the tap to $140^{\circ}+5^{\circ} \mathrm{F}\left(60^{\circ} \mathrm{C}+3^{\circ} \mathrm{C}\right)$ except where other limits are established by applicable authority. See Criterion 2.3.1.

\section{Review drawings and specifications.}

This may be accomplished, for example, by the use of tempering or mixing valves or by the use of controls such as a high temperature cutoff on the solar energy storage device (which may result in wasteful energy loss). If other than the mixing valves or high temperature cutoff are used, it should be demonstrated that the required safe temperature limit will not be exceeded. This should be done by calculation of the temperatures in the system as a function of time throughout three successive clear sunny days in mid-July with the ambient temperature assumed at design conditions. The calculations should include the effect of water draw rate, tank heat losses, and typical collector efficiency values.

The major concern is not only for dangerously high temperatures but also for the sudden rise to such temperature. It is generally suggested that mixing or tempering valves are the most cost effective means for providing for protection from scalding. See also Section 615-6.2 of the MPS, Reference [10] for controls and safety devices for all tankless indirect water heater installations and for installations in housing for the elderly. 
4.3 .5

Criterion

Evaluation

Commentary

$4 \cdot 3.6$

Criterion

Evaluation

Commentary

\subsection{7 \\ Criterion}

Evaluation
The $+5^{\circ} \mathrm{F}\left(+3^{\circ} \mathrm{C}\right)$ margin is given to allow a reasonable margin of error for the design temperature capability that must be provided (see Criterion 2.3.1) and the temperature limitations of this section.

Surface temperature. Components of the H/C/HW systems that are accessible, located in areas normally subjected to public traffic and which are operated at elevated temperatures shall either be insulated to maintain the exposed surface temperatures at or below $140^{\circ} \mathrm{F}\left(60^{\circ} \mathrm{C}\right)$ at all times during their operation or be suitably isolated. Any other exposed areas that are operated at hazardous temperatures shall be insulated or identified with appropriate warnings.

Review drawings and specifications.

The maximum allowable temperature commonly accepted for use in domestic hot water installations without special protection is $140^{\circ} \mathrm{F}\left(60^{\circ} \mathrm{C}\right)$. In addition to the physical safety aspect, hot surfaces should be insulated to conserve energy or to prevent unwanted heat exchange with the space.

Water storage hazards. Water storage containers larger than $200 \mathrm{gal} .\left(755 \mathrm{~L}\right.$ or $\left..755 \mathrm{~m}^{3}\right)$ and located in or immediately adjacent to occupied spaces shall be adequately protected from damage and structurally restrained in such a manner to prevent rupture or collapse into the occupied spaces.

Review drawings and specifications.

Large volumes of stored water are a potential hazard whether heated or not. The flood of water that may result from ruptured tanks as well as the mass of the water-filled containers are of concern. These containers, individually or collectively, may fail due to impact, faulty fabrication or possibly corrosion. The safety hazard is greatly increased if the water is heated. See Criterion 4.6.1 for structural design considerations.

Snow and ice. Provision shall be made over entrances and locations of pedestrian and vehicular ways to restrain or deflect accumulated snow and ice masses which may slide off elevated solar system components.

Review drawings and specifications. 
Solar system components may often include smooth slippery surfaces located in elevated positions at steep angles. These elements may heat up rapidiy and loosen masses of snow or ice which may slide off. Means should be provided to prevent a hazard to people or property. Methods such as deflectors, restraints, low friction materials, or design of "safe fall" areas (pedestrian or vehicular routes located away from the building) should be considered. This criterion is not intended to apply to areas where snow and freezing conditions do not normally occur.

$4 \cdot 3 \cdot 8$

Criterion Lightning. As applicable, lightning protection shall be provided in accordance with the NFPA No. 78 Lightning Protection Code, Reference [15].

Evaluation Review of calculations, drawings, and specifications.

Commentary Damage to control components and the potential of fire are major concerns for lightning protection.

If solar system piping is used as grounding for lightning protection, there must be a continuous electrical path to ground. Care must be taken that this does not short circuit dielectric isolation and thus result in corrosion problems if dissimilar metals are used in the system.

4.4

Requirement Fire safety. The design and installation of the $\mathrm{H} / \mathrm{C} / \mathrm{HW}$ systems and their components shall provide a level of fire safety consistent with applicable codes and standards.

Evaluation Review of drawings and specifications for conformance with the local and nationally recognized codes and standards for fire safety including but not limited to applicable sections of :

NFPA 89M, Reference [16]

NFPA 90A, Reference [17] and 90B, Reference [18] NFPA 211, Reference [19]

NFPA 54, Reference [20]

NFPA 30, Reference [21]

NFPA 31, Reference [22]

NFPA 256, Reference [23]

The National Electrical Code, Reference [24]

ASTM E84, Reference [25]

In cases where sufficient engineering information is not available, testing to show compliance may be required. Potential heat, rate of heat release, ease of ignition, 
and smoke generation will be considered in assessing the potential fire hazards.

It is the intent of the criteria of this requirement to (1) assure that the use of materials, equipment, and fluids will present no greater fire hazard than that allowed for conventional systems; (2) provide proper clearance and venting of heat build-up for those system components that operate at elevated temperatures; and (3) give consideration to the combustibility of materials adjacent to high temperature components in determining the clearance and/or insulation required. Special consideration should be given to the fire safety features of innovative system designs, particularly those utilizing insulation in a way which may present a greater hazard than with conventional designs, such as passive system thermal control elements. Special consideration should also be given to the use of combustible glazing materials, particularly when those materials are used in large quantities and/or exposed to the building interior either directly or through air passages.

$4.4 \cdot 1$

Criterion

Liquid flash point. The flash point of a liquid heat transfer fluid shall equal or exceed the higher temperature determined from $A$ and $B$ below:

a. A temperature of $50^{\circ} \mathrm{F}\left(28^{\circ} \mathrm{C}\right)$ above the design maximum flow temperature of the fluid in the solar system;

b. The design maximum no-flow temperature of the fluid. Exception: When the collector manifold assembly is located outside of the building and exposed to the weather and provided that the relief valves located adjacent to the collector or collector manifold do not discharge directly or indirectly into the building, and such discharge is directed away from flames and ignition sources, only A above applies.

A "liquid heat transfer fluid" is defined as the operating or thermal storage liquid including water or other liquid base and all additives at the concentration used under operating conditions. The flash point shall be determined by the methods determined in NFPA No. 321, "Basic Classification of Flammable and Combustible Liquids," Reference [27]. Flammable liquids shall not be used, and in systems using a gaseous heat transfer fluid, a flammable gas shall not be used. The design maximum flow temperature of the fluid is defined as the maximum fluid temperature that wil1 be obtained when the heat transfer fluid is flowing through the system. Generally, this temperature will occur in the 
Evaluation

Comment ary

4.4 .2

Criterion

Evaluation

Comment ary collector when it is receiving its maximum level of solar radiation at maximum ambient temperature.

Review drawings, specifications, design calculations, and test data for flash point and collector stagnation and operating temperatures. An acceptable way of determining the design maximum flow temperature is to limit temperatures of control devices or relief valves, or through theoretical or test analysis of the system. A method of determining the maximum no-flow temperature is by measuring the fluid temperature under stagnation conditions. The no-flow, 30 day test is presented in Section 10 of Appendix A. The design maximum no-flow temperature of the fluid is equal to the plate temperature at stagnation. It should be noted that this method is not valid for collectors with very low loss coefficients.

Flash point values listed in manufacturer's literature are frequently typical values and may be determined by an open cup flash point test. Flash point values used should be based on actual measurement or certified minimum values determined by the required closed cup flash point test method, Reference [27].

The flash point of aqueous solutions of organic materials depends on the percentage of water in the mixture. In the case of ethylene glycol, a flash point does not exist for certain percentages of ethylene glycol with water. When these mixtures are boiled and vapors allowed to escape, the flash point of the mixture usually will be reduced, ultimately approaching that of the pure substance. Care should be taken that the flash point of the solution is based on the anticipated percentage of water during actual use of the liquid in the system and not necessarily on the percentage as installed. A study of solar heat transfer fluid flash points and flash point criteria is presented in Reference [28].

Combustible liquids. The storage, piping, and handling of combustible liquids shall be in accordance with the Flammable and Combustible Liquids Code NFPA No. 30, Reference [21].

Review specifications or code compliance.

This criterion applies to those liquids which have met Criterion 4.4 .1 for flash point. See also Criteria 4.2.2, 4.2 .3 , and 4.2 .4 . 
$4 \cdot 4 \cdot 3$

Criterion

Evaluation

Comment ary

$4 \cdot 4 \cdot 4$

Criterion
Flame spread classification of insulation. The flame spread classification index for all insulation materials except those installed underground and outside the structure shall not exceed the following values:

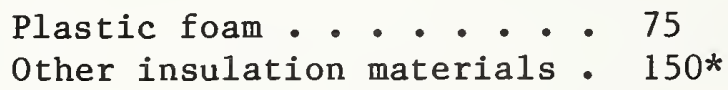

Insulation materials used for duct liners or air passage ways shal1 meet the requirements of either NFPA $90 \mathrm{~A}$, Reference[17] or 90B, Reference [18], whichever is applicable.

The ASTM E84, Reference [25] flame spread test method shall be the basis for evaluating the surface burning characteristics of the insulation materials. Where materials with facings are to be used, the surface burning characteristics of the faced materials shall be measured.

No single test is sufficient to provide a full estimate of performance of a product in a fire. Plastic foams and loose fill insulation are difficult to evaluate by ASTM E84. The requirement of flame spread classification of 75 maximum for plastic foams will provide as much safety assurance as is possible with current test methods. Such a classification sha11 not be construed as the equivalent of "noncombustible." Many insulation materials, including those consisting of cellulose, plastic foam, and fibrous glass (containing organic binder) are combustible materials which will burn and release heat, especially when exposed to continuous large fire sources.

Areas of application of insulation. Materials used for thermal insulation shall be in accordance with Criterion 4.4.3 and may be applied to the following areas: walls, roofs, ceilings, floors, pipes, ducts, vessels, and equipment exposed to the external environment.

Exposed plastic foam (untreated or fire-retardant treated), Kraft-asphaltic vapor barrier on mineral and organic fiber insulations, and non-fire-retardant treated loose fill insulation shall not be permitted in habitable areas unless fully protected from the interior of the building by a

* The Consumer Product Safety Commission "Interim Safety Standard for Cellulose Insulation," Federal Register, Volume 43, No. 153, P. 35240, became effective on September 8,1978 and supercedes these requirements for cellulose insulation where applicable. Modifications to this standard are under consideration by CPSC. 
Evaluation

Commentary

4.4 .5

Criterion

Evaluation

Commentary thermal barrier having a finish rating of not less than 15 minutes as determined by NFPA 251, Reference [29]. Thermal barriers shall be installed in a manner such that they will remain in place for a minimum of 15 minutes under the same test conditions.

Installed insulation and vapor barriers shall not make contact with pipes or pumps containing hot fluids, motors, fans, blowers, and heaters, unless the insulation and/or the heat producing appliances are specifically designed and rated for that purpose.

Review drawings and specifications.

Although a degree of material combustibility is allowed, the intent is to allow thermal insulating materials which are not more combustible (or flammable) than existing construction and insulation materials, and to preclude any increased fire hazard due to the retention of heat from energy dissipating objects. Electric fixtures and circuit wires which are surrounded by substantial thermal insulation may be subject to overheating especially for circuits loaded at or beyond their rated capacity. In areas where occupants are likely to be engaged in normal activities, or in spaces in contact with the air stream, the insulation should perform its intended function without the increased risk of ignition, rapid flame spread, and heat and smoke generation. Attention should be given to the requirements as they pertain to innovative insulation systems such as movable and fixed insulation installed as part of passive systems. Insulation in concealed spaces may be a particular fire problem due to its susceptibility to smouldering and its inaccessibility for firefighting.

Fire resistance requirements. The presence of solar components and their installation (penetration, etc.) shall not reduce the fire resistance of building elements (walls partitions, roofs, floors, etc.) required by the applicable authority.

Review drawings and specifications. Testing to show compliance in accordance with NFPA 251, Reference [29] and applicable standards.

Solar components may form the load bearing elements of walls, roofs, etc. In addition, the presence of solar components (collectors, storage, etc.) and the passage of system components through fire-rated assemblies may adversely affect the fire endurance rating of the assembly in terms of fire penetration or premature collapse of structural ele- 
4.4 .6

Criterion

Evaluation

Commentary

4.4 .7

Criterion ments. Large expanses of combustible glazing or other components used in wall and roof elements may significantly reduce the fire resistance of these components.

Roof covering fire performance. The presence of roof mounted solar collectors or other components shall not reduce the required fire rating of the roof covering materials below that required by the applicable authority.

Review drawings and specifications. Testing when necessary to show compliance shall be in accordance with NFPA 256, Reference [23] with the collectors mounted as intended to use.

Special consideration should also be given to the use of combustible glazing materials, particularly when those materials are used in large quantities and/or exposed to the building interior either directly or through air passages.

The type of testing that should be performed to evaluate the influence of solar collectors on the fire resistance of roof assemblies is described in test method 7.13 of NBSIR 78-1305A, Reference [26]. Testing using these procedures has shown that when collectors are mounted parallel to the roof, with a space greater than $11 / 2$ inches between the collector and the roof, the fire resistance of the roof covering is generally reduced, Reference [44].

Self-ignition of combustibles. Combustible solids used in solar equipment and adjacent combustible solids shall not be exposed to elevated temperatures which may cause ignition.

Clearance between combustible solids and system components having elevated temperatures shall be maintained in accordance with the following: 


\section{Installation Clearances}

Maximum Surface

Temperature $\left({ }^{\circ} \mathrm{F}\right)$

less than 200

200 to 250

250 to 500

over 500

\section{Required Clearance \\ (inches)}

0
1
6
not allowed *

Evaluation

Commentary

4.5

Requirement

Installation arrangement. The location of solar components shall not increase the accident/hazards potential to a greater extent than would be expected for a conventional non-solar building.

Commentary Some examples can be given of how the presence of solar components might increase accident potential: (1) reflected rays from the collector could be distracting to drivers on adjacent highways or annoying to the occupants of nearby buildings, and (2) the ground around a storage unit might settle, creating a hazard because of the uneven ground.

$4 \cdot 5 \cdot 1$

Criterion Identification and location of controls. Main shutoff valves and switches should be conspicuously marked and

* Combustible solids shall not be exposed to temperatures above $500^{\circ} \mathrm{F}$ unless the components are so listed and the clearances to combustible materials as specified in the component listing and marking shall be maintained for such elevated temperatures. 
Evaluation

Commentary

$4 \cdot 5.2$

Criterion

Evaluation

Commentary

$4 \cdot 5 \cdot 3$

Criterion

Evaluation placed in locations that are readily accessible to those personnel who would normally be expected to operate them in the event of an emergency. These valves and switches shall be located in the same manner as specified in 250.24 of NFPA 70, Reference [24] for electrical panels.

Review drawings and specifications.

In large buildings, accessibility would normally be limited to qualified personnel; however, in small buildings, accessibility for the tenants should be provided.

In addition, controls which should only be adjusted by skilled personnel should not be located in areas subjected to normal occupant access.

Emergency egress and access. The design and installation of the $\mathrm{H} / \mathrm{C} / \mathrm{HW}$ systems shall not impair the emergency movement of occupants of the building or emergency personnel to an extent greater than that allowed by NFPA 101, Reference [30] and applicable codes and standards.

Review drawings and specifications. Evaluate alternative means for provision of equal safety protection.

If operable windows or exterior doors, required by many codes for sleeping areas, are eliminated for increased thermal control, such rooms and adjacent corridors should have listed smoke detectors which are interconnected and a door opening directly into a corridor that has access to two remote exits in opposite directions.

The location of solar equipment on a roof could reduce the usability of that roof for firefighting or egress. Solar system components located outside the building but near a means of egress could block the means of egress if a fire occurs.

Electrical wiring. Electric wiring shall be installed in accordance to the requirements of the National Electrical Code, Reference [24] or the applicable authority. Particular attention must be given to the routing of wire and placement of electrical equipment in or near spaces which have higher than normal temperatures as a result of the operation of solar components.

Review of specifications and building drawings. The National Electrical Code, Reference [24], Chapter 3, states the requirements for temperature limits and derating factors for wiring exposed to elevated temperatures. 
Experience from the Solar Demonstration program has shown that spaces adjacent to solar collectors can become heated to higher than normal temperatures. The installation of residential branch circuit wiring in spaces that will experience elevated temperatures requires that special types of wire be used or the type generally used in residential applications having a thermal limit of $140^{\circ} \mathrm{F}\left(60^{\circ} \mathrm{C}\right)$ be derated. Recent studies, References [47, 48] have shown that the $140^{\circ} \mathrm{F}\left(60^{\circ} \mathrm{C}\right)$ limit can be reached when residential branch circuits are located in attic spaces and normal loading is assumed. Thus special precautions should be used when locating electrical equipment and wiring either in or near collectors, or other components which might cause the wire to exceed its rated temperature limit.

4.6

Requirement

Commentary
Structural safety. The $\mathrm{H} / \mathrm{C} / \mathrm{HW}$ system shall provide a level of structural safety consistent with applicable codes and standards.

This requirement deals with the ability of systems and elements to maintain their structural integrity under in-service and extreme conditions. Factors such as wind, snow, operating, seismic, and thermal restraint loads are considered. Typical failures that are to be avoided might include: the collapse of a frame supporting solar collectors due to wind, snow, or earthquake; collapse of the thermal storage vessel or its supporting structure; the blowing off or fracture of a glass cover plate due to wind or thermal stresses.

Note that this applies to all elements of a solar system, not just those with a function of providing support for some other element. In this regard, there is an important distinction made between conventional elements, those elements for which design and construction procedures are contained in existing building regulatory documents, and non-conventional elements, those elements for which such procedures are not available. Elements made of materials documented in existing building regulatory documents, such as structural steel, aluminum, timber, glass, masonry, and concrete, that will be exposed to service conditions that are normally considered in such documencs are examples of conventional elements. Newer materials such as a new alloy of aluminum, or conventional materials exposed to an unusual environment such as welded steel subjected to unusually high or low temperatures, or plastics subject to high and low temperatures are examples of non-conventional elements. Elements with a structural support function will generally be conventional. 
$4 \cdot 6 \cdot 1$

Criterion
Structural resistance of $\mathrm{H} / \mathrm{C} / \mathrm{HW}$ systems. The elements and connections of the $\mathrm{H} / \mathrm{C} / \mathrm{HW}$ systems shall safely support all loads expected during the design life of the system without failure.

The structural resistance of conventional elements shall be determined in accordance with generally accepted engineering practices for the appropriate material, References $[31,32,33,34]$.

When common building materials cannot be judged by conventional criteria because they are exposed to unusual service conditions such as high temperatures, or where new materials are used structurally, the guide performance criteria in section 13.2.4 of Reference [35] should be used to determine structural resistance.

The design load shall include the following loads and shall be taken from and combined in accordance with ANSI Standard A58.1, Reference [36] and as noted:

1. Dead loads. Include the weight of heat transfer fluid contained in the component except when using dead load to resist uplift or overturning.

2. Live loads. Include all static and dynamic loads caused by the operation of the solar energy system and all appropriate maintenance loads. Surfaces that must support maintenance personnel shall resist a single concentrated load of 250 lbs ( $113 \mathrm{~kg}$ ) distributed over a 4 square inch $\left(2580 \mathrm{~mm}^{2}\right)$ area at the most critical locations. Also include vehicular loads as stipulated by AASHTO, Reference [37] on elements at or below grade subjected to traffic.

3. Soil and water pressures on buried elements.

4. Wind loads. Account for any unusual shape or exposure factors in accordance with accepted engineering practice. Reference [38] includes information on wind loads on solar collectors.

5. Snow and ice loads. Include any unusual loads due to drifting or slide-off. Solar components shall resist the appropriate surcharges, as defined in Reference [36]. Reference [39] provides information on ice loads on slender elements.

6. Earthquake loads. For components and connections which cannot be evaluated within the scope of the referenced

$$
\text { 4-20 }
$$


provisions, the value of " $\mathrm{Cp}$ " (horizontal force factor) shall be taken as 1.0. Reference [38] includes information on earthquake loads.

7. Constraint loads. Those loads caused by temperature changes, shrinkage, moisture changes, normal functioning of the system, time-dependent changes within the materials of the system and by differential movement of the supporting structure and foundation settlement shall be taken as the most severe likely to be encountered during the service life.

8. The load from ponding of water on large horizontal surfaces shall be considered.

Evaluation

Commentary

Review drawings, specifications, calculations, and testing.

It is expected that most aspects of structural design for solar installations will fall within the domain of conventional engineering practice and that existing codes and standards may be applied to such. The intent of this criterion is that conventional elements and systems continue to be designed in accordance with applicable building code documents. The performance criteria in Section 13.2.4 of Reference [35] are specified for use in those situations in which accepted engineering standards are not applicable. Considerable care is required in determining the structural resistance in such situations. For structural testing of flat plate collectors, a test method has been proposed in Reference [26] for the following tests: positive live loads, negative and combination wind loads, and longitudinal loads.

It is recognized that some elements will be designed using the ultimate resistance and factored loads while others will be designed using an allowable resistance and unfactored loads.

The loads presented are those expected to occur in the projected lifetime of the installation. Particular attention should be given to the load caused by the thermal cycling of the system, both under normal conditions and "no-flow" conditions.

The following paragraphs of commentary are numbered corresponding to the loads listed under the criterion:

(1) The design dead load of mass storage materials (water tubes, drum walls, etc.) may in some instances need to be considered on other portions of the structure 
(floors, partitions, etc.). These loads can be quite important, particularly in retrofit application.

(2) The design live loads for roofs constitute minimum loading requirements needed primarily for human safety while the building is undergoing maintenance. Resistance to these loads need not be required for collector panels that are mounted on roofs without forming an integral part of the roof if adequate access is provided for service and maintenance personnel. For collectors which form an integral part of the roof, resistance to the design live roof loads should be required, because the roof will need to be repaired from time to time and must support the workman making the repairs.

(3) Wind load pressure coefficients for flat plate collectors are presented in Reference [40] and a tabulation of extreme wind speeds is contained in Reference [41].

Wind loads due to the presence of solar systems may be more severe than those normally acting on buildings and require special attention especially in retrofitting an existing building.

(4) Rows of solar collectors protruding from a roof are sinilar to a snow fence and may significantly increase the amount of snow retained on the roof, requiring special attention especially in retrofitting an existing building. Reference [38] provides design guidelines.

(5) The value of "Cp" for seismic design supplied for elements that are not specified by the referenced provisions is consistent with conservative values for elements appended to structures.

(6) The possibility of stresses being imposed by thermal expansion or contraction, wind movement, seismic loads, vibratory loads, or foundation settlement need to be considered. Thermal expansion and contraction effects should be evaluated for the extreme operating temperature range; note particularly, pipe thrusts at anchors and elbows. Solar components vary in their ability to withstand the effects on their performance of differential settlement. For example, a rock storage bin can probably settle a great deal without affecting its performance; however, a plumbing connection may be able to withstand very little differential settlement. 
Time dependent changes within materials or the system should include consideration of materials degradation. of particular concern may be deterioration of plastics and organic materials, corrosion and electrolytic action between dissimilar metals such as between a collector and its support. Materials degradation is further discussed in Chapter 5.

In some circumstances, such as collectors framed in wood or attic collectors, wood and other fibrous materials may be subject to sustained or cyclic elevated temperatures for extended periods of time (years). Under such conditions, strength reduction of structural members may be very significant and should be considered, References [42, 43]. Uneven heating of such structural members may cause racking or twisting during the normal course of the day. This should be accounted for in the design of the structure.

(7) Ponding is defined as the retention of water due to the deflection of horizontal surfaces. Measures to resist ponding include providing sufficient stiffness to prevent excessive deflections, providing slope to carry excess water away, providing drains to remove water or providing overflow locations to limit the depth of water. 
1. National Interim Primary Drinking Water Regulations, 1977, Environmental Protection Agency, Office of Water Supply, Stock Number 055-000-00157-0.1/

2. Gosselin, Hodge, Smith and Gleason, Clinical Toxicology of Commercial Products, 4th Edition, Williams and Wilkins Co., 428 E. Preston St., Baltimore, MD 21202, 1975.

3. Durham, W., "Toxicology" in Dangerous Properties of Industrial Materials, Sax, N., ed. Van Nostrand Reinhold Co., 135 W. 50th St., New York, NY 10020, 1975.

4. Searcy, J., ed. Hazardous Properties and Environmental Effects of Materials Used in Solar Heating and Cooling (SHAC) Technologies:

Interim Handbook, SAND 78-0842, Sandia Laboratories, Albuquerque, NM, June 1978.3

5. Sherlin, G., Beausoliel, R., Evaluation of Backflow Prevention Devices: A State-of-the-Art Report, NBSIR 76-1070, National Bureau of Standards, Washington, DC 20234, 1976.3 /

6. Kusuda, T., Hunt, C., McNa11, P., "Radioactivity (Radon and Daughter Products) as a Potential Factor in Building Ventilation", ASHRAE Journal, July $1979 . \underline{4}$

7. Johnson, J. and 0lson, H., "Measurement of $222 \mathrm{Rn}$ Build-Up in Solar Heated Buildings and Calculation of Radiation Doses", DoE Publication C00-4546-2, Solar Energy Applications Laboratory, Colorado State University, October 1978.

8. Draft Environmental Impact Statements, DoE Publication EIS-0050-D, Ju1y 1979.

9. Standard for Factory Made Air Duct Materials and Air Duct Connectors, UL 181, Underwriters Laboratories, 333 Pfingsten Road, Northbrook, IL $60062,1974$.

10. HUD Minimum Property Standards, One- and Two-Family Dwellings, No. 4900.1, U.S. Department of Housing and Urban Development, Washington, DC, 1973, revised 1976.1 I

11. HUD Minimum Property Standards, Multifamily Housing, No. 4910.1, U.S. Department of Housing and Urban Development, Washington, DC, 1973, revised $1976.1 /$

12. Federal Hazardous Substances Act, Code of Federal Regulations (CFR) Title 16, Part 1500.11 
13. Federal Mandatory Standard for Architectural Glazing Materials, 16 CFR 1201, Federal Register, January 6, 1977.1/

14. Performance Specification and Method of Test for Safety Glazing Material Use in Buildings, American National Standards Institute, ANSI 297.1-1975.

15. Lightning Protection Code, NFPA No. 78, 1977. 6 /

16. Clearances, Heat Producing Appliances, NFPA No. 89M, 1976. $\underline{6 /}$

17. Air-Conditioning and Venting Systems, NFPA No. 90A, 1981.

18. Warm Air Heating and Air Conditioning, NFPA No. 90B, 1980.6/

19. Chimneys, Fireplaces and Vents, NFPA No. $211,1977 . \underline{6 /}$

20. Gas Appliances and Gas Piping Installation, NFPA No. 54, 1974 (also ANSI 283.1, 1972).5/,6/

21. Flammable and Combustible Liquid Code, NFPA No. 30, $1977.6 /$

22. Oil Burning Equipment, NFPA No. 31, 1974 (a1so ANSI 295.1).지

23. Fire Tests of Roof Coverings, NFPA No. 256, 1976 (a1so ASTM E108, 1975느 and UL 790). 6 /

24. National Electric Code, NFPA No. 70, 1978 (also ANSI C1, 1978). 6/

25. Surface Burning Characteristics of Building Materials, Test for, ASTM E84-77, 1977.니

26. Provisional Flat Plate Solar Collector Testing Procedures, First Revision NBSIR 78-1305A, National Bureau of Standards, Washington, DC, June $1978 . \underline{3}$

27. Basic Classification of Flammable and Combustible Liquids, NFPA No. $321,1976 . \underline{6}$

28. Lee, B. T. and Walton, W. D., Fire Experiments and Flash Point Criteria for Solar Heat Transfer Liquids, NBSIR 79-1931, National Bureau of Standards, Washington, DC 20234, November, 1979. 3 /

29. Standard Methods of Fire Tests of Building Construction and Materials, NFPA No. 251, 1972 (also ASTM E119 and UL 263). 6

30. Life Safety Code, NPPA No. 101, 1976.1/

31. Building Code Requirements for Reinforced Concrete, ACI 318-77, American Concrete Institute, P.0. Box 19150, Redford Station, Detroit, MI 43219, 1977. 
32. Manual of Steel Construction, American Institute of Steel Construction, 1973.

33. Specifications for Aluminum Structures, The Aluminum Association, 1976.

34. National Design Specifications for Stress-Grade Lumber, National Forest Products Association, 1979.

35. Performance Criteria Resource Document for Innovative Construction, NBSIR 77-1316, National Bureau of Standards, Washington, DC, November $1977 . \underline{3}$

36. Building Code Requirements for Minimum Design Loads in Buildings and Other Structures, ANSI A58.1, American National Standards Institute, proposed 1980 revision.

37. Standard Specification for Highway Bridges, American Association of State Highway and Transportation Officials (AASHTO), 444 No. Capital Street, N.W., Washington, DC 20001, 1973.

38. Wind, Earthquake, Snow and Hail Loads on Solar Collectors, NBSIR 81-2199, National Bureau of Standards, Washington, DC, February $1981 . \underline{3}$

39. "Design of Steel Transmission Pole Structures," ASCE Journal of the Structural Division, December 1974.

40. Tieleman, H., Sparks, P., Akins, R., "Wind Loads on Flat Plate Solar Collectors", Department of Engineering Science and Mechanics, Virginia Polytechnic Institute, presented at National ASCE Conference, Atlanta, GA, October 22-26, 1979.

41. Simiu, E., Changery, M., Filliben, J., Extreme Wind Speeds at 129 Stations in the Contiguous United States, BSS 118, National Bureau of Standards, Washington, DC 20234, 1979.1/

42. Wood Handbook, 1974, p. 4-32, 4-40, Forest Product Laboratory, P.0. Box 5130, North Walnut Street, Madison, WI 53705.

43. MacLean, J., Rate of Disintegration of Wood Under Different Heating Conditions, American Wood Preservers Association, 1625 Eye Street, N.W., Washington, DC 20036, 1951 .

44. Walton, William D. and Waksman, David, Fire Testing of Roof-Mounted Solar Collectors by ASTM E108, NBSIR 81-2344, National Bureau of Standards, Washington, DC 20234, 1981. 3 / 
45. ASME Boiler and Pressure Vessel Code, ANSI/ASME BPV-VIII-1, 1980, Division 1, Pressure Vessels. 5 / 8 /

46. Indoor Pollutants, National Research Council, National Academy Press, 1981.

47. Beausoliel, R.W., Meese, W.J. and Galowin, L.S., Exploratory Study of Temperatures Produced by Self-Heating of Residential Branch Circuit Wiring When Surrounded by Thermal Insulation, NBSIR 78-1477, National Bureau of Standards, Washington, DC 20234, 1978. 3 /

48. Faison, T.K., Field Measurement of Branch Circuit Wire Temperatures, NBSIR 81-2347, National Bureau of Standards, Washington, DC 20234 , $1981 . \underline{3}$

49. Walton, William D., Solar Collector Fire Incident Investigation, NBSIR 81-2326, National Bureau of Standards, Washington, DC 20234 , $1981 . \underline{3}$

1/ Superintendent of Documents, U.S. Government Printing Office, Washington, DC 20402.

2/ American Society for Testing and Materials, 1916 Race Street, Philadelphia, PA 19103.

3/ National Technical Information Service, 5285 Port Royal Road, Springfield, VA 22161.

4/ American Society of Heating, Refrigerating and Air Conditioning Engineers, Inc., 1791 Tullie Circle, N.E. Atlanta, GA 30329.

5/ American National Standards Institute, Inc., 1430 Broadway, New York, NY 10018.

6/ National Fire Protection Association, Battery March Park, Quincy, MA 02269 .

7/ Note that the reference is to the proposed new edition, not to the current (1972) edition.

8/ The American Society of Mechanical Engineers, Inc., 345 East 47 th Street, New York, NY 10017.

9/ Council of American Building Officials, 5201 Leesburg Pike, Suite 507 , Falls Church, Virginia 22041. 

- r s s .

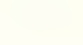

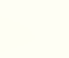

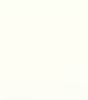

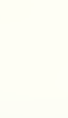

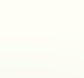

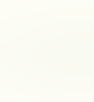

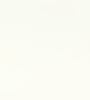

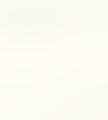

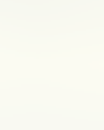

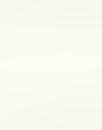

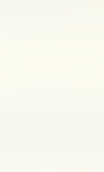

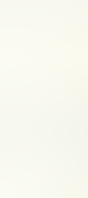


CHAPTER 5

DURAB ILITY/REL IAB ILITY

$\underline{\text { Page }}$

5.0 Introduction $\ldots \ldots \ldots \ldots \ldots \ldots \ldots \ldots \ldots \ldots \ldots \ldots \ldots \ldots \ldots . \ldots \ldots$

5.1 Effect of external environment $\ldots \ldots \ldots \ldots \ldots \ldots \ldots \ldots \ldots \ldots \ldots . \ldots \ldots$

5.1.1 Solar degradation ........................... 5-2

5.1 .2 Moisture penetration/degradation ................. 5-3

5.1.3 Pollutant degradation ........................ 5-5

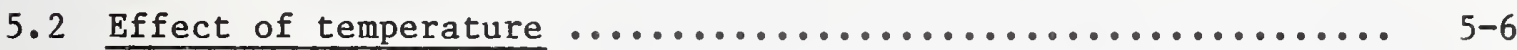

5.2.1 Thermal degradation ......................... 5-6

5.2 .2 Thermal cycling degradation ................... 5-8

5.2 .3 Thermal shock degradation ..................... 5-9

5.3 Effect of chemical compatibility of components $\ldots \ldots \ldots \ldots \ldots$....

5.3.1 Materials/transfer fluid degradation .............. 5-10

5.3.2 Dissimilar metals degradation ................. 5-12

5.3.3 Compatibility of adjacent organic materials ........ 5-13

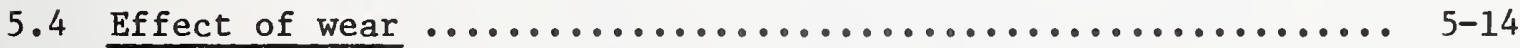

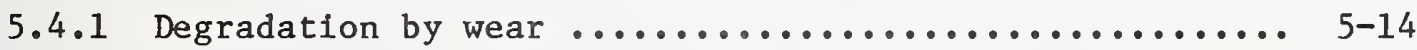

Table 5.1.a Guide for Durability/Reliability Evaluation of

Collector Subsystems, Components and Materials ..... 5-15

Table 5.1.b Guide for Durability/Reliability Evaluation of

Energy Transport Subsystems, Components and

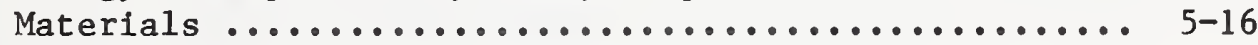

Table 5.1.c Guide for Durability/Reliability Evaluation of

Storage Subsystems, Components and Materials ........ 5-17

Table 5.1.d Guide for Durability/Reliability Evaluation of

Control Subsystems, Components and Materials ....... 5-18

Table 5.2.a Property Assessment of Materials -- Collector

Components ............................. 5-19

Table 5.2.b Property Assessment of Materials -- Energy Transport

Components ............................ 5-20

Table 5.2.c Property Assessment of Materials -- Storage

Components ............................ 5-21

Table 5.3 Open System Parameters: Generally Acceptable and

Unacceptable Use Conditions for Metals in Direct

Contact with Heat Transfer Fluids .............. 5-22

Table 5.4 Closed System Parameters: Generally Acceptable and

Unacceptable Use Conditions for Metals in Direct

Contact with Heat Transfer Liquids .............. 5-24 
CHAPTER 5

DURAB ILITY/RELIABILITY (Cont.)

Page

References

5-26 
CHAPTER 5

DURAB ILITY/RELIAB ILITY

5.0

Introduction The performance requirements and criteria in this chapter deal with the ability of components and materials to maintaln satisfactory long-term performance under in-service and extreme conditions. Factors such as the effect of external environment, temperature, chemical compatibility and wear or fatigue are addressed.

The intent in developing the requirements of Chapter 5 on durability/reliability is to assure that the components and materials designed to work as a system in the application of solar energy have a reasonable level of rellability. Much of the evaluative testing needed to assess performance should already have been carried out as part of the materials manufacturer's product development process, thus much of the requested information should be relatively easy to supply. There may be cases where a proposed design or application creates a unique condition of exposure, and additional testing will be needed to demonstrate compliance with the intent of the criteria. When testing of components or assembly of components is necessary, the performance of the assembly should indicate whether or not more detalled materials evaluation may be required. For instance, water leakage into a component would indicate that either the material must be resistant to molsture damage or the component must be redesigned to prevent water penetration. If the material is to resist degradation from molsture, evidence must be made avallable to show that the proposed materials possess the required characteristics to resist exposure to moisture.

As an ald to the user, a guide has been prepared which lists requirements and criteria for various components and materials, and the corresponding need for evaluative testing and analysis. A general guide for the consideration of each requirement and criterion for the various components and materials is contained in Tables 5.1a, 5.1b, 5.1c and 5.1d. The subsystems covered by these tables include the collector, the energy transport, the sitorage and the control subsystems and their components. These tables delineate the types of environmental conditions to which solar components and their materials could be exposed in actual service.

Tables 5.2a, 5.2b and 5.2c on collector, energy transport and storage components, respectively, are provided as an 
aid to identifying the need for assessing properties of materials. These tables do not relate directly to specific criteria, but guide the evaluator in determining which materials properties are critical for various subsystem components. The designated critical properties, when evaluation is required, should be measured before and after exposure to the environmental conditions or aging procedures presented in Chapter 5. Table B.1 (see Appendix B) presents standard practices which are available for determining physical properties of materials.

Appendix A provides test methods for evaluating components and materials to determine if satisfactory performance is achieved. The test methods listed in Appendix A are to be used when standard practices, such as ASTM standards, are not available. If standard practices are available, and satisfactorily address the issues of conditioning exposure and measurement of performance, such standards are preferred over the test method presented in Appendix A.

Appendix B contains several tables intended to assist evaluators and designers with durability/reliability issues when materials are considered for solar application. In addition to Table B.l, which lists avallable ASTM standards useful in materials property measurement, tables of materials properties and characteristics are presented. Tables B.2, B.3, B.4 and B.5, which were derived from literature sources, provide the evaluator/designers with baseline information on properties of: cover plates, absorptive coatings, heat transfer liquids, and selected building materials.

5.1 Requirement Effect of external environment. The $\mathrm{H} / \mathrm{C} / \mathrm{HW}$ systems and environmental factors to an extent that will significantly impair their function during their design lives.

5.1 .1

Criterion

Solar degradation. Solar components or materials shall not be adversely affected by exposure to sunlight in service to an extent that will significantly impair their function during their design lives.

When components or materials are exposed to ultraviolet radiation, there shall be no signs of excessive deterioration of optical, physical, or mechanical properties, or any other changes that would significantly affect the performance of the components in the system. 
Compliance may be documented with data on satisfactory long-term performance under in-service conditions or engineering analysis. Where adequate information is unavallable, evaluation shall, where applicable, be carried out using the following standard practices which include solar degradation provisions: for cover plate materials, ASTM E765-80, "Standard Practice for Evaluation of Cover Materlals for Flat Plate Solar Collectors", Reference [1]; and ASTM E782-81, "Standard Practice for Exposure of Cover Materlals for Solar Collectors to Natural Weathering Under Conditions Simulating Operational Mode", Reference [2]. For absorptive coatings ASTM E744-80, "Standard Practice for Evaluating Solar Absorptive Materials for Thermal Applications", Reference [3], and/or as appropriate ASTM E781-81, "Standard Practice for Evaluating Absorptive Solar Recelver Materials When Exposed to Conditions Simulating Stagnation in Solar Collectors with Cover Plates", Reference [4]. If the test methodology described in these standards is not appropriate for the component or materlal in question or for the environmental conditions expected in service, the methodology outlined in Section 3 of Appendix A or other methods, shall be used to demonstrate that the intent of the criterion is met.

Commentary Organic materials may be particularly susceptible to degradation resulting from prolonged exposure to solar radiation. Ultimate fallure of these materials is frequently caused by physical impact, wind flutter, etc. Components of particular concern include cover plates, coatings, sealants, gaskets, absorber surfaces, collector heat traps, exposed coupling hoses, coatings or coverings of exposed insulation, devices for controlling entrance of sunlight (shutters, shades, drapes, blinds, etc.), reflectors, and collector casing assemblies. Combinations of materials (i.e., dissimilar metals) may give rise to corrosion problems that are not obvious from testing individual materials.

5.1 .2

Criterion

Molsture penetration/degradation. Solar components or materials shall not be adversely affected by exposure to moisture in service to an extent that will significantly impair their function during their design lives.

Evaluation When components, materials, or combinations thereof are exposed to molsture, there shall be no signs of excessive material degradation or reduction in insulation effectiveness that would significantly affect the performance of the components or the system.

* Numbers in brackets [] Indicate references at the end of this chapter. 
Compliance with the above criterion may be documented with data on satisfactory long-term performance under in-use conditions or engineering analysis. If evaluative testing is required, the complete collector assembly shall be assessed for water leakage according to tests in Section 10 of Appendix A; or Section 7.5 of NBSIR 78-1305A, Reference [5] for thermal shock/water spray penetration and rain penetration. Consideration of water vapor stability of materials can be determined by the method described in ASTM D2247-68 (1973), "Standard Method for Testing Coated Metal Specimens at 100 Percent Relative Humidity", Reference [6] or ASTM E744-80, "Standard Practice for Evaluating Solar Absorptive Materials for Thermal Applications", Reference [3]. The effect of moisture upon the weathering of cover plate materials can be evaluated using ASTM E765-80, "Standard Practice for Evaluation of Cover Materials for Flat Plate Solar Collectors", Reference [1]. ASTM E765-80 describes both natural and artificial weathering accompanied by water spray cycles. For determining the effect of moisture and water upon thermal insulation used in solar collectors, ASTM E861-82, "Standard Practice for Evaluating Thermal Insulation Materials for Use in Solar Collectors", Reference [7] can be used. Where other tests are available, that meet the intent of evaluating resistance to moisture penetration/ degradation, such tests may be used.

Commentary Moisture can exhibit itself in several forms, e.g., rainfall, melting snow and ice, condensation or vapor. The intent of this criterion is to ensure adequate performance of components or materials that are exposed to moisture from the external environment or exposed to condensation in the collector interior. Some components, such as collector insulation, are usually intended to be used in low molsture environments; however, it is still possible for them to be periodically exposed to moisture from condensation. Such components would not usually be expected to meet the intent of this criterion if moisture exposure could not occur, e.g., in collectors that are hermetically sealed. Guidance for the waterproofing of exposed insulation both above and below ground is given in the HUD MPS Section 607-2, Reference [8], and also the ASHRAE Handbook of Fundamentals Chapter 17, Reference [9]. Salts extracted by moisture from some types of insulation or from organic components may cause corrosion of other system components in close proximity. Chlorides or sulfates that may be leached are a particular concern in regard to metallic corrosion. This criterion is not intended to address the effect that water in heat transfer fluid can have on system components which contact the fluid. 
Efflorescence on the absorber surface of masonry walls such as greenhouse and Trombe walls can cause the deterioration of the absorber coating. Efflorescence is commonly caused by high mineral content in water used for the production of masonry units or the mixing of mortar and is activated by the presence of moisture in the wall.

5.1 .3

Criterion

Evaluation

Pollutant degradation. Solar components and materials that are exposed to regionally prevalent air pollutants such as photochemical oxidents (ozone), sulphur dioxide, nitrogen oxides, or salt spray shall not be adversely affected to the extent that will significantly impair their function during their design lives.

Compliance may be documented with data on satisfactory long-term performance under in-use conditions or engineering analysis. Several standard specifications have been developed for solar energy system components that address the problem of pollutant degradation. The procedures cited in the specifications which address pollutant degradation shall be used as appropriate. Specifications related to rubber seals and hoses are: ASTM D3667-78, "Standard Specifications for Rubber Seals Used in Flat Plate Solar Collectors", Reference [10]; ASTM D3771-79 "Standard Specification for Rubber Seals Used in Concentrating Solar Collectors", Reference [11]; ASTM D3832-79, "Standard Specification for Rubber Seals Contacting Liquid in Solar Energy Systems", Reference [12]; ASTM D3903-80, "Standard Specification for Rubber Seals Used in Air-Heat Transport of Solar Energy Systems", Reference [13]; and ASTM D3952-80, "Standard Specification for Rubber Hose Used in Solar Energy Systems", Reference [14]. For other components or materials where adequate information regarding resistance to degradation from pollutants is unavailable, testing using elther the methodology outlined in Section 4 of Appendix A or other methods which can be shown to meet the intent of the criterion shall be used.

The maximum pollutant levels in the geographic areas where the system will be installed shall be used to determine the pollutant levels required for testing. The pollutant levels shall be obtained from the most recent edition of "Air Quality Data - Annual Statistics Including Summaries with References to Standards", Reference [15]. If components are to be used in areas where they are exposed to very low pollutant concentrations, then the degradation test(s) for pollutants need not be conducted.

When components or materials are tested in accordance with the procedure outlined in Section 4 of Appendix A, there 
Commentary

\section{2}

Requirement

5.2 .1

Criterion

Evaluation shall be no signs of excessive deterioration of optical, physical, or mechanical properties, or any other changes that would significantly affect the performance of the components of the system.

The effects of solar radiation in combination with air pollutants may also be an important consideration in the dry as well as wet conditions. Factors of concern include surface erosion and consequent transmission loss of cover plate, deterioration of coupling hoses, exposed seals, and corrosion of metallic elements.

A potential problem with collectors in industrial atmospheres is that pollutants can go into solution in molsture and cause permanent etching of the cover plates and absorber surfaces and other metallic components over a period of time. Such etching can permanently reduce optical properties and may cause deterioration of mechanical properties. When this possible condition exists, design consideration must be given to avoid the problem.

Effect of temperature. Solar components or materials and building elements with which they interact shall be capable of performing their intended function for their design lives when exposed to temperatures that can develop in the system.*

Thermal degradation. When exposed to maximum service temperatures, solar components or materials shall not degrade to the extent that will significantly impair their function during their design lives.

Compliance may be documented with data on satisfactory long-term performance under in-use conditions or engineering analysis. Evaluation may occur at the collector, component and/or material level. There are several recently developed standard practices and standard specifications which address thermal degradation problems. When assessing the assembled collector for resistance to thermal degradation, ASTM E823-81 "Standard Practice for Nonoperational Exposure and Inspection of a Solar Collector", Reference [16], Section 5 of Appendix A, or Section 10 of Appendix A, as appropriate, shall be used. Test methods for thermal degradation of cover plates are addressed in ASTM E765-80, "Standard Practice for Evaluation of Cover Materials for

* Maximum and minimum service temperatures are defined in Section 1 of Appendix A. 
Flat Plate Solar Collectors", Reference [1], and ASTM E782-81, "Standard Practice for Exposure of Cover Matertals for Solar Collectors to Natural Weathering Under Conditions Simulating Operational Mode", Reference [2]. Absorptive coatings shall be evaluated using ASTM E744-80, "Standard Practice for Evaluating Solar Absorptive Materials for Thermal Applications", Reference [3] and ASTM E781-81, "Standard Practice for Evaluating Absorptive Solar Receiver Materials when Exposed to Conditions Simulating Stagnation in Solar Collectors with Cover Plates", Reference [4]. For sealants and gaskets the following ASTM specifications address the problem of thermal degradation and shall be used as appropriate: ASTM D3667-78, "Standard Specification for Rubber Seals Used in Flat Plate Solar Collectors", Reference [10]; ASTM D3771-79, "Standard Specification for Rubber Seals Used in Concentrating Solar Collectors", Reference [11]; ASTM D3903-80 "Standard Specification for Rubber Seals Used in Air-Heat Transport of Solar Energy Systems", Reference [13]; and ASTM 3952-80, "Standard Specification for Rubber Hose used in Solar Energy Systems", Reference [14]. Thermal degradation is also covered in the recently developed insulation standard ASTM E861-82, "Standard Practice for Evaluating Thermal Insulation Materials Used in Solar Collectors", Reference [7] and ASTM E862-82; "Standard Practice for Screening Polymeric Containment Materials for the Effects of Heat and Heat-Transfer Fluids in Solar Heating and Cooling Systems", Reference [19].

When information is not available on performance regarding outgassing of materials, the thermal stability of components or materials and the long-term performance of heat-transfer fluid under in use conditions, testing using either the methdology outlined in Section 5 of Appendix A or other methods which can be shown to meet the intent of the criterion shall be used. When components or materials are tested in accordance with the procedures outlined in Section 5 of Appendix A, there shall be no signs of excessive deterioration of optical, physical, or mechanical properties or any other changes that would significantly affect the performance of the components or the system.

Commentary Organic components in the system may be particularly susceptible to thermal degradation under prolonged exposure. Organic collector components of particular concern include glazing, absorbers, absorptive coatings, heat traps, insulation, sealants, gaskets, and collector casing assemblies. Storage containers, piping, ducts, storage liners, and coatings composed of organic materials may also be affected. Organic materials may change shape or dimensions and may lose strength or become more brittle. 
5.2 .2

Criterion Thermal cycling degradation. The $\mathrm{H} / \mathrm{C} / \mathrm{HW}$ systems, their various components, and building elements with which they interact shall be capable of withstanding the stresses induced by thermal cycling for their respective design lives.

Evaluation Compliance may be documented with data on satisfactory long-term performance under in-use conditions or engineering analysis. Evaluation may occur at the collector, component, and/or material level.

When adequate information is unavailable to assess the effects of thermal cycling upon absorber materials, ASTM E744-80, "Standard Practice for Evaluating Solar Absorptive Materials for Thermal Applications", Reference [3] may be used.

For other materials and components which require assessment of the effects of thermal cycling, testing procedures outlined in Section 6 of Appendix A or other methods which meet the intent of the criterion shall be used.

After components or materials have been exposed to thermal cycling between their maximum and minimum service temperatures, there shall be no signs of excessive deterioration of optical, physical, chemical or mechanical properties or any other changes that would significantly affect the performance of the components or the system.

Commentary This criterion is intended to identify potential problems that may occur as a result of differential thermal movement. Physical restraints (including support conditions) 
that will be imposed on the system in actual use shall be considered when testing is required. Permanent dimensional changes caused by expansion or contraction can result from thermal cycling.

If thermal expansion or contraction is cumulative in system or subsystem design, the test must be designed to reflect this condition. Areas of concern include cover plate/ frame, collector/support, collector/collector, collector/ piping, reflective surface/substrate, piping, solder joints, coupling hoses, sensors, the bond of tubing or coatings to absorber plates, and warping or shrinkage of cover plate or absorber.

Standardized methods to evaluate the durability of phase change thermal storage materials due to temperature cycling have not been developed. Evidence of the ability of a phase change material to remain stable through a number of cycles representative of a specified portion of its design life would be useful.

5.2 .3

Criterion

Evaluation

Commentary
Thermal shock degradation. Solar components and materials shall be capable of withstanding the stresses induced by thermal shock for their respective design lives.

Compliance may be documented with data on satisfactory long-term performance under in-use conditions, by engineering analysis, or by review of plans and specifications. When adequate information regarding thermal shock resistance of collectors is unavallable, Section 7.4 (cold fil1) of NBSIR 78-1305A, Reference [5] shall be used. Other tests which can be shown to meet the intent of this criterion may also be used.

After the thermal shock test, there shall be no signs of excessive deterioration of physical or mechanical properties or any other changes that would significantly affect the performance of components, collectors, or materials.

The intent of the criterion is to determine the ability of the solar collector to withstand thermal shock caused by heavy rains falling on heated collectors and also to ensure the reliability of solar collectors to withstand thermal shock induced through filling the hot collector with relatively cool heat transfer fluid during daytime start-up. It has been reported that cover plates have falled due to the thermal differential created in the glass by the rapid sliding off of snow cover, exposing cold collectors to the heat of solar radiation. 
For collectors not capable of withstanding cold fill under stagnation conditions, if the collector is protected with means of preventing circulation of cold fluid in the hot collector, this provision may be walved.

\section{3}

Requirement

5.3 .1

Criterion

Evaluation
Effect of chemical compatibility of components. Materials used in the solar energy system, its various components and the building elements with which they interact shall have sufficient chemical compatibility to prevent corrosion, deterioration, or wear that would significantly shorten their intended service lives under in-use conditions.

Materials/transfer fluid degradation. Materials designed to be used in contact with heat transfer fluids or the fluid itself shall not be deteriorated or otherwise adversely affected by such contact to the extent that their function will be significantly impaired under in-use conditions during their design life.

Compliance may be documented with data or satisfactory long-term performance under in-use conditions, engineering analysis, or testing.

Where adequate information is unavallable regarding the performance of containment materials in contact with heat transfer fluids, evaluative testing will be required. For rubber materials several ASTM standard specifications are available, ASTM D3832-79, "Standard Specification for Rubber Seals Contacting Liquids in Solar Energy Systems", Reference [12] and ASTM D3952-80, "Standard Specification for Rubber Hose Used in Solar Energy Systems", Reference [14] can be used as applicable.

For metallic containment materials, ASTM E712-80, "Standard Practice for Laboratory Screening of Meta11ic Containment Materials for Use with Liquids in Solar Heating and Cooling Systems", Reference [17] and ASTM E745-80, "Standard Practices for Simulated Service Testing for Corrosion of Metal1ic Containment Materials for Use with Heat-Transfer Fluids in Solar Heating and Cooling Systems", Reference [18] as appropriate shall be used.

For the evaluation of polymeric containment materials in contact with heat transfer fluids, ASTM E862-82, "Standard Practice for Screening Polymeric Containment Materials for the Effects of Heat and Heat-Transfer Fluids in Solar Heating and Cooling Systems", Reference [19] shall be used. For the evaluation of containment materials not addressed by the above specifications and standard practices, testing 
shall be conducted using the methodology outlined in Section 7 of Appendix A or other methods which can be shown to meet the intent of the criterion.

This criterion is intended to address the compatibility of the heat transfer fluid and the materials and components in the energy transport system, 1.e., collectors, piping, tanks, connectors, pumps, valves, heat exchangers, and their related seals and gaskets. Metals and plastics are used in these applications. The heat transfer fluid may be water, aqueous-organic liquid solutions, or organic fluids. Al1 may contain various additives. Metals may be susceptible to corrosion in systems with aqueous or organic heat transfer fluids. See also discussion of problems created by the thermal degradation of heat transfer liquids in 5.2.1. Some plastic materials are sensitive to exposure to either aqueous or organic fluids. Corrosion of metals by heat transfer fluids could be a serious problem in solar energy systems. SAE Standard J447a (1964), Reference [20] provides guidance in preventing corrosion. Experience indicates that tight closed-loop systems help to minimize metallic corrosion by reducing the oxygen content of the transfer fluid.

Any use of inhibitors in heat transfer fluids should be keyed to the characteristics of all elements of the solar energy system which come in contact with the fluid including collectors, piping, connectors, tanks, pumps, valves, heat exchangers, and their related seals and gaskets. Inhibitors used with non-toxic heat transfer fluids should be selected to comply with the fluid safety requirements of Requirement 4.1. Further discussion is included in Reference [21].

Although bolling can be prevented by pressurization, excessive temperatures can break down some constituents of the fluid to form organic acids. Buffers can counter the $\mathrm{pH}$ balance but only until they are exhausted. Changes in $\mathrm{pH}$ can be accepted but when the level is outside the allowable range, the transfer fluid or at least the buffers must be renewed. Buffer or transfer fluid renewal can be an acceptable maintenance requirement.

Thermal cycling may cause precipitation to occur which may lead to a build up of solids in pump seals and valve seats which may lead to malfunction.

When heat transfer fluids are used as absorbers, a bleaching of the fluid may significantly reduce system performance. See also Criterion 5.1.1. 
Tables 5.3 and 5.4 are intended to provide general guidelines for the selection of metals or alloys for use in solar collectors. Various alloys of the same base metal may show significant variation in resistance to corrosion. Small concentration changes in a number of chemical elements may significantly change the corrosion behavior of a material at a specific temperature. A complete description of this behavior is not possible in this document. Generally unacceptable use conditions as stated should be avoided unless it has been demonstrated that the metal or alloy perform suitably in the anticipated use condition. Adequate performance is anticipated for normal operation in generally acceptable use conditions if these general guidelines are followed.

Since plastics are generally nonconductors, galvanic and electrochemical corrosion encountered with metals are nonexistent in plastic components. However, the physical and mechanical properties of some plastics can be affected significantly by heat transfer fluids. These effects are usually more pronounced at the elevated temperatures which accompany the heat transfer fluid in an operating solar system. Incompatibility can cause plastics to swell, delaminate, soften, crack, become brittle, lose strength, etc. The specific response is dependent upon the combination of polymer and heat transfer fluid. The Uni-Bell Plastic Pipe Association has developed a Handbook of PVC Pipe Design and Construction, Reference [22] which provides tables of the resistance of PVC pipe and elastomeric seals to reaction with or attack by the chemical agents. The information in it should be used as a guide only. Due to the complexity of some organic chemical reactions, additional long-term testing should be performed to determine performance of plastic components with fluids at elevated temperatures.

5.3 .2

Criterion

Evaluation
Dissimilar metals degradation. Non-isolated dissimilar metals shall not be degraded to the extent that their function will be significantly impaired under in-use conditions during their design lives.

Compliance may be documented with data on long-term performance under in-use conditions ing analysis. Where adequate information is unavailable, testing using either the methodology outlined in section 8 of Appendix A or other methods which can be shown to meet the intent of the criterion shall be used. Dissimilar metals used in contact with heat transfer or other fluids shall be tested to reflect this condition. Where protective finishes are normally provided, they shall be used on the specimens tested. 
The use of corrosion inhibitors and dielectric fittings that electrically isolate dissimilar metals is desirable. When using an electrically conductive heat transfer fluid, dielectric isolation of dissimilar metal connections should occur whenever there is a galvanic couple. The use of dielectric fittings may conflict with electrical grounding or lightning protection requirements. The presence of pinholes in protective coatings can drastically accelerate corrosive action.

Attention should be pald to all elements of a solar energy system when considering compatibility of dissimilar metals. This should include energy transport system, structural support and connections, and fabricated parts.

5.3 .3

Criterion

Evaluation

Commentary
Compatibility of adjacent organic materials. Organic solids in contact with other organic solids or inorganic materials shall not be degraded to the extent that their function will be significantly impaired during their design lives.

Compliance may be documented with data on satisfactory long-term performance under in-use conditions on engineering analysis. For compatability of collector components and thermal insulation used in the collector, ASTM E861-82, "Standard Practice for Evaluating Thermal Insulation Materials for Use in Solar Collectors", Reference [7] shall be used, as applicable, to demonstrate satisfactory performance, if testing is required. If adequate information is unavallable for other materials or components, testing is required. If adequate information is unavallable for other materials or components, testing using either the methodology outlined in Section 9 of Appendix A or other methods which can be shown to meet the intent of the criterion shall be used.

Incompatibility can occur between organic materials and between organic materials and inorganic materials such as metals or phase change salts. Some sealants and gaskets are incompatible with plastic glazing materials. Plasticizer migration can result in discoloration, softening, and other types of deterioration.

Inorganic phase change salts have been stored in plastic containers. Leakage in the containers can result from deterioration of the material caused by either mechanical (e.g., thermal expansion) or chemical incompatibility of the salt and plastic. 
This criterion is not intended to address the compatibility of organic transfer fluids with adjacent materials covered in Criterion 5.3.1.

5.4

Requirement Effect of wear. Components that involve moving parts shall, with normal maintenance, be capable of performing their intended function without excessive wear or deterioration for their design lives.

5.4 .1

Criterion Degradation by wear. Dampers, check valves, pressure regulators, pumps, control devices, collector tracking mechanisms, insulation movement mechanisms and assemblies, and similar components shall be capable of operating under in-use conditions without exhibiting wear or fatigue that would significantly impair their ability to perform their intended function over their design lives.

Evaluation Compliance may be documented with data on satisfactory long-term performance under in-use conditions, engineering analysis, or testing using an experimental verification procedure which can be shown to meet the intent of the criterion.

Commentary Inclusion of the heat transfer fluid during tests of components with moving parts may be necessary to meet the intent of this criterion. Many of the components described in this criterion involve the use of conventional components in unusual applications. A record of satisfactory performance in conventional applications may not be sufficient to adequately predict performance in solar applications and careful evaluation is desirable. Components containing moving parts whose use rarely occurs, except for safety reasons such as pressure relief devices, vacuum breakers, etc., are of particular concern. 


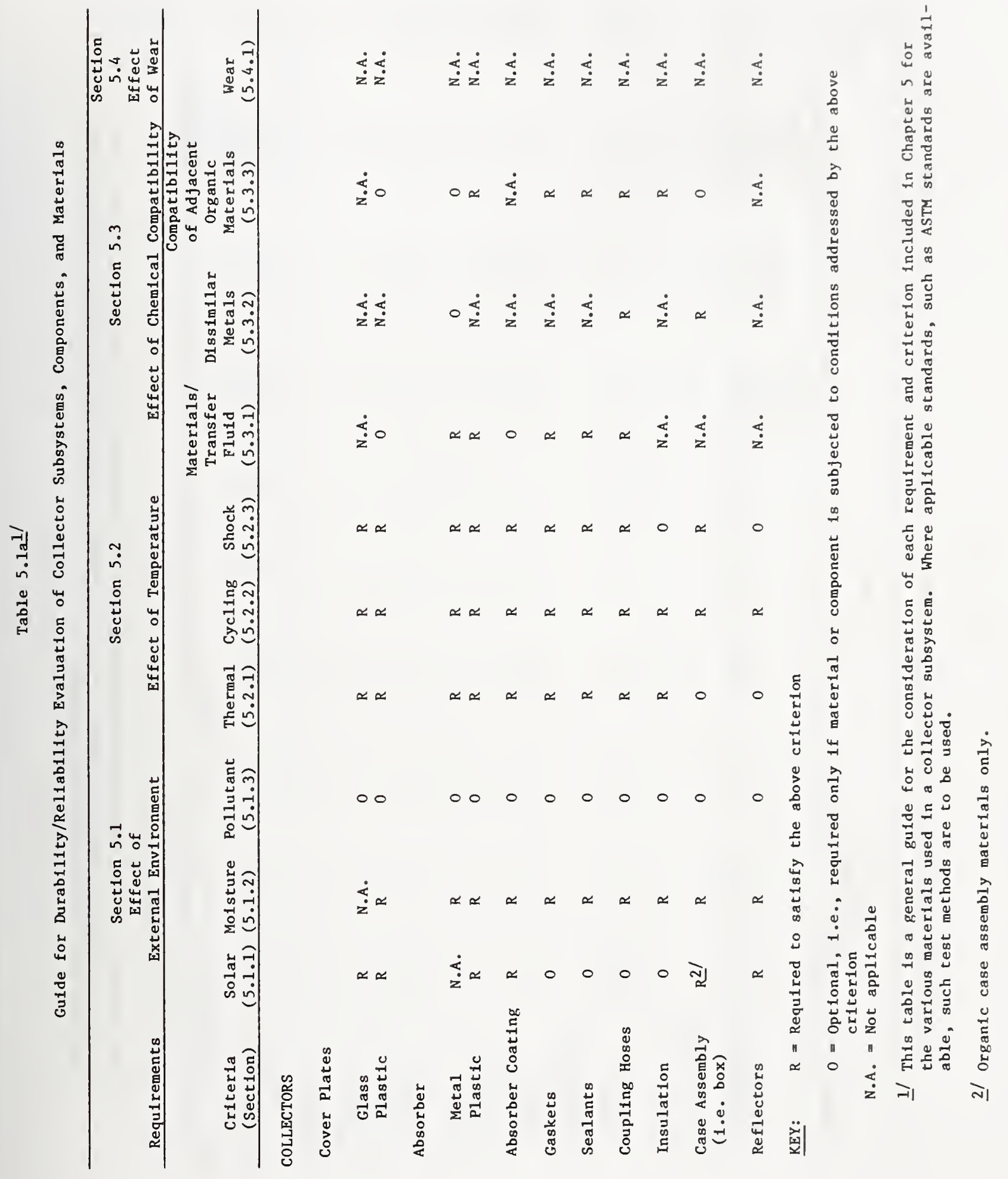




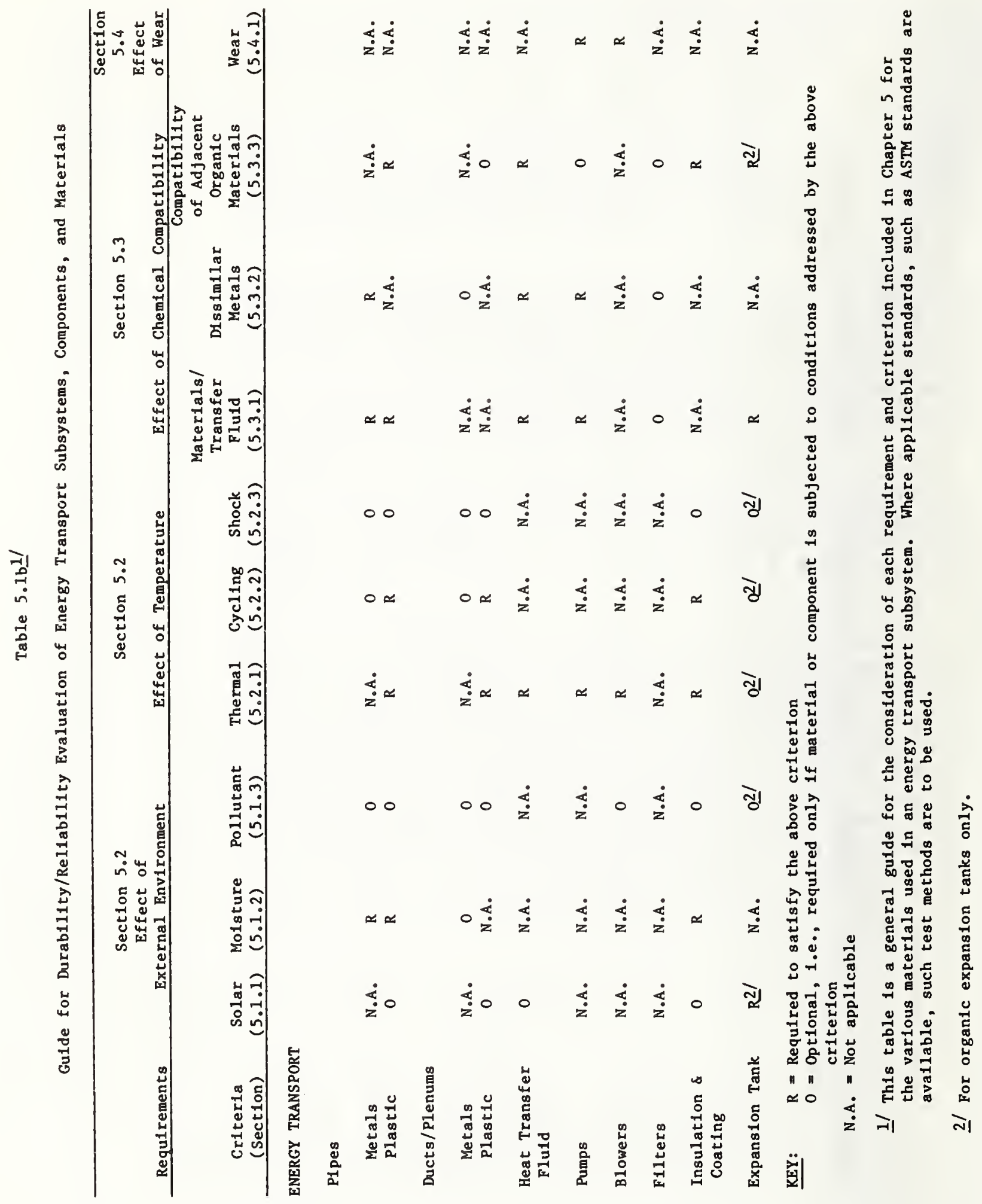




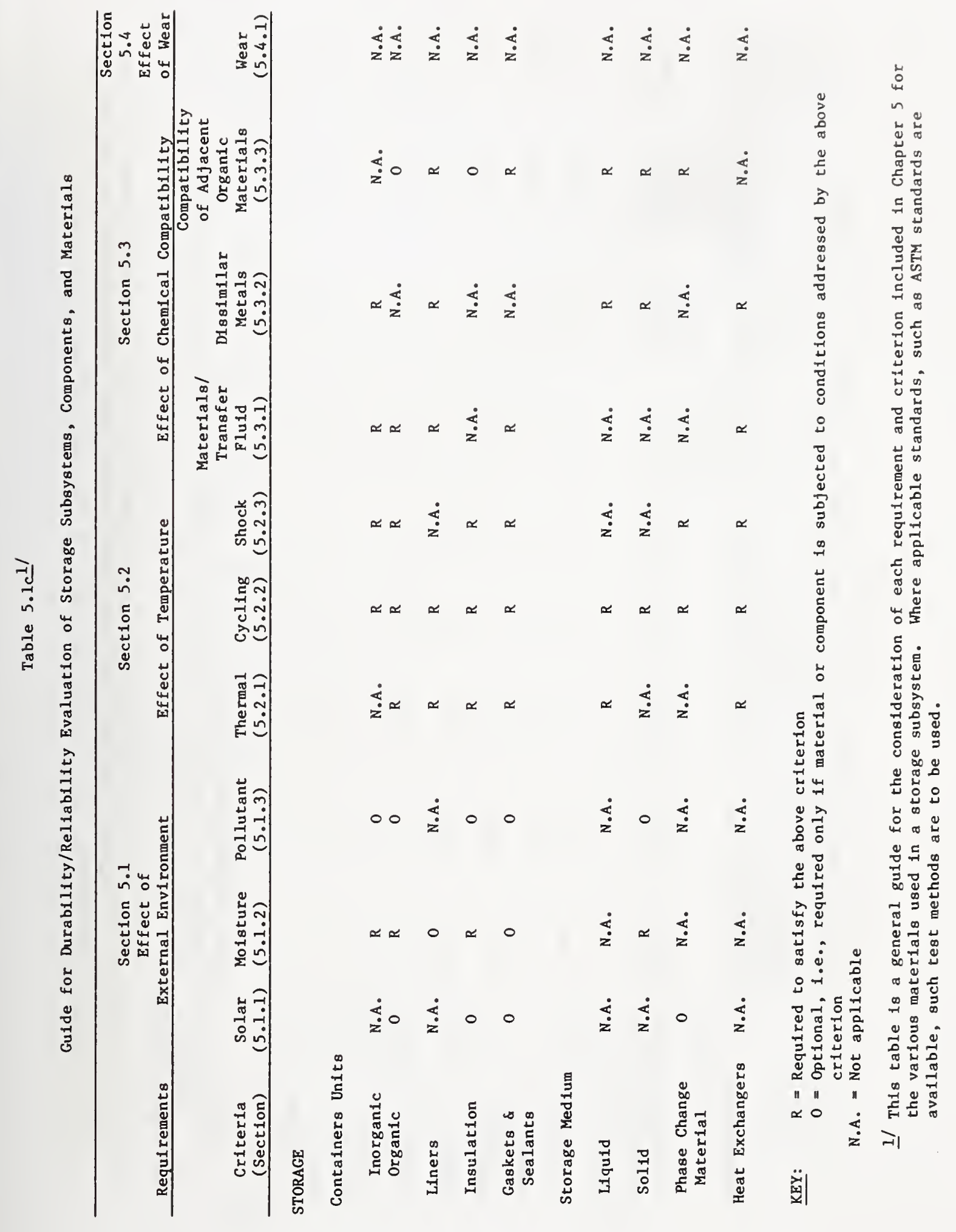




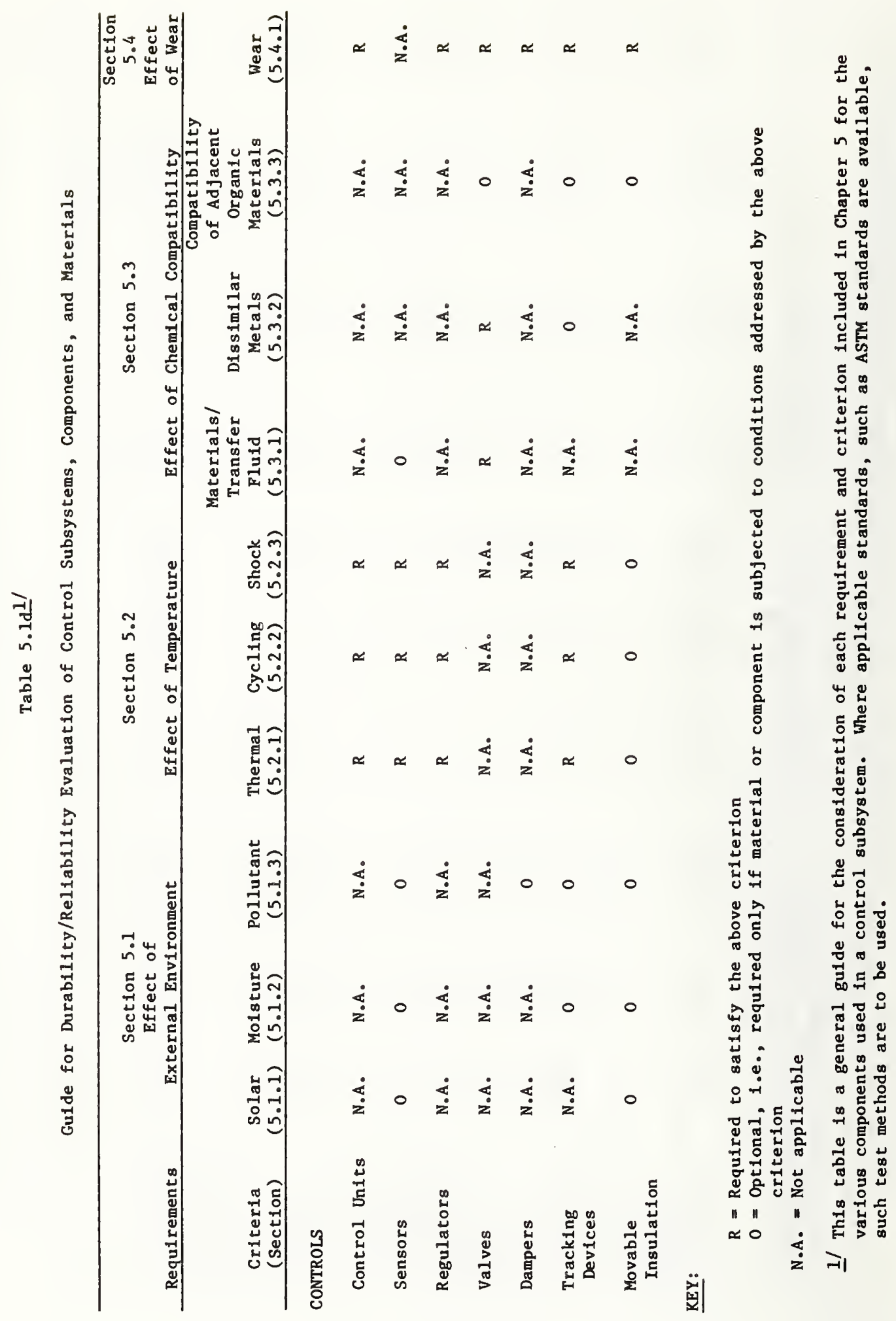




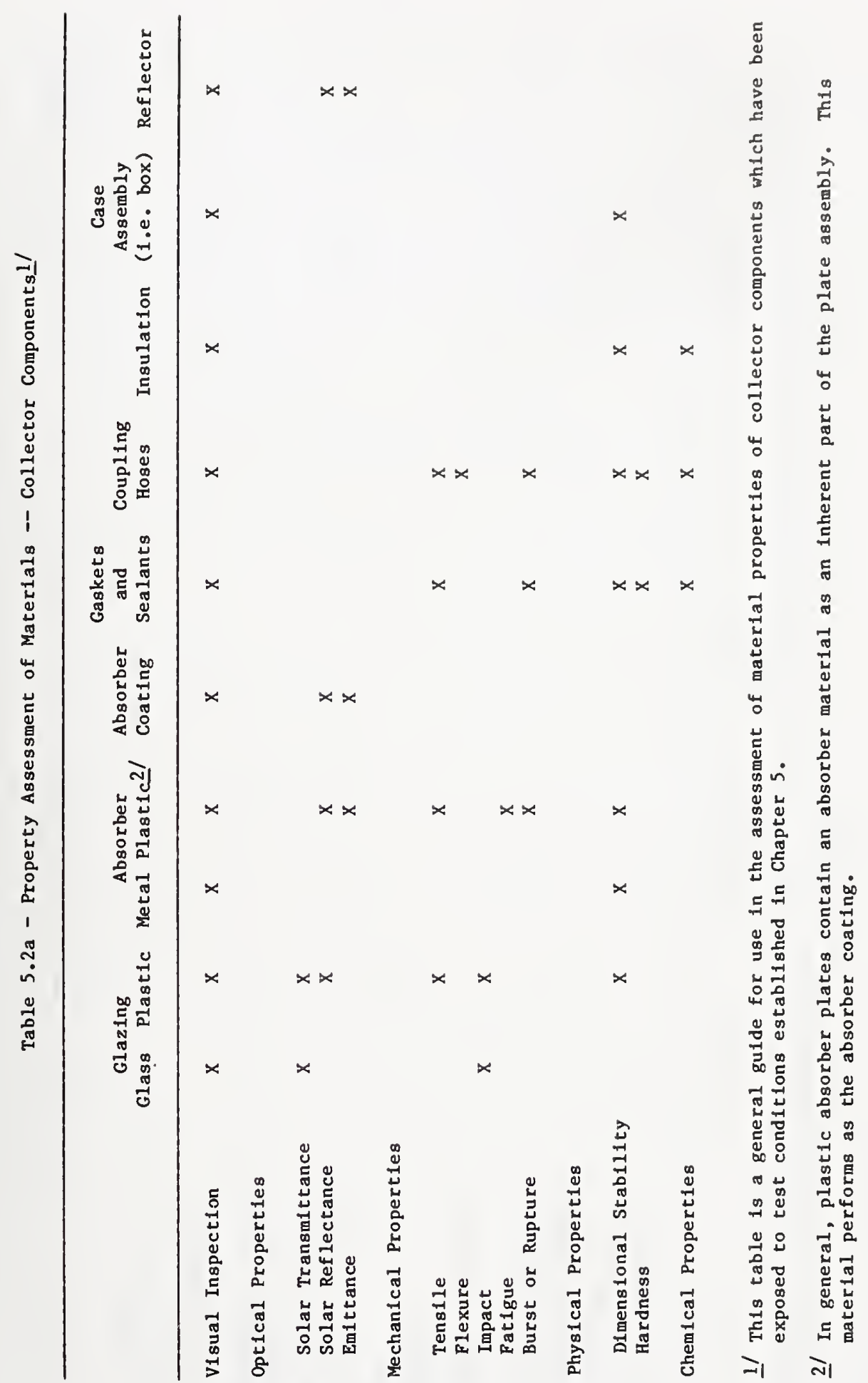




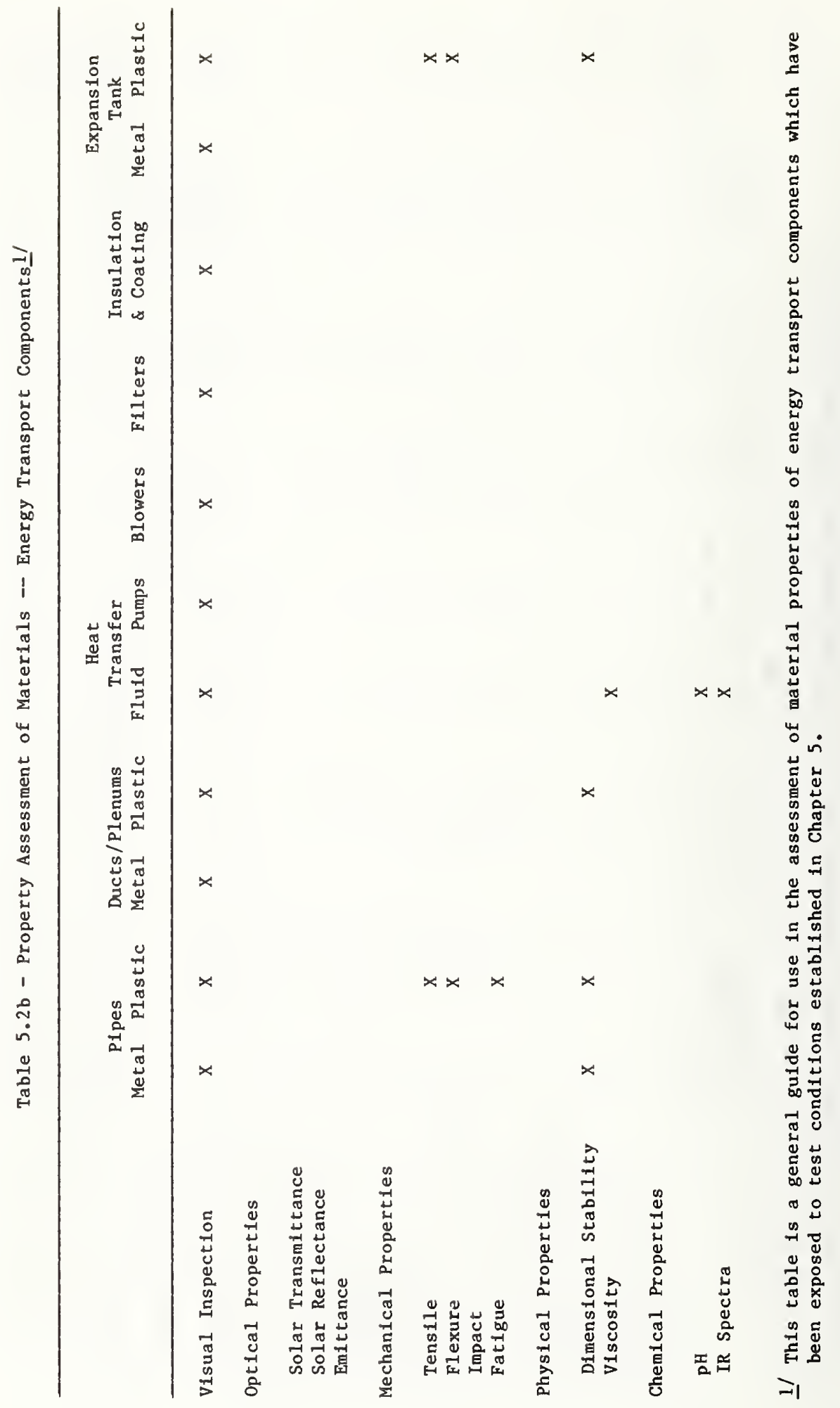




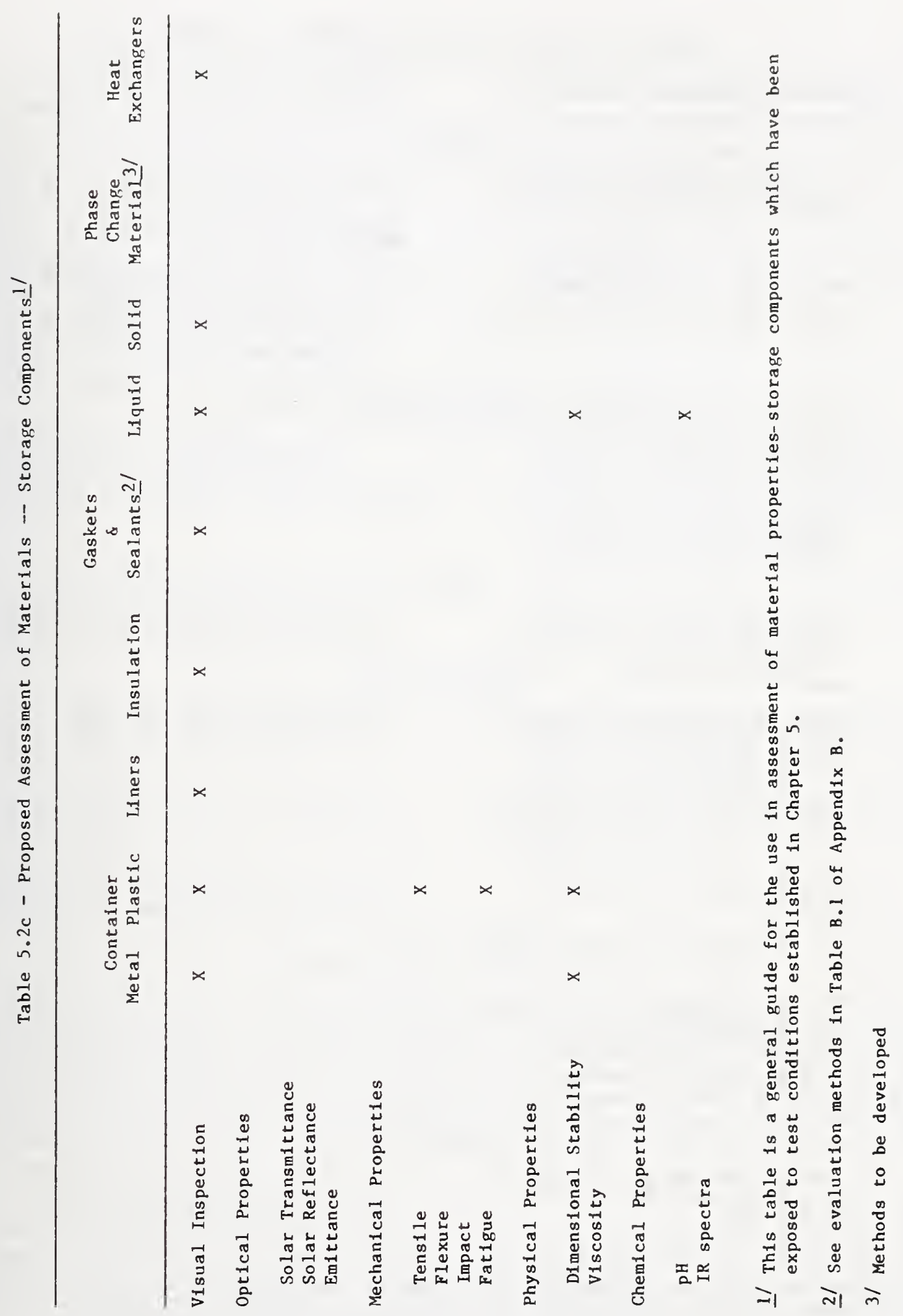


Table 5.3 - Open System Parameters: Generally Acceptable and Unacceptable Use Conditions for Metals in Direct Contact with Heat Transfer Fluids

\section{Aluminum}

1. When in direct contact with untreated, uninhibited tap water with $\mathrm{pH}<5$ or $>9$

2. When in direct contact with aqueous liquid contalning hallde lons or less electro positive metals lons, such as copper or Iron.

3. When specific data regarding the behavior of a particular alloy are not avallable, the velocity of aqueous liquid shall not exceed $4 \mathrm{ft} / \mathrm{s}$ $(1.22 \mathrm{~m} / \mathrm{s})$.

4. When in direct contact with a liquid which is in contact with corrosive fluxes.
1. When in direct contact with distilled or delonized water which contains appropriate inhibitors and does not contact copper or 1ron.

2. When in direct contact with distilled or delonized water which contains appropriate inhibitors and a means of removing heavy metal lons obtalned from contact with copper or Iron.

3. When in direct contact with stable anhydrous organic liquids.

\section{Copper}

1. When In direct contact with aqueous liquid containing high concentrations of chlorides, sulfates, or liquid which contain hydrogen sulfide.

2. When in direct contact with chemicals that can form copper complexes such as ammontum compounds.

3. When in direct contact with an aqueous liquid having a velocity greater than 4 $\mathrm{ft} / \mathrm{s}(1.22 \mathrm{~m} / \mathrm{s}) . \underline{2}$

4. When in direct contact with a liquid which is in contact with corrosive fluxes.

5. When in contact with an aqueous 11quid with a $\mathrm{pH}$ lower than 5 .

6. When the copper surface is intelally locally covered with a copper oxide film or a carbonaceous film.

7. When operating under conditions

conducive to water line corrosion.

Steel

1. When In direct contact with untreated tap, distilled, or delonized water with $\mathrm{ph}<8$ or $>12$.
1. When in direct contact with distilled, delonized or low chloride, low sulfate, and low sulfide tap water.

2. When in direct contact with stable anhydrous organic liquids.

1/ The use of suitable antifreeze agents and buffers 18 acceptable provided they do not promote corrosion of the metallic liquid containment system. The use of sultable corrosion inhibitors for specific metals 18 acceptable provided they do not promote corrosion of other metals present in the system. If thermal or chemical degradation of these compounds occurs, the degradation products shall not promote corrosion.

2/ The flow rates at which erosion/corrosion becomes significant will vary with the conditions of operation. Accordingly, the value listed is approximate. 
Table 5.3 - (Cont1nued)

Genera11y Unacceptable Use Conditions

Generally Acceptable Use Conditions1/

2. When in direct contact with a liquid which is in contact with corrosive fluxes.

3. When in direct contact with an aqueous liquid having a velocity greater than $6 \mathrm{ft} / \mathrm{s}(1.83 \mathrm{~m} / \mathrm{s}) .2$ /
2. When in direct contact with stable anhydrous organic liquids.

3. When adequate cathodic protection of the steel is used (practical only for storage tanks).

4. When operating under conditions conducive to water line corrosion.

Stainless Steel

1. When the grade of stainless steel selected is not corrosion resistant in the anticlpated heat transfer liquid.

2. When in direct contact with a liquid which is in contact with corrosive fluxes.
1. When the grade of stainless steel selected is resistant to pitting, crevice corrosion, intergranular attack and stress corrosion cracking in the anticlpated use conditions.

2. When in direct contact with stable anhydrous organic 1iquids.

\section{Galvanized Steel}

1. When in direct contact with aqueous liquid containing copper lons.

2. When in direct contact with aqueous liquid with $\mathrm{pH}<8$ or $>12$.

3. When in direct contact with aqueous liquid with a temperature $>131^{\circ} \mathrm{F}\left(55^{\circ} \mathrm{C}\right)$.
1. When adequate cathodic protection of the galvanized parts is used (practical only for storage tanks).

2. When in contact with stable anhydrous organic liquids.

\section{Brass and Other Copper Alloys}

Binary copper-zinc brass alloys (CDA $2 X X X$ series) exhibit generally the same behavior as copper when exposed to the same conditions. However, the brass selected should resist dezincification in the operating conditions anticipated. At zinc contents of 15 percent and greater, these alloys become increasingly susceptible to stress corrosion. Selection of brass with a zinc content below 15 percent is advised. There are a varlety of other copper alloys avallable, notably copper-nickel alloys, which have been developed to provide improved corrosion performance in aqueous environments.

1/ The use of suitable antifreeze agents and buffers is acceptable provided they do not promote corrosion of the metallic liquid containment system. The use of suitable corrosion inhibitors for specific metals is acceptable provided they do not promote corrosion of other metals present in the system. If thermal or chemical degradation of these compounds occurs, the degradation products shall not promote corrosion.

2/ The flow rates at which erosion/corrosion becomes significant will vary with the conditions of operation. Accordingly, the value listed is approximate. 
Table 5.4 - Closed System Parameters: Generally Acceptable and Unacceptable Use Conditions for Metals in Direct Contact with Heat Transfer Liquids

Generally Unacceptable Use Conditions

Generally Acceptable Use Conditions 1/

\section{Aluminum}

1. When in direct contact with untreated, uninhibited tap water with $\mathrm{pH}<5$ or $>9$.

2. When in direct contact with uninhibited aqueous liquid contalning copper, iron, or hallde lons.

3. When specifled data regarding the behavior of a particular alloy are not avallable, the velocity of aqueous liquid shall not exceed $4 \mathrm{ft} / \mathrm{s}(1.22 \mathrm{~m} / \mathrm{s})$.

- . . . . . . . . . . . . .

Copper

1. When in direct contact with an aqueous liquid having a velocity greater than $4 \mathrm{ft} / \mathrm{s}(1.22 \mathrm{~m} / \mathrm{s}) .2$ I

2. When in contact with a chemical that can form copper complexes such as ammonium compounds.
1. When in direct contact with distilled or defonized water which contains appropriate corrosion inhibitors.

2. When in direct contact with stable anhydrous organic liquids.

1. When in direct contact with untreated tap, distilled, or delonized water.

2. When in direct contact with stable anhydrous organic liquids.

3. When Indirect contact with aqueous liquids which do not form complexes with copper.

$\underline{\text { Steel }}$

1. When in direct contact with untreated tap, distilled, or delonized water with $\mathrm{pH}<8$ or $>12$.

2. When in direct contact with liquid having a velocity greater than $6 \mathrm{ft} / \mathrm{s}(1.83 \mathrm{~m} / \mathrm{s}) .2 /$
1. When in direct contact with untreated tap, distilled, or defonized water with $\mathrm{pH}>8$ or $<12$.

2. When in direct contact with stable anhydrous organic liquids.

3. When in direct contact with aqueous liquids of $\mathrm{pH}>8$ or $<12$.

\section{Stainless Stee1}

1. When the grade of stainless steel selected is not corrosion resistant in the anticipated heat transfer 11quid.

2. When in direct contact with a liquid which is in contact with corrosive fluxes.
1. When the grade of stainless steel selected is resistant to pitting, crevice corrosion, intergranular attack, and stress corrosion cracking in the anticipated use conditions.

2. When in direct contact with stable anhydrous organic liquids.

I/ The use of sultable antifreeze agents and buffers is acceptable provided they do not promote corrosion of the metallic liquid containment system. The use of sultable corrosion inhibitors for specific metals is acceptable provided they do not promote corrosion of other metals present in the system. If thermal or chemical degradation of these compounds occurs, the degradation products shall not promote corrosion.

2/ The flow rates at which erosion/corrosion becomes significant will vary with the conditions of operation. Accordingly, the value listed is approximate. 
Table $5.4-$ (Continued)

Generally Unacceptable Use Conditions Generally Acceptable Use Conditionsl/

\section{Galvanized Steel}

1. When in direct contact with water of $\mathrm{pH}<8$ or $>12$.

1. When in contact with water of $\mathrm{pH}>8$ but $<12$.

2. When in direct contact with an aqueous IIquid with a temperature $>131^{\circ} \mathrm{F}\left(55^{\circ} \mathrm{C}\right)$

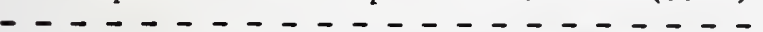

Brass and Other Copper Alloys

Binary copper-zinc brass alloys (CDA 2 XXX serles) exhiblt generally the same behavior as copper when exposed to the same conditions. However, the brass selected shall resist dezincification in the operating conditions anticlpated. At zinc contents of 15 percent and greater, these alloys become increasingly susceptible to stress corrosion. Selection of brass with a zinc content below 15 percent is advised. There are a variety of other copper alloys avallable, notably copper-nickel alloys, which have been developed to provide improved corrosion performance in aqueous environments.

1/ The use of sultable antifreeze agents and buffers is acceptable provided they do not promote corrosion of the metallic liquid contalnment system. The use of sultable corrosion inhibitors for specific metals is acceptable provided they do not promote corrosion of other metals present in the system. If thermal or chemical degradation of these compounds occurs, the degradation products shall not promote corrosion. 
1. Standard Practice for Evaluation of Cover Materials for Flat Plate Solar Collectors, ASTM E765-80. If

2. Standard Practice for Exposure of Cover Materials for Solar Collectors to Natural Weathering Under Conditions Simulating Operational Mode, ASTM E782-81. 1f

3. Standard Practice for Evaluating Solar Absorptive Materials for Therma1 Applications, ASTM E744-80.1

4. Standard Practice for Evaluating Absorptive Solar Receiver Materials When Exposed to Conditions Simulating Stagnation in Solar Collectors with Cover Plates, ASTM E781-81.If

5. Provisional Flat Plate Solar Collector Testing Procedures, First Revision, NBSIR 78-1305A, National Bureau of Standards, Washington, D.C., June 1978, PB 283-721.I

6. Standard Method for Testing Coated Metal Specimens at 100 Percent Relative Humidity, ASTM D2247-68 (1973). If

7. Standard Practice for Evaluating Thermal Insulation Material for Use in Solar Collectors, ASTM E861-82. If

8. HUD Minimum Property Standards, One-and Two-Family Dwellings, No. 4900.1, U.S. Department of Housing and Urban Development, Washington D.C., 1973.

9. ASHRAE Handbook of Fundamentals - 1981. 4/

10. Standard Specification for Rubber Seals Used in Flat Plate Solar Collectors, ASTM D3667-78.I

11. Standard Specification for Rubber Seals Used in Concentrating Solar Collectors, ASTM D3771-79.1/

12. Standard Specification for Rubber Seals Contacting Liquid in Solar Energy Systems, ASTM D3832-79.1

13. Standard Specification for Rubber Seals Used in Air-Heat Transport of Solar Energy Systems, ASTM D3903-80. It

14. Standard Specification for Rubber Hose Used in Solar Energy Systems, ASTM D3952-80.11

15. "Air Quality Data - Annual Statistics Including Summaries with Reference Standards," EPA-450-2-78-040. $\underline{\text { I }}$ 
16. Standard Practice for Nonoperational Exposure and Inspection of a Solar Collector, ASTM E823-81. II

17. Standard Practice for Laboratory Screening of Metallic Containment Materials for Use with Liquids in Solar Heating and Cooling Systems, ASTM E712-80. 1/

18. Standard Practices for Simulated Service Test1ng for Corrosion of Metallic Containment Materials for Use with Heat-Transfer Fluids in Solar Heating and Cooling Systems, ASTM E745-80. I

19. Standard Practice for Screening Polymeric Containment Materials for the Effects of Heat and Heat-Transfer Fluids in Solar Heating and Cooling Systems, ASTM E862-82. If

20. Prevention of Corrosion of Metals, Society of Automotive Engineers, Standard J447a, 1964.

21. State-of-the-Art Study of Heat Exchangers Used with Solar Assisted Domestic Hot Water Systems, F. E. Metz and M. J. Orloski, NBSIR 78-1542, June 1978, PB287-410.21

22. Handbook of PVC Pipe Design and Construction. 7I

1/ American Society for Testing and Materials, 1916 Race Street, Philadelphia, PA 19103.

2/ National Technical Information Service, 5285 Port Royal Road, Springfield, VA 22161 .

3/ Superintendent of Documents, U.S. Government Printing Office, Washington, DC 20402.

4/ American Society of Heating, Refrigerating and Air Conditioning Engineers, Inc., 1791 Tullie Circle, N.E., Atlanta, GA 30329.

5/ U.S. Environmental Protection Agency, Office of Air Quality Planning and Standards, Monitoring and Data Analysis Division, Research Triangle Park, NC 27711 .

6/ Society of Automotive Engineers, Inc., Two Pennsylvania Plaza, New York, NY 10001 .

7/ Uni-Bell Plastic Pipe Association, 2655 Villa Creek Drive, Suite 164, Dallas, TX 75234. 
CHAPTER 6

OPERATION AND SERVICING

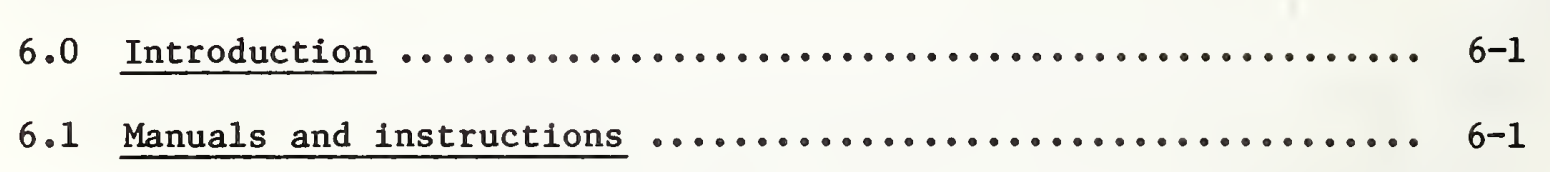

6.1 .1 Installation instructions $\ldots \ldots \ldots \ldots \ldots \ldots \ldots \ldots \ldots \ldots \ldots . . .6$ 6.

6.1 .2 Operation and maintenance instructions $\ldots \ldots \ldots \ldots \ldots \ldots .6$ 6-2

6.1 .3 Maintenance plan ........................... 6-2

6.1 .4 Maintenance hazards ......................... 6-3

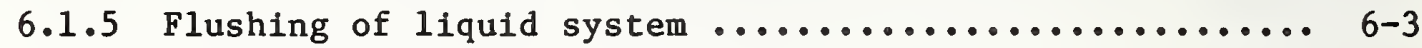

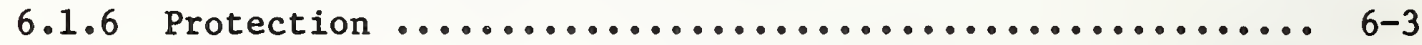

6.1 .7 Normal operation by occupant $\ldots \ldots \ldots \ldots \ldots \ldots \ldots \ldots \ldots \ldots .6$ 6 4

6.2 Maintenance and servicing $\ldots \ldots \ldots \ldots \ldots \ldots \ldots \ldots \ldots \ldots \ldots . \ldots \ldots$

6.2 .1 Heat transfer liquid quality $\ldots \ldots \ldots \ldots \ldots \ldots \ldots \ldots \ldots . . .6-4$

6.2 .2 Access for system maintenance $\ldots \ldots \ldots \ldots \ldots \ldots \ldots \ldots \ldots . . \ldots 6$

6.2 .3 Servicing of $\mathrm{H} / \mathrm{C} / \mathrm{HW}$ systems $\ldots \ldots \ldots \ldots \ldots \ldots \ldots \ldots \ldots \ldots . \ldots . \ldots 6$

6.2 .4 Maintainability of building and site ............. 6-6

6.2 .5 Maintainability of roof surfaces ................ 6-6

6.3 System monitoring $\ldots \ldots \ldots \ldots \ldots \ldots \ldots \ldots \ldots \ldots \ldots \ldots \ldots \ldots \ldots . \ldots . \ldots . \ldots$

6.3 .1 Checkout ................................ 6-8

6.3 .2 Minimum operating information $\ldots \ldots \ldots \ldots \ldots \ldots \ldots \ldots \ldots . . . .6-8$

6.3 .3 Access for system monitoring $\ldots \ldots \ldots \ldots \ldots \ldots \ldots \ldots \ldots \ldots$ 6. 6 .

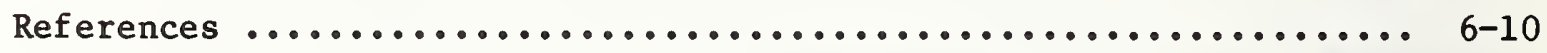


CHAPTER 6

OPERATION AND SERVICING

6.0

Introduction The installation, operation, and servicing phases are most critical to the performance of solar energy systems. There has been consistent evidence that faulty actions during these phases are a primary cause of poor performance, accelerated deterioration, and system damage. The difficulties of mandating performance criteria for installation, operation, and maintenance is acknowledged; however, it is essential that owners and installers be provided with appropriate instructions for their systems and that good practice methods are followed.

This chapter complements and extends certain provisions in Chapter 3 such as: system balancing, 3.1 .2 ; 1iquid quality, 3.2.3; draining and filling, 3.2.5; and freeze protection in general, 3.6. An initial checkout must verify that the system is installed correctly and that it functions properly in all modes of operation including proper flow rates. It is important that adequate information and access be provided for monitoring of the system to assure a high level of performance and to anticipate problems.

6.1

Requirement Manuals and instructions. A manual sha11 be provided containing instructions for the installation, operation, and
maintenance of the $\mathrm{H} / \mathrm{C} / \mathrm{HW}$ systems and/or components. The extent of detail of the manuals shall be consistent with the need for descriptive information to properly operate and maintain the system.

Commentary This manual may consist in whole or in part of a series of instruction sheets provided by the various system or component manufacturers. It may be a single manual, or installation instructions may be separate from operation and maintenance. Complex installations should be provided with comprehensive manuals. A packaged hot water system conversely may require only a simple manual. The simplest passive system may warrant no more than an attached informative label or tag.

6.1 .1

Criterion

Installation instructions. Instructions shall be provided which describe the installation and removal (when required) of each solar energy system component in step-by-step fashion with appropriate detail. 
Evaluation

Commentary

6.1 .2

Criterion

Evaluation

Commentary

$6 \cdot 1 \cdot 3$

Criterion

Evaluation
These instructions shall describe the interconnection requirements of the various systems and components and their interface requirements with the building and site.

The instructions shall be available at the installation site or from normally accessible sources.

Review installation instructions.

It is not the intent of this criterion to require the provision of complete, detailed system installation specifications. For active systems, such specifications would normally be project specific and part of the procurement process. Construction drawings and specifications may be required for passive and other site built systems.

Reference [1]* provides guidelines for installing, operating, and servicing solar HW systems. Reference [2] provides standard practice for installation and service of solar space heating systems (H) for one-and two-family dwellings.

Operation and maintenance instructions. Operation instructions shall be provided which describe operation in all modes, including start-up and shutdown under normal and emergency conditions. Description of important temperature, flow, and pressure information for checkpoints throughout the system shall be given. The maintenance manual shall provide a system schematic diagram and describe required periodic maintenance and detailed information for selected repair procedures such as removal and replacement of cover plates.

Review maintenance and operating instructions.

For most active systems, flow diagrams and wiring diagrams should be included. In any system where performance requirements are dependent upon specific maintenance procedures, these should be tabulated. The manual should specify acceptable methods of cleaning glazed surfaces.

Maintenance plan. The manual shall include a comprehensive plan for maintaining the specified performance of the $\mathrm{H} / \mathrm{C} /$ HW systems for their design service lives.

Review of maintenance plan.

* Numbers in brackets [] indicate references at the end of this chapter. 
This criterion is applicable to both active and passive systems in new as well as existing buildings. The plan should include all the necessary ordinary maintenance, preventive maintenance and minor repair work, and projections for equipment replacement and maintenance of heat transfer fluid quality as appropriate. Perlodic changing or cleaning of strainers and filters is one example of ordinary maintenance. Cleaning, repairing, or replacing of cover plate materials should also be included.

6.1 .4

Criterion Maintenance hazards. The manual shall provide prominently displayed warning against hazards that could arise in the maintenance of the system and shall fully describe the precautions that should be taken to avold these hazards.

Evaluation Review the maintenance instructions.

Commentary Some systems contain toxic and/or combustible materials that could result in $i l l$ effects to maintenance personnel or result in fires, explosions, or toxic fumes when repairs involving soldering or welding are undertaken. See Criterion 4.2.4 for handling and disposal of toxic fluids.

Hot pipes or valves and discharge points should be identified.

6.1 .5

Criterion

Flushing of liquid system. The manual shall provide instructions for initial flushing as required and periodic flushing (cleaning), if required, of the liquid passages.

Evaluation Review drawings, specifications, and operation manual.

Commentary Metal filings, flux, solder, silt, and other contaminants should be flushed out of the system prior to operation. Water should not be used to flush systems that use hydrocarbon or silicone heat transfer fluids. Systems using oil as the heat transfer fluid should be flushed with a cleaner which is soluble with the solder flux used and then thoroughly dried before filling with the oil.

Flux within the system may be caught in crevices. At this point, with elevated temperature, any moisture would rapidly oxidize the adjacent metal. See also Criterion 3.2.2.

6.1 .6

Criterion Protection. The instructions shall provide information for protection of the system during installation and maintenance. 
Evaluation

Commentary

6.1 .7

Criterion

Evaluation

Commentary

6.2

Requirement

6.2 .1

Criterion

Evaluation

Commentary
Review installation and maintenance instructions.

Collectors, controls, and other components may require special protective measures during installation and shutdown for maintenance such as covering of collectors to prevent breakage of glazings and to prevent stagnation. Caution should be exercised in the selection and use of temporary coverings to avoid permanent damage of glazing such as etching and staining, and adhesive materials which may become difficult to remove.

Normal operation by occupant. Instructions shall be written to inform the occupant of the minimum actions required for the normal operation of the solar energy system including the probable heat gains or losses dependent on occupant actions.

Review operation instructions.

Required occupant activity such as operating movable insulation, shades, or controls may be critical, especially for some passive installations. Required manual operations should be minimized and the occupant should be advised of the consequences of energy gained or lost and potential system or building damage (e.g. water freezing) for actions taken on a daily and seasonal basis including times of building vacancy.

Maintenance and servicing. The $\mathrm{H} / \mathrm{C} / \mathrm{HW}$ systems shall be designed, constructed, and installed to provide sufficient access and appurtenances for general maintenance and convenient servicing.

Heat transfer liquid quality. Provisions shall be made to maintain the quality of the heat transfer liquid at a level that does not significantly impair its heat transfer function, reduce its compatibility with adjacent materials, or reduce freeze protection.

Review specifications and monitoring of the heat transfer liquid for $\mathrm{pH}$, buffering level, viscosity, and concentration.

Experience from demonstration programs indicates the importance of heat transfer liquids and their quality in preventing freeze-ups and corrosion, and for general system performance. When make-up water is of such a quality that excessive corrosion is known to exist, a suitable water treatment system as recommended by the Water Quality 
Association Industry Standards S $-100-75$ and S-200-73 should be provided, Reference [3]. The chemical composition of the heat transfer liquid should be maintained (perhaps by periodic replenishment of additives) at levels adequate to prevent unacceptable deposits on the heat transfer surfaces, corrosion of the surfaces with which the heat transfer 1iquid comes in contact, or loss of freeze resistance. Antifreeze solutions may lose their freeze protection capability over time due to deterioration or the addition of "make-up" water. Provisions for sampling the heat transfer liquid should be available. See Criteria 3.2 .3 and 3.2 .5 for maintenance related devices and Reference [4] for the influence of heat transfer fluid properties on thermal performance.

Heat transfer liquids should be tested and replaced at intervals suggested by the manufacturer. Some sources recommend checking water/glycol mixtures twice a year. See also Criterion 6.1.3. Water in unprotected steel drums or other metal containers in water storage walls should be deionized or distilled and buffered to reduce corrosion $(\mathrm{pH}>8$ or $<12$ for steel).

6.2 .2

Criterion

Evaluation

Commentary
Access for system maintenance. All individual items of equipment and components of the $\mathrm{H} / \mathrm{C} / \mathrm{HW}$ systems which may require periodic examination, adjusting, servicing and/or maintenance shall be accessible for inspection, service, repair, removal, or replacement without dismantling of an adjoining major component or building element.

Review drawings and specifications.

Accessibility as a function of component life is an important consideration. Individual collectors in an array should be replaceable or repairable without disturbing nonadjacent collectors in the array or other access provisions should be made. Cover plates and roof glazing, especially those susceptable to degradation by environmental exposure and hazards such as damage by falling hail, limbs, etc., should be readily accessible for repair or replacement without special skills or tools and with readily available materials. Provisions for recoating of Trombe walls and cleaning of glazing and space between glazing and wall should be considered. Access to collector glazings which require periodic recoating may be necessary.

Access to storage units may be necessary. Rock storage and liquid storage in both active and passive systems may require access for cleaning or replacement. Isolation valves may be necessary for the repair or replacement of system components. Dampers require access for maintenance, 
monitoring, adjusting, and balancing. Information on access provisions is provided in Reference [5].

6.2 .3

Criterion Servicing of $\mathrm{H} / \mathrm{C} / \mathrm{HW}$ systems. The $\mathrm{H} / \mathrm{C} / \mathrm{HW}$ systems shall be capable of being serviced with a minimum amount of special equipment by the appropriate existing trades (HVAC, plumbing, etc.) using a service manual.

Evaluation Review drawings, specifications, and service instruction manuals.

Commentary The complexity and design of certain components may require their removal and replacement to accomplish repair of the system. Routine servicing of many systems may not require special personnel and equipment.

6.2 .4

Criterion Maintainability of building and site. The $\mathrm{H} / \mathrm{C} / \mathrm{HW}$ system shall not impair accessibility for or add significantly to the practical maintainability of the building or site.

Evaluation Review maintenance plans, site plans, and building and solar system drawings.

Commentary Building materials adjacent to solar equipment should not be exposed to elevated temperatures that result in adverse physical, chemical, mechanical, or thermal changes causing additional maintenance problems or such materials should be selected to withstand these effects.

6.2 .5

Criterion Maintainability of roof surfaces. The installation of collectors and other solar energy components on the building roof should not reduce the ability of the roof covering to restrict the entrance of moisture and water, nor reduce its resistance to weather and deterioration.

Evaluation Review drawings and specifications.

Commentary Damage to the roof covering or the roof assembly can occur during installation of the solar energy system or during servicing. Measures to protect the roof from damage and the entry of water during installation and servicing should be taken, Reference [6].

The presence of solar equipment on roofs may lead to numerous potential problems: 
a. Reroofing in future years may be complicated by collectors mounted close to the surface, by supports, and by pipe and wiring penetrations.

b. Numerous penetrations of roof coverings mean greater maintenance problems and potential leakage. It is important that collector supports be flashed properly.

c. Some heat transfer fluids will attack certain roofing materials, and leakage from the solar system may present problems of roof degradation and deterioration.

d. The growth of fungi (mold and mildew) is possible when collectors are applied to a roof surface. If the collectors are in contact with the roof covering or held away from the covering to allow for drainage, the shaded area can support the growth of a fungus leading to roofing deterioration. Special design considerations should be included to avoid this problem.

e. Hot collector surfaces and other heated components closely adjacent to the roof surface can cause softening of the roofing materials leading to damage and deterioration.

f. The presence of solar equipment, its position relative to the roof and the various supports and penetrations, may increase the collection of debris such as branches and leaves, and thus require additional maintenance.

g. The installation of solar collectors and components should not affect the capacity of the roof to drain water completely.

h. The ice and melt water that may occur in the winter due to the presence of solar equipment requires attention to the adequacy of roof moisture barriers. Improper installation and roof details may promote the accumulation of large quantities of ice, or may cause damage to the roof by the weight or expansive action of ice.

1. The foot traffic generated by solar system maintenance personnel may cause deterioration of the roof system.

Roof inspections should be performed at regular intervals and repairs made to the roofing system as soon as they are needed.

For existing roofing systems, its condition should be determined prior to the installation of the solar system. 
Solar system components should only be installed on roofs which are assessed to be in good condition and are expected to provide satisfactory performance for their design lives.

6.3

Requirement System monitoring. Provision shall be made for system monitoring in accordance with the specifications of the operation and maintenance manual.

6.3 .1

Criterion

Checkout. On completion of installation, the system operation shall be checked for adequate performance of all components as well as the system as a whole.

Evaluation Inspection and testing shall be performed on the installation to verify that the system and components are capable of operating as specified in the design and the manuals defined in Requirement 6.1 .

Commentary Monitoring means may involve sensors and indicators or may be as simple as inspection.

Controls should be checked in operation to determine that components operate at the proper set points, that pumps and fans start and stop properly, and that fall safe devices work. Fallure or improper operation of sensors and controls have caused many problems. It is recommended that means be provided during installation to allow temperatures and flow rates to be checked during operation of the system. Poor design and improper installation of components is a major cause of system malfunction. A large proportion of mechanical failures become apparent within a short period of operation. Incorrectly wired controls, improper control set points,improper component location, reversed components, improper sensor installation, etc., are examples of faulty design and/or installation.

It is important to check distribution systems to assure that all spaces intended to receive heating and cooling in the design receive it in the actual installation. This is particularly important with passive systems.

6.3 .2

Criterion Minimum operating information. Provisions shall be made to indicate to the user when the collector loop and/or the auxiliary energy system is operating.

Evaluation Review drawings, specifications, and operation instructions .

Commentary A minimum level of information is essential to the user to assure that the solar system is functioning as intended. 
Monitoring means may involve sensors and indicators or may be as simple as observation and awareness of appropriate radiant temperatures and air movement.

6.3 .3

Criterion

Evaluation

Commentary
Access for system monitoring. Appropriate access shall be provided for checking essential system parameters.

Review drawings and specifications for the placement of fittings and indicators of essential system parameters.

Adequately located test fittings and indicators will permit system monitoring and expedite the maintenance and repair of equipment. Access for sensors and other techniques for monitoring parameters such as temperature, pressure, and critical voltages are of concern in this provision. 
1. Installation Guidelines for Solar DHW Systems in One-and Two-Family Dwellings, HUD-PDR-407, U.S. Department of Housing and Urban Development, GPO 023-000-00520-4, April 1979.1/

2. Standard Practice for Installation and Service of Solar Space Heating Systems for One-and Two-Family Dwellings, ASTM/ANSI E683-79, American Society for Testing and Materials, 1916 Race Street, Philadelphia, PA 19103, 1979.

3. Industry Standard for Household, Commercial and Portable Exchanger Water Softeners, 5-100-75 and Recommended Industry Standards for Household and Commercial Water Filters, S-200-73, Water Quality Association, 447 East Butterfield Road, Lombard, IL 60148, 1974.

4. Chang, C., Singh, H., Chopra, P., Influence of Solar-Fluid Properties on Thermal Performance Based on Nominal and Measured Values, ANL/SDPTM-79-6, SOLAR/0904-79/70.2/

5. Uniform Mechanical Code, International Conference of Building Officials, 5360 South Workman Mill Road, Whittier, CA 90601, 1973.

6. Mathey, Robert G. and Rossiter, Walter J. Jr., Guidelines for the Installation of Solar Components on Low-Sloped Roofs, NBS Technical Note 1134, National Bureau of Standards, Washington, DC 20234, 1980.1/

1/ Superintendent of Documents, Government Printing Office, Washington, DC 20402 .

2/ Technical Information Ceuter, P.0. Box 62, Oak Ridge, TN 37830 . 
Section 1 Temperature Conditions ..................... A-1

2 Evaluation Methods ......................... A-7

3 Test Methodology: Criterion 5.1 .1 Solar Degradation ... A-7

Aging Procedure 1 (Simulated Laboratory Exposure) ..... A-7 Aging Procedure 2 (Outdoor Exposure Using Concentrated

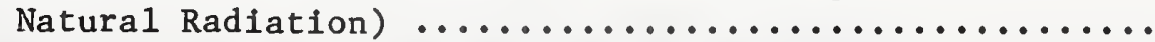

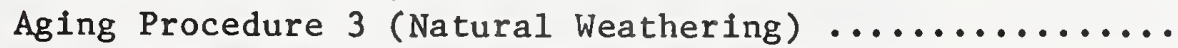

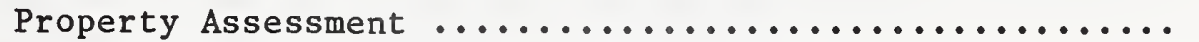
Commentary .............................. A-9

4 Test Methodology: Criterion 5.1.3 Pollutant

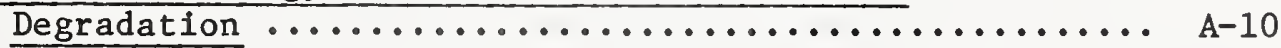

Aging Procedure 1 (Resistance to 0zone) ............. A-10 Aging Procedure 2 (Resistance to Salt Spray) .......... A-10 Aging Procedure 3 (Resistance to $\mathrm{SO}_{2}$ and $\mathrm{NO}_{\mathrm{x}}$ ) ........... $\mathrm{A}-10$ Property Assessment ........................ A-10 Commentary ............................... A $10 \ldots$

5 Test Methodology: Criterion 5.2.1 Thermal Degradation - A-10

Aging Procedure 1 (Resistance of Fluids to Maximum Service Temperature) ...................... A-11 Aging Procedure 2 (Resistance of Components and Materials to Maximum Service Temperature) .......... A-12 Aging Procedure 3 (Resistance of Fluids to Minimum Service Temperature) ......................... A-12

Property Assessment ......................... A 12

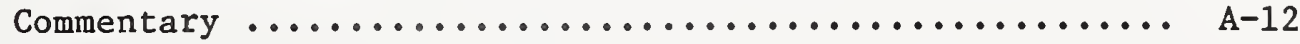

6 Test Methodology: Criterion 5.2.2 Thermal Cycling

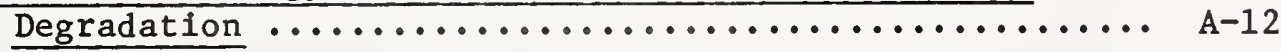

Aging Procedure 1 (Resistance of Components and Materials to Thermal Cycling) .................. A -12 Property Assessment ........................ A-13 Commentary ............................. A -13 
Section 7 Test Methodology: Criterion 5.3.1 Materials/Transfer

Page Fluid Degradation $\ldots \ldots \ldots \ldots \ldots \ldots \ldots \ldots \ldots \ldots \ldots \ldots \ldots \ldots \ldots$

Aging Procedure 1 (Resistance of Metallic Containment Materials to Non-Aqueous Liquids) ............... A-13 Aging Procedure 2 (Resistance of Plastic Containment Materials to Liquids) ....................... A -14 Property Assessment .......................... A -14 Commentary .................................. A-14

8 Test Methodology: Criterion 5.3.2 Dissimilar Metals Degradation ............................. A -14

Aging Procedure 1 (Resistance of Metallic Containment Materials to Liquids) ........................... A-15 Aging Procedure 2 (Resistance to $\mathrm{SO}_{2}$ and $\mathrm{NO}_{\mathrm{x}}$ ) ........ A-15 Property Assessment .......................... A -15 Commentary .............................. A 15

9 Test Methodology: Criterion 5.3.3 Compatibility of Adjacent Organic Materials .................. A -15

Aging Procedure 1 (Resistance of Dissimilar Organic Materials Exposed to Maximum Service Temperature) .... A-15 Property Assessment ............................ A-15

10 No-Flow 30-Day Degradation ....................... A-15 


\section{INTRODUCTION}

Appendix A references conditions for and methods of testing and evaluation of system components and materials. These conditions and methods can be used to prove compliance with stated requirements.

The testing and evaluation methods contained in this Appendix primarily concern corrosion and thermal degradation, and can be used to satisfy many of the durability/reliability requirements stated in Chapter 5 .

Specific criteria from Chapter 5 are listed with the test methodologies which can be used to prove their compliance.

Conditions for and methods of testing and evaluation found in Appendix A are cross-referenced in Chapter 5 as well as throughout the text of this document where their use is potentlally appropriate. 

Temperature Conditions. Many of the criteria given in Chapter 5 and this Appendix contain references to the maximum or minimum service temperatures in specifying the temperature at which testing should be performed. The maximum service temperature is the maximum temperature at which a system and its components are designed to operate, either with or without the flow of heat transfer fluid. The minimum service temperature refers to the minimum temperature at which a system and its components are designed to operate, with or without the flow of heat transfer fluid.

The minimum service temperature to which a component in the system will be exposed will generally occur when (1) the collector is not exposed to solar radiation, (2) the heat transfer fluid is not flowing through the system, and (3) the ambient temperature is at its lowest level. The no-flow condition mentioned above assumes the flow of the heat transfer fluid will be stopped when no useful energy can be removed from the collector to avoid pumping out heat energy. However, if the flow of fluid is not stopped at night, the minimum service temperature of some components may occur as nocturnal radiation and/or evaporative cooling takes place.

The maximum service temperature to which the collector and components that are in intimate contact with it will be exposed, will generally occur when the collector is receiving its maximum level of solar radiation at maximum ambient temperature and the heat transfer fluid is not flowing through the collector (design maximum no-flow temperature). Other components, such as those in the storage system will generally reach their maximum temperature when the collector is receiving its maximum level of solar radiation at maximum ambient temperature and the heat transfer fluid is flowing through the system (design maximum flow temperature). This temperature may be determined by limiting the temperature of control devices or relief valves or through theoretical or test analysis of the system. The design maximum no-flow temperature that will occur at various locations in the collector can be calculated by use of an analytical model and appropriate environmental conditions. Typical examples of this type of information are shown in Figures A.1 through A.4.

Figures A.1 through A.4 are intended to provide assistance in establishing the maximum no-flow temperature of critical components for four "typical" flat plate collector designs. Glazing and absorber plate temperatures are plotted as a function of ambient temperature for exposure to a solar radiation flux of $340 \mathrm{Btu} / \mathrm{ft}^{2} \cdot \mathrm{h}\left(1070 \mathrm{~W} / \mathrm{m}^{2}\right)$. Data are shown for single and double covers and absorber surfaces 
of flat plate collectors assuming two types of cover glass materials (a typical window glass material and a more transparent glass material with a low iron oxide content) and two types of absorbers (spectrally flat and selective black absorber coatings). The calculations were performed with a transient thermal analysis computer program using finite difference techniques [1].* The calculations were based on the following assumptions:

(1) a glass cover plate thickness of $1 / 8$ in. $(0.32 \mathrm{~cm})$; (2) air space thickness of $3 / 8$ in. $(0.95 \mathrm{~cm})$ between the two glazings and between the absorber surface and the inner glazing; (3) zero edge and back losses; (4) incident solar radiation is normal to the collector; and (5) the following properties of the glass glazing:

Conventional

Glass

Absorptance

Extinction

Coefficient

Index of

Refraction

Thermal

Conductivity

Transmittance

Emittance
0.06

0.07 per in. $\left(2.76 \times 10^{-2}\right.$ per $\left.\mathrm{mm}\right)$

1.52

$0.589 \mathrm{BTU} / \mathrm{ft} \cdot \mathrm{h} \cdot{ }^{\circ} \mathrm{F}$

$\left(1.019 \mathrm{~W} / \mathrm{m}^{\circ}{ }^{\circ} \mathrm{C}\right)$

0.86

0.86
Low Iron Oxide Glass

0.02

0.20 per in. $\left(7.87 \times 10^{-3}\right.$ per mm)

1.52

$0.589 \mathrm{BTU} / \mathrm{ft} \cdot \mathrm{h} \cdot{ }^{\circ} \mathrm{F}$ $\left(1.019 \mathrm{~W} / \mathrm{m}^{\circ}{ }^{\circ} \mathrm{C}\right)$

0.90

0.86

It should be noted that the exposure conditions represent typical maximum conditions and that a higher solar radiation flux can be experienced under some atmospheric conditions or by the use of external reflectors. It is recommended that the temperature of critical components be experimentally established for a particular collector design whenever possible.

* Numbers in brackets [] indicate reference at end of this chapter. 


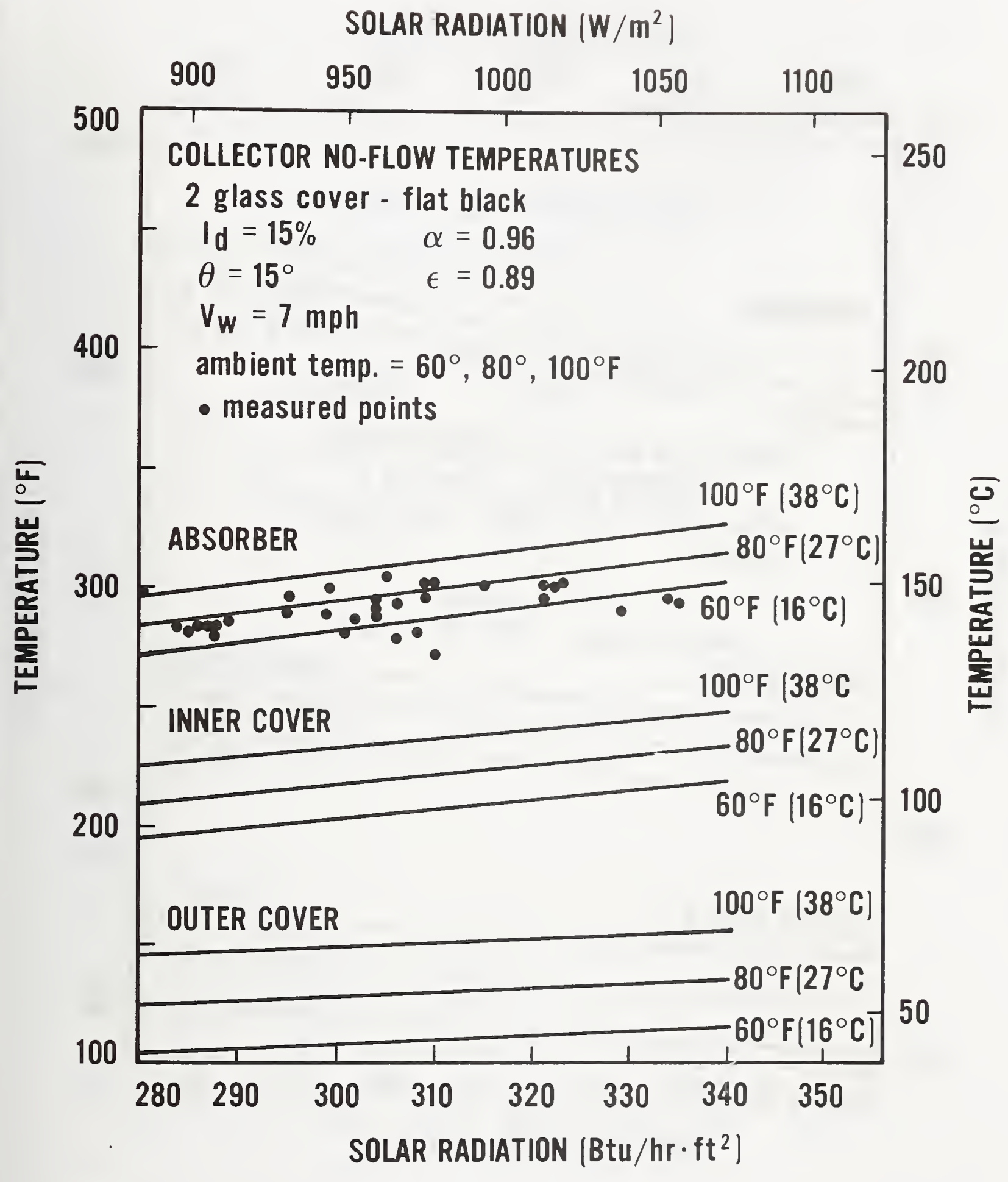

Figure A.1. No-flow temperatures at various locations in a collector with a flat black absorber and two glass cover plates 


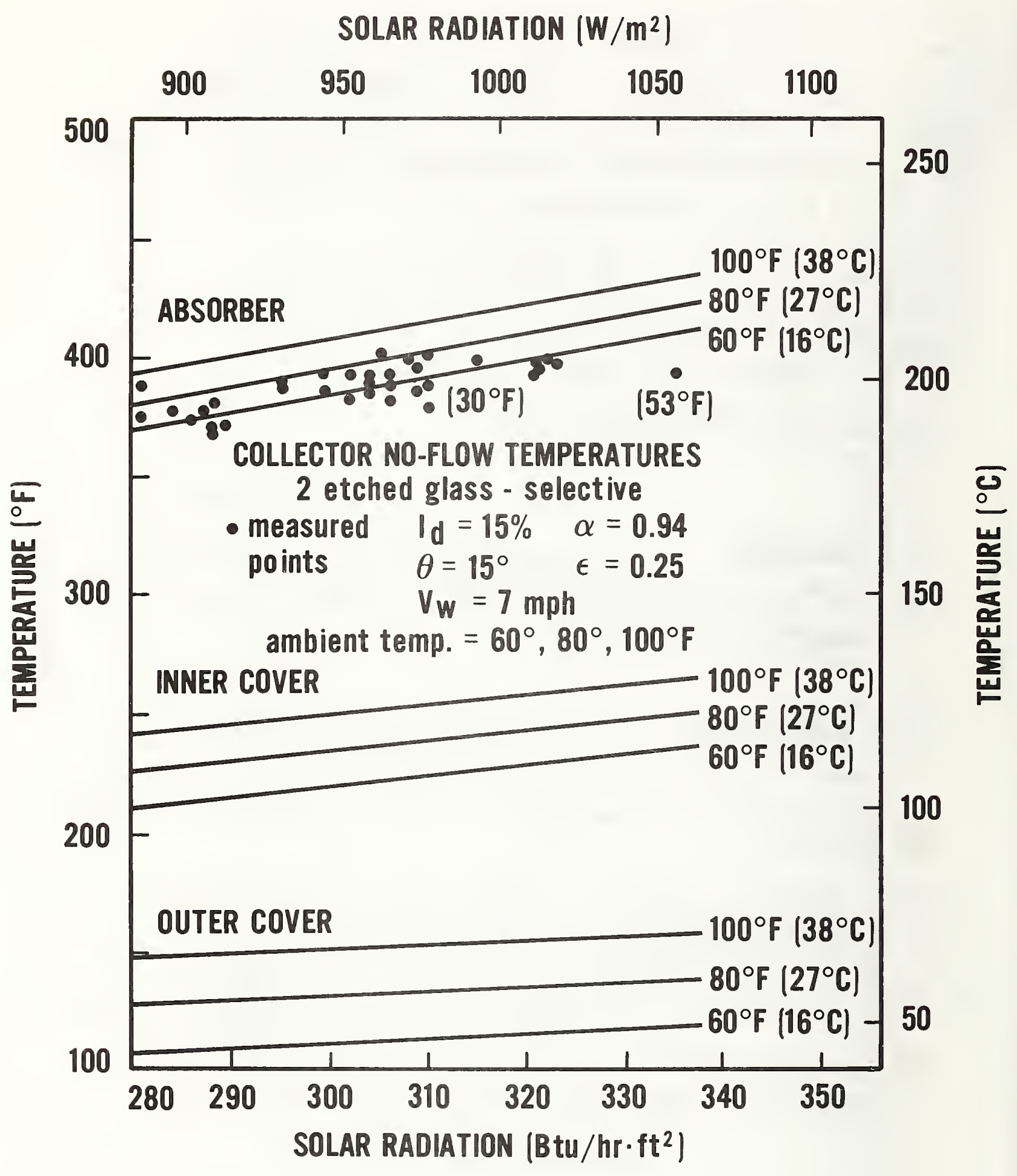

Figure A.2. No-flow temperatures at various locations in a collector with a selective absorber and two glass cover plates 


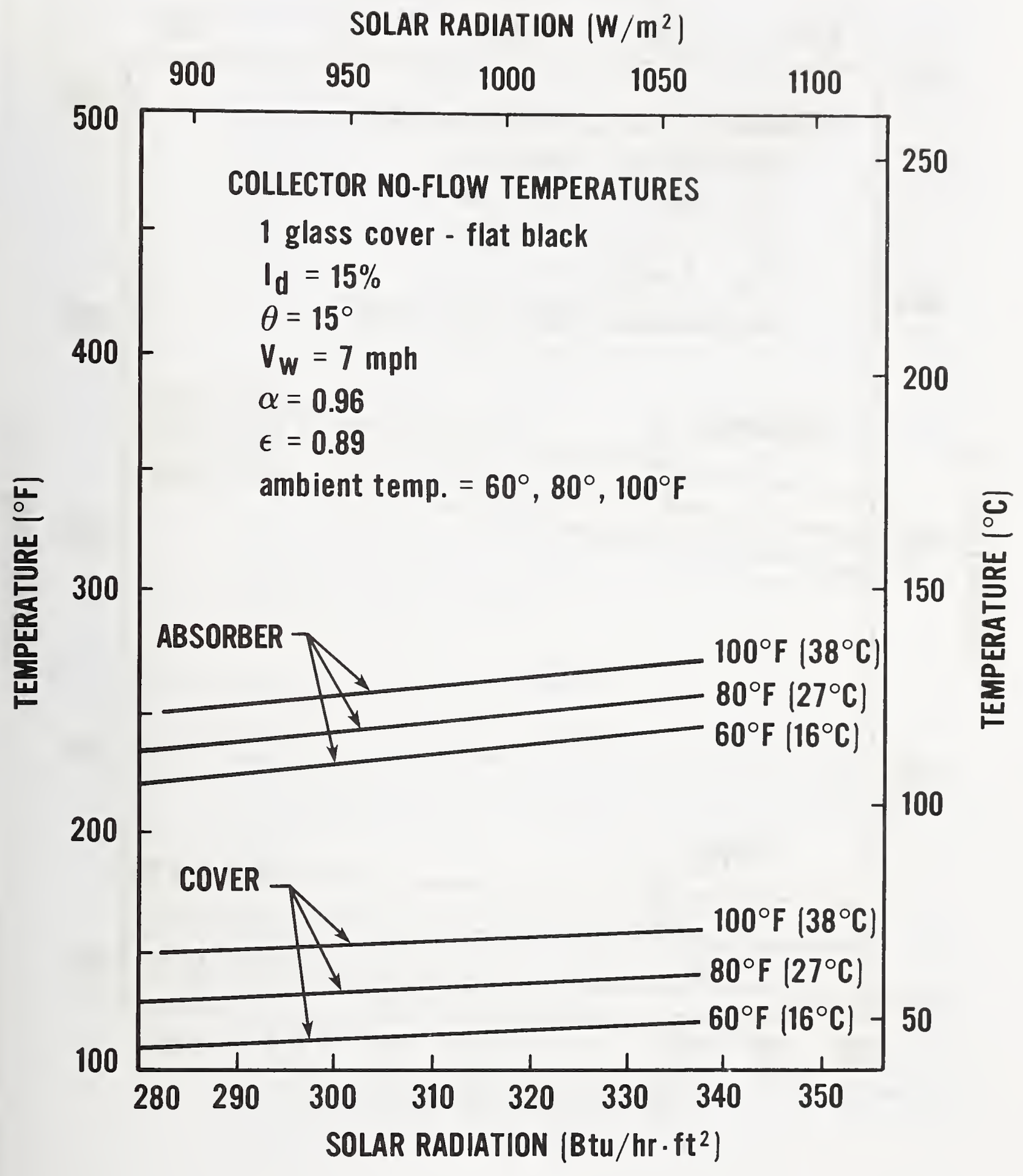

Figure A.3. No-flow temperatures at various locations in a collector with flat black absorber and one glass cover plate 


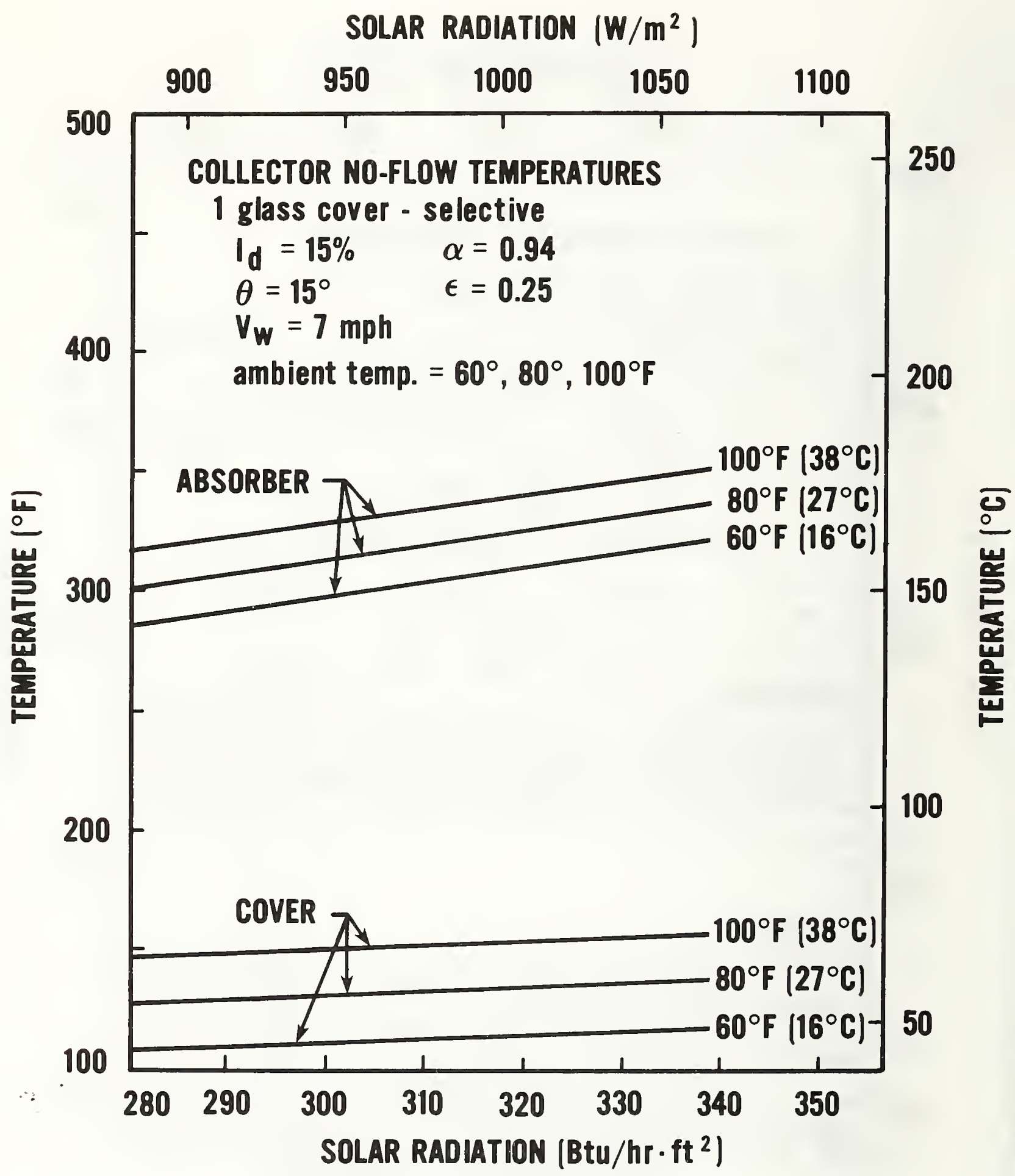

Figure A.4. No-flow temperatures at various locations in a collector with a selective absorber and one glass cover plate 
Evaluation Methods. The evaluations given in Chapter 5 and Sections 3 through 9 of this Appendix are intended to provide a means of measuring the deterioration of materials which would occur during use. Deterioration of materials is a measure of their durability. Deterioration is a result of exposure of the material to an environment which causes changes in its properties. To screen materials and to assess durability, properties must be measured before and after exposure to an environmental aging procedure. Assessment of properties should include: visual inspection of surfaces plus measurement of appropriate optical, physical, mechanical or chemical properties. Important properties will depend upon the application and the type of material. Tables $5.2 \mathrm{a}, 5.2 \mathrm{~b}$, and $5.2 \mathrm{c}$ identify the properties which must be measured before and after aging for various materials and components. Methods to perform typical property tests are listed in Table B.1 of Appendix B. Other test methods may also be used, if necessary, to document performance. Recommended aging procedures and property assessment methods are included in Sections 3 through 9.

Section 3 Test Methodology: Criterion 5.1.1 Solar Degradation. Components or materials shall be tested using at least one aging procedure and appropriate property assessment methods (Table $5.2 a$ of Chapter 5).

Aging

Procedure 1 (Simulated Laboratory Exposure)

Acceptable exposure procedures include ASTM G26-77, Operating Light Exposure Apparatus (Xenon-Arc Type) With and Without Water for Exposure of Non-Metallic Metals, [2] or ASTM D2565-79, Operating Xenon Arc-Type (Water Cooled) Light and Water Exposure Apparatus for Exposure of Plastics [3].

Expose components or materials to simulated solar radiation. With the Type A or AH apparatus, the exposure periods shall be 1400 hours. With the Type B or BH apparatus, the exposure periods shall be 1900 hours. The exterior surfaces of components which are exposed to rainfall in service shall be subjected to a water spray. The exposure cycle should be 90 minutes of 1 ight on $1 y$, followed by 30 minutes of light with water spray. For components not exposed to moisture under normal operating conditions, the water spray shall not be included in the procedure. 
Aging

Procedure 2 (Outdoor Exposure Using Concentrated Natural Radiation)

Using ASTM E838-81, Standard Practice for Performing Accelerated Outdoor Weathering Using Concentrated Natural Sunlight, Reference [4] expose components or materials to concentrated natural solar radiation until they have received a total incident radiant exposure of $5.4 \times 10^{5}$ $\mathrm{Btu} / \mathrm{ft}^{2}\left(6.0 \mathrm{GJ} / \mathrm{m}^{2}\right)$. Exterior surfaces exposed to moisture in service shall be subjected to water spray for a period of 8 minutes during each 60 minutes of sunlight exposure. The water spray should be at a rate of $1.75 \times 10^{-2} \mathrm{gal} / \mathrm{min}$. $\mathrm{ft}^{2}\left(1.18 \times 10^{-2} \mathrm{~L} / \mathrm{s} \cdot \mathrm{m}^{2}\right)+20$ percent. For components not exposed to rainfall under normal operating conditions, the water spray shall not be included in the procedure.

Test specimen mounting and temperature control shall be in accordance with the procedures described in ASTM E838-81, Reference [4].

Aging

Procedure 3 (Natural Weathering)

Expose components and materials to 12 months of solar radiation outdoors by the most appropriate aging procedure listed below. The average daily flux of the solar radiation, as obtained by averaging the daily fluxes over the 12 month period of outdoor exposure, shall be at least 1200 $\mathrm{Btu} / \mathrm{ft}^{2}\left(14.8 \mathrm{Mj} / \mathrm{m}^{2}\right)$.

Cover Materials ASTM E782-81 Standard Practice for (Flat Plate Collectors)

Exposure of Cover Material for Solar Collectors to Natural Weathering Under Conditions Simulating Operational Mode

Absorber

Coatings

ASTM E781-81

Exterior Paints

(Not Absorber Coatings)
ASTM D1006-73

Standard

for Conducting

Exterior Exposure Tests of Paints on Wood
Standard Practice for Evaluating Absorptive Solar Receiver Materials When Exposed to Conditions Simulating Stagnation in Solar Collectors with Cover Plate(s) 


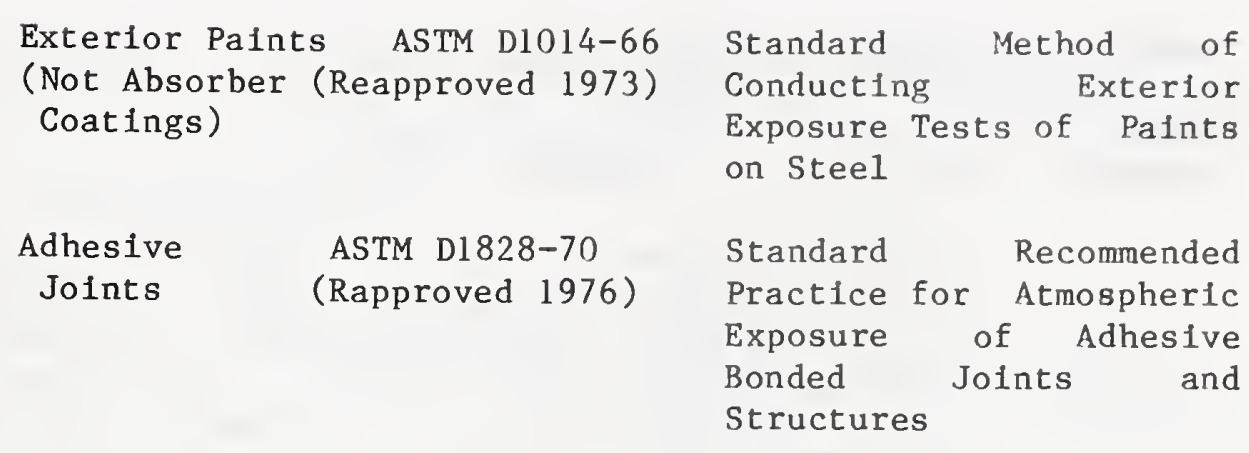

Plastics

ASTM D1435-75

(Reapproved 1979)

Standard

Recommended

Practice for Outdoor

Weathering of Plastics

Non-Metallic ASTM G7-77a

Standard Practice for Atmospheric Environmental Exposure Testing of NonMetallic Materials

Pipeline ASTM G11-79

Standard Test Method for Effects of Outdoor Weathering on Plpeline Coatings

Any material ASTM G24-73
(Rapproved 1980)

Standard Recommended Practice for Conducting Natural Light Exposures Under Glass

Property

Assessment

Properties listed in Tables 5.2a, 5.2b, and $5.2 \mathrm{c}$ shall be measured to determine the effect of aging procedures on visual appearance and important optical, physical, or mechanical properties of the components or materials. Other properties may be used for assessment as appropriate. Properties must be measured for both aged and unaged specimens to establish a basis of comparison.

Commentary The tests are intended to permit estimations to be made of the effect of solar radiation in degrading collector components and in reducing the collector efficiency. The exposure period for the aging procedure is considered to provide approximately the same total energy below $400 \mathrm{~nm}$ as would be recelved in 12 months of actual solar exposure in in Phoenix, Arizona. 
Aging

Procedure 1 (Resistance to Ozone)

Coupon specimens of components shall be exposed for 21 days to an ozone atmosphere of $50+5 \mathrm{pphm} /$ volume in a test chamber of $73.4+3.6^{\circ} \mathrm{F}\left(23+2^{\circ} \mathrm{C}\right)$. An ozone test chamber is described in ASTM D1149-78a, "Rubber Deterioration Surface Ozone Cracking in a Chamber (Flat Specimens)", Reference [5]. Specimens should be stressed to simulate service conditions.

Aging

Procedure 2 (Resistance to Salt Spray)

Coupon specimens of components shall be exposed for 21 days in accordance with ASTM Method B117-73 (1979), Salt Spray (Fog), Reference [6].

Aging

Procedure 3 (Resistance to $\mathrm{SO}_{2}$ and $\mathrm{NO}_{\mathrm{x}}$ )

Coupon specimens of components shall be supported vertically in a closed chamber having openings for gas inlet and outlet and maintained at a temperature of $73.4+3.6^{\circ} \mathrm{F}$ ( 23 $+2{ }^{\circ} \mathrm{C}$ ) for a period of 21 days. An amount of $\left(\mathrm{SO}_{2}\right.$ or $\left.\mathrm{NO}_{\mathrm{x}}\right)$ equivalent to 1 percent of the volume of the test chamber shall be introduced into the chamber each working day. A small amount of water is to be maintained at the bottom of the chamber.

Property

Assessment

Properties listed in Tables 5.2a, 5.2b, and $5.2 \mathrm{c}$ shall be measured to determine the effect of the aging procedures on important optical, physical, mechanical, or chemical properties. In addition, the surfaces of the test specimens shall be visually examined for signs of deterioration such as cracking, blistering, or dimensional changes using a microscope with an eyepiece micrometer at $20 \mathrm{X}$ magnification. Other properties may be used for assessment, as appropriate. Properties must be measured for both aged and unaged specimens to establish a basis for comparison.

Commentary These tests are intended to determine the resistance of components to airborne pollutants.

Section 5 Test Methodology: Criterion 5.2.1 Thermal Degradation. Heat transfer fluids shall be tested using aging procedures 1 and 3. Other components and materials shall be tested using aging procedure 2. Property assessment methods 
listed in Tables 5.2a, 5.2b, and 5.2c shall be performed before and after aging. Supplemental aging procedures are listed below and may be added where applicable. Section 1 of this Appendix may be useful in determining the maximum service temperature.

Sealants ASTM C792-75

(Reapproved 1980)

Standard Method of Test for Effects of Heat Aging on Weight Loss, Cracking and Chalking of Elastomeric Sealants

Rubber ASTM D454-81

Standard Test Method for Rubber Deterioration by Heat and Air Pressure

Plastic ANSI/ASTM D794-68

(Reapproved 1977)

Plastic ANSI/ASTM D1042-51

(Reapproved 1978)

Standard Recommended Practice for Determining Permanent Effect of Heat on Plastics

Standard Test Method for Linear Dimensional Changes of Plastics Under Accelerated Service Conditions

Plastic ANSI/ASTM D1204-78

Standard Test Method for Linear Dimensional Changes of Nonrigid Thermoplastic Sheeting or Film at Elevated Temperatures

Plastic ANSI/ASTM D1299-55

(Reapproved 1979)

Plastic ANSI/ASTM D1203-67

(Reapproved 1974)

Standard Test Method for Shrinkage of Molded and Laminated Thermosetting Plastics at Elevated Temperatures

Standard Test Method for Loss of Plasticizer from Plastics (Activated Carbon Methods)

Aging

Procedure 1 (Resistance of Fluids to Maximum Service Temperature)

Expose the heat transfer fluids to their maximum service temperature for a period of 21 days. In some cases, this may require the use of an autoclave. The fluids shall contain turnings of the metal to be used in service in quantities of $10 \mathrm{~g}$ of metal turnings to $100 \mathrm{cc}$ of fluid. 
Aeration shall be provided in fluids to be used in "open" systems. Fluid aeration need not be included for "closed" system usage. The test must be repeated separately for all metal materials that are present in the sys tem.

Aging

Procedure 2 (Resistance of Components and Materials to Maximum Service Temperature)

Components or coupon test specimens shall be subjected to heat aging for a period of 21 days at the maximum service temperature. Components and materials stressed in normal use should be stressed during the exposure.

Aging

Procedure 3 (Resistance of Fluids to Minimum Service Temperature)

Expose the heat transfer fluids to their minimum service temperature for a period of 24 hours and remove and immediately examine for freezing.

Property

As ses sment

Properties listed in Tables 5.2a, 5.2b, and 5.2c shall be measured to determine the effect of the aging procedures on visual appearance and important optical, physical, chemical, and mechanical properties of the components or materials. At the completion of aging procedure 1 , the fluids shall be visually inspected for signs of undesired changes such as excessive precipitation or boiling. Other properties may be used for assessment as appropriate. Properties must be measured for both aged and unaged specimens to establish a basis for comparison.

Commentary The tests are intended to permit estimations to be made of the effect of heat in degrading collector components and in reducing the system efficiency. Aging procedure 3 is intended to evaluate freezing of transfer fluids at the minimum service temperature. (See Criterion 3.6.1.)

Section 6 Test Methodology: Criterion 5.2.2 Thermal Cycling Degradation. Materials and components shall be subjected to the aging procedure and appropriate property assessment methods (Tables $5.2 \mathrm{a}, 5.2 \mathrm{~b}$, and $5.2 \mathrm{c}$ ).

Aging

Procedure 1 (Resistance of Components and Materials to Thermal Cycling)

Complete components or material test specimens shall be subjected to thermal cycling between the maximum service temperature and minimum service temperature for a total of 
30 cycles. Each cycle shall consist of: 7.5 hours at the maximum service temperature; 0.5 hours at room temperature; 15.5 hours at the minimum service temperature; and 0.5 hours at room temperature.

Property

Assessment

Commentary

Section 7

Aging

Procedure 1
Properties listed in Tables 5.2a, 5.2b, and 5.2c shall be measured to determine the effect of thermal cycling on visual appearance and on important physical, mechanical, and chemical properties of the components or materials. Other properties may be used for assessment as appropriate. Properties must be measured for aged and unaged specimens to establish a basis for comparison.

These tests are intended to permit estimations to be made of the effect of thermal cycling in degrading collector components and materials.

Test Methodology: Criterion 5.3.1 Materials/Transfer Fluid Degradation. Metallic containment materials used with nonaqueous liquids shall be tested using aging procedure 1 and plastic containment materials shall be tested using aging procedure 2. After aging, appropriate property assessment methods (Tables $5.2 \mathrm{a}, 5.2 \mathrm{~b}$, and $5.2 \mathrm{c}$ ) shall be performed.

(Resistance of Metallic Containment Materials to Nonaqueous Liquids)

The apparatus for this test consists of heating tape with appropriate power and control systems, and a variable flow pump with a reservoir for the heat transfer fluid.

The primary sample typically consists of a 36 in. (914 mm) length of tubing bent around an $8 \mathrm{in}$. (203 $\mathrm{mm}$ ) diameter mandril so that each leg of the U-bend is of approximately equal length. Other specimen designs are permitted if they more closely approximate conditions of application. Care should be taken in making the U-bend so that fluid flow through the tube is not significantly restricted. The tubing sample is mounted with an inclination of the plane of the U-bend at about 45 degrees to horizontal during testing. Secondary samples of similar or dissimilar metal tubing may be introduced in the loop. The test shall be carried out for a minimum period of 30 days. During the test, the temperature shall be maintained at the maximum service temperature.

Appropriate modifications including flow rate and degree of fluid aeration shall be included in the test. Protective coatings shall form a part of the test specimen if they are 
Aging

Procedure 2

used in the actual system. Testing shall be followed by visual inspection. With appropriate modification, Standard TM-01-71, "Autoclave Corrosion Testing of Metal in High Temperature Water", Reference [7] of the National Association of Corrosion Engineers for materials used in pressurized systems of ASTM D1384-80, "Corrosion Test for Engine Coolants in Glassware", Reference [8] for materials used in systems at atmospheric pressure, may be used in the evaluation of metal coupons.

(Resistance of Plastic Containment Materials to Liquids)

Plastic containment materials shall be tested for 7 days at maximum service temperature in accordance with ASTM D543-67 (1978), Reference [9] or ASTM D1239-55(1971), Reference [10]. The heat transfer fluid specified by the solar system manufacturer should be used. For organic based heat transfer fluids commonly used in aqueous solutions, the test reagents should include the concentrated heat transfer fluid and dilute solutions at concentrations similar to actual use.

Property

Assessment

Commentary

Section 8
Following the test, the test specimens shall not show signs of pitting, crevices, erosion, or exhibit other signs of general corrosive deterioration with the exception of discoloration.

Properties listed in Tables 5.2a, 5.2b, and 5.2c shall be measured to determine the effect of the aging procedures on visual appearance and on important chemical, physical, or mechanical properties. Other properties may be used for assessment as appropriate. Properties must be measured for both aged and unaged specimens to establish a basis of comparison.

These tests are intended to permit estimations to be made of the effect of chemical imcompatibility of the heat transfer fluids and materials in the energy transport system. Data derived from these aging procedures and property assessment methods may be used as guidelines. Assurance of chemical compatibility of critical components may require additional long-term testing under conditions (temperature, pressure, and flow rates) simulating actual use.

Test Methodology: Criterion 5.3.2 Dissimilar Metals Degradation. Adjoining dissimilar metals used in contact with the transfer fluid should be tested using aging procedure 1. Adjoining dissimilar metals not used in contact with the transfer fluid should be tested using aging procedure 2. After aging, appropriate property assessment methods (Tables 5.2a, 5.2b, and 5.2c) shall be performed. 
Aging

Procedure 1 (Resistance of Metallic Containment Materials to Liquids)

Test specimens consisting of dissimilar metals in direct contact with one another shall be subject to the test as described in aging procedure 1 of section 7.

Aging

Procedure 2 (Resistance to $\mathrm{SO}_{2}$ and $\mathrm{NO}_{\mathrm{X}}$ )

Test specimens consisting of dissimilar materials in direct contact with one another shall be subject to the test as described in aging procedure 3 of Section 4.

Property

As ses sment

Properties 1isted in Tables $5.2 \mathrm{a}, 5.2 \mathrm{~b}$, and $5.2 \mathrm{c}$ shall be measured to determine the effect of the aging procedures on visual appearance and on important chemical, physical, or mechanical properties. Other properties may be used as appropriate. Properties must be measured for both aged and unaged specimens to establish a basis for comparison.

Commentary These tests are intended to permit estimations to be made of the effect of corrosion on non-isolated dissimilar metals.

Section 9 Test Methodology: Criterion 5.3.3 Compatibility of Adjacent Organic Materials

Aging

Procedure 1 (Compatibility of Adjacent Organic Materials)

Test specimens consisting of the dissimilar organic materials in direct contact with one another shall be exposed to the maximum service temperature for a period of 120 hours.

Property

As ses sment

Properties listed in Tables 5.2a, 5.2b, and 5.2c shall be measured to determine the effect of the aging procedure on visual appearance and on important chemical, physical, or mechanical properties. Other properties may be used as appropriate. Properties must be measured for both aged and unaged specimens to establish a basis of comparison.

Section 10 No-Flow 30-Day Degradation

Testing Procedure

Evaluation of changes in collector materials or performance due to environmental conditioning shall be determined in 
accordance with the test procedure described in ASHRAE Standard 93, Reference [11], either before and after or only after exposing the collector panel assembly to the Exposure Test described below. Both the before and after collector thermal performance tests (ASHRAE Standard 93) shall be performed utilizing the same test facility under similar climatic conditions.

Exposure Test:

A. Test specimen shall consist of a complete air or liquid collector panel assembly.

B. Pre-exposure preparation:

1. Air collector duct opening shall be sealed to prevent cooling by convective air flow and the entry of dirt or precipitation. The collector shall be vented to prevent build-up of pressure.

2. Liquid collectors intended for use in all systems (with or without draindown) shall be completely filled with distilled water $1 /$ following which the inlet shall be sealed and the outlet provided with a pressure relief valve set to a value between 0 percent and +10 percent over the manufacturer's recommended maximum operating pressure.

3. Liquid collectors limited to use in systems that draindown when not operating shall be completely filled with distilled waterl/ following which the fluid shall be allowed to gravity drain for 15 minutes with the collector mounted at a $45^{\circ}$ tilt angle. The collector inlet shall then be protected to prevent entry of dirt or precipitation. The collector shall also be vented to prevent buildup of pressure.

1/ Manufacturer's/designer's recommended fluid shall be used in those instances when they specifically prohibit the use of distilled water. 


\section{Exposure Conditions:}

1. Exposure conditions shall consist of 30 days of cumulative exposure to a minimum daily incident solar radiation flux of $1500 \mathrm{Btu} / \mathrm{ft}^{2} \cdot \mathrm{day}(17,000$ $\mathrm{kJ} / \mathrm{m}^{2} \cdot \mathrm{day}$ ) as measured in the plane of the collector aperture. 2 I

2. The exposure conditions shall include at least one consecutive 4-hour period or two $2-1 / 2$ hour periods with a minimum instantaneous $\mathrm{f} 1 \mathrm{ux}$ of $300 \mathrm{Btu} / \mathrm{ft}^{2} \cdot \mathrm{h}$ $\left(946 \mathrm{~W} / \mathrm{m}^{2}\right)$. The exposure test is only concluded after the requirements in the table following paragraph D.3. have been met.

a. Collector orientation changes to maximize the solar radiation or supplementary reflectors may be necessary to obtain the $300 \mathrm{Btu} / \mathrm{ft}^{2} \cdot \mathrm{h}$ ( 946 $\mathrm{W} / \mathrm{m}^{2}$ ) insolation level at certain locations. However, the maximum peak flux shall not exceed $370 \mathrm{Btu} / \mathrm{ft}^{2} \cdot \mathrm{h}\left(1165 \mathrm{~W} / \mathrm{m}^{2}\right)$ under normal sun-sky or simulator exposure conditions.

b. A reflector may be used if it has sufficient width and height to uniformly irradiate the collector aperture during the $300 \mathrm{Btu} / \mathrm{ft}^{2} \cdot \mathrm{h}$ exposure period. Solar irradiance measurements shall be performed in the plane of the collector to verify that the irradiance does not vary by more than 10 percent over the collector aperture and that the minimum instantaneous flux requirement is met.

2/ For collectors governed by paragraph B.2., the filled collector shall be exposed to at least one day with a minimum daily incident solar radiation of $1500 \mathrm{Btu} / \mathrm{ft}^{2}$.day. If freezing conditions are anticipated, the collector may be drained after exposure to this day. The pressure relief valve and inlet seal shall be removed when the collector is drained of all fluid. The collector inlet shall then be protected to prevent entry of dirt or precipitation and shall be vented to prevent pressure buildup. The collector shall be exposed for a total of thirty cumulative $1500 \mathrm{Btu} / \mathrm{ft}^{2}$-days (either filled or unfilled) as described above. The filled exposure day(s) may occur at any time during the 30-day exposure if so desired. 
c. A transparent enclosure may be used to raise the ambient temperature around the collector. The enclosure material shall have a total solar transmittance of at least 0.85 and a spectral transmittance of at least 0.80 in the wavelength band from 0.3 to $0.4 \mu \mathrm{m}$. If used, the pyranometer shall be mounted within the enclosure and within the plane of the collector for measurement of the solar irradiance.

D. Thermal Shock/Water Spray Penetration: This test is intended to induce the thermal stresses that would occur when rain impinges on a heated collector to determine the penetration of rain into the collector and the effect of such penetration or moisure condensation, if any, on collector performance.

1. Period of test: The test shall be performed three times during the 30-day exposure period; once during the first 10 days of the exposure period as defined in paragraph C.1. and once each during the second and third 10 days of the exposure period.

2. Pre-test exposure: The spray test shall be conducted after at least one hour of radiant exposure with a minimum solar irradiance of $270 \mathrm{Btu} / \mathrm{ft}^{2} \cdot \mathrm{h}$ $\left(850 \mathrm{~W} / \mathrm{m}^{2}\right)$ measured in the plane of the collector.

3. Apparatus: The test apparatus consists of three or more spray heads in a water supply rack. The water pressure for all tests is maintained at a minimum of 5 psi (34.47 $\mathrm{kPa})$ at each spray head and is equivalent to simulating a rain of about 12 inches per hour or a water flow rate of 50 gallons per hour per nozzle. The supply water temperature shall not exceed $86^{\circ} \mathrm{F}\left(30^{\circ} \mathrm{C}\right)$. A complete description of the apparatus and procedure is presented in NBSIR 78-1305A, Reference [12]. 
Specific Test Requirements and Options

\begin{tabular}{|c|c|c|c|c|}
\hline $\begin{array}{c}\text { Test } \\
\text { Requirement }\end{array}$ & $\begin{array}{c}\text { Solar } \\
\text { Radiation (min.) }\end{array}$ & $\begin{array}{c}\text { Ambient } \\
\text { Temperature }\end{array}$ & Time & Other \\
\hline 30 -days at & $1500 \mathrm{Btu} / \mathrm{ft}^{2} \cdot \mathrm{day}$ & - & $24-\mathrm{h}$ period & $\begin{array}{l}\text { Liquid collectors } \\
\text { shall be exposed } \\
\text { filled for at } \\
\text { least one of these } \\
\text { days. }\end{array}$ \\
\hline $\begin{array}{l}\text { 4-hour period } \\
\text { or } \\
\text { two } 2-1 / 2 \text { hour } \\
\text { periods }\end{array}$ & $\begin{array}{l}300 \mathrm{Btu} / \mathrm{ft}^{2} \cdot \mathrm{h} \\
\text { or } \\
300 \mathrm{Btu} / \mathrm{ft}^{2} \cdot \mathrm{h} \\
\text { with } 1 \mathrm{~h} \mathrm{minimum} \\
\text { of } 225 \mathrm{Btu} / \mathrm{ft}^{2} \cdot \mathrm{h} \\
\mathrm{preceding} \mathrm{each} \\
2-1 / 2 \mathrm{~h} \text { period }\end{array}$ & $\begin{array}{l}80^{\circ} \mathrm{F} \text { or minimur } \\
\text { of } 70^{\circ} \mathrm{F} \text { if the } \\
\text { solar irradiance } \\
\text { is greater than } \\
300^{\mathrm{Btu} / \mathrm{ft}}{ }^{2} \cdot \mathrm{h} \\
\text { (see NBSIR } 78- \\
1305 \mathrm{~A} \text { for } \\
\text { options). }\end{array}$ & $\begin{array}{l}\text { Continuous } \\
\text { irradiance for } \\
\text { either } 4 \text { hours } \\
\text { or two } 2-1 / 2 \\
\text { hour periods. } \\
\text { Exposure to } \\
\text { occur after } \\
\text { collector has } \\
\text { boiled dry or } \\
\text { been drained. }\end{array}$ & $\begin{array}{l}\text { Reflector and/or } \\
\text { enclosure may be } \\
\text { used to reach } \\
\text { required irradi- } \\
\text { ance or temperature. }\end{array}$ \\
\hline Water spray & $\begin{array}{l}\text { One } \mathrm{h} \text { minimum } \\
\text { of } 270 \mathrm{Btu} / \mathrm{ft}^{2} \cdot \mathrm{h} \\
\text { to preceed each } \\
\text { application }\end{array}$ & Above freezing & $\begin{array}{l}\text { Each application } \\
\text { for } 15 \text { minutes } \\
\text { continous } \\
\text { period. }\end{array}$ & $\begin{array}{l}\text { Supply water } \\
\text { temperature of } \\
86^{\circ} \mathrm{F} \text { or less }\end{array}$ \\
\hline
\end{tabular}

\section{E. Data Requirements}

1. The exposure conditions including hourly irradiation, ambient temperature, wind velocity, and dally precipitation shall be recorded to enable determination of the average dally values. Irradiance and the ambient temperature values shall be recorded every 30 minutes during the 4 -hour $300 \mathrm{Btu} / \mathrm{ft}^{2} \cdot \mathrm{h}$ $\left(946 \mathrm{~W} / \mathrm{m}^{2}\right)$ minimum flux exposure period.

2. A regularly scheduled weekly visual inspection shall be made and a record of changes in the phys1cal construction or appearance of the collector maintained.

3. The results of the pre-test and post-test thermal performance shall be plotted on the same graph for comparison purposes. A written description of observed changes in the physical or optical 
appearance of the collector shall be reported and substantiated with photographs where appropriate.

4. For collectors receiving only a post-test thermal performance measurement, the collector shall be completely disassembled and inspected for any evidence of functional impairment or material deterioration which could result in an abnormally short collector life when operated under normal service conditions. Evidence of material degradation will require documented experimental test data indicating the ability of the material to withstand and continue to function under the conditions commensurate with the application and design lifetime.

Commentary The purpose of this test is to identify, in a relatively short time, potential problems with collector materials or construction resulting from prolonged exposure to natural environments.

Recognizing that elevated temperature is one of the most damaging environments, solar irradiance and ambient temperature levels have been selected which represent typical summer conditions in most U.S. climatic regions. These conditions will produce the temperatures that the various materials used in solar collectors (cover plates, absorptive coatings, sealants, etc.) will experience in use. Until adequate laboratory test procedures are adapted to ensure the ability to select reliable materials and designs, an assembly level test is considered to be necessary for evaluating collector reliability.

A 4-hour or two 2-1/2 hour exposure periods with a minimum flux of $300 \mathrm{Btu} / \mathrm{ft}^{2} \cdot \mathrm{h}\left(946 \mathrm{~W} / \mathrm{m}^{2}\right)$ is specified in the test method. During this exposure period, it is intended that the collector be exposed to the normal peak profile that it would see on a fixed mount facing south.

The test procedure does not include provisions for evaluating tracking concentrating collectors or collectors designed for use with external reflectors to enhance solar radiation. Modifications to the exposure apparatus may be necessary to accommodate these collectors. 


\section{REFERENCES}

1. Ramsey, J. W., Borzoni, J. T. and, Holland T. H., Development of Flat Plate Solar Collectors for the Heating and Cooling of Bufldings, NASA CR-134804, June 1975. If

2. Standard Recommended Practice for Operating Light-Exposure Apparatus (Xenon Arc Type) With and Without Water for Exposure of Nonmetallic Materials, ANSI/ASTM G26-77.2/5/

3. Operating Xenon-Arc Type (Water Cooled) Light- and Water- Exposure Apparatus for Exposure of Plastics, ANSI/ASTM D2565-79.2/5/

4. Standard Practice for Performing Accelerated Outdoor Weathering Using Concentrated Natural Sunlight, ASTM E838-81.2f

5. Standard Test Method for Rubber Deterioration - Surface Ozone Cracking in a Chamber (Flat Specimens), ANSI/ASTM D1149-78a.. / 5/

6. Standard Method of Salt Spray (Fog) Testing, ASTM B117-73 (1979)..2/

7. Autoclave Corrosion Testing of Metal in High Temperature Water, NACE TM-01-71.

8. Standard Method for Corrosion Test for Engine Coolants in Glassware, ANSI/ASTM D1384-80.ㄱ/5/

9. Standard Test Method for Resistance of Plastics to Chemical Reagents, ANSI/ASTM D543-67 (1978).2/5/

10. Standard Test Method for Resistance of Plastic Films to Extraction by Chemicals, ANSI/ASTM D1239-55 (1971).2/5/

11. Methods of Testing to Determine the Thermal Performance of Solar Collectors, Standard 93-77, ASHRAE 1977.4T

12. Provisional Flat Plate Solar Collectors Testing Procedures, First Revision, NBSIR 78-1305A, National Bureau of Standards, Washington, DC, June 1978, PB 283-721.1/ 
1/ National Technical Information Service, 5285 Port Royal Road, Springfield, VA 22161.

2/ American Society for Testing and Materials, 1916 Race Street, Philadelphia, PA 19103.

3/ National Association of Corrosion Engineers, Box 1499, Houston, TX 77001 .

4/ American Society of Heating, Refrigerating and Air Conditioning Engineers, Inc., 1791 Tullie Circle, N.E., Atlanta, GA 30329.

5/ American National Standards Institute, Inc., 1430 Broadway, New York, NY 10018. 
APPENDIX B

$\underline{\text { Page }}$

INTRODUCTION $\ldots \ldots \ldots \ldots \ldots \ldots \ldots \ldots \ldots \ldots \ldots \ldots \ldots \ldots \ldots \ldots \ldots \ldots \ldots \ldots$

MATERIALS TABLES $\ldots \ldots \ldots \ldots \ldots \ldots \ldots \ldots \ldots \ldots \ldots \ldots \ldots \ldots \ldots \ldots$

Table B.1 List of Test Properties, Test Method Designations

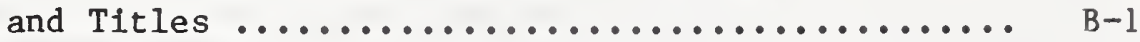

Table B.2 Properties of Typical Cover Plate Materials ......

Table B.3 Characteristics of Absorptive Coatings ..........

Table B.4 Examples of Typlcal Heat Transfer Liquid

Properties ................................. B 6

Table B.5 Typical Properties of Selected Building Materials for Solar Application .................... B-7

TECHNICAL REVIEW ITEMS $\ldots \ldots \ldots \ldots \ldots \ldots \ldots \ldots \ldots \ldots \ldots \ldots \ldots \ldots \ldots$

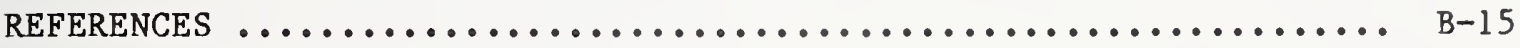

ABBREVIATIONS $\ldots \ldots \ldots \ldots \ldots \ldots \ldots \ldots \ldots \ldots \ldots \ldots \ldots \ldots \ldots \ldots \ldots \ldots \ldots \ldots$

SI CONVERSION UNITS $\ldots \ldots \ldots \ldots \ldots \ldots \ldots \ldots \ldots \ldots \ldots \ldots \ldots \ldots \ldots \ldots \ldots \ldots$ 


\section{INTRODUCTION}

Appendix B contains tables which have been compiled to provide the user with resources related to properties of materials used in solar application. Standards are listed in Table B.1 which could be of assistance in making physical property determination of materials. Typical physical properties and characteristics of materials have been tabulated to provide baseline values of a selected number of materials. These tables provide guidelines for selection and use of components and materials and may be useful in proving compliance with stated requirements.

The Technical Review Items identify major areas of concern with regard to system design and technical evaluation, and could be used as a guide for those purposes. The names of all code groups, associations, and government agencies which appear in the text are listed in Abbreviations. Conversion factors for all quantitative units used in the text can be found in the section on SI Conversion Units. 
Table B.1 List of Test Properties, Test Method Designations and Titles

Test Method

Property

Designation Number

Title

VISUAL OBSERVATION

Chalking

Checking

Cracking

B1istering

Solar Transmittance

Solar Reflectance

Emittance

Hardness

Hardness
ASTM D659-80

ASTM D660-44

(Reapproved 1976)

ASTM D661-44

(Reapproved 1975)

ASTM D714-56

(Reapproved 1974)

OPTICAL PROPERTIES

ASTM E424-71

ANS I Z138.7-1973

ASTM E424-71

ANSI Z138.7-1973

ASTM E408-71

(Reapproved 1980)

ASTM E434-71

(Reapproved 1980)

PHYSICAL PROPERTIES

ANSI/ASTM D785-65

(Reapproved 1976)

ANSI/ASTM D2583-75
Standard Method of Evaluating Degree of Chalking of Exterior Paints

Standard Method of Evaluating Degree of Checking of Exterior Paints

Standard Method of Evaluating Degree of Cracking of Exterior Paints

Standard Method of Evaluating Degree of Blistering Paints

Standard Test Method for Solar

Transmittance and Reflectance (Terrestrial) of Sheet Materials

Standard Test Method for Solar Transmittance and Reflectance (Terrestrial) of Sheet Materials

Standard Test Method for Total Normal Emittance on Surfaces Using InspectionMeter Techniques

Standard Test Method for Calorimetric Determination of Hemispherical Emittance and the Ratio of Solar Absorptance to Hemispherical Emittance Using Solar Simulation

Standard Test Method for Rockwel1 Hardness of Plastics and Electrical Insulating Materials

Standard Test Method for Indentation Hardness of Rigid Plastics by Means of a Barcol Impressor 
Table B.1 (Continued)

Test Method

Property

Designation Number

Title

Dimensional Stability

Tensile Strength

Tens1le Strength

Tensile Strength

Tensile Strength

Tensile Strength

Loading or Compression Strength

Loading or Compression

Flexure Strength

Flexure Strength

Flexure Strength

Fatigue
ANSI/ASTM D2122-76

MECHANICAL PROPERTIES

ANSI/ASTM D638-80

ANSI/ASTM D882-80a

ASTM C297-61

(Reapproved 1980)

ANSI/ASTM D897-78

ANSI/ASTM D412-80

ANSI/ASTM D695-80

ANSI/ASTM D2412-77

ANS I/ASTM C158-80

ASTM C393-62

(Reapproved 1980)

ANSI/ASTM D790-80

ANSI/ASTM D671-71

(Reapproved 1978)
Standard Method of Determining Dimensions of Thermoplastic Pipe and Fittings

Standard Test Method for Tensile Properties of Plastics

Standard Test Method for Tensile Properties of Thin Plastic

Sheeting

Standard Method of Tension Test of Flat Sandwich Constructions in Flatwise Plane

Standard Test Method for Tensile Properties of Adhesive Bonds

Standard Test Method for Rubber Properties in Tension

Standard Test Method for Compressive Properties of Rigid Plastics

Standard Test Method for External Loading Properties of Plastic Pipe by Parallel-Plate Loading

Standard Method for Flexure Testing of Glass (Determination of Modulus of Rupture)

Standard Method of Flexure Test of Flat Sandwich Constructions

Standard Test Method for Flexure Properties of Plastics and Electrical Insulating Materials

Standard Test Method for Flexural Fatigue of Plastics by Constant Amplitude of Force 
Table B.1 (Continued)

Test Method

Property

Designation Number

Title

Burst or Rupture

Burst or Rupture

Burst or Rupture
ANSI/ASTM D1598-76

ANSI/ASTM D1599-74

(Reapproved 1980)

ANSI/ASTM D2143-69

(Reapproved 1976)
Standard Test Method for Time-toFallure of Plastic Pipe Under Constant Internal Pressure

Standard Test Method for ShortTime Rupture Strength of Plastic Pipe, Tubing and Fittings

Standard Test Method for Cyclic Pressure Strength of Reinforced Thermosetting Plastic Pipe 


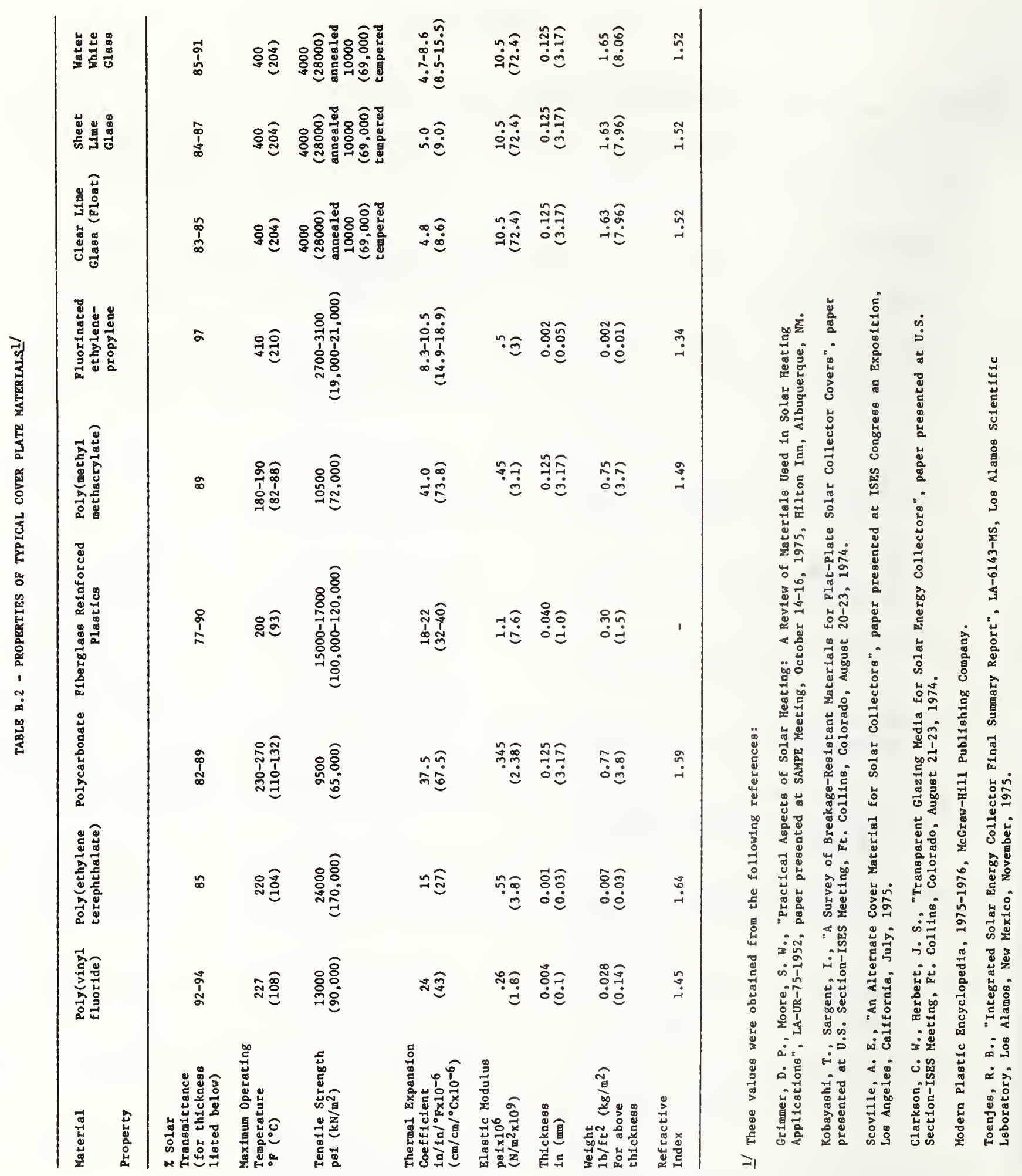


Table B.3 Characteristics of Absorptive Coatingel/

\begin{tabular}{|c|c|c|c|c|c|}
\hline $\begin{array}{l}\text { Property } \\
\text { Material }\end{array}$ & $\begin{array}{c}\text { Absorptance } 2 / \\
\alpha\end{array}$ & $\begin{array}{c}\text { Emittance } \\
\varepsilon\end{array}$ & $\frac{\alpha}{\varepsilon}$ & $\begin{array}{l}\text { Breakdown } \\
\text { Temperature } \\
\cdot g\left({ }^{\circ} \mathrm{C}\right)\end{array}$ & Comenta \\
\hline $\begin{array}{l}\text { Anod 1c } \\
\text { Aluminum }\end{array}$ & $.94-.96$ & $.3-.8$ & $1 \cdot 2-3$ & & $\begin{array}{l}\text { May be Influenced by } \\
\text { moleture }\end{array}$ \\
\hline Black Chrome & $.87-.93$ & .1 & $\sim 9$ & & \\
\hline Alkyd Ename 1 & .9 & .9 & 1 & & $\begin{array}{l}\text { Durability liafted at } \\
\text { high temperatures }\end{array}$ \\
\hline $\begin{array}{l}\text { Black Acrylic } \\
\text { Paint }\end{array}$ & $.92-.97$ & $.84-.90$ & $\sim 1$ & & \\
\hline $\begin{array}{l}\text { Black Inorganic } \\
\text { Paint }\end{array}$ & $.89-.96$ & $.86-.93$ & $\sim 1$ & & \\
\hline $\begin{array}{l}\text { Black S111cone } \\
\text { Paint }\end{array}$ & $.86-.94$ & $.83-.89$ & $\sim 1$ & & Sillcone binder \\
\hline $\begin{array}{l}\text { Pbs/Silicone } \\
\text { Paint }\end{array}$ & .94 & .4 & 2.5 & $662(350)$ & $\begin{array}{l}\text { Has a high emittance } \\
\text { for thicknesses }>10 \text { Ha }\end{array}$ \\
\hline $\begin{array}{l}\text { Flat Black } \\
\text { Paint }\end{array}$ & $.95-.98$ & $.89-.97$ & $\sim 1$ & & \\
\hline Ceramic Enamel & .9 & .5 & 1.8 & & $\begin{array}{l}\text { Stable at high } \\
\text { temperatures }\end{array}$ \\
\hline Black Z1nc & .9 & .1 & 9 & & \\
\hline $\begin{array}{l}\text { Copper Oxide } \\
\text { over Aluminum }\end{array}$ & .93 & .11 & 8.5 & $392(200)$ & \\
\hline $\begin{array}{l}\text { Black Copper } \\
\text { over Copper } \\
\end{array}$ & $.85-.90$ & $.08-.12$ & $7-11$ & $842(450)$ & $\begin{array}{l}\text { Patinates with } \\
\text { molsture }\end{array}$ \\
\hline $\begin{array}{r}\text { Black Chrome } \\
\text { over N1cke1 } \\
\end{array}$ & $.92-.94$ & $.07-.12$ & $8-13$ & $842(450)$ & $\begin{array}{l}\text { Stable at h1gh } \\
\text { temperatures }\end{array}$ \\
\hline $\begin{array}{l}\text { Black N1ckel } \\
\text { over Nicke1 }\end{array}$ & .93 & .06 & 15 & $842(450)$ & $\begin{array}{l}\text { May be Influenced by } \\
\text { molsture at elevated } \\
\text { temperatures }\end{array}$ \\
\hline $\begin{array}{l}\text { N1-Z1n-S over } \\
\text { Nickel }\end{array}$ & .96 & .97 & 14 & $536(280)$ & \\
\hline $\begin{array}{l}\text { Black Iron } \\
\text { over Steel }\end{array}$ & .90 & .10 & 9 & & \\
\hline
\end{tabular}

1/ These values were obtained from the following references:

G. E. McDonald, "Survey of Coatings for Solar Collectors", NASA TMX-71730, paper presented at Workshop on Solar Collectors for Heating and Cooling of Bulldings, November 21-23, 1974, New York C1ty.

G. B. McDonald, "Variation of Solar-Selective Properties of Black Chrome with Plating Time", NASA TMX-71731, May 1975.

S. W. Moore, J. D. Balcomb, J. C. Hedstrom, "Design and Testing of a Structurally Integrated Steel Solar Collector Un1t Based on Expanded Flat Metal Plates", LA-UR-74-1093, paper presented at U.S. Section-ISES Meeting, Ft. Collins, Colorado, August 19-23, 1974.

D. P. Grimmer, S. W. Moore, "Practical Aspects of Solar Heating: A Review of Materials Used In Solar Heating Applications", LA-UR-75-1952, paper presented at SAMPE Meet1ng, October 14-16, 1975, Hilton Inn, Albuquerque, MN.

R. B. Toenjes, "Integrated Solar Energy Collector Final Sumary Report", LA-6143-MS, Los Alamos Scientific Laboratory, Los Alamos, New Mexico, November 1975.

G. L. Merrill, "Solar Reating Proof-of-Concept Experiment for a Public School Bu1lding", Honeywell Inc., Minneapol1s, Minnesota, National Sclence Foundation Contract No. C-870.

D. L. K1rkpatr1ck, "Solar Collector Design and Performance Experience", for the Grover Cleveland School, Boston, Кassachusetts, paper presented at Workshop on Solar Collectors for Reating and Cooling of Bulidings, November 21-23, 1974, New York City.

2/ Dependent on thickness and vehicle to binder ratio. 


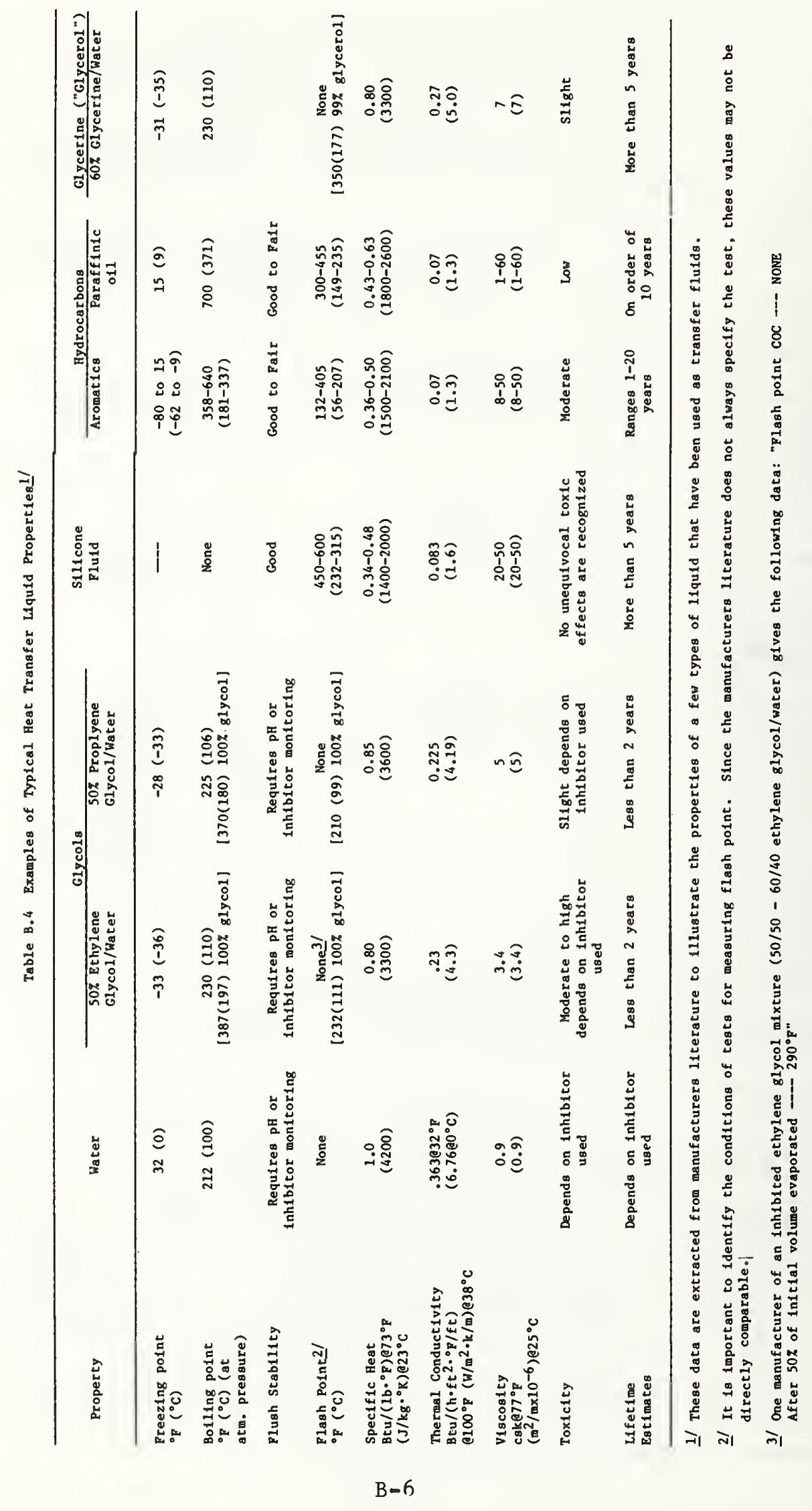


Table B.5 Typicel Properties of Selected Bullding Materiale for Soler Appllcation*

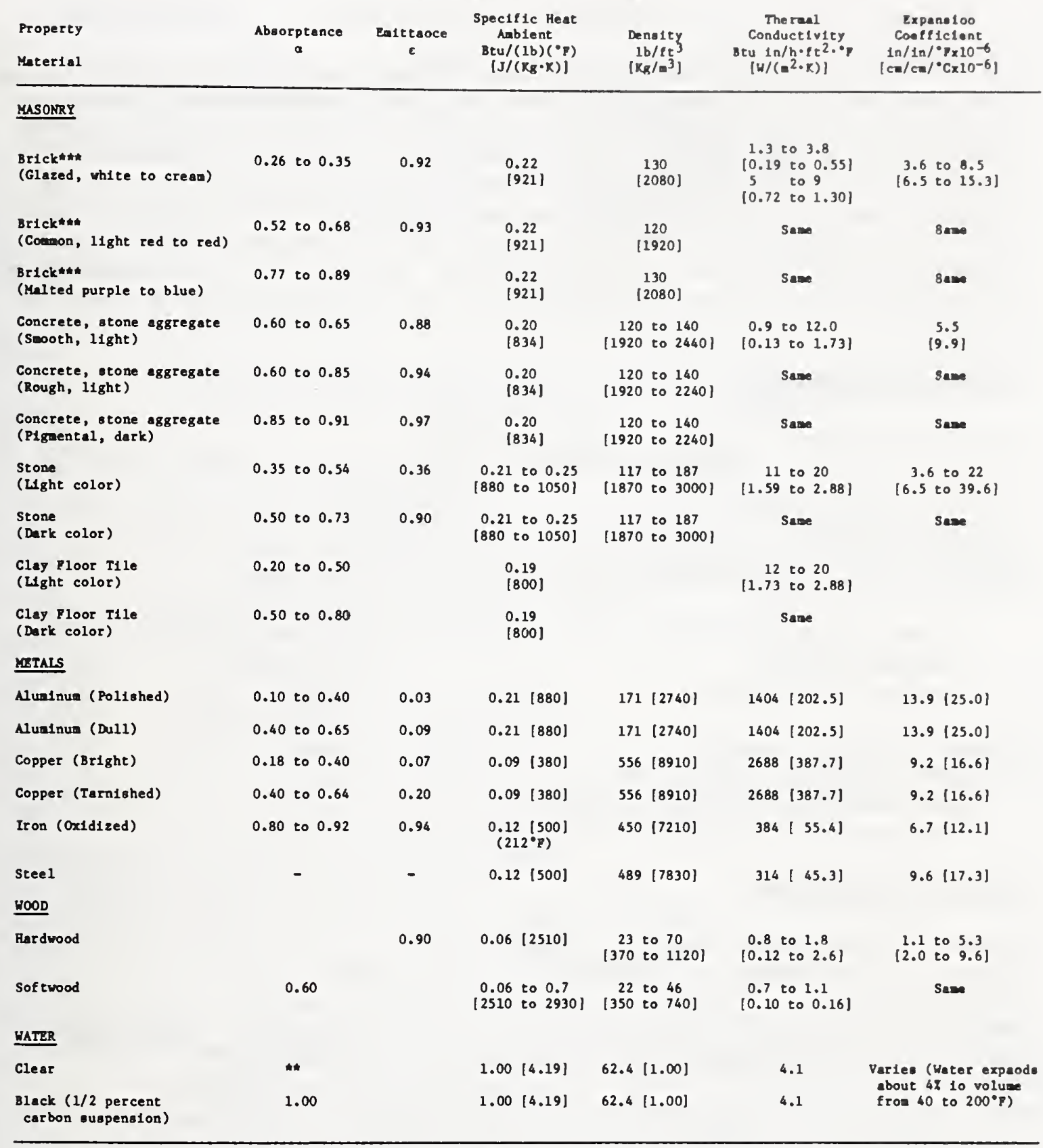

- These values vere taken froa different sources, as refereoced below, and are nesot to serve at a guide only.

1/ "Handbook of Afr Cooditioning, Heating and Ventilating", Clifford Strock aod Richard L. Roral, Iodustrial Prase, Inc., New York, NY, Second Edition, 1965.

2/ "Handbook of Fundasentals", American Society of Heating, Refrigerating and Air Conditioning Engineere, 1791 Tullie Circle, Atlanta GA 30329, ASHRAE 1977.

3/ "Bullding Construction Handbook", Chapter 2, McGraw-H111 Book Coapany, Th1rd Bdition.

4/ "Journal of Research of the National Bureau of Staodards", voluwe 6, page 1003.

s/ "Concrete Manual", Bureau of Reclanation, D.S. Departsent of Interior

* May vary with the water contalnaent device.

th For additional Inforastion on the properties of brick, see Technical Notes on Brick Conetruction, $43 \mathrm{D}$ Sept/Oct 1980. "Brick Passive Solar Heating Systems - Material Properties - Part $\mathbb{N}^{*}$. Brick Institute of Aserica, Mcleao, Virgiola. 
The following list of factors is included here as an aid to system design and evaluation. It identifies areas of major consideration which could be beneficial as a design guide or in the technical review of a system. This list was used in the technical review of proposals in HUD's Cycle 5 Residential Solar Demonstrations. Used as a review form, each of the review items (see Review Items, below) was evaluated satisfactory, marginal, or unsatisfactory and tracks the more detailed application form required of each of the grant applicants. An analysis and evaluation of these factors were used to determine if the proposed projects could be expected to perform reliably.

General Information

Type of Project: Category 1 (Multi-family)

Category 2 (Single family)

Building Size: gross sq. ft. Net heated sq. ft.

Project Location Latitude

Nearest City

Type of Solar Energy System (check all applicable items)

Space Heating

Space Cooling

Domestic Hot water Active Passive If Passive Indicated ( ) ( ) Sun tempered (.) ( ) Direct Gain ( ) ( ) Indirect Gain (

Type of Backup System

Most efficient system type

Most cost efficient fuel type

Is system over or under sized

\section{Heating Conditions}

Total Heating Degree Days

Design Temperature

Winter UA Total

Annual Heating Loads (before solar)

Annual Heating Contributions: Net Passive

Net Active ${ }^{\circ} \mathrm{F}$ outside Isolated Gain

Net Auxiliary Fuel Requirements $\mathrm{DD} / \mathrm{YR}$ ${ }^{\circ} \mathrm{F}$ inside $10^{6} \mathrm{BTU} / \mathrm{YR}$ $\mathrm{BTU} / \mathrm{DD} / \mathrm{SF}$ $10^{6} \mathrm{BTU} / \mathrm{YR}$ $10^{6} \overline{\mathrm{BTU} / \mathrm{Y} R}$ $\mathrm{BTU} / \mathrm{DD} / \mathrm{SF}$ $10^{6} \mathrm{BTU} / \mathrm{YR}$ - BTU/DD/SF $\mathrm{BTU} / \mathrm{YR} / \mathrm{SF}$

\section{Cooling Conditions}

Design Temperature ${ }^{\circ} \mathrm{F}$ inside ${ }^{\circ} \mathrm{F}$ outside

Annual Cooling Loads (before passive) Annual Cooling Contributions: Net Passive Net Active $10^{6} \mathrm{BTU} / \mathrm{YR}$

Net Auxiliary Fuel Requirements $10^{6} \overline{\mathrm{BTU} / \mathrm{YR}}$ $10^{6} \mathrm{BTU} / \mathrm{YR}$ $10^{6} \mathrm{BTU} / \mathrm{YR}$ BTU/YR/SF 
Total No. of People Cold Water Inlet Temperature Gallons per person per day GPP/D

Annual DHW Loads (before solar) ${ }^{\circ} \mathrm{F}$ Distribution Temperature

Annual DHW Contributions: Net Passive $10^{6} \mathrm{BTU} / \mathrm{YR}$

Net Active

Net Auxiliary Fuel Requirements $10^{6} \mathrm{BTU} / \mathrm{YR}$ $10^{6} \mathrm{BTU} / \mathrm{YR}$

\section{Review Items}

\section{A. ENERGY CONSERVATION}

1. Are the design temperatures, relative humidity, thermostat settings, etc., compatible with energy conservation?

2. Protection from outside temperature variation

a. Compact building form - minimum surface exposure

b. Use of earth-berming or underground structures

c. Use of utility spaces as buffers between living spaces and outside

d. Is the building envelope well insulated?

Walls

Ceilings and roof

Windows, storm windows

Doors, vestibules

Perimeter insulation of floor slab - basement insulation

Glass area (double panes or insulated glass)

e. Use of movable insulation

f. Use of time lag effects

3. Protection from infiltration and wind

a. Use of site and vegetation as wind breaks (trees, slope, earth-berming, etc.)

b. Use of building orientation and form for protection from the wind (small exposure of building to wind; proper placement of windows and doors. Use of utility spaces as buffers)

c. Proper caulking and weatherstripping to minimize infiltration

d. Cut down winter wind, but allow summer ventilation

4. Protection from summer overheating

a. Proper siting and orientation to minimize exposure to summer sun. Small east and west glass areas

b. Natural shading devices (vegetation, earth berms)

c. Use of overhangs, recessed windows and doors

d. Use of natural and induced ventilation

e. Summer shading, but solar access in winter 
5. Proper humidity level

a. Avoiding excessive humidity in summer

b. Avoiding excessive dryness

c. Proper use of vapor barriers

6. Use of natural light for lighting

7. Are the load calculations and results given clearly and correctl;
a. Cooling
b. Heating
c. Domestic hot water
d. Time lag
e. Optional

8. Are the relevant climatic data given for the site (or another similar site)?

9. Are the appliances and equipment energy efficient?

10. Is the backup system energy efficient? Is it properly sized?

\section{B. PASSIVE SOLAR HEATING}

1. Proper site and orientation for passive solar heating
a. South facing exposure
b. No winter shading

2. Clear description of system and passive solar methods used (sun tempering, direct gain, indirect gain, isolated gain. Elements such as Trombe wall, Sunspace, etc.)

3. Glazing

a. Adequate south facing glazing area

b. Has heat loss through glazing been minimized?

(e.g. double glazing, shutters, movable insulation)

4. Direct gain systems

a. Will the interior surfaces absorb sunlight sufficiently wel]

b. Have glare problems been minimized?

5. Passive storage

a. Clear description of kinds of storage used - location, dimensions and storage capacity of each

b. Sufficient storage capacity (thermal mass) 
c. Is the massive wall, floor, etc., sufficiently exposed to direct sunlight through the day in winter?

d. Massive walls and floors: Is the thickness too little, too much or just right?

e. Is the insulation located properly?

f. Water walls: Have leakage problems been addressed?

6. Heat distribution

a. If system depends on natural convection and radiation, are these adequate? (Are the air flow distances small? Will the air flow along the desired paths?)

b. If blowers are used, will the operating energy used be small?

c. Thermosiphoning device: Is collecting surface at a lower height than the storage by a proper amount?

7. Passive system controls

a. Are the controls properly designed, simple and reliable?

b. Degree of occupant participation required

8. Protection from overheating

Proper use of storage sizing, venting, shading devices

9. Will the system be easy to install and maintain? (e.g. glazing easily accessible for cleaning, accessible for maintenance, no inaccessible pipes)

10. Backup for passive system

11. Other considerations

a. Use of proper building materials, sealants, etc.

b. Weather proofing and moisture proofing

c. Problems from expansion and contraction

d. Freeze protection

e. Safety features - freedom from fire hazards

f. Structural integrity

12. Are the passive solar heating calculations and results given clearly and correctly?

C. PASSIVE COOLING

1. Clear description of passive cooling methods being used (natural ventilation, induced ventilation, night sky radiation, evaporative cooling, desiccant cooling or dehumidification, use of earth for cooling) 
2. Are the proposed cooling methods appropriate to the climatic region? (e.g. evaporative cooling in hot, arid climates, desiccant cooling in hot humid climates)

3. Have humidity and condensation problems been addressed? (e.g. in rock beds used for cooling)

4. Have sufficient details of the calculations been provided?

D. PASSIVE SOLAR DOMESTIC HOT WATER

E. ACTIVE SOLAR HEATING, DHW, AND COOLING SYSTEMS

1. Collectors (Sections S-515-2,S-615-2 of Reference [1])

a. Collector manufacturer

b. Collector mode1 number

[Test data (refer to stagnation checklist)]

c. Transfer medium

Type

Water

Air

Other

If Other:

Specific Heat

Density

d. Design total flow rate

e. Design flow rate per net

Sq. ft. of collector (guidelines) $\mathrm{Btu} / 1 \mathrm{~b}^{\circ} \mathrm{F}$

$1 \mathrm{~b} / \mathrm{cu} \cdot \mathrm{ft}$.

Note: Does flow rate include allowances for heat transfer

fluid specific heat and density?

f. Total area (guidelines) gross $\mathrm{SF}$ net (aperture) SF

g. Collector type (flat plate, concentrating, etc.)

h. Tilt (Section S-615-2.1.2 of Reference [1])

i. Orientation $\left(0^{\circ}=\right.$ True South)

j. Type of freeze protection

k. Maximum percent shading

1. Provisions for stagnation

m. Number of covers

n. Cover plate material

o. Absorber plate material

p. Liquid passage material

q. Absorber coating material

r. Overall construction

s. Ease of replacement (Section S-615-1.1.10 of Reference [1])

t. Access for maintenance, repairs

u. Mounting (flashing, wind, vandalism/accidents)

v. Snow hang up; blockage of breather vents

w. Provisions for fill/drain/venting

x. Flow balance (reverse return, balance valves, etc.) 
2. Storage (Sections S-515-7, and S-601-12 of Reference [1])

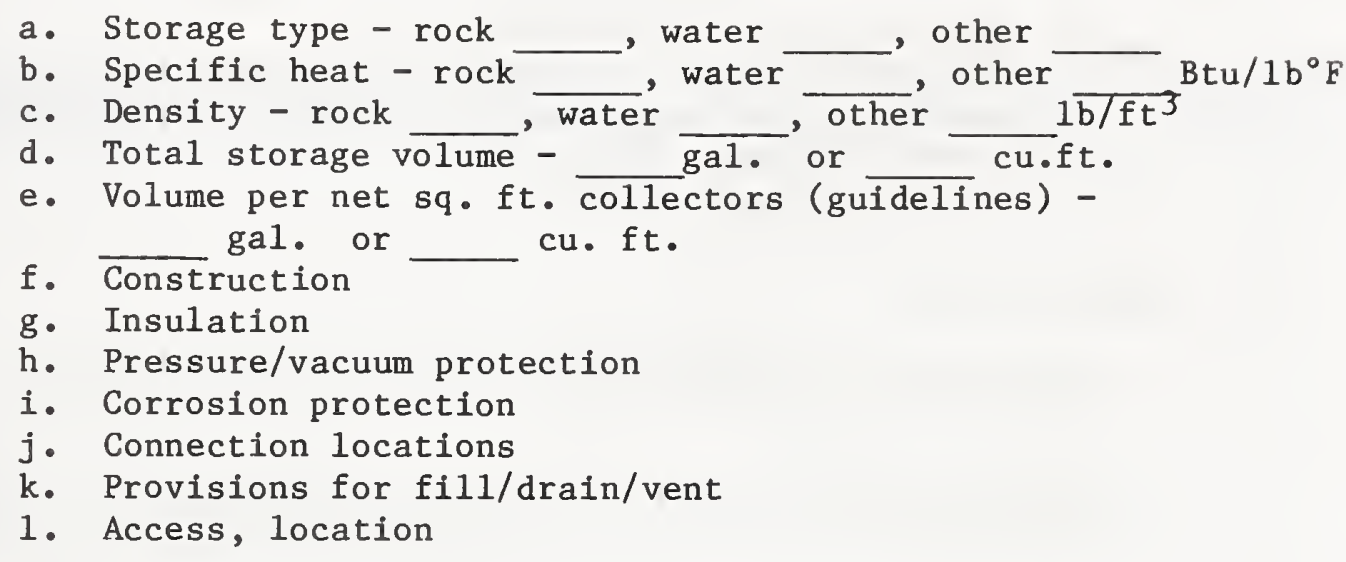

3. Back-up system (Section S-615-11 of Reference [1])
a. Fue1 type
b. Type of heating distribution system
c. Design temperature of heating supply air or water for peak load

4. Heat Exchangers (Section S-615-12 of Reference [1])
a. Load loop exchanger sizing
b. Collector loop exchanger sizing

5. Systems
a. Flow diagram
b. Controls and control diagram
c. Pump fan sizing. Note: Does pump/pipe sizing include allowance for heat transfer fluid viscosity?
d. Piping/ductwork sizing, materials
e. Dampers, proper type, location
f. Expansion/contraction provisions (Sections S-615-10.3 and S-615-10.9 of Reference [1])
(1) Piping
(2) System fluids
g. Drain down provisions (Section S-615-10.9 of Reference [1])
h. Potable/non-potable separation (Section S-615-10.1.1 of Reference [1])
i. Backflow prevention (Section S-615-10.1.3 of Reference
j. Scald protection for DHW (mixing valve, etc.) (Section S-615-10.1.3 of Reference [1])
k. Valving (Section S-615-10.7 of Reference [1])
1. Solar system operating energy use
m. Simplicity 
6. Solar Cooling System (If Any)

a. Type of solar cooling system

b. Cooling capacity, in relation to cooling load

c. Temperature of solar heat delivered to absorption chiller

d. C.0.P. of cooling system

e. Operating energy usage

F. OVERALL SYSTEM

1. Has adequate use been made of energy conservation to reduce the loads?

2. Are the total loads (In BTU/DD/SF or BTU/YR/SF) acceptable?

3. Is there a sufficient contribution of solar heat to the living space?

4. Are the different parts of the system (passive solar, active solar, back up system, and the bullding) well integrated?

5. Is the operating energy use kept relatively small?

6. Simplicity of overall system?

7. Conformity with the HUD Minimum Property Standards, 1ocal codes, etc. 


\section{REFERENCES}

1. HUD Intermediate Minimum Property Standards Supplement, 1977 Edition, Solar Heating and Domestic Hot Water Systems, (No. 4930.2), U.S. Department of Housing and Urban Development, Washington, DC, 1977.1 /

1/ U.S. Government Printing Office, Public Documents Department, Washington, DC 20402. 
ABBREVIATIONS (Code Groups, Associations and Gov't. Agencies)

\begin{tabular}{|c|c|}
\hline $\mathrm{AABC}$ & Associated Air Balance Council \\
\hline AASHTO & American Association of State Highway and Transportation Officials \\
\hline ACCA & Air-Conditioning Contractors of America \\
\hline AIA & American Institute of Architects \\
\hline AIAA & American Industrial Arts Association \\
\hline ANL & Argonne National Laboratory \\
\hline ANSI & American National Standards Institute, Inc. \\
\hline ARI & Air-Conditioning and Refrigeration Institute \\
\hline ASHRAE & $\begin{array}{l}\text { American Society of Heating, Refrigerating and Air-Conditioning } \\
\text { Engineers, Inc. }\end{array}$ \\
\hline ASME & American Society of Mechanical Engineers, Inc. \\
\hline ASPO & American Society of Planning Officials \\
\hline ASSE & American Society of Sanitary Engineers \\
\hline ASTM & American Society for Testing and Materials \\
\hline AWWA & American Water Works Association \\
\hline BOCA & Building Officials and Code Administrators International, Inc. \\
\hline CABO & Council of American Building Officials \\
\hline $\mathrm{CDA}$ & Copper Development Association \\
\hline CPSC & Consumer Product Safety Commission \\
\hline DoE & U.S. Department of Energy \\
\hline EPA & U.S. Environmental Protection Agency \\
\hline FHA & Federal Housing Administration \\
\hline FSEC & Florida Solar Energy Center \\
\hline HUD & U.S. Department of Housing and Urban Development \\
\hline IAPMO & International Association of Plumbing and Mechanical Officials \\
\hline ICBO & International Conference of Building Officials \\
\hline ISES & International Solar Energy Society \\
\hline LASL & Los Alamos Scientific Laboratory \\
\hline NACE & National Association of Corrosion Engineers \\
\hline NAHB & National Association of Home Builders \\
\hline NASA & National Aeronautics and Space Administration \\
\hline NBS & National Bureau of Standards \\
\hline NCSBCS & National Conference of States on Building Codes and Standards \\
\hline NEBB & National Environmental Balancing Bureau \\
\hline NFPA & National Fire Protection Association \\
\hline NOAA & National Oceanographic and Atmospheric Agency \\
\hline NWTI & $\begin{array}{l}\text { National Wood Tank Institute (ceased operations, standards } \\
\text { available) }\end{array}$ \\
\hline ORNL & Oak Ridge National Laboratory \\
\hline $\mathrm{SAE}$ & Society of Automotive Engineers, Inc. \\
\hline SAMPE & Society for the Advancement of Material and Process Engineering \\
\hline $\mathrm{SBCC}$ & Southern Building Code Congress International \\
\hline SEIA & Solar Energy Industries Association, Inc. \\
\hline SERI & Solar Energy Research Institute \\
\hline SEREF & Solar Energy Research and Education Foundation \\
\hline SMACNA & $\begin{array}{l}\text { Sheet Metal and Air-Conditioning Contractors' National } \\
\text { Association, Inc. }\end{array}$ \\
\hline & Underwriters Laboratories, Inc. \\
\hline
\end{tabular}


Length

1 in $=0.0254$ meter (exactly)

$1 \mathrm{ft}=0.3048$ meter $($ exactly)

Area

$1 \mathrm{in}^{2}=6.45 \times 10^{-4}$ meter $^{2}$

$1 \mathrm{ft}^{2}=0.09290$ meter $^{2}$

Volume

1 in $^{3}=1.639 \times 10^{-5}$ meter $^{3}$

1 gal (U.S. Iiquid) $=3.785 \times 10^{-3}$ meter $^{3}$

Mass

1 ounce-mass (avoirdupois) $=2.834 \times 10^{-2} \mathrm{kilogram}$

1 pound-mass (avoirdupois) $=0.4536 \mathrm{kilogram}$

Pressure or Stress (Force/Area)

1 inch of mercury $\left(60^{\circ} \mathrm{F}\right)=3.377 \times 10^{3}$ pascal

1 pound-force/inch ${ }^{2}(\mathrm{psi})=6.895 \times 10^{3} \mathrm{pascal}$

Energy

1 foot-pound-force (ft/Ibf) $=1.356$ joule

1 Btu (International Table) $=1.055 \times 10^{3}$ joule

1 Kilowatt-hour $=3.600 \times 10^{6}$ joule $=3.412 \times 10^{3} \mathrm{Btu}$

Power

1 watt $=1 \times 10^{7} \mathrm{erg} / \mathrm{second}$

$1 \mathrm{Btu} / \mathrm{h}=0.2929$ watt

Temperature

$t^{\circ} \mathrm{C}=5 / 9\left(t^{\circ} \mathrm{F}-32\right)$

Heat

$1 \mathrm{Btu} \cdot \mathrm{in} / \mathrm{h} \cdot \mathrm{ft} 2 \cdot{ }^{\circ} \mathrm{F}=1.442 \times 10^{-1} \mathrm{~W} / \mathrm{m} \cdot \mathrm{K}$ (thermal conductivity)

$1 \mathrm{Btu} / 1 \mathrm{~b} \cdot{ }^{\circ} \mathrm{F}=4.194 \times 10^{3} \mathrm{~J} / \mathrm{kg} \cdot \mathrm{K}$ (specific heat)

1 langley $=4.184 \times 10^{4} \mathrm{~J} / \mathrm{m}^{2}=1 \mathrm{cal} / \mathrm{cm}^{2}=3.69 \mathrm{Btu} / \mathrm{ft}^{2}$ 

ATMOSPHERES

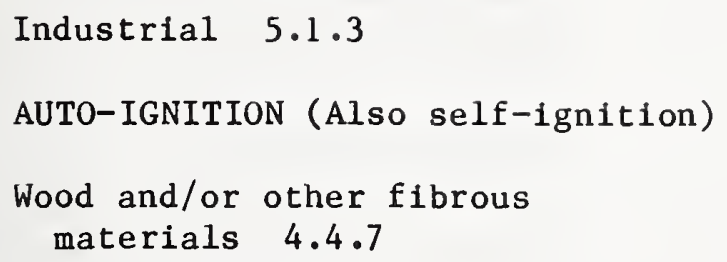

BUILDING ( Continued)

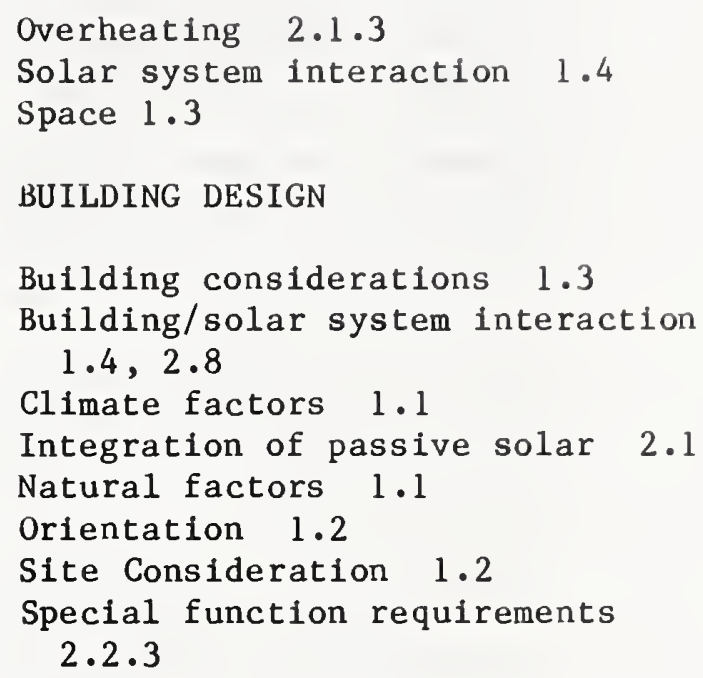

CALCULATION, SOLAR CONTRIBUTION

Heat loss $2.2 .1,2.4 .4$

Monthly 2.1.1, 2.1.3

CHEMICAL COMPATIBILITY

Adjacent organic materials 5.3 .3

Components 5.3

Dissimilar metals 5.3 .2

Galvanic and electrochemical/ corrosion 5.3.1

Materials/transfer fluid 5.3.1

CLOSED SYSTEMS

Prevention of corrosion 3.2.10

COLLECTORS, ACTIVE

Flow 2.4 .2

Orientation 2.4 .1

Performance 2.4 .2

Selection 2.8 .1

Shading $2.4 .1,1.2$

Stagnation test, post 2.4 .2

Tilt angle 2.4.1 Usability of roof for firefighting or egress 4.5 .2 


\section{COLLECTORS}

Air leakage $2.4 .3,3.3 .2,3.3 .4$ Architectural integration 2.4.1 Array performance 2.4.2 Chemical compatibility of components 5.3 .1

Cleaning glazing 3.3 .5

Degradation by wear 5.4.1

Effect of roof deterioration 6.2 .5

Energy transfer rate 2.6 .1

Flow balance 2.4 .2

Fluid circulation 2.7.2

Freeze protection 2.4 .4

Heat loss during non-collection periods 2.4 .4

Insulation 3.1 .3

Lightning protection 4.3.8

Orientation (tilt and azimuth angles) $2.1 .1,2.4 .1$

Panel performance in array 2.4 .2

Pressure drop 3.1.1

Protection during installation and shutdown 6.1 .6

Protection from snow and ice buildup 4.3 .7

Rain penetration 5.1 .2

Storage combination 2.4 .6

Structural safety 4.6

Thermal cycling degradation 5.2.2

Thermal degradation 5.2 .1

COLLECTORS, PASSIVE

Trombe walls 2.1.1

Water walls 2.1 .1

Windows 2.1 .1

COLLECTOR/STORAGE COMBINATION 2.4 .6

COMBUSTIBLE LIQUID

Drain and filling 3.2 .5

Handling 4.4.2

Liquid flash point 4.4 .1
COMBUSTIBLE MATERIALS

Adjacent to high temperature components 4.4 .7

Flame spread 4.4 .3

Warning to maintenance personnel 6.1 .4

COMFORT CONDITIONS

Occupied space $2.1 .3,2.1 .5$, 2.2 .1

COMPONENT/SYSTEM

Interaction 2.8

Sealing 3.3 .2

Thermal expansion 3.2 .8

COMPUTER PROGRAMS

Building design 2.1.1

F-Chart 2.5.2, 2.9.1

Handheld calculators 2.1.1, $2.1 .3,2.9 .1$

NBSLD 2.9.1

PASOLE 2.9.1

SINDA 2.9 .1

SOLCOST 2.9 .1

Thermal loads 2.9.1

TRNSYS 2.9 .1

CONDENSATION

Adverse effects (building or site) 1.4

Performance of components or materials 5.1 .2

CONDITIONED SPACE

Overheating 2.1 .3

Passive contribution 2.1.4

Shading 2.1 .3

Thermal condition 2.1.5 
CONTAINERS, STORAGE

Safety hazards 4.2

CONTAMINATION

Air $4.1 .4,4.1 .5$

Backflow preventor 4.1 .3

Dyes 4.1 .1

Growth of fungi $4.1 .5,4.1$

Hazards 4.1

Heat exchanger 4.1

National Interim Primary Drinking

Water Regulation 4.1.1

Potable water 4.1 .1

CONTROLS

Auxiliary energy 2.7.3, 3.5.5

Domestic hot water 3.5 .2

Effects of wear 5.4, 5.4.1

Emergency requirements 4.5 .1

Fail safe 3.5 .2

Incorrectly wired 6.3 .1

Inhabited space 3.5 .1

Installation $3.5 .4,3.5 .7$

Operating energy $2.6 .2,2.9 .1$

Passive solar components 2.1 .3

Performance $2.7,3.5$

Priority of energy use 2.7.3

Protection during installation and shutdown for maintenance $6.1 .6,3.5 .3,6.1 .7$

Sensor location 3.5 .4

System checkout 6.3.1

Temperature and pressure limit 3.5 .3

Tracking 3.5 .6

CONVE CTION

Forced or natural $2.1 .2,2.0$

Piping (size) 3.2.1

Thermal storage 2.1 .2

CORROSION

Air pollution $1.1,5.1 .3$
OORROSION (Continued)

Chemical compatibility 5.3, $5.3 \cdot 1$

Dissimilar metals 5.3 .2

Extracted salts 5.1 .2

Galvanic $3.2 .3,3.2 .8,4.3 .8$, 4.6 .1

Material compatibility with heat transfer fluid 5.3.1

Treatment of transfer fluid $3.2 .3,6.2 .1,4.1 .2$

OOVER PLATES

Exposed to pollutants 5.1.3, 1.1

Film type 4.3 .3

Injuries due to accidental contact 4.3 .3

Operation and maintenance instructions 6.1 .2

Physical impact 5.1.1

Solar degradation 5.1.1

Thermal cycling degradation 5.2 .2

Thermal shock degradation 5.2 .3

COUPLING HOSES

Thermal cycling degradation 5.2 .2

DAMPERS

Access for maintenance 6.2 .2

Backdraft $2.4 .4,3.3 .3,3.4 .1$

Balancing 3.1 .2

Effects of wear 5.4 .1

Leakage $2.4 .4,2.7 .4,3.3 .3$

Operating conditions 3.3 .3

Sealing 3.3 .3

Sizing 3.3 .1

Thermosiphoning 2.7 .4

DEFLECTION

Caused by loads $3.1 .4,4.3 .3$

Cover plates 4.3 .3

Draindown systems 3.6 .2

Ponding 4.6 .1 
DEGRADATION

Dissimilar metals 5.3 .2

Moisture 5.1 .2

Pollutant 5.1 .3

Solar 5.1 .1

Thermal 5.2 .1

The rmal cycling 5.2 .2

Thermal shock 5.2 .3

Wear 5.4 .1

DEPLETABLE ENERGY

Auxiliary equipment selection 2.8 .4

Depletable energy use 2.9.1

DESIGN LIFE

Effect of temperature 5.2

Thermal degradation 5.2 .1

DIAGRAMS

Flow and wiring 6.1 .2

DOMESTIC HOT WATER (DHW)

Auxiliary system 2.3 .4

Daily water use rate 2.3 .2

Energy use 2.9.1

Fail safe 3.5 .2

Limits controls 3.5 .3

Passive or mechanical 2.3

Recovery rate (hourly) 2.3.3

Scalding 4.3 .4

Storage 2.3 .2

Tap temperature $2.3 .1,4.3 .4$

Temperature control 3.5 .2

DRAINBACK $\quad 3.6 .2$

DRAINDOWN

System $3 \cdot 6 \cdot 2$

DU CTS

Air leakage $2.4 .3,2.6 .1,3.3 .4$, 3.3 .2
DUCTS ( Continued)

Design 3.3 .1

Fibrous glass 3.1 .3

Flow rates 3.1 .2

Heat loss $2.4 .4,2.6 .1$

Insulation $2.6 .1,3.1 .3,4.4 .4$

Sealing 3.3 .2

Thermal degradation 5.2 .1

ECONOMICS OF SOLAR

Life-cycle cost analysis 2.1 .1

EFFICIENCY CURVE

Solar panel 2.4 .2

EFFLORES CENCE

Absorber surfaces, trombe walls 5.1 .2

EMERGENCY REQUIREMENTS

Egress and access 4.5.2

Identification and location of controls 4.5 .1

ENERGY

Blowers 2.0, 2.6.1, 2.9.1 Depletable energy used 2.0 , $2.2 .1,2.2 .2,2.9 .1$

Dumping $4.3 .2,2.4 .5$

Efficiency rating (EER) 2.8 .4

Loss due to damper leakage 2.4 .4

Loss from thermal storage 2.5.1

Loss from transport system 2.6 , 2.6 .1

Operating 2.6 .2

Rejection 2.4 .5

Requirements for mechanical space cooling system 2.1 .4

Total requirement (heating) 2.2.1 Transfer rate .2.6.4

ENERGY TRANSPORT

Air leakage 2.6.1 
ENERGY TRANSPORT (Continued)

Combustible liquids $\quad 4.4 .2$

Flash point 4.4 .1

Liquid quality 6.2 .1

System balancing 3.1 .2

ENVI RONMENT

External factors affecting solar systems $1.1,1.2,5.1$

EXCESS HEAT

Venting $2.1 .1,2.1 .2,2.1 .3,2.4 .5$, $4 \cdot 3.2$

FAIL-SAFE CONTROLS

Pressure and temperature relief devices 4.3 .1

System failure prevention 4.3 .2

F-Chart 2.9 .1

FIRE SAFETY

Auto-ignition (self-ignition) $4 \cdot 4 \cdot 7$

Combustible liquids 4.4 .2

Design and installation of $\mathrm{H} / \mathrm{C} / \mathrm{HW}$ systems 4.4

Insulation $4.4 .3,4.4 .4$

Liquid flash point 4.4 .1

FLAME SPREAD

Insulation $4 \cdot 4 \cdot 3$

FLAMMABLE AND COMBUSTIBLE LIQUIDS

CODE 4.4 .2

FLASH POINT

Determination 4.4 .1

Heat transfer fluids 4.4 .1

FLOW RATE

Balancing 3.1 .2
FLOW RATE (Continued)

Checkout 6.3 .1

Collector loop 2.6 .3

Heat transfer fluid 2.8.3

Liquid velocities $3.1 .2,3.2 .1$

Loss in efficiency 2.4 .2

Operating energy 2.6 .2

System design 3.1

Variations $2.4 .2,2.8 .3,3.1 .2$

Ventilation air 2.1.3

FLUIDS, HEAT TRANSFER

Circulation 2.7.2

Compatibility $3.2,5.3 .1$

Fire safety 4.4

Quality 3.2.3

Thermal expansion 3.2 .4

FLUSHING OF LIQUID SYSTEM 6.1 .5

FREEZE PROTECTION

Back-up, power failure 3.6.2, 3.6 .3

Control setpoints 2.7 .5

Domestic hot water 2.3

Draindown $2.4 .4,2.6 .3,3.6 .2$

Heat loss 2.4 .4

Maintaining chemical composition $3.6,3.6 .1,6.2 .1$

Tolerant design 3.6 .4

FUNGI

Growth 4.1 .5

Rock storage containers 4.1 .5

Roof surface (mold and mildew) 6.2 .5

\section{GASKETS}

Chemical compatibility of components $5.3 .1,5.3 .3$

Factory installed 3.3 .2 Outgassing 5.2 .1

Solar degradation 5.1.1 


\section{GLAZING}

Acceptable methods of cleaning 6.1 .2

Compatability of adjacent materials 5.3 .3

Condensation $3.4 .2,5.2 .1$

Deflection 4.3 .3

Dirt deposits $1.1,1.4,3.3 .5$

Multiple 2.1.1

Reduce risk and injuries from accidental contact 3.1 .4 , 4.3 .3

Safety (See "Safety of Dwelling and Site")

Single 2.1.1

Temporary coverings 6.1 .6

Thermal degradation $3.1 .1,5.2 .1$

Transmissivity $2.1 .1,2.1 .4,5.2 .1$

HAIL

Glazing materials 4.3 .3

HEAT EXCHANGER

Blockage 3.2 .3

Chemical compatibility of components 5.3 .1

Effectiveness $2.6 .3,2.6 .4$

Insulation $2.6 .1,3.1 .3$

Pressure loss $3.3 .1,3.3 .2$

Safety and health 4.1.2, 4.1.4

Separation of circulation loops 4.1 .2

Sizing $2.6 .3,2.6 .4,2.8 .3$

System balance 3.1 .2

HEAT LOSSES

Collector-to-storage 2.6 .1

Due to freeze protection 2.4 .4

Due to thermal capacities 2.4 .4

During non-collection periods 2.4.4, 2.3

During normal operating conditions 2.4 .3

From passive system 2.1.1

From thermal storage 2.5.1, 2.5.2

Thermosiphoning, reverse 2.4.4, 2.7 .4
HEAT PUMPS

Coefficient of performance 2.8.4

HEAT TRANSFER FLUID

Degradation 5.3 .1

Quality 6.2.1

Velocity 2.8 .3

Viscosity changes $5.2 .1,2.6 .2$

HEATING SYSTEM

Auxiliary heating system sizing 2.2 .2

Building heat loss calculation 2.2 .1

Design load calculation 2.2.1

Effect of passive (January) 2.1.1

HOSES

Compatibility with transfer fluids 5.3 .1

Exposed to pollutants 5.1 .3

HYBRID SYSTEM (See "Passive Solar")

INSTALLATION INSTRUCTIONS

Availability and suitability 6.1 .1

Protection of system during installation 6.1 .6

\section{INSULATION}

Degradation and wear 5.4.1 Design and installation 3.1.3, 4.4 .4

Exposed plastic foam 4.4.4

Exposure to sunlight 5.1 .1

Fire hazard 4.4.4, 4.4

Flame spread classification 4.4 .3

Formaldehyde gas 4.1 .4

Heat loss $2.5,2.6,3.1 .3$

Moisture degradation, 5.1.2

Movable 2.1.1, 2.2.2, 2.3, 3.4.2, $4.4 .4,6.1 .7$

Optimum thickness $2.4 .3,2.5 .1,2.6 .1$ 


\author{
INSULATION (Continued) \\ Protection of exposed pipe and duct \\ $3.1 .3,4.4 .4,3.2 .1$ \\ System components 3.1 .3 \\ Thermal degradation 5.2.1 \\ Thermal storage 2.5 .1 \\ INTERIOR ITEMS
}

Effects on thermal storage 1.4

LABELING

Identification of toxic fluids 4.2 .2

LEAKS

Air leaks $2.4 .3,3.3 .2,3.3 .4$

Concentration (heat transfer fluid) 3.6 .1

Control valve 2.7 .4

Dampers 2.4.4, 2.7.4

Ducts and air handling units 2.6.1, 3.3 .2

Protection of potable water 4.1 .1 , $4.1 .2,4.1 .3$

Structural deflection 3.1 .4

Testing $3.2 .2,3.3 .2,3.3 .4$

Thermal storage 2.5 .1

LIQUID SYSTEMS

Entrapped air 3.2 .6

Flushing $3.2 .5,6.1 .5$

Performance 3.2

MAINTAINABILITY

Building and site 6.2 .4

Roof surfaces 6.2 .5

MAINTENANCE

Access 6.2 .2

Hazards 6.1 .4

Operation and maintenance

instruction 6.1 .2

Plan (active and passive systems)

6.1 .3
MAINTENANCE (Continued)

Protection of system 6.1 .6

Servicing 6.2

MAINTENANCE INSTRUCTIONS

System schematic diagram 6.1.2

MAKE UP WATER

Excessive corrosion 6.2 .1

MAN IFOLD

Duct design 3.3

Flow rates 2.4 .2

Heat loss 2.4 .3

Insulation 2.4.3

Relief valves 4.3 .1

Sealing 3.3 .2

MANUAL AND INSTRUCTIONS

Installation operations and maintenance $6.1,6.1 .1$, $6.1 .2,6.1 .3$

Occupant participation 6.1 .7

MECHANICAL EQUIPMENT

Heating and cooling 2.2

Operated automatically 2.2

MECHANICAL SYSTEM

Design load (heating) 2.2.1

MOISTURE DEGRADATION

Collectors 5.1 .2

Efflorescence 5.1 .2

MONITORING

Access for system 6.3 .3 
NO-FLOW

Aging procedure 5.2.1

Excessive pressure and temperature $4.3 .1,4.3 .2$

Provisional tests 3.1 .1

Temperature of fluid 4.4 .1

Thermal cycling loads 5.2 .2

30-day test, Appendix A Section 10

Tracking collector, off-focus

$$
3.5 .6
$$

NOCTURNAL

Night sky 2.4 .5

Radiation $2.2 .3,2.4 .4$

OCCUPANT

Manual of instruction 6.1 .7

Required activity 6.1 .7

OPERATING ENERGY

Blowers, pumps, and valves 2.0 , $2.6 .2,2.9 .1$

Normal conditions 2.6 .2

OPERATION INSTRUCTIONS

Minimum operating information

6.3 .2

Start up and shutdown 6.1 .2

OUTGASSING

Thermal degradation 5.2.1

ORIENTATION, OPTIMUM 1.2

PASSIVE COOLING TECHNIQUES

Desiccate cooling 2.2 .3

Evaporation 2.2.3

Nocturnal radiation 2.2 .3
PASSIVE SOLAR

Classification 2.0

Components 3.4

Contribution to conditioned space $2.1 .1,2.1 .4$

Movable insulation 3.4 .2

Net solar contribution 2.1.1, 2.1 .4

Optimum aperture area 2.1 .1

Overheating 2.1.3

Panels - protection from accidential contact 4.3 .3

Reduce space condition energy requirement 2.1

Seasonal contribution 2.1.1

Shading 2.1 .4

PENETRATIONS

Buildings 1.4

Fire resistance 4.4 .5

Roof 6.2 .5

\section{PERFORMANCE}

Collector panel 2.4 .2

Efficiency curves 2.4.2

Stagnation, post 2.4 .2

System checkout 6.3 .1

PHASE CHANGE MATERIALS

Thermal cycling 5.2 .2

PIPING ASSEMBLY

Chemical compatibility of components 5.3

Design 3.2 .1

Safety and health 4.1.1, 4.1 .3

Sizing 3.2 .1

Thermal cycling degradation 5.2 .2 


\section{PLASTICS}

Effect of heat transfer fluids 5.3 .1

Structural safety 4.6 .1

POLLUTANT DEGRADATION

Effects of design life 5.1 .3

Levels 5.1 .3

Permanent etching of components

5.1 .3

POTABLE WATER

Growth of microoganisms 4.1, 4.1.5

Leak testing 3.2 .2

Protection 4.1.1, 4.1.2, 4.1.3

Quality 4.1 .1

Separation of circulation loops $4 \cdot 1.2$

PRESSURE

Negative, storage tanks 3.2.7

Relief (See Relief devices)

PUMPS

Chemical compatability of components 5.3 .1

Effects of wear 5.4 .1

Insulation 2.6.1

Performance 3.2 .10

Size 2.6.2, 3.2.1

Viscosity changes 3.2 .10

RADIATION

Clear sky solar 2.1.3

Collector selection 2.8.1

Conversion to thermal energy 2.4 , 2.4 .1

Depletable energy 2.9.1

Exclusion during non-heating season 2.1

Incident 2.4 .1

January contribution 2.1.1

Net solar contribution 2.1.1

Nocturnal 2.2.3

\section{RADIATION (Continued)}

No flow conditions 4.3.2, Appendix A, Section 10

Reflectors 2.1.1

Seasonal/annual 2.1.1

Shading devices 2.1.3

Site considerations 1.2

Solar degradation $5.1 .1,5.1 .3$

Thermal storage exposure 2.1.2, 2.8 .2

\section{REFLECTORS} To increase incident solar
radiation 2.1 .1

\section{RELIEF DEVICES}

Pressure and temperature 4.3.1 Protection from freezing 4.3.1

REMOVAL INSTRUCTIONS 6.1 .1

ROCK

Asbestos 4.1 .4
Bins 2.1.2
Cleanliness 4.1 .4
Size 2.5
Washing 3.3 .5
ROOF

Damage due to leaking heat transfer fluid 4.2 .4

Maintainability of surfaces 6.2 .5

Resistance to deterioration due to solar energy components 6.2 .5

\section{SAFETY PROVISIONS}

Emergency egress and access 4.5.2

Fire safety 4.4

Lightning 4.3 .8

Liquid flash point 4.4 .1

Structural $4.6,4.6 .1$ 
SAFETY OF DWELLING AND SITE

Glazing materials 4.3 .3

Scalding 4.3 .4

Snow and ice 4.3.7

Surface temperature 4.3 .5

Water storage hazards 4.3 .6

SEALS

Chemical compatibility of components $5.3 .1,5.3 .3$

Exposed to pollutants 5.1 .3

Thermal degradation 5.2 .1

SELF-IGNITION

Wood and/or other fibrous materials 4.4 .7

SENSORS

Location $2.7 .1,3.5 .4$

Thermal cycling degradation 5.2 .2

SETPOINTS

Collection loop 2.7 .5

SHADING

Devices to reduce cooling load on passive $2.1,2.1 .3$

During winter months 1.2

Fixed 2.1.3

SITE

Design 1.2

Influence of prevailing winds 1.2 Maintainability of building 6.2 .4

Siting criteria 1.2

SNOW AND ICE

Buildup on collectors 4.3 .7

SOLAR ARRAYS

Accident prevention - reflected rays 4.5
SOLAR ARRAYS (Continued)

Lightning protection 4.3 .8 Usability of roof for firefighting as egress 4.5 .2

SOLAR CONTRIBUTION

January 2.1 .1

July 2.1 .3

October 2.1 .3

SOLAR SYSTEM/BUILDING

INTERACTION $1.4,2.8$

SPACE COOLING SYSTEM

Maintain comfort conditions 2.2 .3

SPACE HEATING SYSTEM

Auxiliary design $2.2 .1,2.2 .2$

Building unattended 2.2

Measured performance (F-Chart) 2.9 .1

Operation and maintenance 6.1 .2

SPACE, INTERIOR

Planning and coordinating 1.3

SPACE, OCCUPIED

Design conditions $2.1 .3,2.1 .5$

STORAGE CONTAINERS

Air leakage 2.5.1

Chemical compatibility of components $5.3 .1,5.3 .3$

Corrosion 4.3 .6 .

Drainage provisions 3.3 .5

Energy loss 2.5.1, 2.3.2

Exposed to solar radiation 2.1 .2

Glazing 4.3 .3

Hazards 4.3

Insulation 3.1 .3

Sizing $2.3 .4,2.8 .2$ 
STORAGE CONTAINERS (Continued)

Thermal degradation 5.2.1

Thermal stratification 2.5.2

Vacuum relief 3.2 .7

STORAGE SYSTEM

Thermal capacity 2.8 .2

\section{STAGNATION}

Maximum no flow temperature 4.4 .1

Post 2.8.1, 2.4.2

Protection (installation and maintenance) 6.1 .6

Resistance to 3.1 .1

Tracking collector, off focus 3.5 .6

STRATIFICATION, THERMAL

Mathematical models 2.5 .2

Storage 2.5 .2

STRUCTURAL

Deflection compatibility 4.6.1, $3.1 .4,4.3 .3$

Safety $4.6,4.6 .1$

STRUCTURAL DESIGN LOADS (LOADS, STRUCTURAL)

Constraint $\quad 4.6 .1$

Cyclic 4.6 .1

Dead 4.6 .1

Deflections, specified loads 4.6 .1

Earthquake 4.6 .1

Hail 4.3 .3

Live 4.6 .1

Snow and ice 4.6 .1

Wind 4.6 .1

SUNSHINE PERCENTAGE 2.1 .1

TEMPERATURE

Building materials due solar equipment 6.2 .4
TEMPERATURE (Continued)

Comfort 2.1.3, 2.1.5, 2.2.1

Effect 5.2

Hot water at tap 2.3.1, 4.3.4

Load requirements 2.8 .5

Overheating (passive) 2.1.3

THERMAL DESIGN LOADS (LOADS, THERMAL)

Hot water 2.3

Loads requirement 2.8 .5 (See

"Temperature")

Space cooling 2.2.3

Space heating $2.2 .1,2.2 .2$

THERMAL PROPERTIES

Storage materials 2.1 .2

THERMAL STORAGE

Access for cleaning or replacement 6.2 .2

Addition of auxiliary energy 2.5 .3

Air leakage $2.5 .1,3.3 .2$

Collector/storage combination 2.4 .6

Effect of interior items 1.4

Energy loss 2.5.1

Hot water load $2.3 .4,2.5$

In building mass 2.1 .3

Insulation 2.5.1

Location 2.1.2

Performance 2.5

Potential for fungus growth

4.1 .5

Sealing 3.3 .2

Size 2.8 .2

Size of aperture 2.1 .2

Sizing and location 2.1.2, 2.8 .2

Space cooling 2.5

Space heating 2.5

Stratification 2.5 .2

Thermally-coupled area 2.1.2

Thickness of the mass layer 2.1.2

Trombe walls 2.4 .6

Use of building mass $2.1 .1,2.1 .2$ 


\section{THERMOS IPHON}

Collection loop 2.3, 2.6.3, 2.7.2 Domestic hot water system $2.3,2.4 .4$, $2.6 .3,3.2 .1$

Non-collection period losses

$2.4 .4,2.7 .1,2.7 .2$

Prevention 2.7.2

\section{TOXIC FLUIDS}

Detection of 4.2 .3

Disposal of 4.2 .4

Draining and filling 3.2 .5

Identification of 4.2 .2

Rating of commercial substances 4.1 .2

The Federal Hazardous Substances Act 4.2 .1

Toxicological properties 4.2 .1

Warning for maintenance personnel 6.1 .4

TRANSFER FLUIDS, HEAT

Compatibility $3.2,5.3,5.3 .3$

Flash point 4.4 .1

Fluid flow rates 2.8 .3

Plastics 5.3 .1

Treatment of $3.2 .3,6.2,6.2 .1$

TRANSMISSIVITY

Glazing $2.1 .4,5.1,5.2,5.3$

TRANSMITTANCE

Glazing 2.1.1, 2.1.4, 5.1, 5.2, 5.3

TRANSPORT ENERGY

Collector 1 oop rate 2.6 .3

Load transfer rate 2.6 .4

Losses 2.6.1

Passive 3.4 .1

Performance 2.6

TRANSPORT SYSTEM

Balancing 3.1 .2

Energy loss 2.6.1
TRANSPORT SYSTEM (Continued)

Energy transfer 2.6.3, 2.6.4

Leakage $3.2 .2,3.3 .2$

Operating energy 2.6 .2

Performance 2.6

Testing $3.2 .2,3.3 .2$

TROMBE WALLS

Efflorescence on absorber surfaces

5.1 .2

Provision for recoating 6.2 .2

Thermal storage 2.1 .1

ULTAVIOLET EXPOSURE

Deterioration 5.1.1

Deterioration of organic materials 5.1 .1

VANDAL ISM

Minimize 1.4

VALVES

Chemical compatibility of components 5.3 .1

Effects of wear 5.4 .1

Isolation, system maintenance 6.2 .2

Operating conditions 3.2 .9

Relief devices 4.3.1

Shutoff, conspicuously marked 4.5 .1

Specification and location 3.2.9

\section{VENTILATION}

Whole-house 2.1 .3

VENTING

Draindown systems 3.6 .2

Mass wal1 2.1.2

Piping, during filling operation 3.2 .2

Reduces the net solar contribution $2.1 .1,2.1 .2,2.1 .3$

Thermal expansion of fluids 3.2 .4 


\section{VISCOSITY}

Heat transfer fluids 2.6 .2

Pump selection 3.2 .10

WALLS, THERMAL STORAGE

Trombe walls 2.1.1

Water walls 2.1 .1

WASTE HEAT RECOVERY AND STORAGE

IN THE THERMAL MASS OF PASSIVE

SOLAR BUILDINGS 1.3

WATERPROOFING

Exposed Insulation 5.1 .2

WEAR

Degradation 5.4 .1

WINDOWS

Impact on space cooling loads

$2.1,2.1 .1$

Solar radiation 2.1 .1

WINDS, WINTER

Protection 1.3 
NBS-114A (REV. 2.80)

\begin{tabular}{|c|c|c|}
\hline $\begin{array}{l}\text { U.S. DEPT. OF COMM. } \\
\text { BIBLIOGRAPHIC DATA } \\
\text { SHEET (See in structions) }\end{array}$ & $\begin{array}{l}\text { 1. PUBLICATION OR } \\
\text { REPORT NO. } \\
\text { NBS BSS } 147\end{array}$ & \begin{tabular}{|l|l} 
2. Performing Organ. Report Nof & $\begin{array}{r}\text { 3. Publication Date } \\
\text { September } 1982\end{array}$
\end{tabular} \\
\hline
\end{tabular}

4. TITLE AND SUBTITLE

Performance Criteria for Solar Heating and Cooling Systems In Residential Buildings

5. AUTHOR(S)

Center for Building Technology

6. PERFORMING ORGANIZATION (If joint or other than NBS. see instructions)

NATIONAL BUREAU OF STANDARDS

DEPARTMENT OF COMMERCE

WASHINGTON, D.C. 20234

7. Contract/Grant No.

IAA-H-54-81

MASHINGTON, D.C. 20234

9. SPONSORING ORGANIZATIOH NAAME AND COMPLETE ADDRESS (Street, City, Stote, ZIF)

8. Type of Report \& Period Covered

Final

U.S. Department of Housing and Urban Development

Office of Policy Development and Research

Building Technology Division

Washington, DC 20410

10. SUPPLEMENTARY NOTES

Library of Congress Catalog Card Number: 82-600581

[Document describes a computer program; SF-185, FIPS Software Summary, is attached.

11. ABSTRACT (A 200-word or less factual summary of most significant information. If document includes a significant bibliography or literature survey, mention it here)

This performance criteria, developed for the Department of Housing and Urban Development, is a baseline document for criteria and standards for the design, development, technical evaluation, and procurement of solar heating and cooling systems for residential buildings in accordance with the requirements of section 8 of Public Law 93-409, the "Solar Heating and Cooling Demonstration Act of 1974." The document is intended to establish minimm levels of performance with regard to health and safety and the various aspects of technical performance. The criteria for health and safety put primary emphasis on compliance with existing codes and standards. The criteria on thermal and mechanical performance, durability/ reliability and operation/servicing present performance requirements considered to be representative of acceptable levels. By the use of performance language in the document, it is believed that sufficient latitude has been provided to allow the innovation and flexibility that is essential for the stimulation of a viable solar industry at this time and in the future.

12. KEY WORDS (Six to twelve entries; alphabetical order; capitalize only proper names; and separate key words by semicolons)

building; cooling; heating; hot water; performance criteria; solar energy; standards.

13. AVAILABILITY

$\mathrm{X}$ Unlimited

$\square$ For Official Distribution. Do Not Release to NTIS

X] Order From Superintendent of Documents, U.S. Government Printing Office, Washington, D.C. 20402.

[ Order From National Technical Information Service (NTIS), Springfield, VA. 2216I
14. NO. OF PRINTED PAGES

236

15. Price

$\$ 7.50$ 


\section{NBS TECHNICAL PUBLICATIONS}

\section{PERIODICALS}

JOURNAL OF RESEARCH-The Journal of Research of the National Bureau of Standards reports NBS research and development in those disciplines of the physical and engineering sciences in which the Bureau is active. These include physics, chemistry, engineering, mathematics, and computer sciences. Papers cover a broad range of subjects, with major emphasis on measurement methodology and the basic technology underlying standardization. Also included from time to time are survey articles on topics closely related to the Bureau's technical and scientific programs. As a special service to subscribers each issue contains complete citations to all recent Bureau publications in both NBS and nonNBS media. Issued six times a year. Annual subscription: domestic \$18; foreign $\$ 22.50$. Single copy. \$4.25 domestic; $\$ 5.35$ foreign.

\section{NONPERIODICALS}

Monographs-Major contributions to the technical literature on various subjects related to the Bureau's scientific and technical activities.

Handbooks-Recommended codes of engineering and industrial practice (including safety codes) developed in cosperation with interested industries, professional organizations, and regulatory bodies.

Special Publications-Include proceedings of conferences sponsored by NBS, NBS annual reports, and other special publications appropriate to this grouping such as wall charts, pocket cards, and bibliographies.

Applied Mathematics Series-Mathematical tables, manuals, and studies of special interest to physicists, engineers, chemists, biologists, mathematicians, computer programmers, and others engaged in scientific and technical work.

National Standard Reference Data Series-Provides quantitative data on the physical and chemical properties of materials, compiled from the world's literature and critically evaluated. Developed under a worldwide program coordinated by NBS under the authority of the National Standard Data Act (Public Law 90-396).

NOTE: The principal publication outlet for the foregoing data is the Journal of Physical and Chemical Reference Data (JPCRD) published quarterly for NBS by the American Chemical Society (ACS) and the American Institute of Physics (AIP). Subscriptions, reprints, and supplements available from ACS, 1155 Sixteenth St., NW, Washington, DC 20056.
Building Science Series-Disseminates technical information develoned at the Bureau on building materials, components, systems, and whole structures. The series presents research results test methods, and performance criteria related to the structural and environmental functions and the durability and safety characteristics of building elements and systems.

Technical Notes-Studies or reports which are complete in them selves but restrictive in their treatment of a subject. Analogous to monographs but not so comprehensive in scope or definitive in treatment of the subject area. Often serve as a vehicle for final reports of work performed at NBS under the sponsorship of other government agencies.

Voluntary Product Standards-Developed under procedures published by the Department of Commerce in Part 10. Title 15, of the Code of Federal Regulations. The standards establish nationally recognized requirements for products, and provide all concerned interests with a basis for common understanding of the characteristics of the products. NBS administers this program as a supplement to the activities of the private sector standardizing organizations.

Consumer Information Series-Practical information, based on NBS research and experience, covering areas of interest to the consumer. Easily understandable language and illustrations provide useful background knowledge for shopping in today's technological marketplace.

Order the above NBS publications from: Superintendent of Documents., Government Printing Office, Washington, DC 20402

Order the following NBS publications-FIPS and NBSIR's-from the National Technical Information Services, Springfield, VA 22161.

Federal Information Processing Standards Publications (FIPS PUB)-Publications in this series collectively constitute the Federal Information Processing Standards Register. The Register serves as the official source of information in the Federal Government regarding standards issued by NBS pursuant to the Federal Property and Administrative Services Act of 1949 as amended. Public Law 89-306 (79 Stat. 1127), and as implemented by Executive Order 11717 (38 FR 12315, dated May 11. 1973) and Part 6 of Title 15 CFR (Code of Federal Regulations).

NBS Interagency Reports (NBSIR)-A special series of interim or final reports on work performed by NBS for outside sponsors (both government and non-government). In general, initial distribution is handled by the sponsor: public distribution is by the National Technical Information Services, Springfield, VA 22161. in paper copy or microfiche form. 
Washington, D.C. 20234

Official Business

Penalty for Private Use $\$ 300$

POSTAGE AND FEES PAID U.S DEPARTMENT OF COMMERCE COM-215

SPECIAL FOURTH-CLASS RATE BOOK 